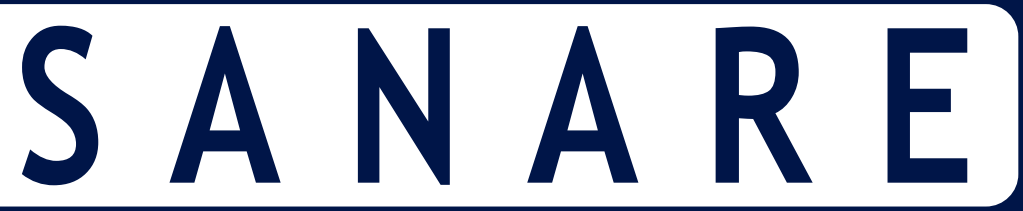

REVISTA DE POLÍTICAS PÚBLICAS

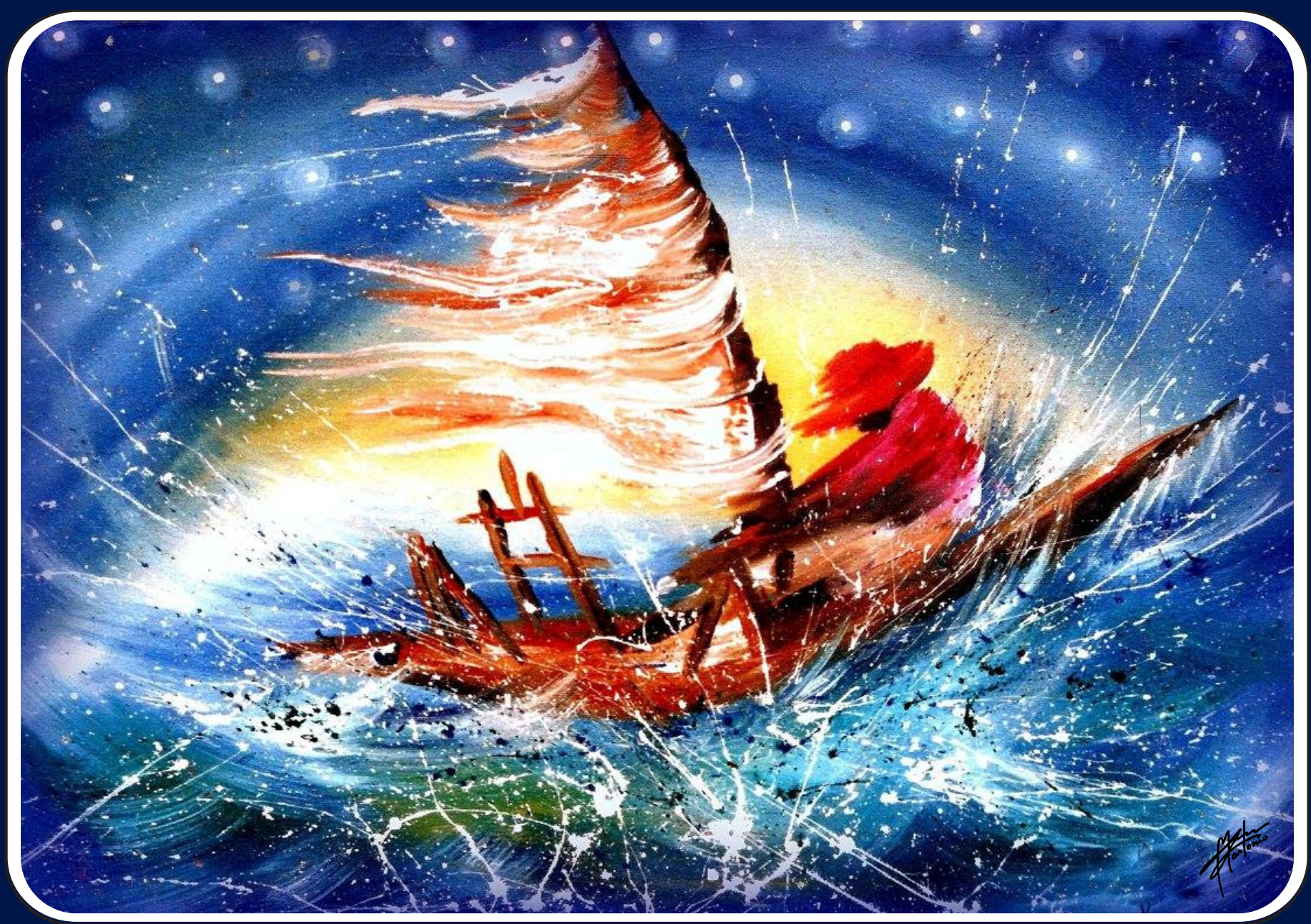




\section{SANARE}

Revista de Políticas Públicas de Sobral/CE v.17, n.1, p.01-135, Jan./Jun. 2018

Tornar sã, em latim, SANARE é uma revista de políticas públicas de Sobral/CE que tem por finalidade divulgar experiências em políticas públicas na área de saúde coletiva como forma de contribuir com o processo de elaboração e sistematização de novos paradigmas sobre gestão governamental.

\section{CONSELHO EDITORIAL}

\section{NACIONAL/NATIONAL}

Adriana Gomes N. Ferreira - UFMA, Imperatriz-MA Aluisio Ferreira de Lima - PUCSP,Fortaleza-CE Ana Cecilia Silveira Lins Sucupira, USP, São Paulo-SP Ana Mattos Brito de Almeida - ESP/CE, Fortaleza-CE

Andrea Silvia Walter de Aguiar - UFC, Fortaleza-CE Ant ${ }^{\circ}$ Germane Alves Pinto - URCA, Juazeiro do Norte - CE Anya Pimentel Gomes F. V. Meyer - FIOCruz, Fortaleza-CE Betise Mery Alencar Sousa Macau Furtado - UPE, Recife-PE Camilla Araújo Lopes Vieira - UFC, Sobral-CE Camilo Darsi de Souza - UNISC, Sta Cruz do Sul - RS Carlos Leonardo F. Cunha - UFRJ, Rio de Janeiro - RJ Cibelly Aliny Siqueira Lima Freitas - UVA, Sobral-CE Cristianne Maria Famer Rocha - UFRGS, Porto Alegre - RS Edson Holanda Teixeira - UFC, Fortaleza-CE Eliany Nazaré Oliveira - UVA, Sobral-CE

Érika Bárbara Abreu Fonseca Thomaz - UFMA, São Luís-MA Fabiane do Amaral Gubert - UFC, Fortaleza-CE Fernando Sérgio Pereira de Sousa - UFPI, Floriano-PI Francisco Arnoldo Nunes de Miranda - UFRN, Natal-RN Francisco Placido Nogueira Arcanjo - UFC,Sobral-CE

Fco Rosemiro Guimarães Ximenes Neto - UVA, Sobral-CE Geison Vasconcelos Lira - UFC, Sobral-CE Gerardo Cristino Filho - UFC, Sobral-CE Glauberto da Silva Quirino - URCA, Crato-CE Ivaldinete de Araújo Delmiro Gémes - UVA, Sobral-CE Izabelle Mont'Alverne N. Albuquerque - UVA, Sobral-CE Jeane Félix da Silva - UFRGS, Porto Alegre - RS José Jailson de Almeida Junior - UFRN, Santa Cruz-RN José Maria Ximenes Guimarães - UECE, Fortaleza-CE
José Olinda Braga - UFC, Fortaleza-CE José Reginaldo Feijão Parente - UVA, Sobral-CE Lucia de Fátima da Silva - UECE, Fortaleza-CE Luis Achilles Rodrigues Furtado - UFC, Sobral-CE Luiza Jane Eyre de Souza Vieira - UNIFOR, Fortaleza-CE Marcia Ma Mont'Alverne de Barros - UFPB, João Pessoa-PB Maria Adelane Monteiro da Silva - UVA, Sobral-CE Maria Corina Amaral Viana - URCA, Crato-CE Maria da Conceição Coelho Brito - EFSFVS, Sobral-CE Maria de Fatima Antero Sousa Machado - URCA, Crato-CE Maria de Nazaré de Oliveira Fraga - UFC, Sobral-CE Maria Fátima de Sousa - UnB, Brasília-DF Maria Rocineide Ferreira da Silva - UECE, Fortaleza-CE Maria Socorro de Araújo Dias - UVA, Sobral-CE Maria Veraci Oliveira Queiroz - UECE, Fortaleza-CE Maristela Inês Osawa Vasconcelos - UVA, Sobral-CE Milena Rodrigues Soares Mota - UNICEL, Manaus-AM Mirna Marques Bezerra Brayner - UFC, Sobral-CE Paulo Roberto Santos - UFC, Sobral-CE Roberta Cavalcante Muniz Lira - UFC, Sobral-CE Simone da Nóbrega Tomaz Moreira - UFRN, Natal-RN Vicente de Paulo Teixeira Pinto - UFC, Sobral-CE Yolanda Flores e Silva - UNIVALI, Itajaí- SC

\section{INTERNACIONAL/INTERNATIONAL}

\author{
Félix Fernando Monteiro Neto - Portugal \\ Francisco Antonio Loiola - Canadá \\ Mirella Maria Soares Veras - Canadá
}

Wilson Jorge Correia Pinto de Abreu - Portugal 


\section{PREFEITURA}

Ivo Ferreira Gomes

Prefeito

Gerardo Cristino Filho

Secretário da Saúde

Maria Socorro de Araújo Dias

Diretora da Escola de Formação em Saúde da Família Visconde de Sabóia

\section{PRODUÇÃO}

\section{Núcleo de Estudos e Pesquisas em Saúde da EFSFVS}

Maria Socorro de Araújo Dias

Editora Chefe

Maria da Conceição Coelho Brito

Editora Assistente

Antônio Felipe de Vasconcelos Neto

Diagramação
Evandro Lisboa Freire

Inglês, Espanhol (tradução)

Evandro Lisboa Freire

Revisões de Português

Martônio Holanda

Capa

Versão Digital

S A N A R E, Revista de Políticas Públicas

v.17, n.1, Jan./Jun. 2018

- Sobral[CE]: Escola de Formação em Saúde da Família Visconde de Sabóia, 2018.

Semestral

ISSN 1676-8019

ISSNe 2317-7748

1. Políticas Públicas - Sobral. 2. Políticas Públicas - Periódicos

É permitida a reprodução do material publicado, desde que citada a fonte.

Assinaturas e números anteriores:

Escola de Formação em Saúde da Família Visconde de Sabóia

Av. John Sanford, no 1320 - Bairro Junco - Sobral/CE

CEP: 62030-362 - Fone/Fax: (88) 3614.5520

e-mail: revista sanare@hotmail.com

Portal Sanare: http://sanare.emnuvens.com.br/ 
ESTRATIFICAÇÃO DE RISCO DAS CONDIÇÕES CRÔNICAS NA ATENÇÃO PRIMÁRIA À SAÚDE: A CONTRIBUIÇÃO DA PSICOLOGIA

RISK STRATIFICATION FOR CHRONIC CONDITIONS IN PRIMARY HEALTH CARE: THE CONTRIBUTION OF PSYCHOLOGY

ESTRATIFICACIÓN DE RIESGO DE LAS ENFERMEDADES CRÓNICAS EN LA ATENCIÓN PRIMARIA DE SALUD: LA CONTRIBUCIÓN DE LA PSICOLOGÍA

Cicero Gomes dos Santos Neto, Maria Idalice Silva Barbosa

15 PERFIL DE PACIENTES INTERNADOS PARA TRATAMENTO DE INSUFICIÊNCIA CARDÍACA DESCOMPENSADA

PROFILE OF PATIENTS HOSPITALIZED TO TREAT DECOMPENSATED HEART FAILURE PERFIL DE PACIENTES INTERNADOS PARA TRATAMIENTO DE INSUFICIENCIA CARDÍACA DESCOMPENSADA Paulo Átila da Silva Viana, Joaquim David Carneiro Neto, Camila Teles Novais, Isabelle Furquim Guimarães, Yan Sousa Lopes, Breno Cotrim Reis

24 WEB RADIO COMO FERRAMENTA DE DIÁLOGO EM SAÚDE COLETIVA NO SERTÃO: JUVENTUDES E MÉTODOS CONTRACEPTIVOS

WEB RADIO AS A TOOL FOR DIALOGUE IN COLLECTIVE HEALTH IN THE BRAZILIAN SERTÃO: YOUTHS AND CONTRACEPTIVE METHODS

WEB RADIO COMO UNA HERRAMIENTA DE DIÁLOGO EN SALUD COLECTIVA EN EL SERTÃO BRASILEÑO: JUVENTUDES Y MÉTODOS ANTICONCEPTIVOS

Leidy Dayane Paiva de Abreu, Raimundo Augusto Martins Torres, Maria Rocineide Ferreira da Silva, Aretha Feitosa de Araújo

32 AVALIABILIDADE DO PROGRAMA SAÚDE NA ESCOLA NO NORDESTE DO BRASIL

EVALUABILITY OF THE SCHOOL HEALTH PROGRAM IN NORTHEASTERN BRAZIL

EVALUACIÓN DEL PROGRAMA SALUD EN LA ESCUELA EN EL NORDESTE DE BRASIL

Maria Socorro de Araújo Dias, Lielma Carla Chagas da Silva, Maria da Conceição Coelho Brito, Alexandro do Vale Silva,

Rayanne Branco dos Santos Lima, Diógenes Farias Gomes, Angelo Brito Rodrihues

43 LEVANTAMENTO ETNOBOTÂNICO DE ESPÉCIES VEGETAIS UTILIZADAS NA ODONTOLOGIA NO RECÔNCAVO BAIANO

ETHNOBOTANICAL SURVEY OF PLANT SPECIES USED IN DENTISTRY IN THE RECÔNCAVO BAIANO, BRAZIL LEVANTAMIENTO ETNOBOTÁNICO DE ESPECIES VEGETALES UTILIZADAS EN ODONTOLOGÍA EN EL RECÔNCAVO BAIANO, BRAZIL

Geovane Silva de Araújo, Elba Brito dos Santos, Patrícia Pinto dos Santos Silva,,Vania Jesus dos Santos de Oliveira, Noelma Miranda de Brito

51 PERFIL EPIDEMIOLÓGICO DOS CASOS DE LEISHMANIOSE VISCERAL EM SOBRAL-CE DE 2011 A 2015

EPIDEMIOLOGICAL PROFILE OF CASES OF VISCERAL LEISHMANIASIS IN SOBRAL, CEARÁ, BRAZIL, FROM 2011 TO 2015

PERFIL EPIDEMIOLÓGICO DE LOS CASOS DE LEISHMANIASIS VISCERAL EN SOBRAL, CEARÁ, BRASIL, DE 2011 A 2015

Natanael Aguiar de Sousa, Carlito Braga Linhares, Francisco Gustavo Barbosa Pires, Taynã Cesário Teixeira, Joab da Silva Lima, Maria do Livramento Oliveira Nascimento

58 O PODER DO PODER DE POLÍCIA À LUZ DO DIREITO SANITÁRIO E DA VIGILÂNCIA SANITÁRIA

THE POWER OF POLICE POWER IN THE LIGHT OF HEALTH LAW AND HEALTH SURVEILLANCE

EL PODER DEL PODER DE POLICÍA A LA LUZ DEL DERECHO SANITARIO Y DE LA VIGILANCIA SANITARIA

Antônio Augusto Vieira de Aragão, Sydia Rosana de Araújo Oliveira 

REVISÃO INTEGRATIVA DE LITERATURA

EVALUATING PROBLEM-SOLVING AND EFFECTIVENESS OF PRIMARY HEALTH CARE: INTEGRATIVE LITERATURE REVIEW

EVALUACIÓN DE LA RESOLUCIÓN DE PROBLEMAS Y LA EFECTIVIDAD DE LA ATENCIÓN PRIMARIA DE SALUD: REVISIÓN INTEGRADORA DE LITERATURA

Maristela Inês Osawa Vasconcelos, Aparecida Lara Carlos Xavier, Maksoane Nobre do Nascimento, Yanka Alcântara Cavalcante, Sibele Pontes Rocha, Josiane da Silva Gomes

74 INCLUSÃO DO EDUCADOR FÍSICO NA ATENÇÃO PRIMÁRIA À SAÚDE: REVISÃO INTEGRATIVA

INCLUDING THE PHYSICAL EDUCATOR IN PRIMARY HEALTH CARE: INTEGRATIVE REVIEW INCLUSIÓN DEL EDUCADOR FÍSICO EN LA ATENCIÓN PRIMARIA DE SALUD: REVISIÓN INTEGRADORA

Jefferson Carlos Araújo Silva, Kamila Santos da Silva, Carlos Martins Neto, Thalita Cristinny Araujo Silva, Alexandre Soares de Campos

84 PRODUÇÃO DO CUIDADO NA REDE DE ATENÇÃO AO CÂNCER DE MAMA: REVISÃO INTEGRATIVA

PRODUCTION OF CARE IN THE BREAST CANCER CARE NETWORK: INTEGRATIVE REVIEW PRODUCCIÓN DEL CUIDADO EN LA RED DE ATENCIÓN AL CÁNCER DE MAMA: REVISIÓN INTEGRADORA Francisca Alanny Rocha Aguiar, Thaianny Cordeiro de Sousa, July Grassiely de Oliveira Branco, Francisca Bertilia Chaves Costa, Amélia Romana Almeida Torres, Lidyane Parente Arruda

93 TIMEROSAL CONTIDO EM VACINAS E TRANSTORNOS DO ESPECTRO AUTISTA: REVISÃO DE LITERATURA

THIMEROSAL-CONTAINING VACCINES AND AUTISM SPECTRUM DISORDERS: LITERATURE REVIEW TIMEROSAL CONTENIDO EN VACUNAS Y TRASTORNOS DEL ESPECTRO AUTISTA: REVISIÓN DE LITERATURA Vinicius da Silva Pires

102 ACOLHIMENTO ÀS PESSOAS EM SOFRIMENTO PSÍQUICO: DESAFIO À REFORMA PSIQUIÁTRICA

EMBRACING PEOPLE WHO SUFFER FROM PSYCHOLOGICAL STRESS: CHALLENGE TO THE PSYCHIATRIC REFORM ACOGIMIENTO A LAS PERSONAS QUE SUFREN DE ESTRÉS PSICOLÓGICO: DESAFÍO A LA REFORMA PSIQUIÁTRICA Karolyne Braga Moreira, Camilla Araújo Lopes Vieira

110 VIVÊNCIAS NA REDE DE SAÚDE E PSICOLOGIA: INTERAÇõES DA RESIDÊNCIA MULTIPROFISSIONAL EM SAÚDE DA FAMÍLIA

EXPERIENCES IN HEALTH NETWORK AND PSYCHOLOGY: INTERACTIONS OF THE MULTIPROFESSIONAL RESIDENCY IN FAMILY HEALTH VIVENCIAS EN LA RED DE SALUD Y PSICOLOGÍA: INTERACCIONES DE LA RESIDENCIA MULTIPROFESIONAL EN SALUD DE LA FAMILIA

Ana Karina de Sousa Gadelha, Amanda Colares Bezerra, George Luiz Costa de Paula, Paulo Cesar de Moura Luz

119 VIVÊNCIAS E ESTÁGIOS NA REALIDADE DO SISTEMA ÚNICO DE SAÚDE: DEBATENDO GÊNERO, FEMINISMO E DIVERSIDADE

EXPERIENCES AND INTERNSHIPS IN THE REALITY OF THE BRAZILIAN NATIONAL HEALTH SYSTEM: DEBATING GENDER, FEMINISM AND DIVERSITY EXPERIENCIAS Y PASANTÍAS EN LA REALIDAD DEL SISTEMA ÚNICO DE SALUD BRASILEÑO: DEBATIENDO GÉNERO, FEMINISMO Y DIVERSIDAD

Gilson Aquino Cavalcante, Jonatas Gomes Neri, Sueli Alves Castanha, Juciano de Sousa Lacerda

125 SOBRECARGA DOS CUIDADORES DE IDOSOS: RELATO DE EXPERIÊNCIA

OVERLOAD OF CAREGIVERS OF THE ELDERLY: EXPERIENCE REPORT

SOBRECARGA DE LOS CUIDADORES DE ANCIANOS: RELATO DE EXPERIENCIA

Gabriela Medeiros Steindorff, Sidnei Batista de Oliveira Junior, Diogo da Rosa Viana, João Nunes Maidana Júnior, Cenir Gonçalves Tier, Vanessa Alvez Mora da Silva 


\section{DESPERTAR A INTERPROFISSIONALIDADE: UM DESAFIO GESTOR}

0 contexto econômico global atual demanda por organizações que tenham em sua dinâmica cotidiana a cultura de buscar melhoria contínua, eliminar desperdícios e desenvolver habilidades e competências no seu capital humano ${ }^{1}$. Tal aspecto harmoniza-se com a proposta da gestão do município de Sobral-CE, que busca potencializar o desenvolvimento de práticas interprofissionais como estratégia que otimiza os processos de trabalho e a resolução de situações complexas.

Nesse intento, o Lean colabora a atuar como um sistema integrado de princípios e de ferramentas de base científica voltadas para a análise dos processos e para a redução dos desperdícios, a sincronização e redução de variabilidade nos processos de trabalho². A introdução do pensamento Lean na saúde, ou seja, Lean healthcare, ocorreu de maneira estruturada e sistemática a partir de $2006^{3}$, em que o foco esta nas atividades que produzem valor às pessoas, além da redução dos tempos de espera e erros ${ }^{4}$.

Sintonizado a isso, o município de Sobral-CE vem incorporando gradativamente o Lean, com movimentos disparados em suas secretarias e alcançando os diversos serviços a elas vinculados. A Secretaria da Saúde de Sobral foi instigada a fomentar processos de trabalhos mais eficientes orientados pelo Lean a partir de 2017.

Além disso, as proposições das práticas de gestão na saúde do município alinham-se a um movimento mundial que reconhece a colaboração interprofissional como essencial para a oferta de serviços de saúde com qualidade e resolubilidade. Uma equipe de saúde colaborativa sabe como otimizar as habilidades de seus membros, compartilhar o gerenciamento de casos e prestar serviços de saúde de melhor qualidade à comunidade 5 .

Esses aspectos se conformam à gestão Lean, pois reiteram a importância do comprometimento da equipe de saúde, da autonomia desta, de sua eficiência e da importância do trabalho colaborativo. Ademais, alinham o município de Sobral com movimentos mundiais de melhoria do acesso e da qualidade dos serviços de saúde.

0 exposto exalta o apresentado nesse primeiro número de 2018 da SANARE - Revista de Políticas Públicas, em que há um convite a pensar a atenção à saúde sob o olhar da interprofissionalidade, considerando a diversidade de percepções e o envolvimento de autores das mais diferentes áreas e cenários.

Os artigos têm como eixos centrais de discussão: as condições crônicas de saúde que geram impactos complexos na atenção a ser ofertada; a utilização da escola como espaço potente e de transformação na atenção à saúde de adolescentes; o despertamento para o necessário entendimento epidemiológico e de vigilância sanitária, de modo a fortalecer práticas eficientes em saúde; a problematização do cuidado na Atenção Básica e em pontos específicos da Rede de Atenção à Saúde.

Convidamos você, apreciador de importantes questões da Saúde Coletiva, a se dedicar à leitura desse número e refletir sobre diferentes dimensões e complexidades da atenção à saúde em diversos coletivos.

Boa leitura!

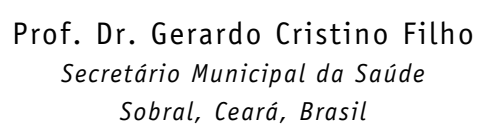

1. Gonçales MF, Prado AE, Campos FC. Logística, cadeia de suprimentos e pensamento enxuto nas organizações: uma análise bibliométrica. Espacios]. 2014;35(13):13.

2. Womack JP, Jones DT, Roos D. The machine that changed the world. New York: Simon and Schuster; 1990.

3. Silberstein ACL. Um estudo de casos sobre a aplicação de princípios enxutos em serviços de saúde no Brasil [dissertação]. Rio de Janeiro: Universidade Federal do Rio de Janeiro; 2006.

4. Lapão LV. Lean na gestão da saúde: uma oportunidade para fomentar a centralidade do doente, o respeito pelos profissionais e a qualidade nos serviços de saúde. Acta Med Port. 2016;29(4):237-9.

5. Organização Mundial da Saúde. Marco para ação em educação interprofissional e prática colaborativa. Redes de profissões de saúde. Enfermagem e obstetrícia. Recursos humanos para a saúde. Brasília (DF): Organização Mundial da Saúde; 2010. 


\title{
ESTRATIFICAÇÃO DE RISCO DAS CONDIÇÕES CRÔNICAS NA ATENÇÃO PRIMÁRIA À SAÚDE: A CONTRIBUIÇÃO DA PSICOLOGIA
}

\author{
RISK STRATIFICATION FOR CHRONIC CONDITIONS IN PRIMARY HEALTH
}

CARE: THE CONTRIBUTION OF PSYCHOLOGY

ESTRATIFICACIÓN DE RIESGO DE LAS ENFERMEDADES CRÓNICAS EN LA ATENCIÓN PRIMARIA DE SALUD: LA CONTRIBUCIÓN DE LA PSICOLOGÍA

Cicero Gomes dos Santos Neto ${ }^{1}$

Maria Idalice Silva Barbosa ${ }^{2}$

Palavras-chave: Psicologia; Atenção Primária à Saúde; Doença Crônica.

Keywords: Psychology; Primary Health Care; Chronic Disease.

Palabras clave: Psicología; Atención Primaria de Salud; Enfermedad Crónica.

Submetido:

$12 / 12 / 2017$

Aprovado:

$10 / 05 / 2018$

Autor(a) para Correspondência: Cicero Gomes dos Santos Neto End: Rua Travessa Fausto Crispim, 190 $B$, Centro

CEP: 62970-000, Alto Santo- CE. E-mail: ciceroneto3331@hotmail.com

\section{RESUMO}

A construção do Sistema Único de Saúde (SUS) e a Reforma Psiquiátrica no Brasil geraram novos espaços para a atuação dos profissionais de psicologia e a necessidade de refletir sobre suas práticas. Este estudo teve por objetivo investigar a percepção do psicólogo na atenção primária à saúde (APS) em Tauá-CE sobre seu papel diante dos usuários com condições crônicas estratificadas. Trata-se de estudo descritivo, exploratório, com abordagem qualitativa. Participaram do estudo 4 psicólogas que trabalhavam na APS do municipio. Aplicou-se uma entrevista semiestruturada e um grupo focal para coleta de informações, mediante gravação. Os dados foram submetidos a análise do conteúdo categorial, que originou as seguintes categorias: 1) Percepção da organização da atenção primaria à saúde em Tauá; $e$ 2) Percepção das contribuições da psicologia no controle das condições crônicas estratificadas. Os profissionais reconheceram a importância da estratificação de risco para o acompanhamento e direcionamento das ações, porém, não se constatou quais são os parâmetros adotados na linha de cuidado a partir do grau de risco identificado para as condições crônicas, tampouco qual é a contribuição específica do psicólogo com o acompanhamento desses usuários, diferenciando sua abordagem a partir do grau de risco identificado por meio da estratificação realizada pela planificação da APS em Tauá.
1. Psicólogo. Especialista em Saúde da Família e Comunidade pela Escola de Saúde Pública do Ceará (ESP/CE). Servidor Público da Prefeitura Municipal de Alto Santo-CE. Alto Santo (CE), Brasil. E-mail: ciceroneto3331@ hotmail.com

2. Psicóloga. Doutora em Saúde Coletiva pela Universidade Federal do Ceará (UFC). Assessora do Núcleo de Educação Permanente da Prefeitura Municipal de Caucaia-CE. Fortaleza (CE), Brasil. E-mail:idaliceb@gmail.com 


\section{ABSTRACT}

The construction of the Brazilian National Health System (SUS) and the Psychiatric Reform in Brazil have generated new working spaces for psychology practitioners and the need to think through their practices. This study aimed to investigate the psychologist's view within primary health care (PHC) in Tauá, Ceará, Brazil, about his role in the face of users with stratified chronic conditions. This is a descriptive, exploratory study with a qualitative approach. Four psychologists who worked within the PHC in the municipality participated in the study. A semistructured interview and a focus group were used to collect information, by means of recording. Data underwent categorical content analysis, which originated the following categories: 1) Perception of the organization of primary health care in Tauá, Ceará, Brazil; and 2) Perception of psychology's contributions to control stratified chronic conditions. Practitioners recognized the significance of risk stratification for following-up and driving the actions, however, there was no evidence of the parameters adhered to in the health care line based on the degree of risk identified for chronic conditions, nor which is the specific psychologist's contribution to monitoring these users, making his approach unique through the degree of risk identified by means of the stratification conducted by planning the PHC in Tauá.

\section{RESUMEN}

La construcción del Sistema Único de Salud Brasileño (SUS) y la Reforma Psiquiátrica en Brasil han generado nuevos espacios de trabajo para los profesionales de psicología y la necesidad de reflexionar sobre sus prácticas. Este estudio tuvo como objetivo investigar la percepción del psicólogo en la atención primaria de salud (APS) en Tauá, Ceará, Brasil, sobre su papel ante los usuarios con condiciones crónicas estratificadas. Este es un estudio descriptivo y exploratorio con un abordaje cualitativo. Cuatro psicólogas que trabajaban en la APS en el municipio participaron del estudio. Se aplicó una entrevista semi-estructurada y un grupo focal para recoger información, mediante grabación. Los datos fueron sometidos al análisis de contenido categórico, que originó las siguientes categorías: 1) Percepción de la organización de la atención primaria de salud en Tauá, Ceará, Brasil; y 2) Percepción de las contribuciones de la psicología para control de las condiciones crónicas estratificadas. Los profesionales reconocieron la importancia de la estratificación del riesgo para el seguimiento y la conducción de las acciones, pero no se constató cuáles son los parámetros adoptados en la línea de cuidado desde el grado de riesgo identificado para las condiciones crónicas, tampoco cuál es la contribución específica del psicólogo con el acompañamiento de estos usuarios, diferenciando su abordaje desde el grado de riesgo identificado mediante la estratificación realizada por la planificación de la APS en Tauá.

\section{INTRODUÇÃO}

As mudanças na organização do setor saúde a partir da criação do Sistema Único de Saúde (SUS) e os efeitos da Reforma Psiquiátrica no Brasil geraram novos espaços para a atuação dos profissionais de psicologia. Em meio a tais transformações, mostra-se necessário refletir sobre as práticas psicológicas no âmbito das políticas de saúde ${ }^{1}$.

Após duas décadas de existência do SUS e a inserção da psicologia nos serviços de saúde, estudos científicos indicam a necessidade de atualizar o processo de formação nessa área para que os profissionais sejam capazes de lidar com a transposição da clínica tradicional - que tende a negligenciar as singularidades do contexto no qual os sujeitos estão inseridos ${ }^{2-4}$.

Para aumentar a resolutividade nas unidades da Estratégia Saúde da Família (ESF) foram criados os núcleos de apoio à saúde da família (Nasf), por meio da Portaria n. 154/20085. Tendo sua atuação pautada por 9 áreas estratégicas, dentre elas a saúde mental, onde o profissional de psicologia costuma atuar como articulador da equipe ${ }^{6}$, o Nasf foi o marco para inserção da psicologia na atenção primária à Saúde (APS) - inicialmente voltada à prática hospitalar ${ }^{7}$.

Os avanços têm sido notáveis nesse processo de reorganização do setor saúde, porém, estudos científicos nacionais e internacionais demonstram que as ações não atendem às demandas de saúde atuais, com prevalência de doenças crônicas atendidas em episódios de agudização ${ }^{8}$.

Segundo o Ministério da Saúde, as doenças cardiovasculares e a diabetes são as principais causas de morte no Brasil; no período de 1996 a 2009 houve declínio da taxa de mortalidade por doenças cardiovasculares e aumento da taxa de mortalidade por diabetes no país. No Ceará e na região Nordeste houve tendência de aumento de ambos os problemas de saúde no período analisado ${ }^{9}$. 
Para superar essas fragilidades, deve-se repensar a organização do cuidado em redes de atenção à saúde (RAS), formadas pelo conjunto de serviços de saúde interligados por objetivos comuns e ações cooperativas de modo contínuo e integral ${ }^{10}$. Assim, busca-se superar a visão fragmentada do sujeito, mudando o foco da doença para a saúde e levando em consideração o contexto social, as condições econômicas e as subjetividades de cada populaçã $0^{8}$.

Tendo em vista a importância da APS para a organização das RAS e a efetivação do SUS, o Conselho Nacional de Secretários de Saúde (Conass) propõe sua planificação como um processo de planejamento em saúde em seus macros e microprocessos ${ }^{11}$.

Considerando a relevância da APS para a efetividade das ações em saúde, Tauá-CE - em parceria com a Secretaria Estadual da Saúde do Estado do Ceará (Sesa), a Escola de Saúde Pública do Ceará (ESP/CE) e a Fundação Oswaldo Cruz (Fiocruz) implantou o Laboratório da Planificação da APS em janeiro de 2014, envolvendo todos profissionais que atuam nesse nível de atenção no município ${ }^{12}$.

A planificação da APS em Tauá é uma experiência pioneira porque ocorre no âmbito municipal. Normalmente, o Conass desenvolve seu trabalho em parceria com os estados, mediante adesão, com o objetivo assessorar as secretarias estaduais na reorganização de seu sistema de saúde, promovendo a integração das ações e serviços de saúde, o fortalecimento da APS e a consequente implantação das RAS, assessorando os municípios ${ }^{11,12}$. A planificação no âmbito municipal, em Tauá, foi possível porque a gestão em saúde já contava com $100 \%$ de cobertura na ESF e esse é um dos municípioslaboratório da Fiocruz, buscando inovar e qualificar seus processos de organização da APS ${ }^{12}$.

Com a planificação da APS realizou-se a estratificação de famílias, crianças até 2 anos e gestantes, além da população com condições crônicas de saúde (diabetes e hipertensão). Em fevereiro de 2015 ocorreu a oficina de estratificação de risco das condições crônicas, hipertensão arterial e diabetes, classificadas como baixo risco, médio risco e alto risco. Até setembro de 2016 se obteve, no município, $69,6 \%$ de hipertensos estratificados e $73,8 \%$ de diabéticos estratificados ${ }^{12}$. A classificação de risco das condições crônicas proporcionou às equipes multiprofissionais a construção de cronogramas de atividades pautados pelo grau de risco.

Em face das mudanças nos processos de trabalho, mostra-se necessário refletir sobre o papel dos

\section{A planificação da APS em Tauá é uma experiência pioneira porque ocorre no âmbito municipal.}

profissionais da saúde, levando em conta a constante avaliação das práticas de cada Nasf e o desenvolvimento de novas competências para lidar com as situações da APS $^{12}$ - como é o caso da atuação do profissional de psicologia. Este estudo teve por objetivo investigar a percepção do psicólogo na APS sobre seu papel diante dos usuários com condições crônicas (diabetes e/ou hipertensão) estratificadas.

\section{METODOLOGIA}

Trata-se de estudo descritivo, exploratório, com abordagem qualitativa realizado na APS de Tauá. Em 2016, o município tinha população estimada de 57.914 habitantes ${ }^{13}$ e contava com 25 equipes da ESF, organizadas em 5 macros (cada macro possui uma equipe que compõe um Nasf). Vale ressaltar que o Nasf da macro $V$ é formado por profissionais do município e, ainda, residentes em Saúde da Família e Comunidade (SFC). Convidamos os profissionais da psicologia que atuam na APS das 5 macrorregiões a participar do estudo, quais sejam, com base nestes critérios de inclusão: a) atuar no Nasf (mesmo que não tenha participado da planificação da APS); e b) assinar o termo de consentimento livre e esclarecido para confirmar sua participação voluntária.

A coleta de informações ocorreu em março de 2017, com aplicação de questionário para levantamento do perfil dos profissionais de psicologia que atuam na APS, tendo como variáveis: a) sexo; b) idade; c) tempo de formação; d) pós-graduação; e e) atuação na APS.

Recorremos ao grupo focal como técnica de coleta de informações, que consiste na utilização de materiais de estímulo para fomentar e sustentar discussões em grupo, possibilitando o intercâmbio de saberes e experiências entre os participantes ${ }^{14}$. As perguntas abordavam as seguintes temáticas: a) 0 papel do psicólogo na orientação dos usuários quanto ao processo de estratificação das condições crônicas; 
b) a abordagem utilizada com os usuários após o processo de estratificação; e c) as ações de educação permanente adotadas com a equipe. As discussões foram gravadas para posterior análise.

Realizamos apenas 1 sessão de grupo focal, devido à dificuldade de encontrar horários disponíveis nas agendas das profissionais, o que inviabilizou a realização de outras sessões.

Para preservar a identidade dos participantes, suas falas são representadas numericamente de 1 a 4 após a letra "P" (participante do estudo).

Os dados foram submetidos a análise do conteúdo categorial, que visa a organizá-los em unidades temáticas e posterior reagrupamento em subcategorias que favorecem sua identificação e diferenciação em consonância com o objeto de pesquisa ${ }^{15}$.

Este estudo seguiu os princípios da Resolução $n$. 466/2012, do Conselho Nacional de Saúde (CNS) que estabelece os aspectos éticos de pesquisas com seres humanos ${ }^{16}$ - e obteve aprovação do Comitê de Ética da ESP/CE, sob o Parecer n. 1.957.227.

\section{RESULTADOS}

Todas as participantes eram do sexo feminino, com idades entre 25 e 39 anos e tempo de graduação variando entre 1 e 5 anos; 3 delas eram especialistas e 1 tinha residência multiprofissional em saúde da família (RMSF). 0 tempo de atuação na APS de todas as participantes variou de 1 a 5 anos. Vale ressaltar que 1 participante colaborou com o processo de planificação da APS na condição de ouvinte (por ter ingressado na fase final das oficinas); 1 participante colaborou como facilitadora; e as demais passaram a atuar na APS após a conclusão das oficinas de planificação.

A partir das reflexões produzidas no grupo focal, os resultados foram organizados em 2 categorias. Uma engloba o contexto do processo de planificação da APS e a outra as contribuições da psicologia no controle das condições crônicas estratificadas.

\section{Percepção da organização da atenção primaria à saúde em Tauá}

Esta categoria expressa reflexões relativas aos processos de organização da APS, sobretudo no que se refere a planificação da APS e a estratificação de risco das condições crônicas.

Os profissionais de psicologia visualizam o processo de planificação da APS como uma

\section{...estratificar os usuários para oferecer ações contextualizadas à realidade de cada sujeito...}

reorganização nos serviços oferecidos à população, mas não se resumindo a oferecer um cardápio de serviços ou ações padronizadas; busca-se a construção de um novo modo de pensar o setor saúde, levando em conta as particularidades de cada sujeito. A planificação da APS é entendida como um processo de constante avaliação e transformação - como evidenciam estas falas:

Planificar eu acredito que seria no intuito de ajustar, fazer ajustes, de verificar o que tem de fato, o que precisa ser melhorado, o que pode ser melhorado. Está relacionado à organização do processo de trabalho. (P1) Organiza o trabalho. Faz com que as filas diminuam. (P2)

[...] reorganizar um processo que estava sendo feito num viés de cima para baixo, mas construir saúde com o paciente e não para o paciente... ( $P 1)$

0 que motivou os profissionais a ter um novo olhar para nossa atuação. Não os usuários, mas nós nos sentirmos importantes. (P1)

Os profissionais reconhecem a importância de estratificar os usuários para oferecer ações contextualizadas à realidade de cada sujeito, direcionando o cuidado às suas reais demandas de saúde. Reconhecem a estratificação como um processo realizado pelo médico, enfermeiro e dentista, fazendo uso posterior dos resultados obtidos por esses profissionais para a construção das ações, a partir dos encaminhamentos da equipe de referência, porém, não sabem se é um processo restrito a esses profissionais. Fazem alusão à necessidade de aprofundamento no instrumental, para uma possível contribuição, assim como evidenciam estas falas:

[...] assim, a estratificação é vista como um dos instrumentos para se conhecer 
melhor tanto a família, o contexto, quanto o paciente. Porque a partir da história da doença, do cotidiano, do olhar voltado para o todo e não só para o processo saúde-doença é que a gente consegue identificar, intervir, encaminhar e ver possibilidade de estar com esse paciente sendo contemplado nas necessidades dele, quais pontos de atenção devem ser encaminhados a partir dessa estratificação, a gente fica conhecendo bem onde pode fazer os encaminhamentos... (P1) [...] eu acho que ainda está muito fechado, [fica] muito entre médico, enfermeiro e dentista. Só apenas quando eles estão estratificados é que são encaminhados, na atenção continuada [...] a gente conhece, sabe a importância, conhece todo o processo, mas participar da estratificação a gente não participa. (P2)

Eu acredito que esse seja um instrumento que foi de responsabilidade desses profissionais específicos que foram falados: médico, enfermeiro e dentista. Por isso que a conduta acontece a partir desses profissionais, mas eu não sei dizer se ele é específico deles. (P1)

[...] a gente precisa conhecer melhor esse instrumento porque, na verdade, eu acredito que a gente, por não participar, não se aprofundou [para] conhecer. (P1)

\section{Percepção das contribuições da psicologia no controle das condições crônicas estratificadas}

Nesta subseção, abordamos as contribuições dos psicólogos com o controle das condições crônicas estratificadas, a partir das seguintes questões: a) colaboração no acompanhamento aos usuários; e b) ações desenvolvidas com a ESF para o acompanhamento das condições crônicas.

Agregamos, aqui, a visão de apoio ao usuário estratificado, no sentido de ajudá-lo a compreender possíveis alterações em seus comportamentos e hábitos em decorrência do processo de adoecimento, identificando possiveis fragilidades e potencialidades em seu contexto que favoreçam o processo de cuidado. Como evidenciam as seguintes falas:

$\mathrm{Na}$ minha realidade, é a partir das estratificações e chega aos encaminhamentos. Por exemplo, um paciente identificado como de alto risco eles fazem encaminhamentos para atenção secundária e as intervenções que são feitas na própria unidade são os atendimentos por cada categoria, individualmente e na participação de grupos. Temos o grupo das condições crônicas, [cuja] meta é qualidade de vida para os pacientes em condições crônicas. Atende diabéticos, hipertensos e outras cronicidades. (P1)

[...] $E$ de rotina. 0 psicólogo pode acompanhar. Ir até a residência pra conhecer a realidade e ver [...] as condições de ambiente. Os familiares, quem ajuda, quem não ajuda. Auxiliamos a pessoa a conviver com a condição crônica, a conviver com a doença. (P2)

[...] A gente tem o autocuidado apoiado. Agora é um plano na unidade que trabalha com esses pacientes estratificados. Aí, sim, são todos os profissionais da unidade. Seleciona os principais pacientes de médio e alto risco. Eles passam por todos os profissionais em um único dia. (P3)

Agrupamos as ideias relacionadas ao apoio matricial com a ESF para aumentar a resolutividade dos casos e o fortalecimento do trabalho interdisciplinar. Como indicam estes relatos:

Uma intervenção que é recorrente na realidade do meu território é porque [trabalhamos] em uma equipe que tem o propósito de apoiar as equipes da saúde, o que acontece. Eu trabalho nessa questão de investigar como está a conduta do profissional, se está dando certo. A gente discute nas reuniões de maneira compartilhada o caso [...] Por exemplo, o nutricionista diz que não tem jeito, que passa dieta, mas o paciente não atende, não faz, não está diminuindo. Vê se está ansioso. E a gente vê a motivação. (P1) Esse acompanhamento acontece a partir dos encaminhamentos e a visita domiciliar junto com ACS [agente comunitário de saúde], enfermeira e médico. (P3)

\section{DISCUSSÃO}

A planificação da APS em Tauá proporciona a construção de uma nova organização dos serviços pautada nas singularidades locais, porém, esse é 
apenas o início das transformações necessárias no sistema local de saúde. Tendo em vista que o modelo biomédico, construído ao longo de décadas, não será desconstruído com apenas 2 anos de formação e qualificação dos profissionais locais, almeja-se evoluir aos poucos diante das condições proporcionadas pela gestão municipal.

Em consonância, um estudo realizado com os profissionais da APS ressalta a importância da priorização da educação permanente em saúde pela gestão municipal e sua compreensão por parte dos profissionais para superação do modelo de saúde supracitado e a construção de serviços de saúde contextualizados com as demandas da comunidade ${ }^{17}$.

Observa-se certa rotatividade dos profissionais de psicologia na APS de Tauá, levando em consideração que, das 4 participantes, apenas 1 vivenciou todo 0 processo de planificação da APS - na condição de facilitadora. Tal fato contribui para a quebra dos processos de trabalho, devido à fragilização do vínculo entre a equipe e a comunidade, o que aponta a necessidade de construir estratégias para 0 fortalecimento da educação permanente como garantia de continuidade dos processos de trabalho implantados, buscando superar a rotatividade dos profissionais.

.Em relação à formação, observa-se que apenas 1 profissional tem especialização voltada à APS e as demais têm especialização em áreas afins da psicologia, indicando a necessidade de refletir 0 processo de formação e qualificação em psicologia voltadas ao compromisso social ${ }^{3-5}$.

No entanto, observamos nas falas ações voltadas aos processos de trabalho de modo geral na APS, que qualificam apenas os profissionais, porém, não foi possível visualizar no discurso momentos que promovam empoderamento dos usuários na construção das ações de saúde local - tão necessário para o fortalecimento da APS. Segundo estudos realizados no âmbito da APS, seus usuários tendem a visualizar as ações de saúde nesse contexto, relacionadas a consultas médicas e tendo, consequentemente, uma visão reducionista do conceito de saúde, com desvalorização de outros serviços disponíveis na APS e do trabalho interdisciplinar ${ }^{18}$.

De acordo com o Conass, a estratificação das condições crônicas da população com diabetes e hipertensão divide-se em 3 grupos: a) pessoas com condição leve, com capacidade de autocuidado e/ou com rede social de apoio; b) portadores de condição moderada; e c) pessoas em condição severa, com

\section{...a psicologia \\ pode enriquecer a \\ construção de práticas contextualizadas...}

baixa capacidade de autocuidado. Há um questionamento dos psicólogos em relação à sua participação no processo de estratificação em si. Ficou evidente a falta de clareza sobre a contribuição da psicologia com a estratificação. Isso é pertinente porque os critérios apontados pelo Conass incluem verificar a capacidade das pessoas com doenças crônicas para o autocuidado, bem como o potencial da rede social de apoio ${ }^{11}$.

Nesse contexto, a psicologia pode enriquecer a construção de práticas contextualizadas, pois o papel do psicólogo na APS se pauta em ações psicossociais, pedagógicas, investigativas e administrativas. 0 psicólogo deve colaborar para promover mudanças nas atitudes da população - seja por meio de grupos ou de modo individual - e identificar na comunidade parceiros que possam contribuir de alguma forma nas práticas de saúde da população. Com esse enfoque, o psicólogo assume um papel-chave no processo, visto que promove com os usuários a mudança de comportamento em relação ao processo de cuidado, facilitando a aproximação entre a equipe de saúde e a comunidade e promovendo a transformação social ${ }^{19}$.

Considerando as funções elencadas acima para 0 profissional de psicologia na APS, observamos algumas ações realizadas no município em atividades psicossociais e pedagógicas, mas que não apresentam um processo de avalição das ações desenvolvidas. A análise das informações obtidas demonstra que as ações específicas da psicologia junto aos pacientes com condições crônicas têm como base os encaminhamentos provenientes do resultado do processo de estratificação, os vínculos construídos com os sujeitos e a oferta de ações interdisciplinares. É notória a oferta de serviços conforme as diretrizes do Nasf. Vale ressaltar que, mesmo sabendo da importância da estratificação para o acompanhamento e direcionamento das ações, não ficam claros para os psicólogos os parâmetros adotados para a linha de cuidado, visto que o acesso, como relatado, decorre de encaminhamento dos pacientes de médio e alto risco por parte da equipe de referência. 
Os profissionais relataram que são realizadas as seguintes atividades junto aos pacientes com condições crônicas estratificadas: a) grupos com foco na educação em saúde (grupo de condições crônicas e sala de espera); b) visitas domiciliares compartilhadas com outros membros da ESF ou apenas por parte do núcleo da psicologia; c) atendimentos individuais, quando necessário; e d) autocuidado apoiado. Contudo, observamos que as falas não apresentam a construção de ações que levam em conta o grau de risco identificado junto aos sujeitos com estratificação, bem como o tipo de cuidado dispensado aos grupos a partir dos riscos.

As atividades em grupo são uma das principais formas de atuação dos profissionais de psicologia na APS, favorecendo a construção de práticas contextualizadas que adequam as ações aos princípios do SUS e à perspectiva da RAS ${ }^{20}$. Todavia, observamos que o desenvolvimento das atividades em grupo com - público das condições crônicas desconsidera 0 produto da estratificação de risco para alinhar o cuidado e, provavelmente, não produz efeitos significativos no território.

A visita domiciliar é uma ferramenta de extrema relevância para o trabalho do psicólogo, possibilitando compreender a dinâmica que envolve cada pessoa em seu contexto e contribuindo para estreitar os vínculos entre profissionais e sujeitos ${ }^{20}$. Desse modo, a visita domiciliar, realizada pelo profissional de psicologia aos pacientes com condições crônicas classificadas como de médio e alto risco, pode favorecer a identificação dos fatores que influenciam nas situações de agudização e dificuldades de adesão ao controle da condição crônica e nas mudanças de comportamento, como evidenciado pelos profissionais de psicologia de Tauá.

Pode-se destacar a tentativa de implantação do autocuidado apoiado como uma prática que não é exclusiva do núcleo da psicologia, porém, favorece o desenvolvimento do trabalho interdisciplinar na APS e o empoderamento dos sujeitos em relação aos cuidados com sua saúde ${ }^{21}$. Observamos no relato do grupo que há participação da psicologia junto aos pacientes com condições crônicas de médio e alto risco, porém, não se constata nos relatos clareza acerca do papel do psicólogo no processo de autocuidado apoiado. 0 profissional de psicologia pode auxiliar os pacientes com condições crônicas estratificadas na mudança de comportamento, no entanto, essa atuação não se mostra evidente no grupo.

\section{Para produzir um novo \\ enfoque em saúde [...] \\ o profissional de psicologia deve ampliar \\ o olhar para além das condições de saúde mental...}

0 apoio matricial na APS favorece o aumento da resolutividade das demandas de saúde no território, porém, não deve ser compreendido como o apoio de um especialista a uma demanda específica ${ }^{22}$. De acordo com os relatos do grupo, as ações são direcionadas apenas aos pacientes estratificados de médio e alto risco, mas não fica claro quais são as estratégias utilizadas para evitar as situações de agudização de pacientes com baixo risco.

Para produzir um novo enfoque em saúde, em especial envolvendo os usuários com condições crônicas estratificadas, o profissional de psicologia deve ampliar o olhar para além das condições de saúde mental, tendo em vista a dinâmica do contexto ${ }^{23}$. É notória a relevância do processo de planificação da APS para o desenvolvimento de um novo modelo de atenção à saúde. Contudo, mostra-se necessário refletir sobre o papel da psicologia diante das condições crônicas estratificadas, já que, mesmo após a implantação dos diversos processos de trabalho, continuam oferecendo as mesmas práticas na maioria das ações, as mesmas práticas - que desconsideram as singularidades da população devido à falta de utilização dos parâmetros na linha de cuidado.

\section{CONCLUSÃO}

Diante dos resultados, é importante salientar o processo de planificação da APS como ponto de partida para reflexões e construção de práticas pautadas pelas necessidades de saúde da população.

Observamos que o processo de estratificação favoreceu o surgimento de novas demandas de saúde, que exige constante avaliação e uma nova postura dos profissionais de psicologia para sua atuação na APS. Nesse sentido, é essencial pensar e favorecer o processo de educação permanente nos territórios para o êxito e a continuidade das ações, em virtude de 
serem espaços dinâmicos, com constantes mudanças que afetam as condições de saúde da população; além disso, as bases curriculares da formação em psicologia não atendem de modo efetivo às atuais questões em saúde.

Torna-se essencial discutir a inserção dos profissionais de psicologia na APS nessa perspectiva, para o desenvolvimento do compromisso social, favorecendo a construção de um amplo conceito de saúde. É fundamental adotar uma reflexão constante sobre as práticas para o desenvolvimento das políticas de saúde locais e o processo de qualificação profissional continuada.

\section{CONTRIBUIÇÃO DOS AUTORES}

Cicero Gomes dos Santos Neto contribuiu com o delineamento e a realização da pesquisa e a estruturação e redação do manuscrito. Maria Idalice Silva Barbosa contribuiu com o delineamento da pesquisa e a redação e revisão crítica do manuscrito.

\section{REFERÊNCIAS}

1. Azevedo NS, Kind L. Psicologia nos núcleos de apoio à saúde da família em Belo Horizonte. Psicol Ciênc Prof [serial on the internet]. 2013 [cited 2018 May 4];33(3):520-35. Available from: http://www.scielo.br/pdf/pcp/v33n3/ v33n3a02.pdf

2. Dimenstein MDB. 0 psicólogo nas unidades básicas de saúde: desafios para a formação e atuação profissionais. Estud Psicol (Natal) [serial on the internet]. 1998 [cited 2018 May 4];3(1):53-81. Available from: http://www.scielo. br/pdf/epsic/v3n1/a04v03n1.pdf

3. Dimenstein MDB. A cultura profissional do psicólogo e o ideário individualista: implicações para a prática no campo da assistência pública à saúde. Estud Psicol (Natal) [serial on the internet]. 2000 [cited 2018 May 4];5(1):95-121. Available from: http://www.scielo.br/pdf/epsic/v5n1/ a06v05n1.pdf

4. Andrade JFSM, Simon CP. Psicologia na atenção primária à saúde: reflexões e implicações práticas. Paidéia [serial on the internet]. 2009 [cited 2018 May 4];19(43):167-75. Available from: http://www.scielo.br/pdf/paideia/ $\underline{v 19 n 43 / 04 . p d f}$

5. Brasil. Portaria n. 154, de 24 de janeiro de 2008. Cria os Núcleos de Apoio à Saúde da Família - NASF [document on the internet]. 2008 [cited 2018 May 18]. Available from: http://bvsms.saude.gov.br/bvs/saudelegis/gm/2008/ prt0154 $2401 \quad 2008 . \mathrm{html}$

6. Brasil. Diretrizes do NASF: núcleo de apoio à saúde da família [document on the internet]. Brasília (DF): Ministério da Saúde; 2010 [cited 2018 May 18]. (Cadernos de Atenção Básica). Available from: http://189.28.128.100/dab/docs/ publicacoes/cadernos ab/abcad27.pdf

7. Pitombeira DF, Xavier AS, Barroso REC, Oliveira PRS. Psicologia e a formação para a saúde: experiências formativas e transformações curriculares em debate. Psicol Ciênc Prof [serial on the internet]. 2016 [cited 2018 May 4];36(2):280-91. Available from: http://www.scielo.br/pdf/ pcp/v36n2/1982-3703-pcp-36-2-0280.pdf

8. Mendes EV. A construção social da atenção primária à saúde [document on the internet]. Brasília (DF): Conselho Nacional de Secretários de Saúde; 2015 [cited 2018 May 18]. Available from: http://www.saude.go.gov.br/wp$\begin{array}{ccccccc}c & 0 & n & t & e & n & t\end{array}$ uploads/2016/12/a-construcao-social-da-atencao-primariaa-saude.pdf

9. Brasil. Sistema Nacional de Vigilância em Saúde: relatório de situação - Ceará [document on the internet]. 5. ed. Brasília (DF): Ministério da Saúde; 2011 [cited 2018 May 18]. Available from: http://bvsms.saude.gov.br/bvs/ publicacoes/sistema nacional vigilancia saude ce 5ed.pdf

10. Mendes EV. As redes de atenção à saúde [document on the internet]. Brasília (DF): Organização Pan-Americana da Saúde; 2011 [cited 2018 May 18]. Available from: http:// bvsms.saude.gov.br/bvs/publicacoes/redes de atencao saude.pdf

11. Brasil. Planificação da atenção primária à saúde nos estados [document on the internet]. Brasília (DF): Conselho Nacional de Secretários de Saúde; 2011 [cited 2018 May 18]. Available from: http://www.conass.org.br/ conassdocumenta/cd_23.pdf

12. Tauá (Município). Relatório da Planificação da Atenção Primária à Saúde de Tauá. Tauá (CE): Prefeitura Municipal de Tauá; 2016.

13. Instituto Brasileiro de Geografia e Estatística. Censo 2010 [homepage on the internet]. Brasília (DF): IBGE; 2010 [cited 2018 May 18]. Available from: https://censo2010. ibge.gov.br/

14. Ressel LB, Beck CLC, Gualda DMR, Hoffmann IC, Silva RM, Sehnem GD. 0 uso do grupo focal em pesquisa qualitativa. Texto \& Contexto Enferm [serial on the internet]. 2008 [cited 2018 May 18];17:779-86. Available from: http:// www.index-f.com/textocontexto/2008pdf/17-779786.pdf

15. Bardin L. Análise de conteúdo. São Paulo: Ed.70;2011.

16. Brasil. Resolução n. 466, de 12 de dezembro de 2012. Dispõe sobre pesquisas que envolvam seres humanos [document on the internet]. 2012 [cited 2018 May 18]. Available from: http://conselho.saude.gov.br/ resolucoes/2012/Res0466.pdf

17. Carvalho TGS, Almeida AMB, Bezerra MIC. Percepção dos profissionais de saúde da atenção primária sobre educação 
permanente em saúde. Sanare (Sobral, Online) [serial on the internet]. 2016 [cited 2018 May 18];15(2):94-103. Available from: https://sanare.emnuvens.com.br/sanare/article/ view $/ 1043 / 589$

18. Barbosa LA, Oliveira CC, Dantas TM. Percepção de usuários da atenção primária sobre a Estratégia de Saúde da Família. Saúde e Transformação Social [serial on the internet]. 2012 [cited 2018 May 18];3(4):37-43. Available from: http://incubadora.periodicos.ufsc.br/index.php/ saudeetransformacao/article/view/1617/2239

19. Ronzani TM, Rodrigues MC. 0 psicólogo na atenção primária à saúde: contribuições, desafios e redirecionamentos. Psicol Ciênc Prof [serial on the internet]. 2006 [cited 2018 May 18];1:132-43. Available from: http:// pepsic.bvsalud.org/pdf/pcp/v26n1/v26n1a12.pdf

20. Gorayeb R, Borges CD, Oliveira CM. Psicologia na atenção primária: ações e reflexões em programa de aprimoramento profissional. Psicol Ciênc Prof [serial on the internet]. 2012 [cited 2018 May 18];32(3):674-85._Available from: http:// www.scielo.br/pdf/pcp/v32n3/v32n3a12.pdf

21. Mendes EV. 0 cuidado das condições crônicas na atenção primária à saúde: o imperativo da consolidação da Estratégia da Saúde da Família [document on the internet]. Brasília (DF): Organização Pan-Americana da Saúde; 2012 [cited 2018 May 18]. Available from: http://bvsms.saude.gov.br/ bvs/publicacoes/cuidado condicoes atencao primaria saude.pdf

22. Campos GWS, Domitti AC. Apoio matricial e equipe de referência: uma metodologia para gestão do trabalho interdisciplinar em saúde. Cad Saúde Pública [serial on the internet]. 2007 [cited 2018 May 18];23(2):399-407. Available from: http://www.scielo.br/pdf/csp/v23n2/16.pdf

23. Franco A, Mota E. Distribuição e atuação dos psicólogos na rede de unidades públicas de saúde no Brasil. Psicol Ciênc Prof [serial on the internet]. 2003 [cited 2018 May 18];23(3):50-9. Available from: http://www.scielo.br/pdf/ $\mathrm{pcp} / \mathrm{v} 23 \mathrm{n} 3 / \mathrm{v} 23 \mathrm{n} 3 \mathrm{a} 08 . \mathrm{pdf}$ $\ldots \ldots \ldots \ldots \ldots \ldots$

$\ldots \ldots \ldots \ldots \ldots$

$\ldots \ldots \ldots \ldots \ldots \ldots$ $\ldots \ldots \ldots \ldots \ldots \ldots$

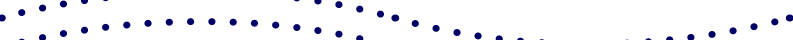
$\ldots \ldots \ldots \ldots \ldots \ldots \ldots$ $\ldots \ldots \ldots \ldots \ldots \ldots \ldots \ldots$ ....................

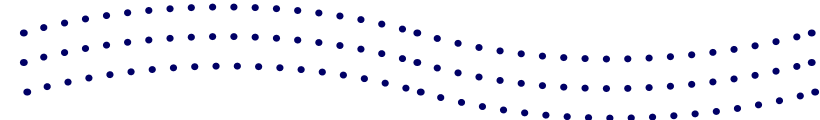

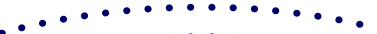

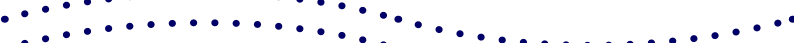
$\ldots \ldots \ldots \ldots \ldots \ldots \ldots$

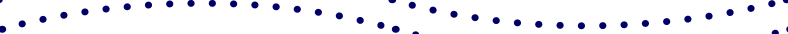
(
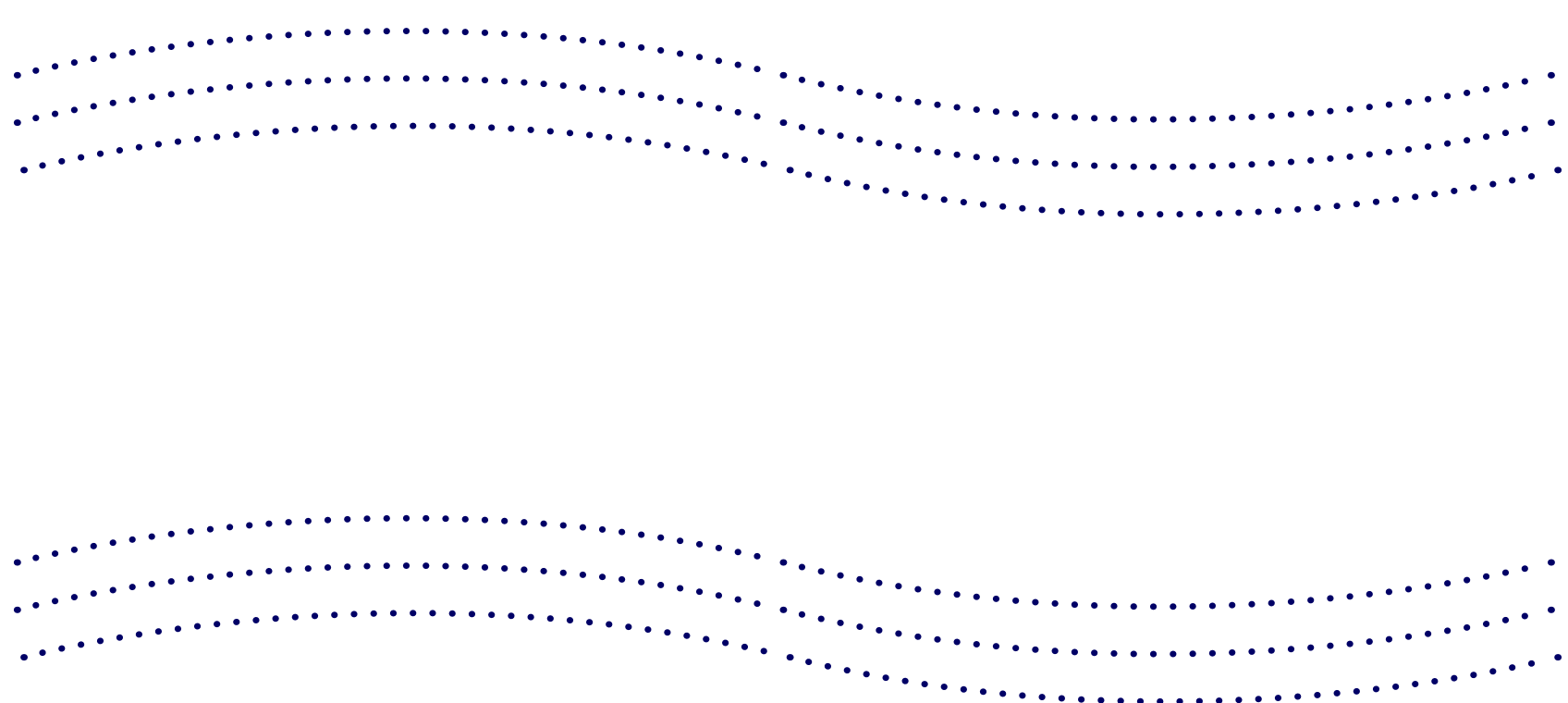


\section{PERFIL DE PACIENTES INTERNADOS PARA TRATAMENTO DE INSUFICIÊNCIA CARDÍACA DESCOMPENSADA}

PROFILE OF PATIENTS HOSPITALIZED TO TREAT DECOMPENSATED HEART

FAILURE

PERFIL DE PACIENTES INTERNADOS PARA TRATAMIENTO DE INSUFICIENCIA CARDÍACA DESCOMPENSADA

Paulo Átila da Silva Viana ${ }^{1}$ Joaquim David Carneiro Neto ${ }^{2}$ Camila Teles Novais ${ }^{3}$ Isabelle Furquim Guimarães 4

Yan Sousa Lopes ${ }^{5}$ Breno Cotrim Reis 6

Palavras-chave: Perfil de Saúde; Insuficiência Cardíaca; Prognósticos.

Keywords: Health Profile; Heart Failure; Prognosis.

Palabras clave: Perfil de Salud; Insuficiencia Cardíaca; Pronósticos.

Submetido: 06/01/2018

Aprovado: 26/04/2018

Autor(a) para Correspondência: Paulo Átila da Silva Viana End: Rua Erlandio de Paula Gomes, 1226 - casa 110- Betânia, Sobral E-mail:paulovianaatila@hotmail.com

\section{RESUMO}

Este estudo teve por objetivo identificar o perfil dos pacientes com insuficiência cardíaca (IC) descompensada internados em hospital terciário da região norte do Ceará. A amostra consistiu em casos de internação por descompensação de IC no período entre $1^{\circ}$ de abril e 31 de dezembro de 2017. As informações foram coletadas a partir de entrevistas com os pacientes e dos prontuários médicos. Dos 148 pacientes selecionados, $63,5 \%$ eram individuos do sexo masculino, 60,1\% tinham acima de 65 anos, $50,7 \%$ cursaram até o Ensino Fundamental e 93,2\% se autodeclararam de cor branca. A classe funcional IV (CF IV) foi a mais prevalente (50,0\%), seguida pela CF III $(39,1 \%)$. Observou-se significância estatística nos preditores de mortalidade: história de cirurgia de revascularização do miocárdio; anemia; diabetes mellitus (DM); perfil hemodinâmico frio/congesto no momento da admissão hospitalar; etiologia isquêmica; creatinina $>1,4 \mathrm{mg} / \mathrm{dL}$; $e$ glicemia $>180 \mathrm{mg} / \mathrm{dL}$. Constatou-se a necessidade de intervenções voltadas ao controle clínico da IC para diminuir a incidência de descompensação em programas de promoção e educação continuada em saúde e para avaliar a adesão ao tratamento e o adequado manejo terapêtico da IC nos serviços públicos de saúde.

1. Aluno de Graduação em Medicina na Universidade Federal do Ceará (UFC). Presidente da Liga MédicoAcadêmica de Cardiologia de Sobral (Limacs).Sobral (CE),Brasil. E-mail: paulovianaatila@hotmail.com

2. Médico. Cardiologista intervencionista no Hospital do Coração Padre José Linhares Pontes (HCPJLP). Sobral (CE), Brasil. E-mail: davidcneto@gmail.com

3. Aluno de Graduação em Medicina na UFC. Membro da Limacs. Sobral (CE), Brasil. E-mail: camilatnovais@ hotmail.com

4. Aluna de Graduação em Medicina na UFC. Membro da Limacs. Sobral (CE), Brasil. E-mail: isabellefurquim@ gmail.com

5. Aluna de Graduação em Medicina na UFC. Membro da Limacs. Sobral (CE), Brasil. E-mail: yansousalopes@ gmail.com

6. Aluno de Graduação em Medicina na UFC. Membro da Limacs. Sobral (CE), Brasil. E-mail: brenocr1997@ gmail.com 


\section{ABSTRACT}

This study aimed to identify the profile of patients with decompensated heart failure (HF) hospitalized in a tertiary hospital in the northern region of Ceará, Brazil. The sample consisted of cases of hospitalization due to decompensation of HF within the period between April 1 and December 31, 2017. The information was collected by means of interviews with patients and medical records. Out of the 148 selected patients, 63.5\% were men, 60.1\% were over 65 years old, 50.7\% attended up to Elementary School, and 93.2\% were self-declared as white-skinned. The functional class IV (FC IV) was the most prevalent (50,0\%), followed by the FC III (39.1\%). Statistical significance was observed in predictors of mortality: history of myocardial revascularization surgery; anemia; diabetes mellitus (DM); cold/congested hemodynamic profile at the time of hospital admission; ischemic etiology; creatinine $>1.4 \mathrm{mg} / \mathrm{dL}$; and glycemia $>180 \mathrm{mg} / \mathrm{dL}$. We found the need for interventions aimed at clinical control of HF in order to reduce the incidence of decompensation in health promotion and continuing education programs and to evaluate treatment adherence and adequate therapeutic management of HF in public health services.

\section{RESUMEN}

Este estudio tuvo como objetivo identificar el perfil de los pacientes con insuficiencia cardiaca (IC) descompensada hospitalizados en un hospital terciario en la región norte de Ceará, Brasil. La muestra consistió en casos de hospitalización por descompensación de IC en el período comprendido entre 1 de abril y 31 de diciembre de 2017. La información se recolectó mediante entrevistas con pacientes y registros médicos. De los 148 pacientes seleccionados, 63,5\% eran hombres, 60,1\% tenían más de 65 años, 50,7\% cursaron hasta la Enseñanza Básica y 93,2\% eran autodeclarados como de piel blanca. La clase funcional IV (CF IV) fue la más prevalente (50,0\%), seguida de la CF III (39,1\%). Se observó significación estadística en los predictores de mortalidad: antecedentes de cirugía de revascularización miocárdica; anemia; diabetes mellitus (DM); perfil hemodinámico frío/congestionado en el momento del ingreso hospitalario; etiología isquémica; creatinina $>1,4 \mathrm{mg} / \mathrm{dL}$; y glucemia > $180 \mathrm{mg} / \mathrm{dL}$. Encontramos la necesidad de intervenciones dirigidas al control clínico de la IC para reducir la incidencia de descompensación en los programas de promoción y educación continua en salud y para evaluar la adherencia al tratamiento y el tratamiento terapéutico adecuado de la IC en los servicios públicos de salud.

\section{INTRODUÇÃO}

A insuficiência cardíaca (IC) é uma síndrome clínica variada e caracteriza-se pela falência do coração, que não consegue suprir adequadamente a demanda sanguínea metabólica em condições normais de pressão ${ }^{1}$. Comumente, a IC consiste no estágio final de várias comorbidades, como hipertensão arterial sistêmica (HAS), diabetes mellitus (DM) e coronariopatias, e constitui grave problema de saúde pública ${ }^{2}$.

Segundo a Organização Mundial da Saúde (OMS), a IC é uma enfermidade crônica prioritária de atenção, atingindo 23 milhões de pessoas em todo o mundo ${ }^{3}$. Dados da American Heart Association (AHA) indicam 5,1 milhões de casos de IC nos Estados Unidos (EUA) entre 2007 e 2012, com perspectiva de aumento de $46 \%$ até 2030, implicando significativa elevação de gastos terapêuticos ${ }^{4}$.

Estima-se que nos países desenvolvidos aproximadamente $2 \%$ da população adulta padeça de IC, número que tem aumentado junto com a expectativa de vida, pois seu risco aumenta exponencialmente com a idade, superando $8 \%$ de incidência após os 75 anos $^{5}$.

Há limitados recursos epidemiológicos relacionados à IC no Brasil; grande parte das informações disponíveis provém do Departamento de Informática do Sistema Único de Saúde (DataSUS), cujos registros indicam cerca de 2 milhões de pacientes acometidos, com 240 mil novos casos diagnosticados por ano, que correspondem a $33 \%$ dos gastos do Sistema Único de Saúde (SUS) com doenças do aparelho circulatório ${ }^{6}$. Estimativas para 2025 apontam o Brasil como sexta maior população de idosos do mundo, com cerca de 30 milhões de pessoas, ou seja, $15 \%$ da população total, com potencial multiplicação dos casos de IC e dos custos com seu tratamento ${ }^{7}$.

Dados relativos ao estado do Ceará indicam, no período de 2008 a 2017, 86.666 internações hospitalares para tratamento de IC, com um total de 6.073 óbitos declarados por essa causa ${ }^{8}$.

Diante da progressão e da tendência agravante da IC, avaliar o perfil epidemiológico, clínico e evolutivo dos pacientes possibilita a elaboração de estratégias 
de intervenção para diagnóstico precoce de IC, além do aprimoramento de medidas efetivas para tratamento e estabilização de pacientes com IC conhecida.

Com isso em vista, este estudo tem por objetivo identificar o perfil dos pacientes internados no Hospital do Coração Padre José Linhares Pontes (HCPJLP), em Sobral (CE), para tratamento de IC descompensada.

\section{METODOLOGIA}

Trata-se de estudo observacional e longitudinal, com amostra constituída por casos de internação por descompensação de IC, realizado no HCPJLP no período entre $1^{\circ}$ de abril e 31 de dezembro de 2017. A coleta de dados ocorreu mediante entrevista com o paciente no leito, acerca da história natural da doença, bem como informações complementares disponíveis nos prontuários médicos.

Os critérios de inclusão dos pacientes com descompensação de IC foram: a) ambos os sexos; b) sem limite de idade; e c) internação no HCPJLP dentro do período estabelecido. Os critérios de exclusão foram: a) incapacidade, por motivo funcional, de fornecer as informações solicitadas; e b) recusa de fornecer as informações solicitadas.

As variáveis consideradas neste estudo foram: a) dados sociodemográficos; b) história da doença atual; c) história de doenças pregressas; d) comorbidades; e) hábitos; f) sinais vitais; g) perfil clínicohemodinâmico no momento da admissão; h) exames laboratoriais de admissão e de alta hospitalar; i) exames de imagem durante a internação; j) tempo de internação; e k) desfecho final do quadro clínico.

As informações foram submetidas a análise estatística no programa computacional Epi Info, versão 7.0, com aplicação do teste $t$ de Student a variáveis não pareadas, além do teste de Fischer, visando a identificar significância estatística entre as categorias de variáveis. Admitiu-se significância para 0 valor $p<0,05$.

Este estudo cumpriu os preceitos da Resolução $n$. 466/2012, do Conselho Nacional de Saúde (CNS), e foi aprovado pelo Comitê de Ética em Pesquisa da Universidade Estadual Vale do Acaraú (UVA), sob o Protocolo n. 1.957.872.

\section{RESULTADOS E DISCUSSÃO}

Foram selecionados para compor a amostra 148 pacientes internados no HCPJLP para tratamento de IC descompensada; destes, 20 foram a óbito durante a hospitalização. A Tabela 1 ilustra as características sociodemográficas. A média de idade foi de 65 anos (variação de 16 a 93 anos). 0 sexo masculino apresentou maior prevalência $(63,5 \%)$, sem significância estatística quanto à evolução para óbito. Houve predomínio do Ensino Fundamental $(50,7 \%)$ e da cor branca $(93,2 \%)$.

Tabela 1 - Dados sociodemográficos dos pacientes incluídos na amostra de estudo. Sobral, 2017.

\begin{tabular}{|c|c|c|c|c|}
\hline Variáveis & & $N=148$ & $(\%)$ & $\mathbf{P}$ \\
\hline \multicolumn{5}{|l|}{ Sexo } \\
\hline & Masculino & 94 & 63,5 & Não significativo \\
\hline & Feminino & 54 & 36,5 & Não significativo \\
\hline \multicolumn{5}{|c|}{ Faixa etária } \\
\hline & Até 50 anos & 21 & 14,2 & Não significativo \\
\hline & 51 a 64 anos & 38 & 25,7 & Não significativo \\
\hline & Acima de 65 anos & 89 & 60,1 & Não significativo \\
\hline \multicolumn{5}{|c|}{ Escolaridade } \\
\hline & Analfabeto & 52 & 35,1 & Não significativo \\
\hline & Ensino Fundamental & 75 & 50,7 & Não significativo \\
\hline & Ensino Médio & 19 & 12,8 & Não significativo \\
\hline & Ensino Superior & 2 & 1,4 & Não significativo \\
\hline \multicolumn{5}{|l|}{ Cor } \\
\hline & Branca & 138 & 93,2 & Não significativo \\
\hline & Negra & 10 & 6,8 & Não significativo \\
\hline
\end{tabular}

Fonte: Elaborada pelos autores. 
A IC é uma das principais causas de morbidade e acomete com maior prevalência o sexo masculino. Apesar da maior prevalência entre os homens, a IC tem maior impacto na qualidade de vida do sexo feminino $0^{9}$. Além disso, apesar da idade média ser de 65 anos neste estudo, a doença prevalece em pacientes > 65 anos - a incidência de IC aumenta exponencialmente com a idade, sendo de $1 \%$ em pacientes $<55$ anos e de até $30 \%$ entre aqueles $>85$ anos ${ }^{10}$.

Quanto à escolaridade, há maior prevalência entre aqueles com Ensino Fundamental $(50,7 \%)$ e os analfabetos $(35,1 \%)$ - o que pode estar relacionado a classe socioeconômica baixa. A cardiomiopatia por doença valvar reumática ainda é frequente em nosso país e a classe socioeconômica constitui fator importante no desenvolvimento da febre reumática, pois esta é sensível à qualidade do atendimento médico oferecido, corroborando a relevância dessa informação.

Quanto à história patológica pregressa, o infarto agudo do miocárdio (IAM), o acidente vascular encefálico (AVE) e a história prévia de cirurgia de revascularização do miocárdio foram relatados por $23,0 \%, 10,1 \%$ e $10,1 \%$ dos pacientes, respectivamente (Tabela 2).

Em se tratando de hábitos de vida, evidenciou-se que $83,1 \%$ dos pacientes não realizavam nenhuma atividade física, $23,6 \%$ eram tabagistas e $24,3 \%$ consumiam álcool mais de 4 vezes por mês. Considerando as comorbidades, a HAS e o DM foram bastante prevalentes, acometendo $68,9 \%$ e $36,5 \%$ dos pacientes, respectivamente. Anemia, fibrilação atrial e DM apresentaram significância estatística na comparação com o grupo de pior desfecho.

Tabela 2 - História patológica pregressa, hábitos de vida e comorbidades na amostra de estudo. Sobral, 2017.

\begin{tabular}{|c|c|c|c|}
\hline Variáveis & & $\mathrm{N}(\%)$ & $\mathbf{P}$ \\
\hline \multicolumn{4}{|c|}{ História patológica pregressa } \\
\hline & Infarto agudo do miocárdio & $34(23,0)$ & Não significativo \\
\hline & Acidente vascular encefálico & $15(10,1)$ & Não significativo \\
\hline & Revascularização do miocárdio & $15(10,1)$ & 0,01 \\
\hline \multicolumn{4}{|c|}{ Hábitos de vida } \\
\hline & Não realiza atividade física & $123(83,1)$ & Não significativo \\
\hline & Etilista & $36(24,3)$ & Não significativo \\
\hline & Tabagista & $35(23,6)$ & Não significativo \\
\hline & Drogas ilícitas & $2(1,3)$ & Não significativo \\
\hline \multicolumn{4}{|c|}{ Comorbidades } \\
\hline & Hipertensão & $102(68,9)$ & Não significativo \\
\hline & Diabetes mellitus & $54(36,5)$ & 0,01 \\
\hline & Dislipidemia & $47(31,7)$ & Não significativo \\
\hline & Anemia & $44(29,7)$ & 0,01 \\
\hline & Fibrilação atrial & $37(25,0)$ & 0,01 \\
\hline & Hipotireoidismo & $11(7,4)$ & Não significativo \\
\hline & Osteoporose & $8(5,4)$ & Não significativo \\
\hline
\end{tabular}

Fonte: Elaborada pelos autores.

A redução da complacência do ventrículo esquerdo, associada à sua maior rigidez, constitui alteração fisiológica natural de fibrose com o avanço da idade. Entretanto, tais mudanças cardíacas podem ser adiantadas e/ou agravadas por vários mecanismos, que cursam com desequilíbrio de cargas, como isquemia, processos infiltrativos e, sobretudo, pela presença de cicatriz focal ou de aneurisma após IAM. A perda de cardiomiócitos decorrente de IAM determina a disfunção ventricular, cujo prejuízo é o aumento do volume residual do ventrículo esquerdo e, cronicamente, dilatação ventricular, responsável pelo remodelamento miocárdico ${ }^{11}$.

Sabe-se que os portadores de IC convivem com certa intolerância a atividade física, por insuficiente energia fisiológica ou psicológica para suportar ou completar rotinas diárias, requeridas ou desejadas. Essa intolerância é justificada pelos sintomas envolvidos na doença basal, como desconforto respiratório, fadiga e palpitações, presentes, em graus variáveis, devido à incapacidade do coração manter débito cardíaco que satisfaça as necessidades teciduais de oxigênio, além do reduzido aporte sanguíneo periférico ${ }^{12}$. 
Admite-se que os portadores de IC também apresentam alterações morfológicas e metabólicas na musculatura esquelética que influem negativamente na atividade física, independente do baixo débito cardíaco ou do inadequado fluxo circulatório. Identificou-se, nesse sentido, substancial redução de mitocôndrias nas fibras musculares de portadores de IC, acarretando depressão da capacidade oxidativa durante o trabalho muscular ${ }^{13}$.

Até os anos 1980, a atividade física foi considerada contraindicação relativa ou absoluta para indivíduos com aumento de área cardíaca, diminuição de função sistólica do ventrículo esquerdo e IC - eles eram aconselhados a evitá-la para não deteriorarem sua função cardiovascular. No entanto, repouso prolongado ou inatividade podem causar atrofia muscular, exacerbação dos sintomas de IC, tromboembolismo e redução de tolerância ao exercício ${ }^{14}$. Desse modo, atualmente, a atividade física é considerada uma importante ferramenta terapêutica em casos de disfunção cardíaca crônica estabilizada, capaz de melhorar a capacidade funcional e a qualidade de vida dos pacientes ${ }^{15}$.

0 consumo excessivo de bebidas alcoólicas e 0 tabagismo devem ser desencorajados, por serem deletérios ao sistema cardiovascular. 0 álcool reduz a contratilidade miocárdica e pode causar arritmias; em altas doses, relaciona-se com efeitos indesejáveis: mortalidade, incidência de IAM, AVE, cirrose, cardiomiopatia e deficiência nutricional, além de outras consequências físicas e sociais ${ }^{16}$. 0 consumo de tabaco deve ser criteriosamente excluído, por interferir nos processos respiratórios e agravar lesões na aorta. A não restrição de fumo e álcool foi relacionada de modo significativo ao número de admissões hospitalares por IC descompensada ${ }^{17}$.

Sabe-se que, no Brasil, a principal causa de IC é a cardiopatia isquêmica crônica relacionada a $\mathrm{HAS}^{18}$, como reafirmado por este estudo, onde a principal comorbidade associada a IC é a HAS - um fator que contribui para várias outras doenças cardiovasculares, como $A V E$, doença arterial periférica e doença renal. 0 acometimento de IC é 2 ou 3 vezes maior entre hipertensos e hipertensas, respectivamente, quando comparados a normotensos ${ }^{3}$. Existe a ideia de que 0 aumento da pós-carga, na HAS, esteja associado a hipertrofia ventricular e desenvolvimento da IC, porém, vale destacar a combinação de HAS a doença do aparelho circulatório (DAC) como principal causa de falência cardíaca. Entretanto, a HAS por si só pode provocar IC, uma vez que a redução dos níveis

\section{...a principal comorbidade associada a IC é a HAS...}

pressóricos do hipertenso reduz significativamente a incidência de $\mathrm{IC}^{19}$.

A dislipidemia constitui importante fator de risco no desenvolvimento de IC, especialmente no que se refere à formação de placas ateroscleróticas, cuja fisiopatologia é um dos mecanismos para DAC, uma das principais etiologias da IC ${ }^{20}$. Ademais, existe associação positiva entre DM e a etiologia isquêmica. A DM é uma doença que cursa com risco cardiovascular alto e a glicemia de jejum, independente do diagnostico prévio de DM, é um preditor de prognóstico ${ }^{21}$. Este estudo revela alta prevalência de DM, bem como de dislipidemia, associando o IAM como principal etiologia da IC, como já demonstrado em outros estudos.

A anemia $(29,7 \%)$ foi um importante achado como fator de risco, por se relacionar a pior prognóstico ao longo do tempo, o que indica necessidade de atenção especial. Além disso, a anemia está associada a maior mortalidade, independente do sexo, da fração de ejeção (FE) ou da doença ser crônica ou descompensada, com aumento de até $50,0 \%$ do risco relativo de morte ${ }^{21}$. Apesar disso, a fisiopatologia da relação ente anemia e IC não está bem estabelecida, o que justifica a inexistência de padronização em seu manejo, embora evidências sugiram repercussões de melhora clínica e hemodinâmica dos cardiopatas com diagnóstico e tratamento precoce ${ }^{22}$.

A fibrilação atrial (FA) também é considerada um fator de risco para IC e contribui para maior mortalidade e hospitalização entre pacientes idosos portadores dessa síndrome ${ }^{22}$. Igualmente, disfunções tireoidianas também cursam com manifestações que implicam negativamente a IC, uma vez que o hormônio tireoidiano atua em diversos órgãos e sistemas, além de provocar mudanças nos canais iônicos, como nos canais de cálcio do músculo cardíaco. Dessa forma, a triiodotironina em quantidade reduzida pode levar a bradicardia, diminuição do enchimento ventricular, disfunção diastólica e aumento da resistência vascular periférica. Tais fatores, mesmo que raramente, podem levar a IC ou descompensar a doença previamente existente $\mathrm{e}^{23}$. 
As características clínicas da IC são apresentadas na Tabela 3. Comparando os grupos de pacientes na admissão hospitalar, segundo a New York Heart Association (NYHA), aqueles com pior desfecho apresentavam pior classe funcional (CF) $(p=0,0007)$, perfil hemodinâmico frio/congesto $(p=0,002)$ e sua principal etiologia era a isquêmica $(p=0,0001)$.

Tabela 3 - Características da insuficiência cardíaca descompensada. Sobral, 2017.

\begin{tabular}{|c|c|c|c|c|}
\hline Variáveis & & Sobreviventes (N) & Não sobreviventes $(\mathrm{N})$ & $\mathbf{P}$ \\
\hline \multicolumn{5}{|c|}{ Classe funcional na admissão } \\
\hline & I & 3 & 0 & Não significativo \\
\hline & II & 13 & 0 & Não significativo \\
\hline & III & 55 & 3 & 0,002 \\
\hline & IV & 57 & 17 & 0,0007 \\
\hline \multicolumn{5}{|c|}{ Perfil hemodinâmico } \\
\hline & Quente/seco & 39 & 1 & 0,005 \\
\hline & Quente/congesto & 65 & 10 & Não significativo \\
\hline & Frio/seco & 4 & 0 & Não significativo \\
\hline & Frio/congesto & 20 & 9 & 0,002 \\
\hline \multicolumn{5}{|l|}{ Etiologia } \\
\hline & Idiopática & 48 & 5 & Não significativo \\
\hline & Isquêmica & 26 & 9 & 0,012 \\
\hline & Valvar & 21 & 3 & Não significativo \\
\hline & Chagásica & 18 & 3 & Não significativo \\
\hline & Hipertensiva & 15 & 0 & Não significativo \\
\hline
\end{tabular}

Fonte: Elaborada pelos autores.

Corroborando os dados apresentados na Tabela 3, tem-se uma relação direta e linear entre óbitos e capacidades funcionais indicadas pela NYHA, sendo a classe I caracterizada por ausência de limitações para as atividades físicas e a classe IV marcada por total incapacidade para as atividades físicas, com manifestações sintomáticas inclusive durante 0 repouso. Entre os pacientes admitidos que se enquadravam na classe funcional IV, $30,9 \%$ apresentaram como desfecho o óbito, parcela reduzida para $5,4 \%$ entre os pacientes admitidos que se enquadravam na classe funcional III. Não houve óbitos entre os pacientes admitidos que se enquadravam nas classes I e II, o que demonstra que tal classificação, apesar de subjetiva, constitui excelente preditor de morbimortalidade ${ }^{24}$.

A determinação do perfil clínico/hemodinâmico do paciente durante a admissão se mostra fundamental para o delineamento e o êxito da abordagem terapêutica. Nesse contexto, inserem-se as alterações da pressão de enchimento do ventrículo esquerdo e a redução do débito cardíaco como fatores determinantes para a caracterização de 4 categorias do perfil hemodinâmico: quente/seco, frio/congesto, quente/congesto e frio/seco. Os 2 primeiros são caracterizados, respectivamente, pela ausência e presença concomitante de ambos os fatores. De acordo com a Tabela 3, os perfis frio/congesto $(45,0 \%)$ e quente/congesto $(15,4 \%)$ apresentaram maiores taxas de mortalidade em comparação aos perfis quente/seco $(2,5 \%)$ e frio/seco $(0,0 \%)$, evidenciando que as disfunções conjuntas nos gradientes da pré-carga e da pós-carga implicam prognóstico mais reservado ${ }^{25}$.

Em contrapartida, pacientes que chegaram ao hospital não edemaciados apresentaram taxas de mortalidade significativamente reduzida, sendo tal sinal clínico, além de extremamente frequente, um importante preditor de desfecho negativo nas descompensações agudas. Ao considerar que a maioria dos pacientes em curso de IC faz uso de diuréticos de alça - indicadores proeminentes de retenção hídrica (estertores, turgência jugular, além do próprio edema) -, temos um reflexo do grau de comprometimento hemodinâmico do portador ${ }^{25}$.

Em relação à etiologia sindrômica para a $\mathrm{IC}$, este estudo aponta a cardiomiopatia dilatada não isquêmica (idiopática) como causa mais comum da manifestação do quadro de insuficiência, correspondendo a $37,5 \%$ dos casos registrados. Em seguida aparece a cardiomiopatia isquêmica como etiologia mais abundante $(20,3 \%)$, sucedida pelas 
cardiopatias valvar $(16,4 \%)$, chagásica $(14,0 \%)$ e hipertensiva $(11,8 \%)$. Tais achados corroboram a literatura de referência, onde se evidencia a doença de Chagas com alta representatividade na etiologia global em países sulamericanos e as causas isquêmicas são responsáveis por parcelas cada vez maiores do número total de casos, assumindo primazia no que tange às etiologias para a $\mathrm{IC}^{26}$.

Dentre os motivos para a ocorrência relatada se destacam aumento da expectativa de vida e elevado consumo de produtos industrializados com alto teor de gordura, além da tendência global ao sedentarismo, salientando, portanto, a importância e o impacto benéfico das atividades físicas aliadas a uma alimentação saudável na melhora da qualidade de vida em longo prazo ${ }^{27}$.

Também se pode aferir a grande contribuição dos fatores hereditários nas doenças cardiovasculares (visto o relato histórico de acometimento cardíaco em familiares de primeiro grau). Assim, a maior parte das cardiomiopatias genéticas se deve a herança de caráter autossômico dominante, na qual mutações em genes que codificam componentes da matriz extracelular e citoesqueleto geram quadro de IC com redução da fração de ejeção ventricular esquerda (comprovada na análise ecocardiográfica) ${ }^{28}$.

Os exames laboratoriais são importantes no auxílio terapêutico em pacientes com IC. Diante de tal cenário, analisou-se a correlação entre os valores críticos para tais exames (Tabela 4) e a chamada razão de chances (odds ratio - OR) para a mortalidade dos participantes do estudo.

Tabela 4 - Correlação entre exames laboratoriais e odds ratio para a mortalidade. Sobral, 2017.

\begin{tabular}{lccc}
\hline Valores laboratoriais na admissão & N & OR $(\mathbf{I C})$ & $P$ \\
\hline Ureia $>40 \mathrm{mg} / \mathrm{dL}$ & 110 & $2,13(0,5-7,72)$ & Não significativo \\
Creatinina $>1,4 \mathrm{mg} / \mathrm{dL}$ & 55 & $6,60(2,2-19,4)$ & 0,0001 \\
Potássio $>5 \mathrm{mEq} / \mathrm{L}$ & 18 & $2,94(0,9-9,4)$ & 0,0500 \\
Hemoglobina $<12 \mathrm{mg} / \mathrm{dL}$ & 48 & $1,14(0,4-3,0)$ & Não significativo \\
Glicemia $>180 \mathrm{mg} / \mathrm{dL}$ & 19 & $3,79(1,2-11,5)$ & 0,0130 \\
\hline
\end{tabular}

Legenda: $O R=$ odds ratio; $I C=$ insuficiência cardíaca.

Fonte: Elaborada pelos autores.

Observou-se que pacientes com desordens na função renal concomitantemente à descompensação aguda da IC evoluíram com maior mortalidade (OR = $6,6)$, seguida pela associação conjunta da IC com níveis glicêmicos > $180(0 R=3,79)$ e com potássio sérico $>5 \mathrm{mEq} / \mathrm{L}(0 \mathrm{R}=2,94)$. Paralelamente, as análises relacionadas aos altos e baixos níveis de ureia e hemoglobina, respectivamente, não obtiveram significância estatística.

Como relatado, pior prognóstico é associado ao aparecimento da síndrome cardiorrenal, mensurada no estudo por meio da análise da creatinina sérica. Pacientes com déficit renal apresentam significativa redução da capacidade de excreção da creatinina, produto da degradação da fosfocreatina no músculo. 0 surgimento de tal complicação é embasado, fisiopatologicamente, na diminuição da perfusão renal atrelada a diminuição do débito cardíaco. Secundariamente, a vasoconstrição renal decorrente da ativação neuro-hormonal desempenha importante papel nesse processo ${ }^{29}$.

0 DM, por contribuir para a exacerbação da doença arterial coronariana, para a HAS ou mesmo para a piora da função renal, apresenta-se como importante preditor de mortalidade nos casos agudos, corroborando os resultados encontrados. A hipercalemia, evidenciada, sobretudo, em pacientes que usam diuréticos poupadores de potássio, como a espironolactona, também se relaciona a aumento da probabilidade de desfecho negativo em pacientes com descompensação da IC mediante desenvolvimento de quadros arritmogênicos ou complicação renal; porém, com incidência menor em comparação aos anteriores ${ }^{30}$

\section{CONCLUSÃO}

Os resultados levantados neste estudo demonstram a prevalência de IC em pacientes do sexo masculino, com idade > 65 anos, com Ensino Fundamental completo e autodeclarados de cor branca. Além disso, na correlação entre as variáveis, evidenciou-se significância do preditor de mortalidade para pacientes com história patológica pregressa de revascularização do miocárdio e que apresentavam comorbidades, como DM, anemia e fibrilação atrial. Os pacientes com pior desfecho apresentavam classe funcional III e IV, perfil hemodinâmico frio/congesto e etiologia isquêmica. 
Diante desse cenário, mostram-se necessárias intervenções para a prevenção e o diagnóstico precoce de IC, principalmente na população idosa, para diminuir a incidência de descompensação e os prognósticos reservados em casos de IC. Tais intervenções devem ser direcionadas à adoção de programas efetivos de promoção e educação continuada em saúde, principalmente os voltados à abordagem das condições clínicas mais prevalentes, à avaliação da adesão ao tratamento, à busca de novos casos e ao adequado manejo terapêutico de IC nos mais diversos serviços públicos de saúde.

Ademais, a implementação de medidas de prevenção que alcancem principalmente os indivíduos de maior risco, o diagnóstico precoce e a intensificação dos diversos métodos terapêuticos disponíveis são medidas essenciais que podem trazer mudanças favoráveis no controle da IC.

\section{CONTRIBUIÇÃO DOS AUTORES}

Paulo Átila da Silva Viana contribuiu com o delineamento e a realização da pesquisa e a redação do manuscrito. Joaquim David Carneiro Neto contribuiu com o delineamento da pesquisa e a revisão crítica do manuscrito. Camila Teles Novais, Isabelle Furquim Guimarães e Yan Sousa Lopes contribuíram com o delineamento e a realização da pesquisa e a redação do manuscrito. Breno Cotrim Reis contribuiu com a realização da pesquisa e a redação do manuscrito.

\section{AGRADECIMENTO}

Os autores agradecem a Santa Casa de Misericórdia de Sobral - Ceará pelo apoio financeiro para desenvolvimento desta pesquisa.

\section{REFERÊNCIAS}

1. Yanci CW, Jessup M, Bozkurt B, Butler J, Casey Jr DE, Drazner MH, et al. 2013 ACCF/AHA guideline for the management of heart failure: executive summary - a report of the American College of Cardiology Foundation/American Heart Association Task Force on Practice Guidelines. J Am Coll Cardiol [serial on the internet]. 2013 [cited 2018 May 4];62(16):1495-1539. Available from: file:///D:/HFG\%20 $3 \% 202013 \% 20$ ACCFAHA\%20Guideline.pdf

2. McMurray JJ, Adamopoulos S, Anker SD, Auricchio A, Bohm M, Dickstein K, et al. Guía de práctica clínica de la ESC sobre diagnóstico y tratamiento de la insuficiencia cardiaca aguda y crónica 2012. Rev Esp de Cardiol [serial on the internet]. 2012 [cited 2018 May 4];65(10):938.e1-e59.
Available from: http://appswl.elsevier.es/watermark/ctl servlet? f $=10 \&$ pident articulo $=90154894$ \&pident usuario $=0 \&$ pcontactid $=\&$ pident revista $=25 \&$ ty $=103 \&$ accion $=$ L\&origen $=$ cardio \& $w e b=w w w$. revespcardiol.org\&lan=es\&fiche ro $=25 v 65 \mathrm{n} 10 \mathrm{a} 90154894 \mathrm{pdf001}$.pdf\&anuncioPdf $=E R R O R$ publi_pdf

3. Ho KKL, Pinsky JL, Kannel WB, Levy D. The epidemiology of heart failure: the Framingham study. J Am Coll Cardiol. 1993;22(Suppl A):6A-13A.

4. Go AS, Mozaffarian D, Roger VL, Benjamin EJ, Berry JD, Blaha MJ, et al. Heart disease and stroke statistics: 2014 update - a report from the American Heart Association. Circulation [serial on the internet]. 2014 [cited 2018 May 4];129(3):e28-e292. Available from: http://circ.ahajournals. org/content/circulationaha/early/2013/12/18/01. cir.0000441139.02102.80.full.pdf

5. Mosterd A, Hoes AW. Clinical epidemiology of heart failure. Heart. 2007;93:1137-46.

6. Sociedade Brasileira de Cardiologia. Revisão das III Diretrizes da Sociedade Brasileira de Cardiologia para o diagnóstico e tratamento da insuficiência cardíaca. Arq Bras Cardiol. 2002;79(Suppl 4):1-30.

7. Batlouni M, Freitas EV, Savioli Neto F. Insuficiência cardíaca no idoso. In: Freitas EV, Py L, Cançado FAX, Doll J, Gorzoni ML. Tratado de geriatria e gerontologia. 2. ed. Rio de Janeiro: Guanabara-Koogan; 2006. p. 480-99.

8. Brasil. DataSUS: incidência e morbidade do SUS, 2008 a 2017, por insuficiência cardíaca - Ceará, Brasil [document on the internet]. Brasília (DF): Ministério da Saúde; c2017 [cited 2017 Dec 20]. Available from: http://tabnet.datasus. gov.br/cgi/tabcgi.exe?sih/cnv/qiuf.def

9. Barbosa RR, Franklin RV, Stefenoni AV, Moraes VD, Jacques TM, Serpa RG, et al. Quality of life analysis among men and women with heart failure. Rev Bras Cardiol. 2014;27(2):97-103

10. Heidenreich PA, Albert NM, Allen LA, Bluemke DA, Butler $\mathrm{J}$, Fonarow $\mathrm{GC}$, et al. Forecasting the impact of heart failure in the United States: a policy statement from the American Heart Association. Circ Heart Fail [serial on the internet]. 2013 [cited 2018 May 4];6(3):606-19. Available from: file:///D:/606.full.pdf

11. White HD, Norris RM, Brown MA, Brandt PWT, Whitlock RML, Wild CJ. Left ventricular end-systolic volume as the major determinant of survival after recovery from myocardial infarction. Circulation. 1987;76(1):44-51.

12. Drexler $H$, Riede $U$, Münzel $T$, König $H$, Funke $E$, Just $H$. Alterations of skeletal muscle in chronic heart failure. Circulation. 1992;85(5):1751-9.

13. Minotti JR, Christoph I, Oka R, Weiner MW, Wells L, Massie BM. Impaired skeletal muscle function in patients with congestive heart failure. Relationship to systemic 
exercise performance. J Clin Invest. 1991;88(6):2077-82.

14. Belardinelli R, Georgiou D, Cianci G, Purcaro A. Randomized controlled trial of long-term moderate exercise training in chronic heart failure effects on function capacity, quality of life, and clinical outcome. Circulation. 1999;99:1173-82.

15. Gomes DVC, Bezerra EMA, Silva JCA, Costa TPS, Ribeiro MDA, Campelo G0. Avaliação da qualidade de vida em idosos hipertensos atendidos em clínica de fisioterapia. Sanare (Sobral, Online) [serial on the internet]. 2015 [cited 2018 May 4];14(1):33-7. Available from: file:///D:/605-1327-1-SM. $\underline{\mathrm{pdf}}$

16. Forti N, Giannini SD, Diament J, Issa J, Fukushima J, Dal Bó $C$, et al. Fatores de risco para doença arterial coronariana em crianças e adolescentes filhos de coronariopatas jovens. Arq Bras Cardiol [serial on the internet]. 1996 [cited 2018 May 4];66(3):119-23. Available from: http://publicacoes. cardiol.br/abc/1996/6603/66030001.pdf

17. Evangelista LS, Doering LV, Dracup K. Usefulness of a history of tobacco and alcohol use in predicting multiple heart failure readmissions among veterans. Am J Card Imaging. 2000;86:1339-42.

18. Rossi Neto JM. A dimensão do problema da insuficiência cardíaca do Brasil e do Mundo. Rev Soc Cardiol Estado de São Paulo [serial on the internet]. 2004 [cited 2018 May 4];14(1):1-7. Available from: file:///D:/revsocesp2004.pdf

19. Pereira Barretto AC. Hipertensão arterial e insuficiência cardíaca. Rev Bras Hipertens [serial on the internet]. 2001 [cited 2018 May 4];8:339-43. Available from: http:// departamentos.cardiol.br/dha/revista/8-3/hipertensa01.pdf

20. American Heart Association. Guidelines for the evaluation and management of chronic heart failure in the adult. Circulation. 2001;104:2996-3007.

21. Latado AL, Passos LCS, Braga JCV, Santos A, Guedes R, Moura SS, et al. Preditores de letalidade hospitalar em pacientes com insuficiência cardíaca avançada. Arq Bras Cardiol [serial on the internet]. 2006 [cited 2018 May 4];87(2):185-92. Available from: http://www.scielo.br/pdf/ abc/v87n2/a18v87n2.pdf

22. Nogueira PR, Rassi S, Corrêa KS. Perfil epidemiológico, clínico e terapêutico da insuficiência cardíaca em hospital terciário. Arq Bras Cardiol [serial on the internet]. 2010 [cited 2018 May 4];95(3):392-8. Available from: http:// www.scielo.br/pdf/abc/v95n3/aop09910.pdf

23. Barisic Jr S, Barisic GFT, Markman Filho B. Cardiopatias e tireoide. Rev Bras Clín Ter. 2006;63(3):127-33.

24. Naso FC, Pereira JS, Beatricci SZ, Bianchi RG, Dias AS, Monteiro MB. The relationship between NYHA class and the functional condition and quality of life in heart failure. Circulation. 2011;18:157-63.
25. Miranda CH, Castro RBP, Pazin Filho A. Medical management of acute decompensation of chronic heart failure in the emergency room. Circulation. 2003;36:179-86.

26. Santos IS, Bittencourt MS. Insufi ciência cardíaca. Rev Med (São Paulo) [serial on the internet]. 2008 [cited 2018 May 4];87(4):224-31. Available from: file:///D:/59083-75874-1-PB.pdf

27. Carneiro JC, Veríssimo R, Veríssimo MT. Exercício físico e insuficiência cardíaca. Medicina Desportiva Informa [serial on the internet]. 2012 [cited 2018 May 4];3:25-8. Available from: http://www.revdesportiva.pt/files/PDFs site 2012/5 Setembro/Rev 17 P25 28 Tema 5 Insuf card site.pdf

28. Nohria A, Tsang AW, Fang JC, Lewis EF, Jarcho JA, Mudge GH, et al. Clinical assessment identifies hemodynamic profiles that predict outcomes in patients admitted with heart failure. J Am Coll Cardiol. 2003;41(10):1797-804.

29. Locatelli F, Bommer J, London GM, Martin-Malo A, Wanner $C$, Yaqoob $M$, et al. Cardiovascular disease determinants in chronic renal failure: clinical approach and treatment. Nephrol Dial Transplant. 2001;16(3):459-68.

30. Schrier RW. Role of diminished renal function in cardiovascular mortality: marker or pathogenetic factor? J Am Coll Cardiol. 2006;47(1):1-8.
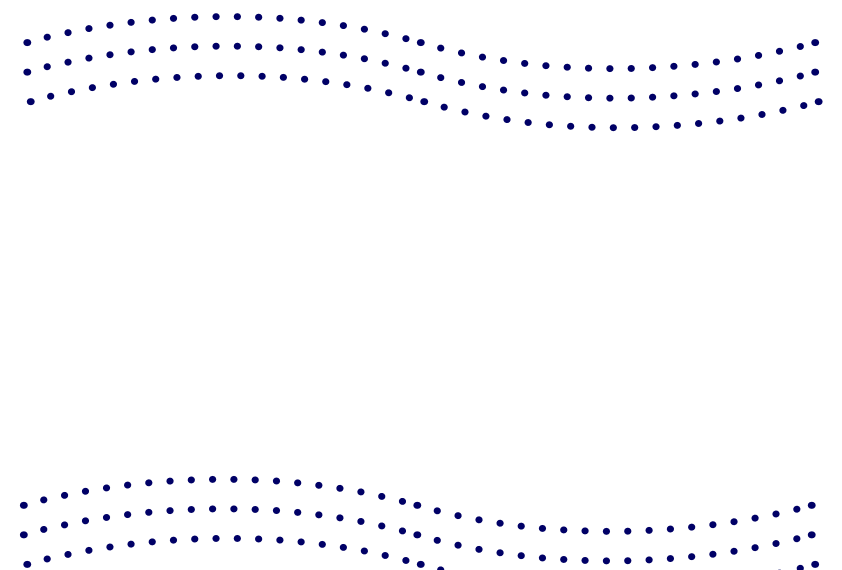
$\ldots \ldots \ldots \ldots \ldots \ldots$ $\cdots \ldots \ldots \ldots \ldots$

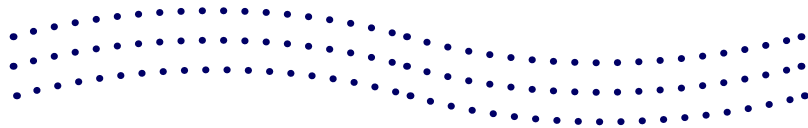




\title{
WEB RADIO COMO FERRAMENTA DE DIÁLOGO EM SAÚDE COLETIVA NO SERTÃO: JUVENTUDES E MÉTODOS CONTRACEPTIVOS
}

\author{
WEB RADIO AS A TOOL FOR DIALOGUE IN COLLECTIVE HEALTH IN THE \\ BRAZILIAN SERTÃO: YOUTHS AND CONTRACEPTIVE METHODS
}

WEB RADIO COMO UNA HERRAMIENTA DE DIÁLOGO EN SALUD COLECTIVA EN EL SERTÃO BRASILEÑO: JUVENTUDES Y MÉTODOS ANTICONCEPTIVOS

Palavras-chave: Juventude; Saúde; Tecnologias.

Keywords: Youth; Health; Technologies.

Palabras clave: Juventud; Salud; Tecnologías.

Submetido: 23/11/2017

Aprovado: 02/05/2018

Autor(a) para Correspondência: Leidy Dayane Paiva de Abreu End: Av. Antônio Justa, Condomínio Edificio Bolzano, 3799 CEP: 60165-090, Varjota, Fortaleza-CE E-mail: dayannepaiva@hotmail.com

\section{RESUMO}

Este artigo descreve o uso de uma web radio como ferramenta de diálogo em saúde coletiva no sertão brasileiro, com enfoque nas juventudes $e$ nos métodos contraceptivos. Trata-se de pesquisa exploratória e descritiva realizada em agosto de 2016 em Hidrolândia-CE, no âmbito do projeto "Em Sintonia com a Saúde", com estudantes de uma escola estadual de educação profissional (EEEP) e com jovens do "Baú da Leitura", da Associação dos Jovens do Irajá (AJIr). Foram realizadas observações in loco e 3 sessões educativas. As "perguntas-discursos" foram extraídas das redes sociais e de áudios do mural de recados da web radio e a análise recorreu à categorização das falas. Este estudo foi aprovado pelo Comitê de Ética em Pesquisa da Universidade Estadual do Ceará (UECE), em conformidade com a Resolução n. 466/2012 do Conselho Nacional de Saúde (CNS), e sua discussão enfoca os métodos contraceptivos e as tecnologias da comunicação. Nesse contexto, o uso da web radio se mostrou de suma importância para identificar dúvidas, conhecimentos e práticas relativas à contracepção. A enfermagem se destaca como categoria do setor saúde responsável pela qualidade da assistência, com uso das tecnologias da comunicação no cenário da saúde coletiva a serviço das juventudes.

\footnotetext{
1. Enfermeira. Aluna no Programa de Pós-Graduação Cuidados Clínicos em Enfermagem e Saúde da Universidade Estadual do Ceará (UECE). Fortaleza (CE), Brasil. E-mail: dayannepaiva@hotmail.com

2. Enfermeiro. Professor no Curso de Graduação em Enfermagem e no Programa de Pós-Graduação Cuidados Clínicos em Enfermagem e Saúde da UECE. Fortaleza (CE),Brasil.E-mail: augustomtorres@gmail.com 3. Enfermeira. Professora no Curso de Graduação em Enfermagem e no Programa de Pós-Graduação Cuidados Clínicos em Enfermagem e Saúde da UECE. Fortaleza (CE), Brasil. E-mail: rocineideferreira@gmail.com 4. Enfermeira. Aluna no Programa de Pós-Graduação Cuidados Clínicos em Enfermagem e Saúde da UECE. Fortaleza (CE),Brasil.E-mail: aretha.feitosa@gmail.com
} 


\section{ABSTRACT}

This article describes the use of a web radio as a tool for dialogue in collective health in the Brazilian sertão, with a focus on youths and contraceptive methods. This is an exploratory and descriptive research conducted in August 2016 in Hidrolândia, Ceará, Brazil, within the project 'Em Sintonia com a Saúde,' with students from a Brazilian professional education state school (EEEP) and with young individuals from the 'Baú da Leitura,'of the Associação dos Jovens do Irajá (AJIr). On-site observations and 3 educational sessions were carried out. The 'questions-discussions' were extracted from the social networks and audios on the message board of the web radio and the analysis resorted to categorization of the speeches. This study has been approved by the Research Ethics Committee of the Ceará State University (UECE), according to Resolution no. 466/2012 of the Brazilian National Health Council (CNS), and its discussion focuses on contraceptive methods and communication technologies. In this context, using the web radio showed to be extremely significant to identify doubts, knowledge, and practices related to contraception. Nursing stands out as a category in the health sector responsible for the quality of care, with use of communication technologies in the scenario of collective health at the service of youths.

\section{RESUMEN}

Este artículo describe el uso de una web radio como una herramienta de diálogo en salud colectiva en el sertão brasileño, con enfoque en las juventudes y los métodos anticonceptivos. Esta es una investigación exploratoria y descriptiva realizada en agosto de 2016 en Hidrolândia, Ceará, Brasil, dentro del proyecto "Em Sintonia com a Saúde", con estudiantes de una escuela estatal de educación profesional brasileña (EEEP) y con jóvenes del "Baú da Leitura", de la Associação dos Jovens do Irajá (AJIr). Se realizaron observaciones in loco y 3 sesiones educativas. Las "preguntas-discusiones" se extrajeron de redes sociales y audios en el tablero de mensajes de la web radio y el análisis recurrió a la categorización de las hablas. Este estudio ha sido aprobado por el Comité de Ética en Investigación de la Universidad del Estado de Ceará (UECE), de acuerdo con la Resolución no. 466/2012 del Consejo Nacional de Salud brasileño (CNS), y su discusión se centra en métodos anticonceptivos y tecnologías de comunicación. En este contexto, el uso de la web radio demostró ser extremadamente significativo para identificar dudas, conocimientos y prácticas relacionadas con la anticoncepción. La enfermería se destaca como categoría en el sector salud responsable de la calidad de la atención, con uso de las tecnologías de comunicación en el escenario de la salud colectiva al servicio de las juventudes.

\section{INTRODUÇÃO}

Adolescentes e jovens adoecem menos que outros grupos etários e, de fato, apresentam taxas de morbidade e mortalidade mais baixas do que as da população em geral. Entretanto, se esse público for observado em detalhe, evidencia-se, além do aumento da gravidez precoce, o avanço das infecções sexualmente transmissíveis (IST) denominadas vírus da imunodeficiência humana (HIV) e síndrome da imunodeficiência adquirida (AIDS), que, associadas a fatores socioeconômicos e culturais, têm profundas repercussões na qualidade de vida dessa parcela da população ${ }^{1}$.

Percebe-se, no setor saúde, uma imprecisão conceitual de adolescência, jovens e juventude partindo dos limites etários. Dentre as diversas políticas de Estado relativas à adolescência há aquelas que levam em conta os limites estabelecidos pelo Estatuto da Criança e do Adolescente (ECA) - de 12 a 18 anos - ou pelo Ministério da Saúde - de 10 a
19 anos. Para os jovens e a juventude, o Conselho Nacional de Juventude (Conjuve) estabelece a faixa etária de 15 a 29 anos - e também há propostas de organizações internacionais que ora aumentam, ora diminuem os limites da adolescência e da juventude ${ }^{2}$.

Preferiu-se adotar os termos jovens e juventudes ao invés de adolescentes e adolescências, uma vez que podem não se referir estritamente a uma faixa etária específica ou a uma série de comportamentos reconhecidos biologicamente. A escolha do termo jovem decorre do fato desse público estar imerso em cenários culturais diversos, produzindo suas vidas mediadas pelos cotidianos de suas experimentações e vivências em grupos e em outros territórios.

A problemática da saúde sexual e reprodutiva, mais especificamente dos métodos contraceptivos, constitui um tema relevante a abordar com os jovens logo no início de sua vida sexual - que ocorre cada vez precocemente. Isso se deve ao fato de que muitos indivíduos são suscetíveis a HIV, AIDS e gravidez indesejada, o que pode trazer consequências como 
aborto e mortalidade materno-infantil, dentre outras.

Comumente, as abordagens educativas sobre saúde sexual e reprodutiva ficam restritas à informação sobre doenças. Nesse cenário, surgem as novas tecnologias de educação em saúde; a informática educativa oferece as chamadas tecnologias interativas como ferramentas do saber teórico-prático. 0s jovens têm incorporado o universo digital como canal para o diálogo em saúde dentro e fora da escola. Nada obstante, o profissional da saúde, em especial o enfermeiro, deve lançar mão de recursos que envolvam o público jovem nos serviços de saúde, como no caso das tecnologias digitais de informação e comunicação (TDIC), propondo aos jovens um novo foco sem os tirar de seu campo de interesses ${ }^{3}$.

Assim, as práticas de cuidados em saúde requerem a apropriação do uso de novas tecnologias do cuidar, compreendidas estas como práticas virtuais que possibilitam ampliar o poder de diálogo e comunicação entre os sujeitos envolvidos no processo de promoção da saúde 4 .

Essas tecnologias se materializam por diversas ferramentas virtuais de que a própria internet dispõe, como web TV, fóruns, blogs, chats, aplicativos de smartphone, entre outros. A grande vantagem de seu uso é a rapidez no compartilhamento de informações, que se dá em poucos segundos, com ampla abrangência (praticamente mundial). Assim, seu uso constitui ferramenta pedagógica eficaz que o enfermeiro pode usar no compartilhamento de saberes com as juventudes ${ }^{5}$.

0 uso de tecnologias de comunicação nos processos do cuidar cria possibilidades e gera atração, sobretudo quando se trata das juventudes, que as utilizam com maior frequência em seu cotidiano de vida ${ }^{6}$. Assim, esses espaços virtuais, quando utilizados nas práticas de educação em saúde e promoção da saúde, representam um avanço na saúde coletiva.

Como exemplo do uso das TDIC, pode-se destacar o uso de web radio, um ambiente virtual de promoção do cuidado de enfermagem com jovens nas escolas e nos mais variados cenários da vida, o qual constitui uma experiência do uso das tecnologias digitais no processo de comunicação e educação em saúde.

Esta pesquisa adotou a seguinte questão norteadora:

- De que modo o uso de uma web radio potencializa as práticas de cuidado em saúde coletiva junto aos jovens, pautando-se em estratégias voltadas à saúde sexual e reprodutiva, com ênfase no uso de métodos contraceptivos?

\section{Os jovens têm \\ incorporado o universo \\ digital como canal para \\ o diálogo em saúde \\ dentro e fora da escola.}

Assim, esta pesquisa descreve o uso de uma web radio como ferramenta de diálogo em saúde coletiva, com enfoque nos métodos contraceptivos junto às juventudes do sertão brasileiro.

\section{METODOLOGIA}

Trata-se de pesquisa exploratório-descritiva com abordagem qualitativa, realizada no ciberespaço da web radio da Associação dos Jovens do Irajá (AJIr) e no espaço real, por meio de atividade de extensão universitária realizada por monitores do projeto “Em Sintonia com a Saúde" - alunos de mestrado e doutorado do Programa de Pós-Graduação Cuidados Clínicos em Enfermagem e Saúde da Universidade Estadual do Ceará (UECE). Essa etapa ocorreu em agosto de 2016 em Hidrolândia-CE, com estudantes do 2 o ano da do Curso Técnico em Agronegócio da Escola Estadual de Educação Profissional (EEEP) Francisca Maura, com idades de 15 a 17 anos, e jovens do "Baú da Leitura", da AJIr, com idades de 10 a 19 anos.

Os ciberespaços podem ser definidos como ambientes de interação e comunicação entre as pessoas que, intermediados pela rede de computadores e internet, faz circular informações de natureza virtual e real. 0 s termos virtual e real, com o primeiro não sendo a ausência do segundo, põem em destaque tensões que implicam tal dualidade, ainda que não sustentem uma teoria geral?

Os programas são produzidos em estúdio na UECE, no âmbito do projeto "Em Sintonia com a Saúde", e transmitidos via internet ao vivo pela web radio, às quartas-feiras, das $16: 00$ às 17:00. As discussões englobam temas de saúde coletiva em sessões semanais de debate. Para falar sobre cada tema são convidados profissionais especialistas na área, que dialogam e interagem com os jovens.

Primeiro, realizou-se um levantamento da realidade e planejamento, com visita in loco, conversa prévia com as juventudes e uso da observação sistemática. Constatou-se que o grupo está inserido no cenário de 
palavras que envolvem a saúde sexual e reprodutiva, mais especificamente 0 uso dos métodos contraceptivos. Posteriormente, foram realizadas 2 sessões educativas sobre saúde sexual e métodos contraceptivos, desenvolvidas em 2 momentos diferentes. 0 primeiro momento para os jovens do "Baú da Leitura" e o segundo para juventudes da EEEP.

A interação de jovens estudantes e entrevistados, para elaboração de perguntas-discussões e esclarecimento de dúvidas, ocorreu por meio de um dos links adotados (<www.ajir.com.br> ou <www. uece.ajir.com.br>) e dos demais canais de comunicação: Twitter; Skype; Facebook; mural de recados do site, blog e WhatsApp.

Para coleta de dados foi usado material das entrevistas sobre métodos contraceptivos, por meio de perguntas-discursos que os participantes enviaram via web radio, durante as interações da produção do programa na sala-estúdio com as juventudes nos territórios. Adotou-se para análise a técnica de agrupamentos e categorização das falas ${ }^{8,9}$.

Para garantir o anonimato dos participantes, recorreu-se a codinomes: Jovem 1, Jovem 2 [...] Jovem 24. Os locais foram denominados Território A e Território B. Este estudo foi aprovado pelo Comitê de Ética em Pesquisa da UECE, sob o Parecer n. 1.761.115, em conformidade com a Resolução n. 466/2012 do Conselho Nacional de Saúde (CNS).

\section{RESULTADOS E DISCUSSÃO}

Os resultados foram divididos em 3 categorias: a) Levantamento da realidade - apreensão do real por meio da observação in loco e da interação dialógica produzida entre pesquisador, web radio e juventudes; b) Primeira sessão - dialogando com as juventudes sobre os métodos contraceptivos; e c) Segunda sessão - protagonismo dos jovens acerca dos métodos contraceptivos no cotidiano escolar.

$$
\begin{aligned}
& \text {..os jovens } \\
& \text { expressaram desejo } \\
& \text { de dialogar sobre } \\
& \text { saúde sexual e } \\
& \text { reprodutiva. }
\end{aligned}
$$

Levantamento da realidade - apreensão do real por meio da observação in loco e da interação dialógica produzida entre pesquisador, web radio e juventudes

Por meio das visitas in loco e conversas prévias com as juventudes dos 2 territórios (EEEP e AJIr), observou-se no decorrer das ações de extensão universitária e em conversas informais que os jovens expressaram desejo de dialogar sobre saúde sexual e reprodutiva.

Além disso, as juventudes se mostraram mais ativas e mais comunicativas e não se dispersaram durante a discussão dos temas saúde sexual e reprodutiva via web radio. A sessão sobre os métodos contraceptivos constituiu tema central das perguntasdiscussões, seguida pelo planejamento familiar, IST/ HIV/AIDS, identidade e gênero.

No decorrer das observações in loco, apreenderamse os termos mais frequentes no universo das juventudes: namoro, gravidez, IST/HIV/AIDS, camisinha, métodos contraceptivos, celulares, tablets, aplicativos, blogs, chats, Facebook, Twitter, WhatsApp, games e YouTube, entre outros.

Em uma das atividades do projeto de extensão universitária, realizada na EEEP com um grupo de 25 jovens do $2^{\circ}$ ano (15 do sexo feminino e 10 do sexo masculino), com idades de 15 a 17 anos, perguntouse:

- "Se fosse para construir uma tecnologia educativa, o que vocês construiriam?"

A maioria (21) respondeu:

- “Um jogo para celulares dinâmico e lúdico, com perguntas relacionadas a namoro, relação sexual e como se prevenir."

Descreveram-se impressões, conhecimentos e como os jovens desejavam a construção do software. Para isso foram realizadas 2 sessões, 1 em cada território, em dias diferentes. A primeira sessão foi realizada na AJIr e a segunda na EEEP, abordando o uso dos métodos contraceptivos, como se descreve a seguir.

\section{Primeira sessão - dialogando com as juventudes sobre os métodos contraceptivos}

Descreve-se, aqui, a participação de 11 jovens, com idades de 10 a 19 anos, que participaram do "Baú da Leitura". Analisaram-se as perguntasdiscursos dos jovens sobre métodos contraceptivos. Vale ressaltar que essa foi uma programação especial, 
já que as atividades do "Baú da Leitura" ocorrem na AJIr aos sábados e as atividades da web radio ocorrem às quartas-feiras. 0 programa foi produzido das 17:00 às 18:00.

Os jovens enviavam perguntas pelas redes sociais Facebook e WhatsApp para o debatedor. Essas perguntasdiscursos apresentam diversos sentidos, como linhas de força nas falas dos participantes sobre sexualidade e saúde reprodutiva em cada categoria discursiva.

Quadro 1 - Perguntas-discursos dos jovens do Território A

\section{Temática: métodos contraceptivos}

- O que são métodos contraceptivos? Dizem que a camisinha é um. (Jovem 1)

- Quais são os mais usados? Só conheço a camisinha masculina. (Jovem 8)

- Várias amigas já engravidaram sem querer. Eu queria saber o que devemos saber para prevenir a gravidez e qual é o melhor método. (Jovem 9)

- A camisinha é o método mais seguro? Porque me disseram que ela previne contra as doenças. (Jovem 5)

- Conheço e a maioria dos meus amigos só conhece a camisinha masculina e a pílula, que são as mais usadas. Quais são os outros? (Jovem 7)

- O que devemos fazer para nos prevenir da AIDS? (Jovem 10)

- É verdade que posso pegar AIDS se eu não me prevenir? (Jovem 2)

- Eu tenho uma amiga que ficou grávida porque usou o coito interrompido e outra que pegou uma doença do namorado. Eles são irresponsáveis. Fiquei preocupada. Quais são as doenças que pegamos se não nos prevenimos? Como sei se tenho uma? 0 que vou sentir? (Jovem 4)

- Tudo que sei eu aprendi com meus amigos, tenho vergonha de meus pais, professores e enfermeiros. Como é que falamos pros pais da gente sobre isso? (Jovem 6)

- O que é DIU? O diafragma é o DIU? É a gente que bota? E não machuca? (Jovem 3)

Fonte: Elaborado pelos autores.

0 Quadro 1 evidencia a participação ativa da maioria (10) dos jovens do "Baú da Leitura" na realização de perguntas-discursos; 3 jovens mencionaram conhecer a camisinha masculina e 2 citaram a pílula e a camisinha masculina como métodos mais utilizados no planejamento familiar. Relataram, ainda, que a camisinha masculina é o método mais seguro para evitar doenças e 1 participante mencionou não conhecer alguns métodos contraceptivos (como DIU e diafragma), além de dúvidas em relação ao uso deles.

Apesar dos jovens verbalizarem algum conhecimento sobre métodos contraceptivos, gravidez indesejada e IST/HIV/AIDS, observaram-se dúvidas, curiosidades e falhas nos conceitos citados, surgindo a necessidade de abordar esse tema com maior ênfase ${ }^{9}$.

Nas perguntas, o preservativo masculino assume papel de destaque dentre os métodos contraceptivos, observando-se desconhecimento acerca dos outros métodos. 0 preservativo masculino e a pílula anticoncepcional são amplamente conhecidos pela juventude no Brasil ${ }^{10}$.

A discussão sobre gravidez e IST/HIV/AIDS possibilitou identificar as principais necessidades a trabalhar com esse público - particularmente preocupado com esses problemas.

0 HIV e a AIDS se encontram entre os principais problemas contemporâneos de saúde pública, em especial entre os jovens, mais suscetíveis a tais agravos, com as mais diversas implicações para a sociedade, perpassando aspectos objetivos e subjetivos. Vale ressaltar que se convive com duas epidemias distintas, embora intimamente relacionadas ${ }^{11}$.

No momento da sessão, os participantes citaram que a falta de responsabilidade de muitos jovens e relataram experiências de amigas que tiveram gravidez não planejada. Mencionaram, ainda, a falta de diálogo com os pais, professores e profissionais da saúde (como os enfermeiros).

Dentre os fatores que influenciam o não uso de métodos anticoncepcionais ou seu uso incorreto temos a falta de diálogo e a esporadicidade e o não planejamento das relações sexuais. Esse fato pode ser explicado pelo desconhecimento acerca dos modos seguros de prevenir essas situações ou do uso correto dos métodos ${ }^{12}$.

A juventude tem iniciado precocemente sua vida sexual, o que aumenta a incidência de gravidez não planejada. 0 conjunto de transformações fisiológicas, culturais, sociais, emocionais e psicológicas, 
combinado à falta de orientação sexual e discussão adequada sobre o planejamento familiar por parte da escola e do núcleo familiar, concretiza esse fato ${ }^{13}$.

Em relação à comunicação, percebe-se que a juventude se sente mais à vontade ao conversar com amigos e, muitas vezes, diante da falta de diálogo em seu núcleo familiar, os amigos constituem sua fonte de informações mais acessivel. Na família, o diálogo ainda é frágil ou inexistente; na escola, o debate se mostra tímido e, quando ocorre, volta-se mais aos aspectos biológicos, reforçando a ideia da sexualidade ligada à reprodução. Tanto educadores como profissionais da saúde ainda mantêm posturas impregnadas de preconceitos e tabus ${ }^{14}$.

Observou-se que o tema abordado faz parte da realidade e do convívio dos jovens. 0 momento foi proveitoso no sentido de esclarecer dúvidas sobre os métodos contraceptivos, abrindo espaço para discussão e contribuindo para uma reflexão crítica. Daí provém a importância da discussão das juventudes por meio da web radio, um meio de informação que rompe barreiras e favorece a comunicação e o diálogo mais aberto acerca do tema, menos carregado de timidez ou de dificuldade para se expressar livremente.

Independente da participação familiar no processo educativo, a sexualidade vem sendo abertamente debatida em meios de comunicação como a televisão, o rádio e a internet e isso tem influenciado o comportamento dos jovens com um bombardeio de informações - em sua maioria distorcidas - sobre sexualidade. É necessário adotar um olhar mais cuidadoso em relação a quais redes de informação esse público vem acessando. Os pais e familiares devem conhecer os espaços de comunicação e informação que esse público adentra ${ }^{15}$.

Mostra-se fundamental combinar informação e comunicação a discussão e orientação, no sentido de proporcionar à juventude maior esclarecimento quanto a suas dúvidas, seus receios e seus tabus relativos ao tema para, assim, abrir espaço à busca de informações e ao interesse em prevenir possíveis agravos relacionados à falta de cuidados voltados à vida sexual e reprodutiva.

\section{Segunda sessão - protagonismo dos jovens acerca dos métodos contraceptivos no cotidiano escolar}

A segunda sessão foi realizada na EEEP, mais especificamente em 2 turmas do $2^{ }$ano do Curso Técnico de Agronegócio. Ao todo, estavam presentes 70 alunos e essa sessão possibilitou 0 compartilhamento de dúvidas, ideias, conhecimentos e opiniões sobre o tema em questão. Foram realizadas 13 perguntas-discursos e o codinome dos jovens teve a mesma sequência da primeira sessão, como se pode observa no Quadro 2.

Quadro 2 - Perguntas-discursos dos jovens do Território B

\section{Temática: métodos contraceptivos}

- Existe uma possibilidade da camisinha masculina causar uma reação alérgica ao látex? (Jovem 12)

- O DIU previne contra as DST? (Jovem 13)

- O DIU incomoda de alguma forma o homem na relação sexual? (Jovem 14)

- Já ouvi comentários de que o DIU pode causar câncer. É verdade? (Jovem 15)

- Por que o DIU não previne em 100\% a gravidez? (Jovem 16)

- O anticoncepcional regula a menstruação? (Jovem 17)

- Se uma pessoa esquecer de tomar os comprimidos, pode correr risco de engravidar? (Jovem 18)

- Quando se toma anticoncepcional por muito tempo, há possibilidade da mulher ter dificuldade para engravidar? (Jovem 19)

- Onde os jovens podem obter informações sobre o tema? (Jovem 20)

- O que podemos fazer nas escolas para passar o que aprendemos para os estudantes e a comunidade onde moramos? (Jovem 21)

- Porque o setor saúde não está tão presente nas escolas? (Jovem 22)

- Qual é a importância de tratar esse tema com os jovens nas escolas? (Jovem 23)

- Por que, apesar de termos tantas informações, existem muitos amigos meus que não têm conhecimento e pegam doenças como a AIDS e outras pessoas ficam grávidas? (Jovem 24)

Fonte: Elaborado pelos autores.

Algumas dúvidas apresentavam um olhar mais social, ressaltando a importância da comunicação voltada ao 
tema e exigindo estratégias para que as informações cheguem à escola e à comunidade.

Vale ressaltar que há outras dúvidas a esclarecer, como no caso da camisinha masculina, do incômodo de alguns métodos contraceptivos, da pílula anticoncepcional e do uso correto do DIU.

Como se pôde verificar por meio dos questionamentos, os jovens não usam 0 anticoncepcional adequadamente, por não acreditarem na possibilidade de gravidez ou de IST/HIV/AIDS. Em razão da baixa frequência das relações sexuais, os jovens se consideram em situação de segurança, acham difícil obter os contraceptivos e sentem incômodo ao usá-los, além de assumirem a premissa de que "isso não vai acontecer comigo"14.

Novas perguntas surgiram e outros pontos foram questionados, como as informações em tempo real repassadas à juventude via internet; apesar delas, muitos jovens ainda desconhecem o tema ou fazem mau uso dos métodos contraceptivos. A web radio é um meio eficiente de diálogo e constitui uma ferramenta de escuta, promovendo a saúde, esclarecendo dúvidas e prevenindo ou diminuindo riscos e vulnerabilidades, além de fortalecer vínculos.

Nas interações, os participantes mostraram interesse em discutir, por meio das TDIC, o tema na escola, via diálogo aberto que permita sua livre expressão para o esclarecimento de dúvidas. Mencionaram a necessidade de espaços para a escuta e o compartilhamento dessas informações nos diversos locais em que estão inseridos, além da criação de estratégias para a difusão das informações sobre os métodos contraceptivos, onde possam ser protagonistas das ações e estabelecer vínculos com os professores, proporcionando a educação em saúde na escola.

Um dos pontos fundamentais para a efetividade das ações de planejamento reprodutivo é o vínculo estabelecido com o parceiro, os familiares, os professores e os profissionais da saúde, com acesso a informações e técnicas corretas, que possibilitem ao indivíduo fazer escolhas conscientes a partir de sua própria realidade, com autonomia, melhorando suas condições de vida e saúde ${ }^{15,16}$.

Vale salientar que o planejamento familiar não deve enfocar apenas o uso ou não dos métodos contraceptivos; deve-se orientar, dialogar e debater com a juventude os riscos e as consequências de iniciar sua vida sexual sem proteção, alertando sobre os modos de prevenção e transmissão de IST/HIV/ AIDS e os sintomas de tais doenças. Deve-se

\section{A web radio é um meio eficiente de diálogo e constitui uma ferramenta de escuta, promovendo a saúde...}

implementar uma educação em saúde crítica e reflexiva para intervenções comprometidas com os princípios da democracia - que rejeita qualquer modo de discriminação e dominação e busca a inovação e renovação no setor saúde ${ }^{17}$.

Depreende-se das perguntas a preocupação dos jovens em aprofundar seus conhecimentos acerca do tema, além do importante papel de debate assumido pelos profissionais da saúde na escola.

As estratégias de ensino e as pedagogias inovadoras, conhecidas como metodologias ativas, corroboram a ideia de que a busca do saber em Enfermagem deve aproximar a prática assistencial à prática educacional, já que o enfermeiro utiliza o processo ensino-aprendizagem em suas ações de saúde coletiva e na promoção da saúde junto aos jovens ${ }^{18}$. Logo, o empoderamento das juventudes passam a interferir em seu processo saúde-doença potencializa-se por meio do autocuidado ${ }^{19}$.

É necessário trabalhar a saúde dos jovens abordando o processo de educação em saúde, com uso das diversas tecnologias (como as TDIC), trazendo interação que enseje uma vivência participativa com ênfase no diálogo - campo profícuo para a reflexãoação e a elaboração coletiva de propostas sistematizadas de educação emancipatória em saúde.

Os participantes demonstraram interesse em construir um software educativo (jogo) para dialogar e discutir a promoção da saúde sexual e reprodutiva, de modo a combinar a ideia de cidadania aos direitos humanos, considerando que as atividades nos territórios constituem modos de fortalecer as ações de promoção da saúde junto à comunidade, com a aproximação entre os serviços de saúde e os indivíduos. As intervenções de educação em saúde assumem grande valor para o empoderamento dos jovens, que são estimulados a participar de seu plano terapêutico e a desenvolver sua autonomia.

\section{CONCLUSÃO}

A liberdade de diálogo proporcionada pela web radio apresentou resultados satisfatórios, tendo em 
vista o universo de palavras com que os jovens dialogam. Termos e expressões voltadas à saúde sexual e reprodutiva e às tecnologias digitais auxiliaram, nessa etapa exploratória, o planejamento da construção de um jogo (nos moldes de um aplicativo para celulares) voltado aos métodos contraceptivos.

Assim, este artigo traz um novo olhar às práticas em saúde coletiva com uso de ferramentas tecnológicas específicas sobre os métodos contraceptivos, com abordagem amplificada, a partir de uma web radio, que considera as realidades, as necessidades e as potencialidades das juventudes no sertão brasileiro.

\section{CONTRIBUIÇÃO DOS AUTORES}

Leidy Dayane Paiva de Abreu e Raimundo
Augusto Martins Torres contribuíram com o
delineamento e a realização da pesquisa e a
estruturação e redação do manuscrito. Maria
Rocineide Ferreira da Silva e Aretha Feitosa de
Araújo contribuíram com a revisão crítica do
manuscrito.

\section{REFERÊNCIAS}

1. Martins MG, Santos GHN, Sousa MS, Costa JEFB, Simões VM. Associação de gravidez na adolescência e prematuridade. Rev Bras Ginecol obstet [serial on the internet]. 2011 [cited 2018 May 4];33(11):354-60. Available from: http://www.scielo.br/pdf/rbgo/v33n11/a06v33n11. pdf

2. Brasil. Parâmetros Curriculares Nacionais: pluralidade cultural e orientação sexual. 2. ed. Rio de Janeiro: DP \& A; 2014.

3. Oliveira Júnior JK, Silva MAD. As tecnologias de informação e comunicação como ferramenta complementar no ensino da histologia nos cursos de odontologia da região Norte. J Health Inform [serial on the internet]. 2014 [cited 2018 May 15];6(2):60-6. Available from: http://www.jhisbis.saude.ws/ojs-jhi/index.php/jhi-sbis/article/ view $/ 293 / 196$

4. Amante LN, Rossetto AP, Schneider DG. Sistematização da assistência de enfermagem em unidade de terapia intensiva sustentada pela teoria de Wanda Horta. Rev Esc Enferm USP [serial on the internet]. 2009 [cited 2018 May 15];43(1):5464. Available from: http://www.scielo.br/pdf/reeusp/ v43n1/07.pdf

5. Rangel SML, Lamego G, Gomes ALC. Alimentação saudável: acesso à informação via mapas de navegação na internet. Physis (Rio J) [serial on the internet]. 2012 [cited 2018 May 15];22(3):919-39. Available from: http://www.scielo. br/pdf/physis/v22n3/05.pdf

6. Lira C, Ferreira L, Costa MJ, Pinto MK, Fernandes S. Discutindo violência e saúde na web-rádio: uma proposta intervencionista. Revista Extendere [serial on the internet]. 2015 [cited 2018 May 15];2(2):64-72. Available from: file:///D:/1287-3403-1-PB.pdf
7. Lévy, P. 0 que é virtual? Rio de Janeiro: Ed. 34; 2012

8. Minayo MC. 0 desafio do conhecimento: pesquisa qualitativa em saúde. 14. ed. São Paulo: Hucitec; 2014.

9. Torres RAM, Freitas GHF, Vieira DVF, Sales LMS. Tecnologias digitais e educação em enfermagem: a utilização de uma web rádio como estratégia pedagógica. J Health Inform [serial on the internet] . 2012 [cited 2018 May 15];4(1):1526. Available from: file:///D:/248-916-1-PB.pdf

10. Martins LB, Costa-Paiva L, Osis MJ, Sousa MH, Pinto Neto AM, Tadini V. Conhecimento sobre métodos anticoncepcionais por estudantes adolescentes. Rev Saúde Pública [serial on the internet]. 2006 [cited $2017 \mathrm{Mar}$ 12]; 40(1):57-64. Available from: http://www.scielo.br/pdf/ rsp/v40n1/27116.pdf

11. Carvalho AM, Rodrigues CS, Medrado KS. Oficinas em sexualidade humana com adolescentes. Estud Psicol (Natal) [serial on the internet]. 2015 [cited 2018 May 15];10(3):4316. Available from: http://www.scielo.br/pdf/epsic/v10n3/ a 06 v10n3.pdf

12. Chiamenti C. Uso de tecnologias da informação e comunicação no ensino presencial em enfermagem. Rio Grande (RS): Universidade Federal do Rio Grande; 2012.

13. Arcanjo CM, Oliveira MIV, Bezerra MGA. Gravidez em adolescentes de uma unidade municipal de saúde em Fortaleza - Ceará. Esc Anna Nery Rev Enferm [serial on the internet]. 2007 [cited 2018 May 15];11(3):445-51. Available from: http://www.scielo.br/pdf/ean/v11n3/v11n3a08.pdf

14. Berlofi LM, Alkmin ELC, Barbieri M, Guazelli CAF, Araújo FF. Prevenção da reincidência de gravidez em adolescentes: efeitos de um Programa de Planejamento Familiar. Acta Paul Enferm [serial on the internet]. 2006 [cited 2018 May 15];9(2):196-200. Available from: http://www.scielo.br/ $\mathrm{pdf} / \mathrm{ape} / \mathrm{v} 19 \mathrm{n} 2 / \mathrm{a} 11 \mathrm{v} 19 \mathrm{n} 2 . \mathrm{pdf}$

15. Imeida ACP. Produção de vídeos em sala de aula: uma proposta de uso pedagógico de celulares e câmeras digitais. \#Tear: Revista de Educação, Ciência e Tecnologia [serial on the internet]. 2013 [cited 2018 May 15];2(1):1-13. Available from: file:///D:/1785-5293-1-PB.pdf

16. Abreu LDP, Mendonça GMM, Andrade AC, Oliveira GR Aurélio D0, Rocha FAA. Abordagem educativa utilizando os Círculos de Cultura de Paulo Freire: experiência de acadêmicos de enfermagem no "Grupo Adolescer". Adolesc Saúde [serial on the internet]. 2013 [cited 2018 May 15];10(4):66-70. Available from: file:///D:/v10n4a09.pdf

17. Freire P. Educação como prática da liberdade. 27. ed. Rio de Janeiro: Paz e Terra; 2013.

18. Gartner Inc. Market share: mobile communication devices by region and country, 3011 [document on the internet]. 2012 [cited 2018 May 15]. Available from: https://www.gartner.com/doc/1847315/market-sharemobile-communication-devices.

19. Andrade MLR, Brito MCC, Freitas CASL. Planejamento familiar: um recurso estratégico à maternidade responsável de adolescentes primíparas. Sanare (Sobral, 0nline) [seria on the internet]. 2013 [cited 2018 May 15];12(1):27-32. Available from: file:///D:/325-628-1-SM.pdf

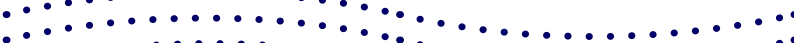

$\ldots \ldots \ldots \ldots$

$\ldots \ldots \ldots \ldots \ldots$

SANARE, Sobral - v.17, n.01,p.24-31, Jan./Jun. - 2018 - 31 


\section{AVALIABILIDADE DO PROGRAMA SAÚDE NA ESCOLA NO NORDESTE DO BRASIL}

EVALUABILITY OF THE SCHOOL HEALTH PROGRAM IN NORTHEASTERN

BRAZIL

EVALUACIÓN DEL PROGRAMA SALUD EN LA ESCUELA EN EL NORDESTE DE

BRASIL

Maria Socorro de Araújo Dias ${ }^{1}$

Lielma Carla Chagas da Silva ${ }^{2}$

Maria da Conceição Coelho Brito ${ }^{3}$

Alexandro do Vale Silva 4

Rayanne Branco dos Santos Lima ${ }^{5}$

Diógenes Farias Gomes 6

Angelo Brito Rodrigues ?

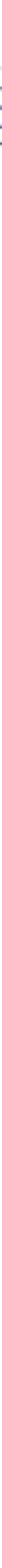




\section{ABSTRACT}

The objective is to analyze the evaluability of the School Health Program in Ceará, from the Logical Model and Analysis and Judgment Matrix. evaluability study of qualitative approach, carried out from August 2012 to August 2015 by documentary analysis of 32 documents Program and semi-structured interviews with 13 key informants from 13 cities of three Ceará health macro-regions. The results of the Logical Model feature that intersectoral coordination is weakened in the 13 cities, and only the actions of nutrition and ophthalmologic evaluations are conducted more frequently (in 10 and 8 cities, respectively). Other important actions of the program occur between 6 and 1 cities. Actions on psychosocial assessment are absent, promoting physical activity and tobacco control and other cancer factors in all cities. Dialoging with the Logic Model, the Analysis Matrix and Judgment points 23,3\% of implementation of the School Health Program in Ceará, the incipient indicative of this.

\section{RESUMEN}

Se pretende analizar la evaluación del Programa Salud en la Escuela en Ceará, a partir del Modelo Lógico y de la Matriz de Análisis y Juicio. Estudio de evaluación, de abordaje cualitativo, realizado de agosto de 2012 a agosto de 2015, mediante análisis documental con 32 documentos del Programa y entrevistas semiestructuradas con 13 informantes clave de 13 municipios de tres macrorregiones de salud de Ceará. Los resultados del Modelo Lógico presentan que la articulación intersectorial es fragilizada en los 13 municipios, y que sólo las acciones de evaluación nutricional y oftalmológica se realizan más frecuentemente (en 10 y 8 municipios, respectivamente). Otras acciones importantes del Programa ocurren entre 6 y 1 municipios. Se están ausentes las acciones sobre evaluación psicosocial, promoción de la actividad física, y control del tabaquismo y otros factores de cáncer en todos los municipios. Dialogando con el Modelo Lógico, la Matriz de Análisis y Juicio apunta el 23,3\% de implantación del Programa Salud en la Escuela en Ceará, indicativo de la incipiente de ésta.

\section{INTRODUÇÃO}

Dentre os esforços para materialização de uma política intersetorial no Estado brasileiro envolvendo os setores da saúde e da educação, destaca-se o Programa Saúde na Escola (PSE). Instituído pelo decreto presidencial n. 6.286 , de 05 de dezembro de 2007, este Programa é resultado do trabalho integrado entre os Ministérios da Saúde (MS) e o da Educação (MEC), na perspectiva de ampliar as ações de saúde aos alunos da rede pública de ensino ${ }^{1}$.

0 PSE se propõe a ser um novo desenho de política de educação em saúde. Compreende as áreas saúde e educação de forma integral e parte de uma formação ampla para a cidadania e usufruto pleno dos direitos humanos, de forma a promover também a articulação de saberes, a participação de alunos, pais, comunidade escolar e sociedade em geral na construção e controle social da política².

Para sua operacionalização, o PSE apresenta cinco componentes: 1) avaliação clínica e psicossocial; 2) ações de promoção da saúde e prevenção das doenças e agravos; 3) educação permanente e capacitação de profissionais da educação e saúde e de jovens para o PSE; 4) monitoramento e avaliação da saúde dos estudantes; e, 5) monitoramento e avaliação do PSE. 0 quinto componente sinaliza a necessária inclusão de processos avaliativos para o desenvolvimento do $\mathrm{PSE}^{2}$.

0 PSE encontra-se em desenvolvimento. Concernente ao proposto no quinto componente desse Programa é que se propõe realizar um estudo de avaliabilidade para verificar em que medida o PSE pode ser avaliado ${ }^{3}$. Estudos de avaliabilidade são importantes por subsidiarem gestores no processo de avaliação de programas, de modo a reunir informações para a tomada de decisões sobre a continuidade destes. Permite, assim, que a avaliação tenha objetividade necessária para tornar o processo factível dentro do tempo e dos recursos disponíveis, mesmo que para isso seja necessário simplificar processos, limitar a profundidade do estudo e relativizar a precisão e a abrangência dos resultados, preservando o que the é essencial: a contribuição para a tomada de decisão e para sua implementação ${ }^{4}$.

No Ceará, em 2012, 161 municípios receberam incentivo federal para que, em 298 escolas estaduais e 4.431 municipais, fossem desenvolvidas ações para reforçar o cuidado e a promoção à saúde dos alunos, incluindo ações concretas para o enfrentamento de doenças crônicas não transmissiveis ${ }^{5}$.

Desse modo, este artigo objetiva realizar uma análise da avaliabilidade do Programa Saúde na Escola no estado do Ceará. 


\section{METODOLOGIA}

Estudo de avaliabilidade ${ }^{6}$, de abordagem qualitativa, realizado no período de agosto de 2012 a agosto de 2015, em 13 municípios de três macrorregiões de saúde do Ceará.

Os municípios pesquisados de cada macrorregião de saúde foram identificados considerando a classificação, por porte populacional, utilizada pelo Instituto de Pesquisa e Estratégia Econômica do Ceará (IPECE): pequeno porte I (até 20.000), pequeno porte II (20.001 a 50.000), médio porte (50.001 a 100.000), grande porte $(100.001$ a 900.000) e metrópole $(>900.000)^{7}$.

Houve, então, a associação dos critérios de base populacionais antes mencionados com a configuração do processo de regionalização da saúde vigente no período da coleta de dados. 0 Ceará, em tal momento, apresentava o Sistema Estadual de Saúde estruturado em três (03) macrorregionais: Fortaleza, Sobral e Cariri $^{8}$. Assim, compuseram o cenário do estudo 13 municípios cearenses.

Para o alcance do objetivo do estudo, a coleta de informações procedeu-se da seguinte forma:

1. Realizou-se uma busca nos sítios eletrônicos do Ministério da Saúde e da Educação com vistas a identificar documentos que regulamentavam o PSE. Chegou-se ao número de 32 documentos de cunho normativos, informativos e educativos. Essa análise foi guiada por perguntas-chave para a construção de programas e políticas, que incluíam aspectos sobre a criação, finalidade e operacionalização do Programa ${ }^{9}$.

2. Entrevistas semiestruturadas com 13 informantes-chave, representados pelos coordenadores municipais do Programa. Foram abordados questionamentos acerca da apropriação do Programa pelo município, sua operacionalização e desafios.

As etapas 1 e 2 foram necessárias para a construção do Modelo Lógico-ML do PSE no Ceará. Esse processo teve por finalidade delinear o Programa, e a busca pela coerência com o que estava sendo implementado e o que era previsto.

1. Oficina de validação do ML com um representante de cada macrorregião. Para essa etapa utilizou-se como critérios: maior tempo de implantação do Programa no município, coordenador com exercício na função há mais de um ano e a disponibilidade para participação.

2. Realinhamento do ML mediante o julgamento realizado na etapa 3. Essa etapa almejou detalhar o

\section{Os critérios ou indicadores foram representados pelas ações desempenhadas pelo PSE...}

Programa em termos de seus componentes e de sua forma de operacionalização, identificando todas as ações e produtos necessários aos resultados esperados. 0 ML foi reapresentado aos informanteschave que validaram o conteúdo e as relações estabelecidas entre os elementos expostos.

3. A partir do ML procedeu-se à construção da Matriz de Análise e Julgamento, também chamada de Matriz Final da Avaliação, cuja função é avaliar o desempenho do Programa ${ }^{10}$. Esta foi construída considerando o que do Programa deve ser avaliado e com base em que parâmetros isto deve ser feito. Para isso, elencaram-se para cada componente extraído do ML os critérios, os indicadores e os padrões que foram utilizados na mensuração dos dados. 0s critérios ou indicadores foram representados pelas ações desempenhadas pelo PSE nos municípios pesquisados, haja vista que estas atividades devem ser operacionalizadas para o alcance dos resultados do programa.

0s padrões foram adotados e discutidos a partir das indicações dos documentos legais e estudos afins disponivel na literatura. 0 parâmetro ou padrão consistiu num valor de referência para mensuração de um fenômeno ou objeto, considerado como ideal, podendo ou não ser expresso numericamente ${ }^{11}$. A definição dos padrões da Matriz de Análise e Julgamento foi delimitada tendo como base a normatização proposta nos documentos oficiais e nos produtos das entrevistas.

A Matriz foi, posteriormente, submetida à apreciação de um comitê de especialistas formados por três profissionais da área acadêmica, que também são vinculados aos serviços de saúde e desenvolvem suas atividades na atenção primária à saúde. As observações do comitê de especialistas foram incorporadas, os valores dos referenciais padrões foram consolidados e os resultados devidamente calculados para que a matriz de critérios e julgamentos fosse validada. 
0 estudo atendeu aos princípios éticos das diretrizes e normas regulamentadoras para pesquisa envolvendo seres humanos, por meio da Resolução n 466 de 12 de dezembro de 2012. A pesquisa foi aprovada pelo Comitê de Ética em Pesquisa da Universidade Estadual Vale do Acaraú - UVA, sob Parecer N. 212.998/2013.

\section{RESULTADOS E DISCUSSÃO}

Os resultados do estudo estão organizados mediante apresentação, análise e discussão do Modelo Lógico do PSE no Ceará e da Matriz de Análise e Julgamento.

\section{Modelo Lógico do PSE no Ceará}

0 ML do PSE no estado do Ceará (Figura 1) mostra os componentes, recursos, ações, produtos, resultados intermediários e resultado final. A análise documental e as entrevistas evidenciaram que no estado as ações se desdobram a partir dos componentes: avaliação clínica e psicossocial; promoção da saúde e prevenção de doenças; e educação permanente e capacitação de profissionais da educação e da saúde e de jovens. 0 ML ainda considera fatores apontados pelos informantes-chave como aqueles que interferem no processo de implantação do PSE, e que se tornam desafios que permeiam a operacionalização do Programa.

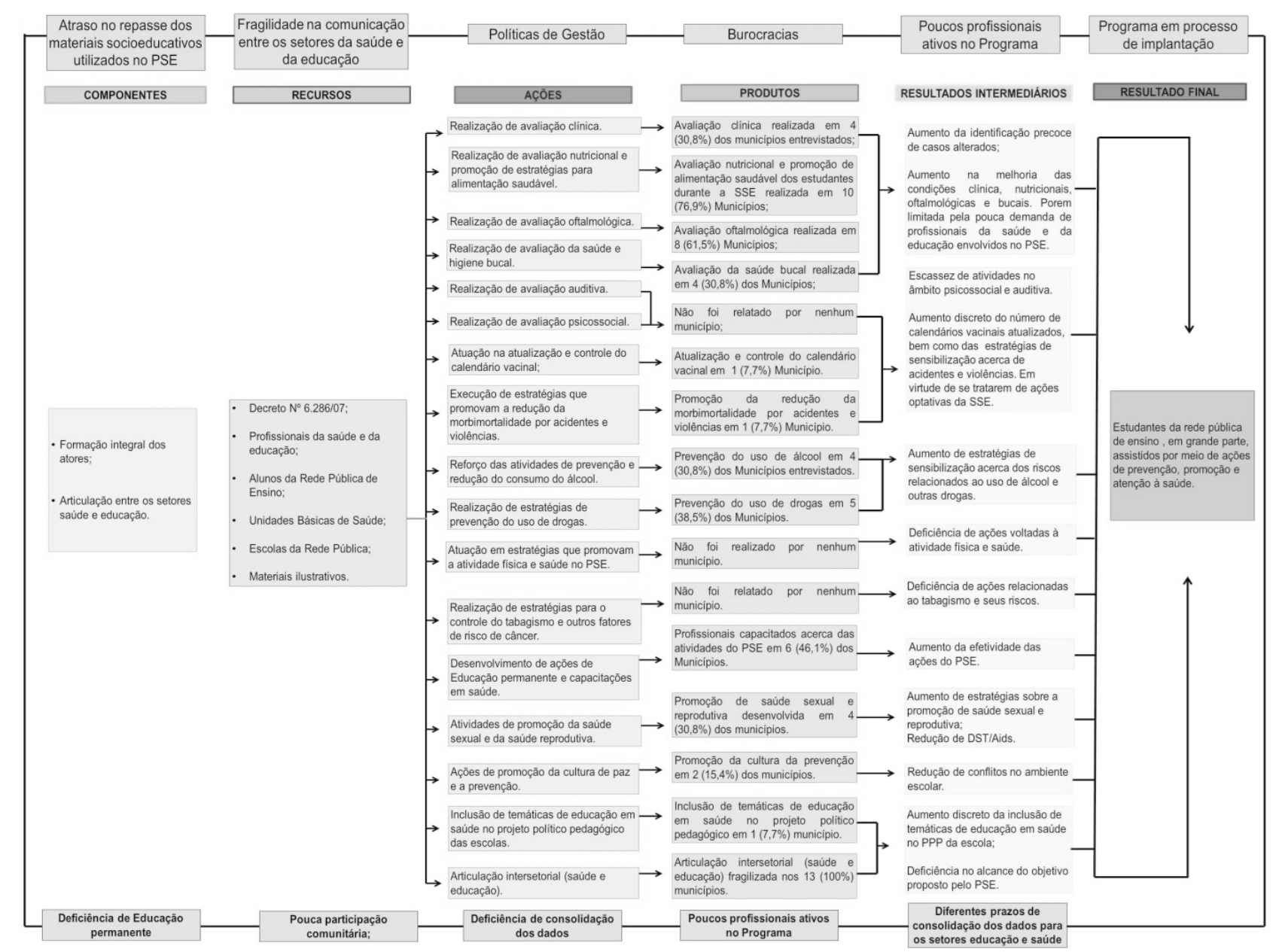

Fonte: dados do estudo.

Analisando o ML, verifica-se a menção da avaliação clínica como realizada em quatro (04) dos municípios analisados. Tal dado se repete quando relacionado à avaliação de saúde bucal, ações para prevenção do uso do álcool e para atividades direcionadas para a promoção da saúde sexual e reprodutiva. 0s produtos identificados demonstram a necessidade de mais investimentos nesses campos, inferindo que intervir neles colabora para o retardamento, controle e até não ocorrência de situações de alto custo para o sistema de saúde brasileiro e que 
repercutem no desenvolvimento educacional e na qualidade de vida do aluno, a exemplo de distúrbios nutricionais, infecções recorrentes, gravidezes indesejadas que elevam a incidência de abortos clandestinos, e os acidentes de trânsitos fatais ou com severas sequelas.

Com relação à promoção da redução da morbimortalidade por acidentes e violências, um (01) município sinalizou desenvolver atividades para esse fim. Os acidentes e violências impõem uma carga negativa na qualidade de vida das pessoas. À saúde pública compete zelar por comunidades seguras e sadias, estabelecendo planos e políticas nacionais para prevenir os acidentes e violências, realizando parcerias entre os vários setores e assegurando dotação de recursos para as ações preventivas ${ }^{12}$. São a partir dessas parcerias que as escolas entram como um espaço potente na transformação de práticas consideradas inseguras para a manutenção da saúde e no conviver tolerante às diferenças. Verifica-se que nesse critério é necessário maior desenvolvimento de atividades entre os municípios elencados no estudo.

Aspectos a serem ponderados para a redução das violências são a prevenção do uso de drogas e a promoção da cultura de paz, sendo o primeiro importante para o segundo. Essas ações são apontados em cinco (05) e dois (02) municípios, respectivamente, como tendo ações direcionadas.

Ações com ocorrências relativamente significativas foram àquelas voltadas para as avaliações nutricional e oftalmológica que ocorreram, respectivamente, em dez (10) e oito (08) municípios. Cabe ponderar que apesar da expressividade dessas informações, algo pontuado como importante por um coordenador municipal foi que as ações, muitas vezes, existem, identificam-se problemas, mas não apresentam resolutividade por não contar com recursos suficientes para isso.

0 ML evidencia que um (01) município realiza controle do calendário vacinal nas escolas. Ainda provoca reflexão a não menção de atividades desenvolvidas nos municípios no que se referem à avaliação psicossocial, estratégias promotoras de atividade física e de controle do tabagismo.

Instiga-se a refletir sobre a invisibilidade dessas três ações. Estariam os municípios desconsiderando de que escolares não se expõem a riscos com implicações psicossociais? Está sendo negligenciado o potencial da atividade física enquanto estratégia para o enfrentamento de desvios nutricionais e situações de estresse tão na comunidade de escolares?

\section{...atitudes interdisciplinares (...) essencial aos movimentos de educação permanente...}

Os riscos e acesso ao tabagismo pelos adolescentes estariam sendo naturalizados?

A inclusão de temáticas relacionadas à saúde e bem-estar foi mencionada como realizada em um (01) município. Isso pode ter influência da ainda distante articulação entre os setores educação e saúde nos municípios estudados; esta é apontada pelos informantes-chave como frágil nos treze (13) municípios participantes do estudo.

A atuação intersetorial na realização das ações do PSE foi identificada no estudo como necessária ao alcance dos resultados esperados pelo programa. Embora o Decreto $n^{\circ} 6286$ de 05/12/07, que institui - PSE, aponte, especificamente, que as equipes de Saúde da Família juntamente com a Educação Básica devam desenvolver estratégias para a integração e a articulação permanente entre as políticas e ações de educação e de saúde ${ }^{13}$, ainda há o que progredir. A falta de habilidade de desenvolver atividades conjuntas com outras categorias profissionais dificulta o diálogo e a atuação interdisciplinar.

Para haver essa interação é necessário inicialmente que dois ou mais profissionais tenham o interesse de interagir e compartilhar seus conhecimentos e saberes em prol de uma unidade e um objetivo comum. Essas trocas geram uma nova configuração interna, que, se ouvida e entendida, cria a possibilidade de atitudes interdisciplinares ${ }^{14}$. Isso é essencial aos movimentos de educação permanente que devem existir para a eficácia do PSE no estado, pois estes ainda se apresentam discretos nos municípios; sendo verificado em apenas seis (06) dos municípios estudados.

\section{Matriz de Análise e Julgamento}

0 processo de construção da Matriz de Análise e Julgamento deu-se a partir da identificação dos elementos que constituem a Matriz (Quadro 1), e suas respectivas definições. Esta produção foi realizada levando em consideração as características individuais 
dos componentes do PSE devidamente apresentados no ML.

Quadro 1 - Elementos componentes da Matriz de Análise e Julgamento do Programa Saúde na Escola no estado do Ceará, 2015.

\begin{tabular}{|c|c|}
\hline Elementos da matriz & Definição \\
\hline Componente & Palavras-chave que agregam um conjunto de atividades do modelo lógico. \\
\hline Indicador & $\begin{array}{l}\text { Medida ou fator quantitativo ou qualitativo da expressão do componente a } \\
\text { ele relacionado. }\end{array}$ \\
\hline Padrão & Um valor de referência para mensuração de cada indicador. \\
\hline Fonte de verificação & Lugar onde os dados serão coletados. \\
\hline Ponto de corte & $\begin{array}{c}\text { Valor de referência para o julgamento. Foi atribuído um indicador com valores } \\
\text { variando entre } 10 \text { (dez), } 5 \text { (cinco) e } 2 \text { (dois), sendo que o valor dois } \\
\text { corresponde ao padrão não atingido, o valor } 5 \text { corresponde ao padrão } \\
\text { parcialmente atingido e o valor } 10 \text { significa que o padrão foi atingido em sua } \\
\text { plenitude. }\end{array}$ \\
\hline Julgamento & $\begin{array}{l}\text { É uma qualificação dada aos subcomponentes e à política na sua dimensão } \\
\text { unitária, considerando o somatório dos pontos alcançados pelos indicadores. }\end{array}$ \\
\hline
\end{tabular}

Fonte: Adaptado de Bezerra et al (2012, p. 887) ${ }^{3}$

Assim, com base no ML, elegeram-se os indicadores para a Matriz de Análise e Julgamento apresentada no Quadro 2. Na Matriz é considerado o que deve ser avaliado e com base em que parâmetros, elencando-se para cada componente do ML os indicadores e os padrões relacionados aos recursos, ações e produtos. Têm-se ainda as fontes de verificação nas quais as informações de cada indicador devem ser buscadas e os pontos de corte para efeito de julgamento. 


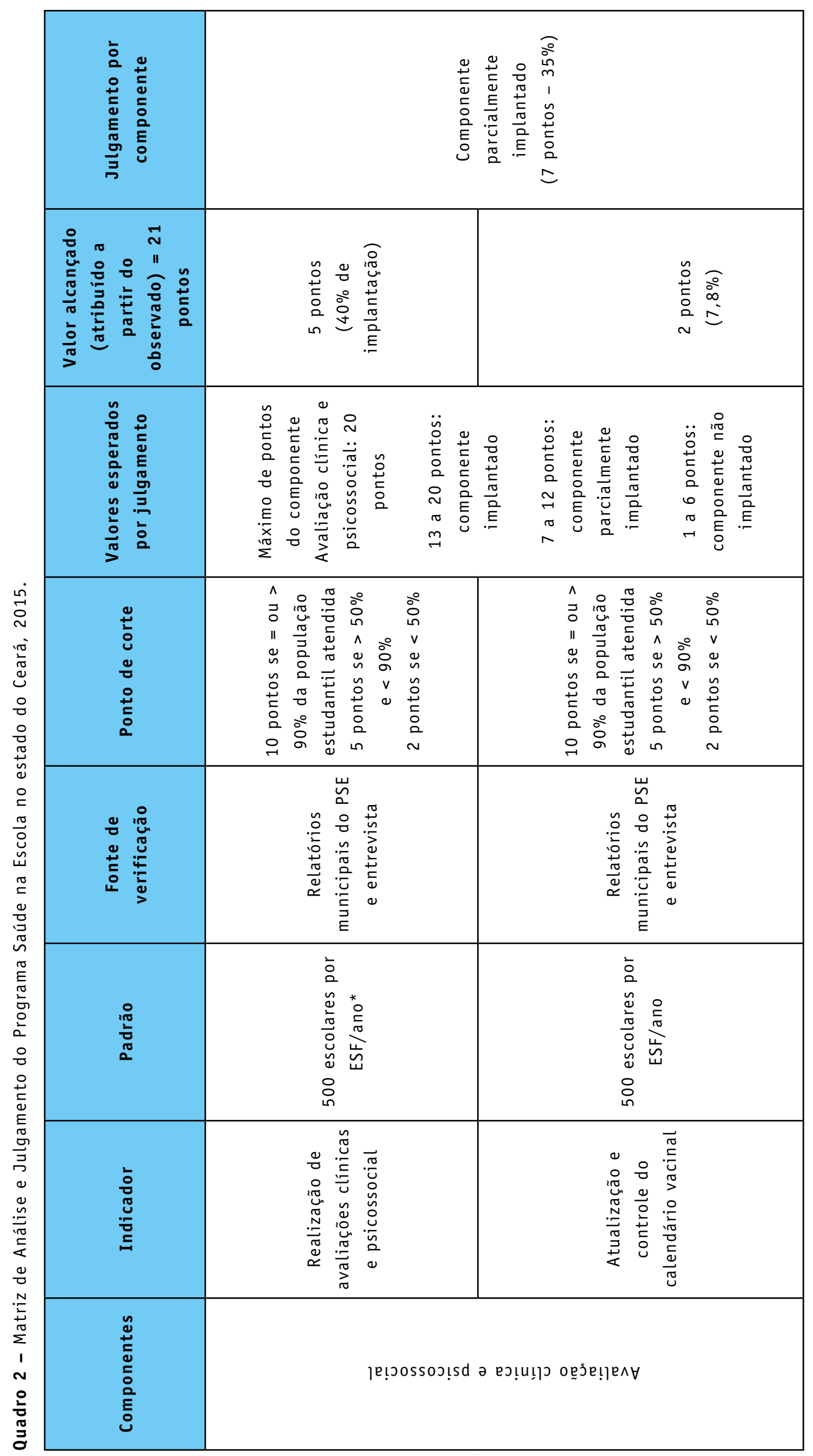

38 - SANARE, Sobral - v.17, n.01,p.32-42, Jan./Jun. - 2018 


\begin{tabular}{|c|c|c|c|c|}
\hline \multirow{2}{*}{ 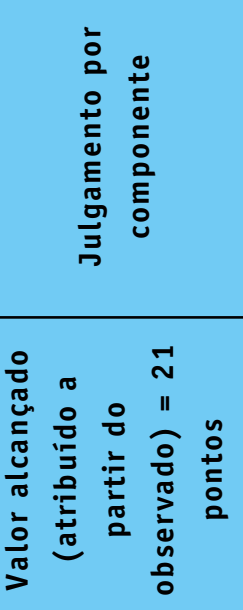 } & \multicolumn{4}{|c|}{ 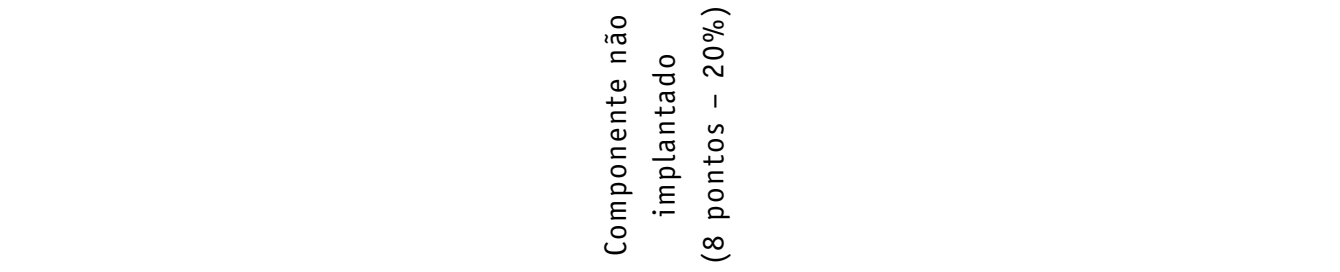 } \\
\hline & $\begin{array}{ll}\tilde{0} & \widehat{o} \\
+ & 0 \\
\vdots & 0 \\
0 & 0 \\
0 & 0 \\
\sim & 0\end{array}$ & 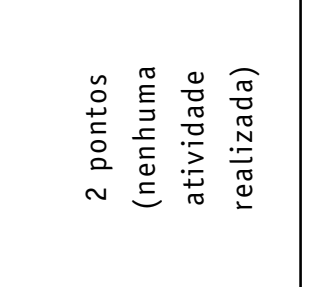 & 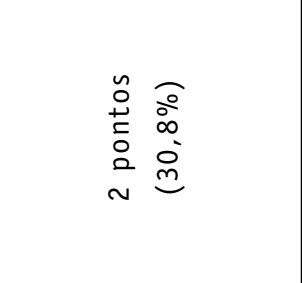 & 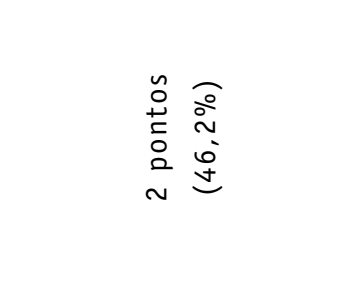 \\
\hline 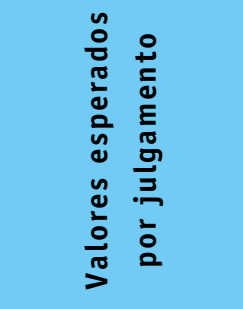 & \multicolumn{4}{|c|}{ 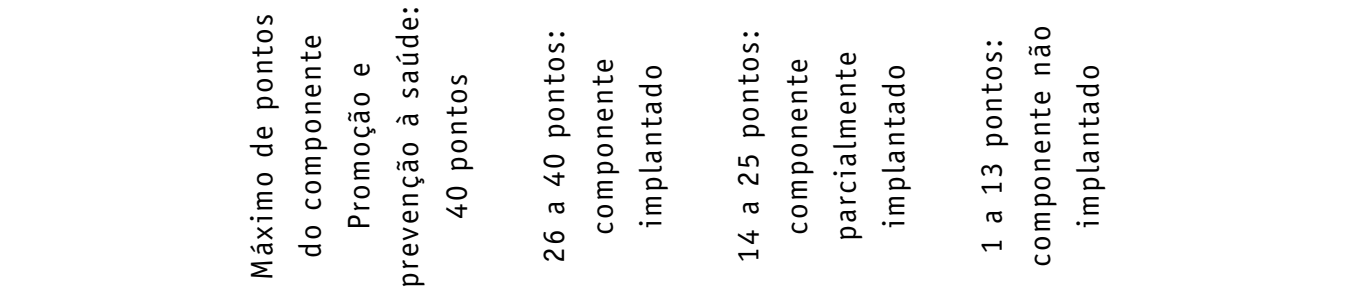 } \\
\hline $\begin{array}{l}0 \\
\pm \\
0 \\
0 \\
0 \\
0 \\
0 \\
+ \\
0 \\
0\end{array}$ & 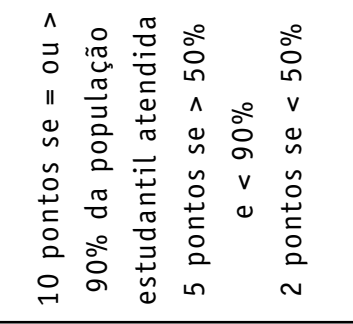 & 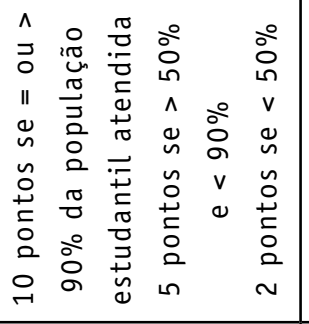 & 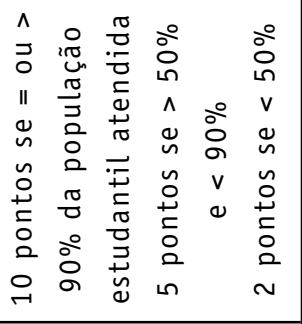 & 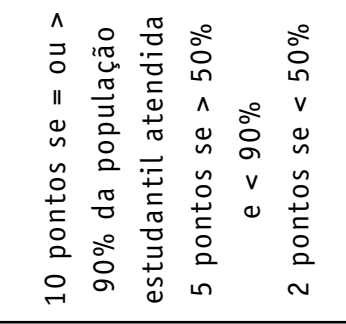 \\
\hline 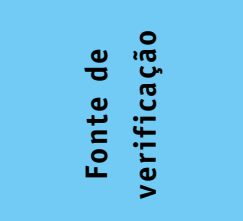 & 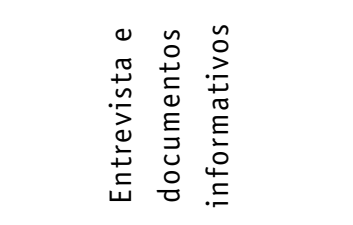 & 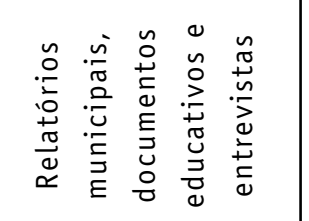 & 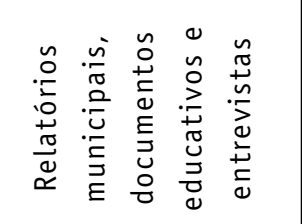 & 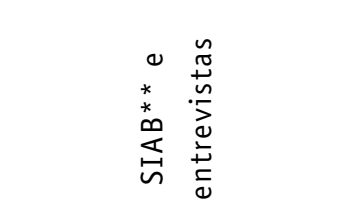 \\
\hline$\frac{\substack{\pi \\
\frac{\pi}{\pi} \\
\frac{\pi}{2}}}{2}$ & 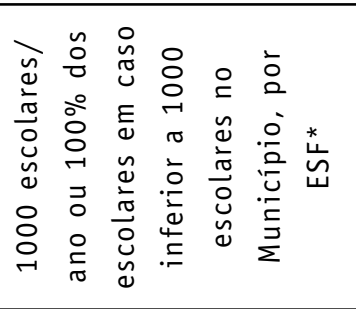 & 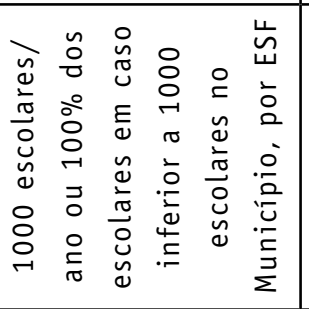 & 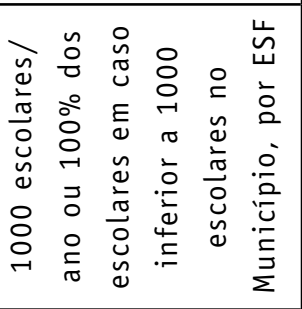 & 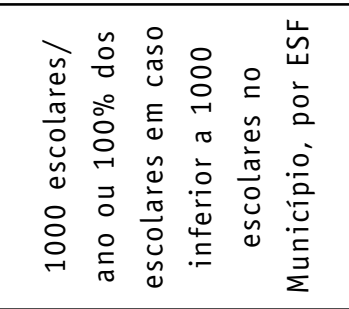 \\
\hline 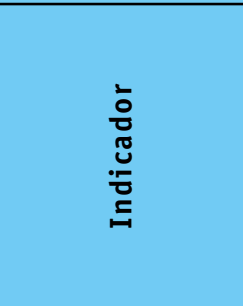 & 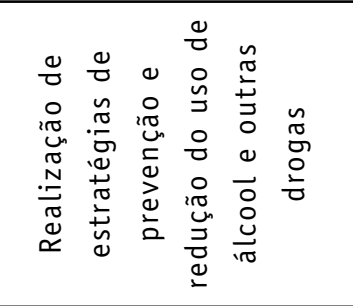 & 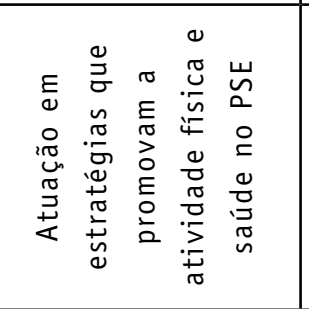 & 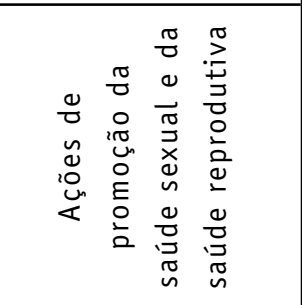 & 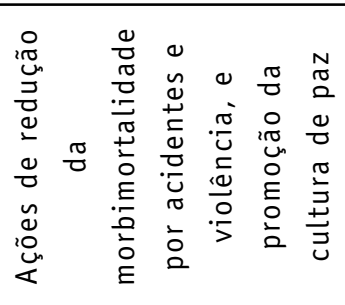 \\
\hline 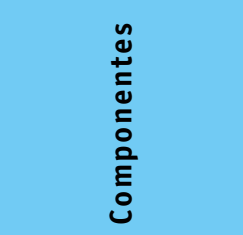 & & олецбе әр орд́ & apnes ep opjomodd & \\
\hline
\end{tabular}




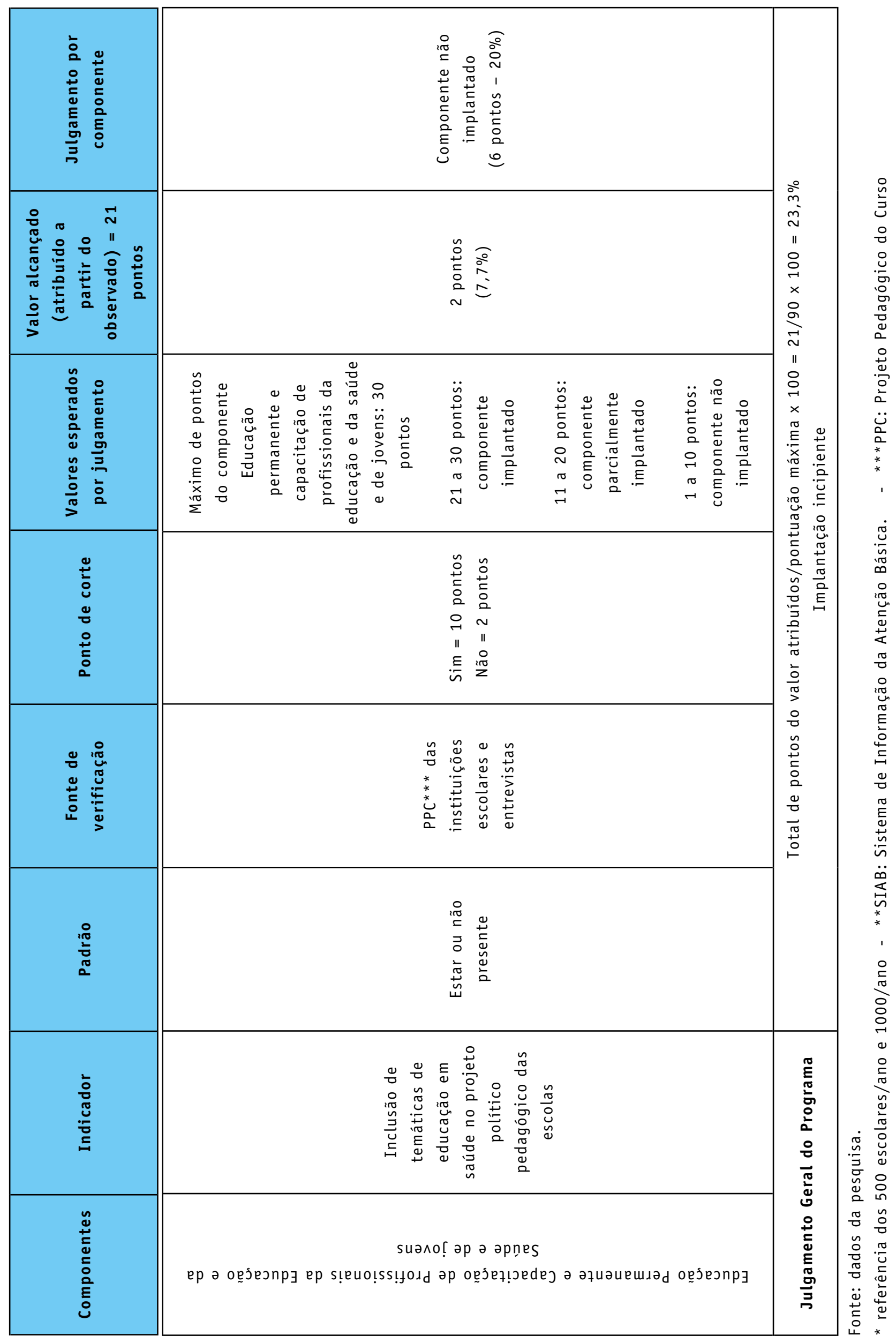

40 - SANARE, Sobral - v.17, n.01,p.32-42, Jan./Jun. - 2018 
0 julgamento constante na Matriz (Quadro 2) foi realizado segundo o valor atribuído, que se refere à categorização na qual aquele item estudado será enquadrado, e considerando a quantidade de estratos em sua composição. Adotou-se a divisão em tercis, que propõe os seguintes intervalos para julgamento: De $66,6 \%$ a $100 \%$ - implantação satisfatória ou plena; De $33,3 \%$ a $<66,6 \%$ - implantação parcial ou média; e, de $1 \%$ a $<33,3 \%$ - implantação incipiente ${ }^{10}$.

A Matriz aponta que muito há que se avançar com vistas à implantação adequada do PSE no Ceará. Ao analisar cada componente individualmente foi possível verificar que apenas o componente "Avaliação clínica e psicossocial" apresenta pontuação que o coloca como parcialmente implantado; os demais, "Promoção da saúde e prevenção de agravos" e "Educação permanente e capacitação de profissionais da educação e da saúde e de jovens", apresentam-se como componentes não implantados.

Considerando que a implantação do PSE prevê uma articulação de diversas ações de promoção da saúde na escola, envolvendo avaliação das condições de saúde dos estudantes, prevenção de agravos, formação de profissionais, monitoramento do PSE, dentre outros aspectos ${ }^{15}$. 0 exposto apresentado pela Matriz direciona para uma implantação incipiente do PSE no Ceará, que dialoga com o percebido no ML no sentido de compreender aspectos que dificultam sua implantação.

\section{CONCLUSÃO}

0 Programa Saúde na Escola, como uma estratégia de produção social da saúde, está contribuindo para o enfrentamento das vulnerabilidades que comprometem o pleno desenvolvimento dos estudantes brasileiros. 0s resultados ainda são incipientes, mas representam uma iniciativa potente dos gestores federal, estaduais e municipais na execução de políticas públicas voltadas a esse importante segmento, a partir de uma articulação interministerial.

0 PSE constitui uma possibilidade de suprimento de uma necessidade há tempos discutida: o fortalecimento da integração entre os setores educação e saúde, promovendo a intersetorialidade e a corresponsabilização entre estes setores, habituados a trabalhar isoladamente. Contudo ainda se faz necessário uma reflexão crítica de todo o seu processo, haja vista, que este pode não estar correspondendo plenamente ao proposto inicialmente.

Consideramos que o presente estudo atingiu seus

\section{O PSE constitui uma possibilidade de suprimento de uma necessidade há tempos discutida...}

objetivos no sentido de apontar e mensurar áreas da saúde estudantil que precisam ser melhor identificadas e cuidadas. Por conseguinte, a identificação dos indicadores apontados no estudo, pode-se ser importante no reconhecimento de áreas prioritárias que devem ser definidas para a avaliação.

A construção do Modelo Lógico evidenciou os componentes, recursos, ações, produtos, resultados intermediários e resultado final, bem como, os fatores limitantes que configuram o PSE no Ceará. Cada uma das ações foi exibida com a mensuração das suas respectivas taxas de execução, isso foi importante para mostrar-nos o quanto está sendo executado no Programa. Insuficiência nos processos de educação permanente, participação comunitária incipiente, defectível consolidação dos dados, poucos profissionais ativos no programa e diferentes prazos de consolidação dos dados para os setores saúde e educação, foram apontados como os fatores limitantes que precisam ser trabalhados no sentido de eliminálos ou atenuá-los para que os objetivos do PSE sejam alcançados.

Entendemos que a construção do modelo lógico e da matriz de julgamento do PSE no Ceará pode ser um importante subsídio pré-avaliativo para 0 desenvolvimento de estratégias que sejam capazes de aprimorar as ações que já vem sendo executadas e estabelecer outros possiveis caminhos que culminem na melhoria da qualidade de vida dos estudantes, e isso proporcione o pleno desenvolvimento dos jovens estudantes brasileiros.

É importante ressaltar que o tanto o Modelo Lógico quanto a Matriz de Critérios e Julgamentos do PSE, no Ceará, pode ser revisado a qualquer tempo, à medida que novas informações forem sendo coletadas e incorporadas ao desenho do Programa.

\section{CONTRIBUIÇÃO DOS AUTORES}

Maria Socorro de Araújo Dias, Lielma Carla Chagas da Silva e Maria da Conceição Coelho Brito contribuíram com o delineamento e realização da 
pesquisa, a redação do manuscrito e revisão crítica do manuscrito. Alexandro do Vale Silva, Rayanne

Branco dos Santos Lima, Diógenes Farias Gomes contribuíram com a pesquisa e redação do manuscrito. Angelo Brito Rodrigues contribuiu com 0 delineamento da pesquisa e revisão crítica do manuscrito.

\section{REFERÊNCIAS}

1. Brasil. Ministério da Saúde. Gabinete do Ministro. Portaria $n^{\circ}$ 154, de 24 de janeiro de 2008. Cria os Núcleos de Apoio à Saúde da Família - NASF. Diário Oficial da União, Poder Executivo. Brasília: Ministério da Saúde; 2008.

2. Brasil. Ministério da Saúde. Programa Saúde na Escola, 2010. [acessado $2013 \mathrm{dez}$ 02]. Disponível em: http://dab. saude.gov.br/programa saude na escola.php

3. Bezerra LCA, Alves CKA, Reis YAC, Samico I, Felisberto E, Carvalho ALB et al. Identificação e caracterização dos elementos constituintes de uma intervenção: pré-avaliação da política ParticipaSUS. Ciênc. saúde coletiva. 2012; 12(4):883-900.

4. Tanaka OU, Tamaki EM. 0 papel da avaliação para a tomada de decisão na gestão dos serviços de saúde. Ciênc. saúde coletiva. 2012;17(4):821-28.

5. Ceará. Seminário fortalece ações da política de saúde na escola [internet]. 2012. [citado em 2014 abr 13]. Disponível em: http://www.ceara.gov.br/index.php/sala-de-imprensa/ noticias/6066-seminario-fortalece-acoes-da-politica-desaude-na-escola

6. Lima LRF, Vieira-da-Silva LM. Ampliação do acesso à atenção oftalmológica: um estudo sobre a avaliabilidade da campanha "De Olho na Visão", Goiás, 2004. Ciênc. saúde coletiva. 2008;13(Sup 2):2059-64.

7. IPECE. Instituto de Pesquisa e Estratégia Econômica do Ceará. Nota técnica $n^{\circ}$ 18: taxa de vulnerabilidade social dos municípios cearenses. Fortaleza; 2006.

8. Ceará. Secretaria de Saúde. Microrregiões de Saúde [Internet]. 2014 [citado em 2014 jun 10]. Disponível em: http://geolivre.saude.ce.gov.br/egroupware/sitemgr/ sitemgr-site $/$ ?page name=Microregioes .

9. Bezerra LCA, Cazarin G, Alves CKA. Modelagem de programas: da teoria à operacionalização. In: Samico et al. (0rg.). Avaliação em saúde: bases conceituais e operacionais. Rio de Janeiro: Medbook; 2010. p. 65-78.

10. Telles PR, Buchele F. Redução de danos. In: Prevenção ao uso de drogas: curso de capacitação para conselheiros municipais. Brasília: Secretaria Nacional Antidrogas, 2008.
11. Samico I, et al $(0 \mathrm{rg})$. Avaliação em saúde: bases conceituais e operacionais. Rio de Janeiro: Medbook, 2010. p 89-105.

12. Anjos RMP, Rodrigues JMS, Rodrigues MP, Simoneti FS, Cunha L0. Acidentes e violências, vulnerabilidade e fortalecimento da rede de proteção: morbimortalidade no município de Sorocaba, São Paulo, Brasil. Rev. Fac. Cienc. Med. Sorocaba. 2015;17(2):62-8.

13. Brasil. Presidência da República. Decreto $n^{0} 6.286$, de 05 de dezembro de 2007. Institui o Programa Saúde na Escola (PSE), e dá outras providências. Diário Oficial da União. Brasília: Poder Executivo, 2007.

14. Maia DB, Sousa ETG, Gama RM, Lima JC, Rocha PCF, Sassaki Y. Atuação interdisciplinar na Atenção Básica de Saúde: a inserção da Residência Multiprofissional. Saúde transform. Soc. 2013;4(1):103-10.

15. Machado WD, Oliveira KMCP, Cunha KG, Araújo Júnior DG, Silvino RHS, Dias MAS. "Programa Saúde na Escola": um olhar sobre a avaliação dos componentes. Sanare (Sobral, Online) [serial on the internet]. 2016 [cited 2018 jan 16]; 15(1): 62-8. Available from: https://sanare.emnuvens.com. br/sanare/article/view/929/558
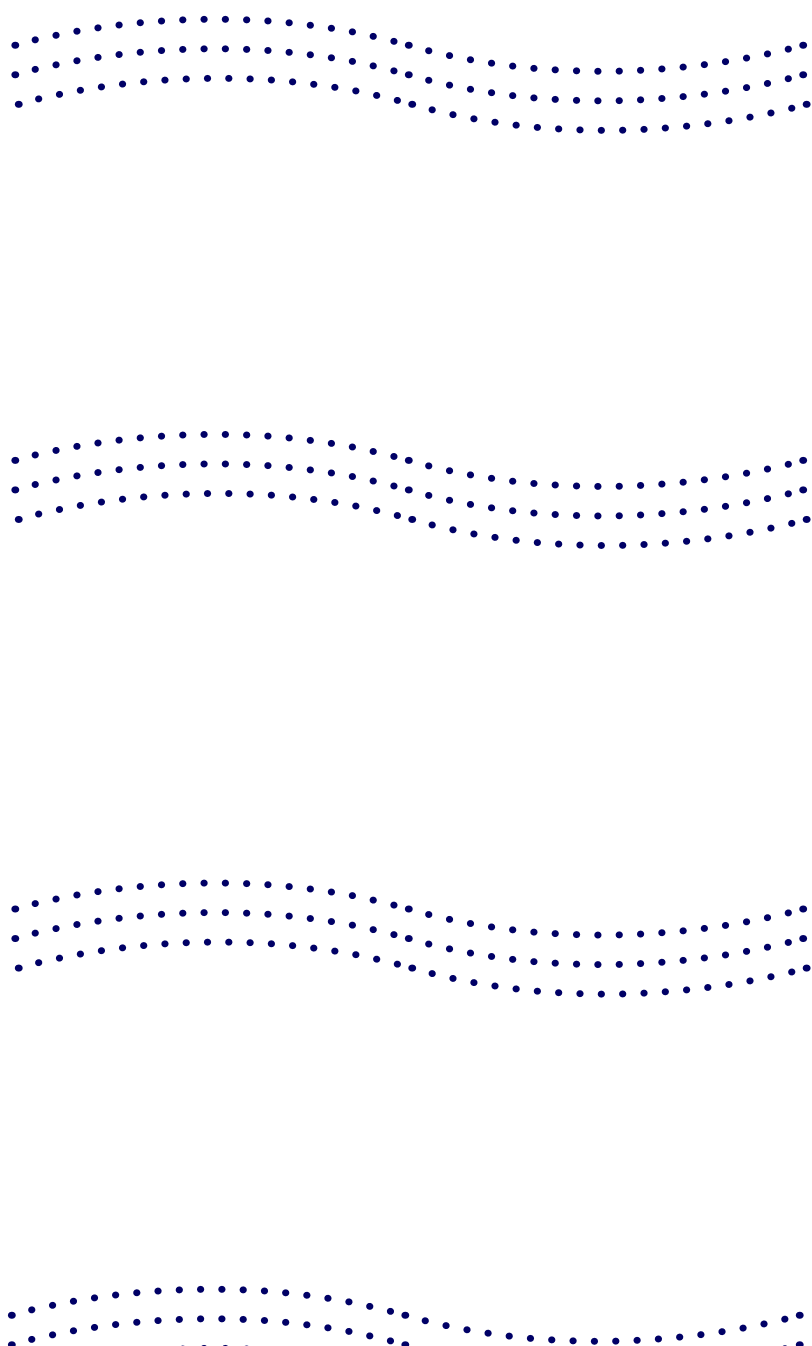
$\ldots \ldots \ldots \ldots \ldots \ldots \ldots \ldots \ldots \ldots \ldots \ldots \ldots \ldots \ldots$ (1) 


\title{
LEVANTAMENTO ETNOBOTÂNICO DE ESPÉCIES VEGETAIS UTILIZADAS NA ODONTOLOGIA NO RECÔNCAVO BAIANO
}

\author{
ETHNOBOTANICAL SURVEY OF PLANT SPECIES USED IN DENTISTRY IN THE \\ RECÔNCAVO BAIANO, BRAZIL
}

LEVANTAMIENTO ETNOBOTÁNICO DE ESPECIES VEGETALES UTILIZADAS EN ODONTOLOGÍA EN EL RECÔNCAVO BAIANO, BRAZIL

Geovane Silva de Araújo 1

Elba Brito dos Santos 2

Patrícia Pinto dos Santos Silva ${ }^{3}$

Vania Jesus dos Santos de Oliveira ${ }^{4}$

Noelma Miranda de Brito ${ }^{5}$

Palavras-chave: Odontologia Comunitária; Fitoterapia; Plantas Medicinais.

Keywords: Community Dentistry; Phytotherapy; Plants, Medicinal.

Palabras clave: Odontología Comunitaria; Fitoterapia; Plantas Medicinales.

Submetido: $28 / 06 / 2017$

Aprovado: $24 / 11 / 2017$

Autor(a) para Correspondência: Geovane Silva de Araújo End: Rua 05, Papagaio, Feira de Santana

CEP: 44059-680, Bahia E-mail:geovane.ba@outlook.com

\section{RESUMO}

O emprego de plantas medicinais para tratar enfermidades é uma prática milenar. Nas comunidades tradicionais brasileiras, as plantas medicinais são adotadas em forma de chás e fitoterápicos no tratamento de diversas enfermidades - dentre elas as patologias bucais. Este artigo apresenta um levantamento etnobotânico de espécies vegetais comercializadas para tratar patologias bucais em Cruz das Almas, município do Recôncavo Baiano. Aplicou-se um questionário sobre a adoção de plantas medicinais na saúde bucal aos raizeiros e aos usuários na sala de espera de unidades da Estratégia Saúde da Família (ESF) de Cruz das Almas. As plantas mais comercializadas pelos raizeiros foram: sara-tudo (Byrsonima intermedia A. Juss.); fruto da noz-moscada (Myristica fragrans Houtt.); aroeira (Schinus terebinthifolius Raddi); dente-de-cravo (Syzygium aromaticum L. Merrill \& Perry); e misturas, como as 7 ervas. Já os usuários da ESF dizem recorrer a sara-tudo (B. intermedia) para alívio de dor de dente e inflamação. Evidências disponiveis na literatura científica comprovam a eficácia de tais plantas no tratamento de patologias bucais. Contudo, mostra-se necessário investigar em maior profundidade a ação dessas plantas medicinais.

1. Estudante de Graduação em Farmácia na Faculdade Maria Milza (Famam). Governador Mangabeira (BA), Brasil. E-mail: geovannedearaujo@gmail.com

2. Estudante de Graduação em Farmácia na Famam. Governador Mangabeira (BA),Brasil. E-mail: elbabritods@ hotmail.com

3. Estudante de Graduação em Farmácia na Famam. Governador Mangabeira (BA),Brasil. E-mail: 01patyps@ gmail.com

4. Agrônoma. Doutora em Farmácia. Professora na Famam. Governador Mangabeira (BA), Brasil. E-mail: vania79br@yahoo.com.br

5. Engenheira agrônoma. Doutora em Ciências Agrárias. Professora na Famam. Governador Mangabeira (BA), Brasil. E-mail: britonoelma@yahoo.com.br 


\section{ABSTRACT}

The use of medicinal plants to treat diseases is an age-old practice. In the traditional Brazilian communities, medicinal plants have been adopted as teas and herbal medicines in the treatment of various diseases - among them oral pathologies. This article presents an ethnobotanical survey of plant species commercialized to treat oral pathologies in Cruz das Almas, a municipality in the Recôncavo Baiano, Brazil. A questionnaire on the adoption of medicinal plants in oral health was applied to root workers and users in the waiting room of Family Health Strategy (FHS) units in Cruz das Almas. The plants most widely commercialized by root workers were: 'sara-tudo' (Byrsonima intermedia A. Juss.); nutmeg fruit (Myristica fragrans Houtt.); Brazilian peppertree (Schinus terebinthifolius Raddi); clove (Syzygium aromaticum L. Merrill \& Perry); and mixtures, like the 7 herbs. FHS users are said to resort to 'sara-tudo' (B. intermedia) for relief of tooth pain and inflammation. Evidence available in the scientific literature confirms the efficacy of such plants in the treatment of oral pathologies. However, there is a need to investigate in greater depth the action of these medicinal plants.

\section{RESUMEN}

El empleo de plantas medicinales para tratar enfermedades es una práctica milenaria. En comunidades tradicionales brasileñas, las plantas medicinales se adoptan en forma de tés y fitoterápicos en el tratamiento de diversas enfermedades - entre ellas las patologías bucales. Este artículo presenta un levantamiento etnobotánico de especies vegetales comercializadas para tratar patologías bucales en Cruz das Almas, municipio del Recôncavo Baiano. Se aplicó un cuestionario sobre la adopción de plantas medicinales en la salud bucal a los raiceros y a los usuarios en la sala de espera de unidades de la Estrategia Salud de la Familia (ESF) en Cruz das Almas. Las plantas más comercializadas por los raiceros fueron: 'sara-tudo' (Byrsonima intermedia A. Juss.); fruto de nuez moscada (Myristica fragrans Houtt.); aroeira (Schinus terebinthifolius Raddi); árbol del clavo (Syzygium aromaticum L. Merrill \& Perry); y mezclas, como las 7 hierbas. A su vez, los usuarios da la ESF dicen recurrir a 'sara-tudo' (B. intermedia) para aliviar el dolor de diente y la inflamación. Evidencias disponibles en la literatura científica demuestran la eficacia de tales plantas en el tratamiento de patologías bucales. Sin embargo, es necesario investigar en mayor profundidad la acción de estas plantas medicinales.

\section{INTRODUÇÃO}

Desde os primórdios há relatos da utilização de plantas medicinais com o intuito de tratar enfermidades. Com base nisso, por meio do conhecimento acerca das propriedades medicinais de plantas acumulado ao longo de gerações, o homem pode utilizá-las na terapia convencional. Nas comunidades tradicionais brasileiras, as plantas medicinais são adotadas como chás e fitoterápicos ${ }^{1}$; em muitas dessas comunidades, o principal mecanismo de renda é a agricultura e predomina o cultivo próprio de plantas medicinais para uso como remédios caseiros $^{2}$.

A manifestação cultural do uso de plantas está diretamente relacionada à etnobotânica, que inclui o modo, os costumes e as tradições das populações e sua interação com a natureza ${ }^{3}$. A etnobotânica está diretamente ligada à fitoterapia - definida como ramo das Ciências Médicas que utiliza plantas medicinais e drogas vegetais para tratar enfermidades sem recorrer a substâncias de outra origem ${ }^{4}$.

Do ponto de vista sociocultural, a fitoterapia se mostra muito importante, uma vez que na maioria das vezes os usuários dos serviços de saúde veem as plantas medicinais como meras opções terapêuticas paliativas ${ }^{5}$; porém, na perspectiva dos profissionais de saúde, o desconhecimento acerca das indicações e dos cuidados no uso de plantas medicinais ainda constitui um problema ${ }^{6}$.

Apesar das inúmeras possibilidades de uso de plantas medicinais por parte dos profissionais da saúde, o potencial das plantas medicinais tem sido pouco explorado na odontologia, seja para tratar doenças bucais ou doenças sistêmicas com manifestações bucais ${ }^{6}$. 0 maior avanço nesse sentido se refere às plantas com ação antimicrobiana e antifúngica, devido ao considerável avanço no desenvolvimento de derivados naturais com propriedades bactericidas ou fungicidas ${ }^{7}$.

Assim, com base nessas informações, este artigo apresenta um levantamento etnobotânico de espécies vegetais comercializadas para tratar patologias bucais em Cruz das Almas, município do Recôncavo Baiano. 


\section{METODOLOGIA}

A pesquisa foi realizada em 5 unidades da Estratégia Saúde da Família (ESF) e na feira livre do centro de Cruz das Almas - onde se investigou o uso tradicional de plantas medicinais com vistas à saúde bucal.

0 levantamento etnobotânico foi realizado com 2 etapas de entrevistas: a) dos 10 raizeiros que comercializavam plantas medicinais na feira livre; e b) dos 31 usuários presentes na sala de espera das unidades da ESF. Os raizeiros responderam questões acerca de seus produtos, que correspondem às informações repassadas para a população a respeito das plantas medicinais que serão consumidas. Já os usuários da ESF responderam questões sobre 0 consumo dessas plantas medicinais como remédios e sua efetividade terapêutica.

Os dados obtidos foram tabulados e analisados por meio das técnicas de estatística descritiva, com apresentação de percentuais de frequência.

Este estudo seguiu os preceitos da Resolução n. 466/2012, do Conselho Nacional de Saúde (CNS), que dispõe sobre a pesquisa envolvendo seres humanos, e foi aprovado pelo Comitê de Ética em Pesquisa da
Universidade Federal do Recôncavo da Bahia (UFRB), sob o Parecer n. 1.063.134/2015.

\section{RESULTADOS}

Foram entrevistados 10 raizeiros ( 6 homens e 4 mulheres): 2 com 40 a 49 anos de idade, 5 com 50 a 59 anos e 3 com 60 a 69 anos. Esses comerciantes podem ser apontados como representantes de gerações mais antigas, tendo em vista que a média foi de 57,6 anos de idade entre os homens e de 51 anos entre as mulheres (com variação de 46 a 68 anos).

Em relação à escolaridade, houve prevalência do Ensino Fundamental (7 dos 10 raizeiros). Parte dos entrevistados relatou ter enfrentado dificuldades para estudar, pois a maioria era de origem rural e teria de locomover-se para a zona urbana mais próxima para ter acesso a uma escola.

Dos 31 usuários da ESF entrevistados, $21(67,7 \%)$ são mulheres. A média de idade foi de 41 anos entre as mulheres (variação de 21 a 67 anos) e de 45 anos entre os homens (variação de 23 a 63 anos), como ilustra a Tabela 1.

Tabela 1 - Caracterização dos usuários da ESF entrevistados no levantamento etnobotânico. Cruz das Almas, 2015.

\begin{tabular}{|c|c|c|c|c|}
\hline \multirow{3}{*}{ Faixa etária } & \multicolumn{4}{|c|}{ Sexo } \\
\hline & \multicolumn{2}{|c|}{ Masculino } & \multicolumn{2}{|c|}{ Feminino } \\
\hline & $(\%)$ & $\mathrm{N}$ & $(\%)$ & $\mathrm{N}$ \\
\hline 20-29 anos & 10 & 3 & 19 & 6 \\
\hline 30-39 anos & 3 & 1 & 13 & 4 \\
\hline 40-49 anos & 3 & 1 & 6,5 & 2 \\
\hline 50-59 anos & 13 & 4 & 6,5 & 2 \\
\hline $60-69$ anos & 13 & 4 & 13 & 4 \\
\hline Total & 42 & 13 & 58 & 18 \\
\hline
\end{tabular}

Fonte: Elaborada pelos autores.

Dentre os entrevistados, $9(29 \%)$ disseram não ser alfabetizados ou não ter estudo formal e $2(6 \%)$ tinham completo (Tabela 2). Todos vivem em área urbana, porém, uma parte significativa relata ser de origem rural e apresenta grande influência dos costumes e das práticas de seus avós e demais parentes de origem rural.

Tabela 2 - Escolaridade dos usuários da ESF entrevistados no levantamento etnobotânico. Cruz das Almas, 2015.

\begin{tabular}{lcc}
\hline Escolaridade & $(\%)$ & $\mathbf{N}$ \\
\hline Sem estudo formal & 29 & 9 \\
Ensino Fundamental incompleto & 16 & 5 \\
Ensino Fundamental completo & 26 & 8 \\
Ensino Médio incompleto & 10 & 3 \\
Ensino Médio completo & 13 & 4 \\
Ensino Superior completo & 6 & 2 \\
\hline Total & 100 & 31 \\
\hline
\end{tabular}

Fonte: Elaborada pelos autores. 
Os resultados demonstraram que todos os raizeiros da feira livre do centro de Cruz das Almas comercializam plantas medicinais para tratar patologias bucais. Dentre as plantas utilizadas, 4 raizeiros indicaram que a mais vendida é a sara-tudo (Byrsonima intermedia A. Juss.). 0 fruto da nozmoscada (Myristica fragrans Houtt.), a aroeira (Schinus terebinthifolius Raddi) e o dente-de-cravo (Syzygium aromaticum L. Merrill \& Perry) também são plantas medicinais bastante comercializadas (relatos de 3 entrevistados). Misturas, como as 7 ervas - isto é, manjericão (Ocimum basilicum L.), alecrim (Rosmarinus officinalis L.), espada-de-são-jorge (Sansevieria trifasciata Prain, 1903), comigoninguém-pode (Dieffenbachia amoena Hort. ex L. Gentil), pimenta-do-reino (Capsicum spp.), guiné (Petiveria alliacea L.) e arruda (Ruta graveolen L.) são vendidas por 2 raizeiros e as pessoas acreditam que seu chá é mais potente e eficaz devido à combinação de espécies vegetais. Outras plantas, como tansagem (Plantago major L.) e erva-cidreira (Melissa officinalis L.), são comercializadas por 1 raizeiro.

Dentre as complicações dentárias relatadas pelos raizeiros como mais comuns entre os usuários se destacam a dor de dente e a gengivite - a planta mais indicada nesses casos é a tansagem ( $P$. major), que os comerciantes dizem conter propriedades antiinflamatórias. Sua forma de uso geralmente é tópica em casos de inflamação (Tabela 3). Entretanto, há predomínio da venda da casca de sara-tudo ( $B$. intermedia); de acordo com os raizeiros, seu chá tem potencial efeito analgésico e combate a inflamação, por isso é indicada para a dor de dente. Além dessas plantas, o alecrim ( $R$.officinalis), a erva-cidreira ( $M$. officinalis) e a tansagem ( $P$. major) são compradas pelos usuários para tratar úlceras bucais. 0s comerciantes acreditam que essas plantas têm propriedades antibacterianas e anti-inflamatórias.

Tabela 3 - Plantas medicinais comercializadas em feira livre para tratar patologias bucais. Cruz das Almas, 2015.

\begin{tabular}{|c|c|c|c|c|}
\hline Táxons & NP & PU & FP & FU \\
\hline B. intermedia & Sara-tudo & Casca do caule seca & Decocção & Tomar 2 vezes ao dia \\
\hline M. fragrans & Noz-moscada & $\begin{array}{c}\text { Semente seca e } \\
\text { triturada }\end{array}$ & Infusão & Tomar 1 vez ao dia \\
\hline S. terebinthifolius & Aroeira & Casca do caule seca & Decocção & Gargarejo 2 vezes ao dia \\
\hline 0. basilicum & Manjericão & Folhas e caules & Infusão & Enxague bucal e gargarejo \\
\hline R. officinalis & Alecrim & Folhas & Infusão & Tomar 2 vezes ao dia \\
\hline Capsicum spp. & $\begin{array}{l}\text { Pimenta-do- } \\
\text { reino }\end{array}$ & Fruto & Extrato & $\begin{array}{c}\text { Diluído em água para } \\
\text { enxague bucal e aplicação } \\
\text { tópica no dente }\end{array}$ \\
\hline S. aromaticum & Dente-de-cravo & Botão da flor seco & $\begin{array}{l}\text { Extrato ou } \\
\text { decocção }\end{array}$ & $\begin{array}{c}\text { Enxague bucal e aplicação } \\
\text { tópica no dente }\end{array}$ \\
\hline P. alliacea & Guiné & Folha & Infusão & $\begin{array}{c}\text { Gargarejo de } 3 \text { a } 4 \text { vezes ao } \\
\text { dia }\end{array}$ \\
\hline P. major & Tansagem & Folha & Infusão & $\begin{array}{c}\text { Gargarejo e aplicação } \\
\text { tópica no dente e na } \\
\text { gengiva }\end{array}$ \\
\hline M. officinalis & Erva-cidreira & Folhas & Infusão & Tomar 2 vezes ao dia \\
\hline
\end{tabular}

Legenda: NP = nome popular; PU = parte utilizada, FP = forma de preparo; FU = forma de uso.

Fonte: Elaborada pelos autores.

Os raizeiros informam, ainda, que o óleo essencial do cravo-da-índia (S. aromaticum) e da pimenta-doreino (Capsicum spp.) é predominantemente comercializado em forma de extrato ou óleo essencial e é aplicando pelos usuários no dente para aliviar a dor.

Dentre os usuários atendidos nas unidades da ESF, $24(76 \%)$ utilizam plantas medicinais para tratar patologias. As plantas medicinais são utilizadas para fins odontológicos por 18 indivíduos (57\%), sendo que 12 (39\%) adotam sara-tudo (B. intermedia), 9
(28\%) recorrem a erva-cidreira (M. officinalis), 6 $(18 \%)$ empregam tansagem ( $P$. major) e $3(9 \%)$ usam mastruz (Chenopodium ambrosioides L.).

De acordo com o levantamento deste estudo, saratudo ( $B$. intermedia) é a planta mais adotada para tratamento odontológico pelos usuários da ESF: 12 entrevistados $(39 \%)$. Esse achado coincide com os relatos da planta mais comercializada por raizeiros. A planta mastruz (C. ambrosioides), pouco citada pelos raizeiros, foi bastante citada pelos usuários da ESF estes relatam tanto utilizá-la como cultivá-la no 
quintal de casa: 14 (44\%) adquiriram o hábito da fitoterapia por meio de seus avós, que detinham bastante conhecimento acerca dessa prática.

Dentre as plantas com relato de efeito adverso, destaca-se a erva-cidreira (M. officinalis), que além de analgésica tem potencial calmante, por isso, muitos usuários da ESF dizem apresentar diminuição de sua pressão arterial após a ingestão do chá dessa planta para aliviar a dor de dente. Todos os usuários da ESF dizem que os medicamentos são mais efetivos do que as plantas por apresentar efeito imediato no tratamento, porém, alguns afirmam que as plantas também são bastante eficazes. A maioria dos usuários da ESF não informou ao odontologista que recorre a planta medicinal.

\section{DISCUSSÃO}

$\mathrm{Na}$ literatura, há ensaios clínicos com plantas medicinais que comprovam cientificamente sua ação na terapia bucal. A maioria dos ensaios in vitro indicam atividade antibacteriana e os ensaios in vivo indicam atividade anti-inflamatória (Tabela 4). Já no levantamento deste estudo, a maioria dos usuários relata utilizar tais plantas para fins de antissepsia bucal e inflamações.

Tabela 4 - Ensaios clínicos com plantas medicinais que abordam seu potencial terapêutico.

\begin{tabular}{|c|c|c|c|}
\hline Planta & Ensaios & Forma fitoterápica & Referência \\
\hline \multirow{3}{*}{ B. intermedia } & $\begin{array}{c}\text { Atividade anti-inflamatória (in } \\
\text { vivo) }\end{array}$ & Extrato da folha & Moreira et al., $2011^{10}$ \\
\hline & $\begin{array}{c}\text { Atividade antimicrobiana (in } \\
\text { vitro) }\end{array}$ & Extrato da folha & Moraes $2006^{9}$ \\
\hline & $\begin{array}{c}\text { Atividade anti-inflamatória (in } \\
\text { vivo) }\end{array}$ & Extrato da casca do caule & Orlandi et al., $2011^{11}$ \\
\hline \multirow{3}{*}{ M. fragrans } & Atividade antibiofilme (in vitro) & Extrato da semente & Yanti et al., $2008^{12}$ \\
\hline & $\begin{array}{c}\text { Atividade antimicrobiana (in } \\
\text { vitro) }\end{array}$ & Extrato da semente & Chung et al., $2006^{13}$ \\
\hline & $\begin{array}{l}\text { Isolamento de inibidores da } \\
\text { produção de óxido nítrico }\end{array}$ & Extrato da semente & Cao et al., $2013^{14}$ \\
\hline \multirow{3}{*}{ S. terebinthifolius } & $\begin{array}{c}\text { Reduções dos índices de placa e } \\
\text { de sangramento gengival }\end{array}$ & Extrato da folha & Lins et al., $2013^{15}$ \\
\hline & $\begin{array}{l}\text { Atividade anti-inflamatória e } \\
\text { cicatrizante (in vivo) }\end{array}$ & Extrato da folha & Martorelli al., $2011^{16}$ \\
\hline & Atividade antifúngica & $\begin{array}{l}\text { Tintura da casca do caule } \\
\text { seca }\end{array}$ & Freires et al., $2011^{17}$ \\
\hline \multirow{3}{*}{ S. aromaticum } & $\begin{array}{c}\text { Redução do crescimento micelial } \\
\text { (in vitro) }\end{array}$ & $\begin{array}{l}\text { Óleo essencial dos botões } \\
\text { florais }\end{array}$ & Santos et al., $2007^{20}$ \\
\hline & $\begin{array}{c}\text { Atividade antimicrobiana (in } \\
\text { vitro) }\end{array}$ & $\begin{array}{l}\text { Óleo essencial dos botões } \\
\text { florais }\end{array}$ & $\begin{array}{l}\text { Rodríguez et al., } \\
\qquad 2014^{18}\end{array}$ \\
\hline & $\begin{array}{l}\text { Atividade anti-inflamatória e } \\
\text { cicatrizante (in vivo) }\end{array}$ & Extrato dos botões florais & Valente $2006^{19}$ \\
\hline P. alliacea & $\begin{array}{c}\text { Atividade de antimicrobiana (in } \\
\text { vitro) }\end{array}$ & $\begin{array}{c}\text { Extratos brutos (partes } \\
\text { aéreas) }\end{array}$ & Guedes et al., $2009^{21}$ \\
\hline \multirow{2}{*}{ M. officinalis } & $\begin{array}{c}\text { Atividade anti-inflamatória (in } \\
\text { vivo) }\end{array}$ & Extrato da folha & Bounihi et al., $2013^{24}$ \\
\hline & $\begin{array}{c}\text { Identificação de compostos } \\
\text { antibacterianos }\end{array}$ & óleo essencial & $\begin{array}{l}\text { H ncianu et al., } \\
2008^{22}\end{array}$ \\
\hline
\end{tabular}

Fonte: Elaborada pelos autores.

Em relação ao costume de utilizar plantas medicinais, os resultados deste estudo se assemelham a outras publicações ${ }^{8}$, pois os usuários relatam que vem dos avós a influência para o uso de plantas medicinais, decorrente de seu maior conhecimento sobre a "cura" por meio de plantas.

$\mathrm{Na}$ literatura, a $B$. intermedia é predominantemente citada em ensaios clínicos in vivo e in vitro. Outro estudo 
comprova inibição in vitro do crescimento de cepas de Escherichia coli, Staphylococcus aureus, Yersinia enterocolitica e Aeromonas hydrophila, por meio do extrato da folha da $B$. intermedia ${ }^{9}$. E existem relatos da atividade anti-inflamatória do extrato da casca e da folha de $B$. intermedia, em ensaios in vivo realizados com ratos ${ }^{10,11}$.

Por meio do isolamento da macelignan da semente de $M$. fragrans, detectou-se atividade contra colonizadores primários orais; os resultados do ensaio clínico com $M$. fragrans comprovam a atividade antibacteriana contra a Streptococcus mutans ${ }^{12}$. Também foram identificados 6 eolignanas e dihidrobenzofuranos, compostos inibidores da produção de óxido nítrico ${ }^{13,14}$.

Existem evidências, proporcionadas por estudos clínicos, da significativa redução dos índices de placa e de sangramento gengival por meio do gargarejo do extrato hidroalcoólico da folha da S. terebinthifolius ${ }^{15}$. Em outros ensaios in vivo, o extrato hidroalcoólico da folha de $S$. terebinthifolius apresenta atividade antiinflamatória em ratos ${ }^{16}$. No ensaio in vitro de Freires et al. ${ }^{17}$, a tintura de sua casca apresenta atividade antifúngica diante das cepas de Candida spp.

Em ensaios utilizando o óleo essencial de botões florais secos de $S$. aromaticum há testes de inibição microbiana de ensaio in vitro, inibindo Streptococcus mutans ${ }^{18}$, e inflamatória em ensaios in vivo ${ }^{19}$. Além disso, segundo relato da literatura, o óleo essencial da $S$. aromaticum reduz o crescimento micelial in vitro de Fusarium oxysporum e Rhizoctonia solani ${ }^{20}$.

Relatos da literatura comprovam que o extrato bruto da $P$. alliacea apresenta potencial antibacteriano diante das bactérias Bacilus subtilis, Pseudomonas aeruginosa, Escherichia coli, Streptococcus mutans, Staphylococcus aureus, Staphylococcus epidermidis, Enterococcus faecalis ${ }^{21}$.

A M. officinalis, além de propriedades relaxantes, apresenta ensaios confirmando na literatura que 0 extrato tem potencial anti-inflamatório. Um estudo fotoquímico identificou compostos com potencial antibacteriano citral (neral e geranial), citronelal e transcariofileno no óleo essencial da M. officinalis ${ }^{22}$.

\section{CONCLUSÃO}

Esta pesquisa possibilitou a constatação de que a faixa etária dos raizeiros não variou muito e é alta, visto que decorre da cultura de gerações mais antigas de feirantes. Entretanto, a busca dessas plantas pelos usuários ainda se mostra ascendente, mesmo no que

\section{0 uso de plantas medicinais como prática terapêutica pela população é uma prática constante.}

diz respeito à saúde bucal - há usuários de ambos os sexos e de todas as idades.

Esta pesquisa confirma, ainda, que a transmissão de conhecimentos acerca de plantas medicinais advém de gerações mais antigas, tendo em vista que a maioria dos usuários afirmou adquirir informações sobre as plantas medicinais com os parentes mais velhos, como os avós. 0s raizeiros participantes desta pesquisa comercializam diversas plantas medicinais voltadas a tratamento odontológico.

0 cultivo dessas plantas pelos feirantes de Cruz das Almas ocorre na modalidade orgânica, predominantemente comercializada como droga vegetal, porém, tais plantas também são mantidas in natura. Cruz das Almas é um município com bom mercado consumidor, inclusive para tratamento odontológico, uma vez que grande parte dos usuários da ESF afirmou ter obtido a planta no comércio.

Segundo os resultados levantados em ensaios clínicos utilizando as plantas mais adotadas pelos usuários, observou-se que as plantas mais comuns, como sara-tudo ( $B$. intermedia), noz-moscada ( $M$. fragrans), aroeira ( $S$. terebinthifolius) e dente-decravo (S. aromaticum), apresentam comprovação científica de atividade antibacteriana, prevenindo e combatendo temporariamente o surgimento de cáries, além da dor e das inflamações.

0 uso de plantas medicinais como prática terapêutica pela população é uma prática constante. Isso possibilita que se estabeleça uma troca entre o conhecimento empírico e o conhecimento científico - relacionados às práticas das regiões em questão nos estudos científicos ${ }^{23}$.

\section{CONTRIBUIÇÃO DOS AUTORES}

Geovane Silva de Araújo contribuiu com a concepção e realização da pesquisa e a estruturação e redação do manuscrito. Elba Brito dos Santos e Patrícia Pinto dos Santos Silva contribuíram com a estruturação e redação do manuscrito. Vania Jesus dos Santos de Oliveira e Noelma Miranda de Brito 
contribuíram com a redação e revisão crítica do manuscrito.

\section{REFERÊNCIAS}

1. Vieira SCH, Sólon S, Vieira MC, Zárate NAH. Levantamento de fitoterápicos manipulados em farmácias magistrais de Dourados-MS. Rev Bras Farmacogn [serial on the internet]. 2010 [cited 2018 Apr 22];20(1):28-34. Available from: http://www.scielo.br/pdf/rbfar/v20n1/v20n1a07.pdf

2. Oliveira FCS, Barros RFM, Moita Neto JM. Plantas medicinais utilizadas em comunidades rurais de 0eiras, semiárido piauiense. Rev Bras Plantas Med [serial on the internet]. 2010 [cited 2018 Apr 22];12(3):282-301. Available from: http://www.scielo.br/pdf/rbpm/v12n3/06. pdf

3. Albuquerque UP, Lucena RFP, Cunha LVFC. Métodos e técnicas na pesquisa etnobotânica. 2. ed. Recife: Comunigraf; 2008.

4. Carvalho JCT. Fitoterápicos anti-inflamatórios: aspectos químicos, farmacológicos e aplicações terapêuticas. Ribeirão Preto (SP): Tecmedd; 2004.

5. Ness J, Sherman FT, Pan CX. Alternative medicine: what the data say about common herbal therapies. Geriatrics. 1999;54(10):33-8.

6. Oliveira CJ, Araujo CJ. Plantas medicinais: usos e crenças de idosos portadores de hipertensão arterial. Rev Eletrônica Enferm [serial on the internet]. 2007 [cited 2018 Apr 22];9(1):93-105. Available from: https://www.fen.ufg. br/revista/v9/n1/pdf/v9n1a07.pdf

7. Das K, Tiwari RKS, Shrivastava DK. Techniques for evaluation of medicinal plant products as antimicrobial agents: current methods and future trends. Journal of Medicinal Plants Research [serial on the internet]. 2010 [cited 2018 Apr 22];4(2):104-11. Available from: http:// www.academicjournals.org/article/article 1380375549 Das\%20et\%20al.pdf

8. Borba AM, Macedo M. Plantas medicinais usadas para a saúde bucal pela comunidade do bairro Santa Cruz, Chapada dos Guimarães, MT, Brasil. Acta Bot Bras [serial on the internet]. 2006 [cited 2018 Apr 22];20(4):771-82. Available from: http://www.scielo.br/pdf/abb/v20n4/03.pdf

9. Moraes HP. Avaliação in vitro da atividade antibacteriana de extratos de Byrsonima spp. e Alchornea spp.: estudo comparativo entre as técnicas de diluição em tubos e microplacas. Araraquara (SP): Unesp; 2006.

10. Moreira LQ, Vilela FC, Orlandi L, Dias DF, Santos AL, Da Silva MA, et al. Anti-inflammatory effect of extract and fractions from the leaves of Byrsonima intermedia A. Juss. in rats. J Ethnopharmacol [serial on the internet]. 2011 [cited 2018 Apr 22];138:610-5. Available from: https://www. sciencedirect.com/science/article/pii/S0378874111007331
11. Orlandi L, Vilela FC, Santa-Cecília FV, Dias DF, Alves-DaSilva G, Giusti-Paiva A. Anti-inflammatory and antinociceptive effects of the stem bark of Byrsonima intermedia A. Juss. J Ethnopharmacol [serial on the internet]. 2011 [cited 2018 Apr 22];137(3):1469-76. Available from: https://www.sciencedirect.com/science/ article/pii/S0378874111006052

12. Yanti, Rukayadi Y, Kim KH, Hwang JK. In vitro antibiofilm activity of macelignan isolated from Myristica fragrans Houtt. against oral primary colonizer bacteria. Phytother Res. 2008;22(3):308-12.

13. Chung JY, Choo JH, Lee MH, Hwang JK. Anticariogenic activity of macelignan isolated from Myristica fragrans (nutmeg) against Streptococcus mutans. Phytomedicine. $2006 ; 13(4): 261-6$.

14. Cao GY, Yang XW, Xu W, Li F. New inhibitors of nitric oxide production from the seeds of Myristica fragrans. Food Chem Toxicol. 2013;62:167-71.

15. Lins R, Vasconcelos FHP, Leite RB, Coelho-Soares RS, Barbosa DN. Avaliação clínica de bochechos com extratos de Aroeira (Schinus terebinthifolius) e Camomila (Matricaria recutita L.) sobre a placa bacteriana e a gengivite. Rev Bras Plantas Med [serial on the internet]. 2013 [cited 2018 Apr 22];15(1):112-20. Available from: http://www.scielo.br/ $\mathrm{pdf} / \mathrm{rbpm} / \mathrm{v} 15 \mathrm{n} 1 / \mathrm{a} 16 \mathrm{v} 15 \mathrm{n} 1 . \mathrm{pdf}$

16. Martorelli SBF, Pinheiro AL, Souza IA, Higino JS, Bravo F. Efeito anti-inflamatório e cicatrizante do extrato hidroalcoólico de Schinus terebinthifolius Raddi (Aroeira) a $30 \%$ em orabase - estudo "in vivo". Int J Dent. 2011;10(2):80-90.

17. Freires IA, Alves LA, Jovito VC, Castro RD. Atividade antifúngica de Schinus terebinthifolius (Aroeira) sobre cepas do gênero Candida. Revista Odontológica do Brasil-Central [serial on the internet]. 2011 [cited 2018 Apr 22];20(52):415. Available from: http://robrac.org.br/seer/index.php/ ROBRAC/article/view/491/534

18. Rodríguez $0 E$, Sánchez $R$, Verde $M$, Núnez $M$, Ríos $R$, Chávez A. Obtaining of the essential oil of Syzygium aromaticum, identification of eugenol and its effect on Streptococcus mutans. J Oral Res [serial on the internet]. 2014 [cited 2018 Apr 22];3(4):218-24. Available from: http://www.joralres.com/index.php/J0R/article/ view/104/120

19. Valente ROH. Avaliação das propriedades tóxicas, antiinflamatórias e cicatrizantes do extrato de cravo-da-índia Syzygium aromaticum (L) Merr. e LM Perry. João Pessoa: Universidade Federal da Paraíba; 2006.

20. Santos LGM, Cardoso MG, Lima RK, Souza PE, Guimarães LGL, Andrade MA. Avaliação do potencial fungitóxico do óleo essencial de Syzygium aromaticum (L.) Merr \& Perry (Cravo-da-Índia). Tecno-Lógica [serial on the internet]. 2007 [cited 2018 Apr 22];11(1):11-4. Available from: https://online.unisc.br/seer/index.php/tecnologica/ article/view/154/125 
21. Guedes RCM, Nogueira NGP, Fusco Almeida AM, Souza CRF, Oliveira WP. Atividade antimicrobiana de extratos brutos de Petiveria alliacea L. Latin American Journal of Pharmacy [serial on the internet]. 2009 [cited $2018 \mathrm{Apr}$ 22];28(4):520-4. Available from: http://www.latamjpharm. org/trabajos/28/4/LAJ0P_28_4_1_7_AIT6W1N9TT.pdf

22. Hancianu M, Aprotosoaie AC, Gille E, Poiat A, Tuchilu $C$, Spac $A$, et al. Chemical composition and in vitro antimicrobial activity of essential oil of Melissa officials L. from Romania. Rev Med Chir Soc Med Nat Iasi. $2008 ; 112(3): 843-7$.

23. Teixeira AH, Bezerra MM, Chaves HV, Val DR, Pereira Filho S, Rodrigues e Silva MAA. Conhecimento popular sobre o uso de plantas medicinais no município de Sobral-Ceará, Brasil. Sanare (Sobral, Online) [serial on the internet]. 2014 [cited 2018 Apr 22];12(1):23-8. Available from: https://sanare.emnuvens.com.br/sanare/article/ view $/ 429 / 284$

24. Bounihi A, Hajjaj G, Alnamer R, Cherrah Y, Zellou A. In Vivo Potential Anti-Inflammatory Activity of Melissa officinalis L. Essential 0il. Adv Pharmacol Sci. 2013; 2013(1): 1-7.

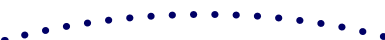

$\ldots \ldots \ldots \ldots \ldots$

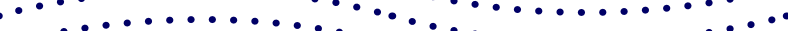
$\cdots \cdots$ $\cdots \cdots \cdots \cdots$
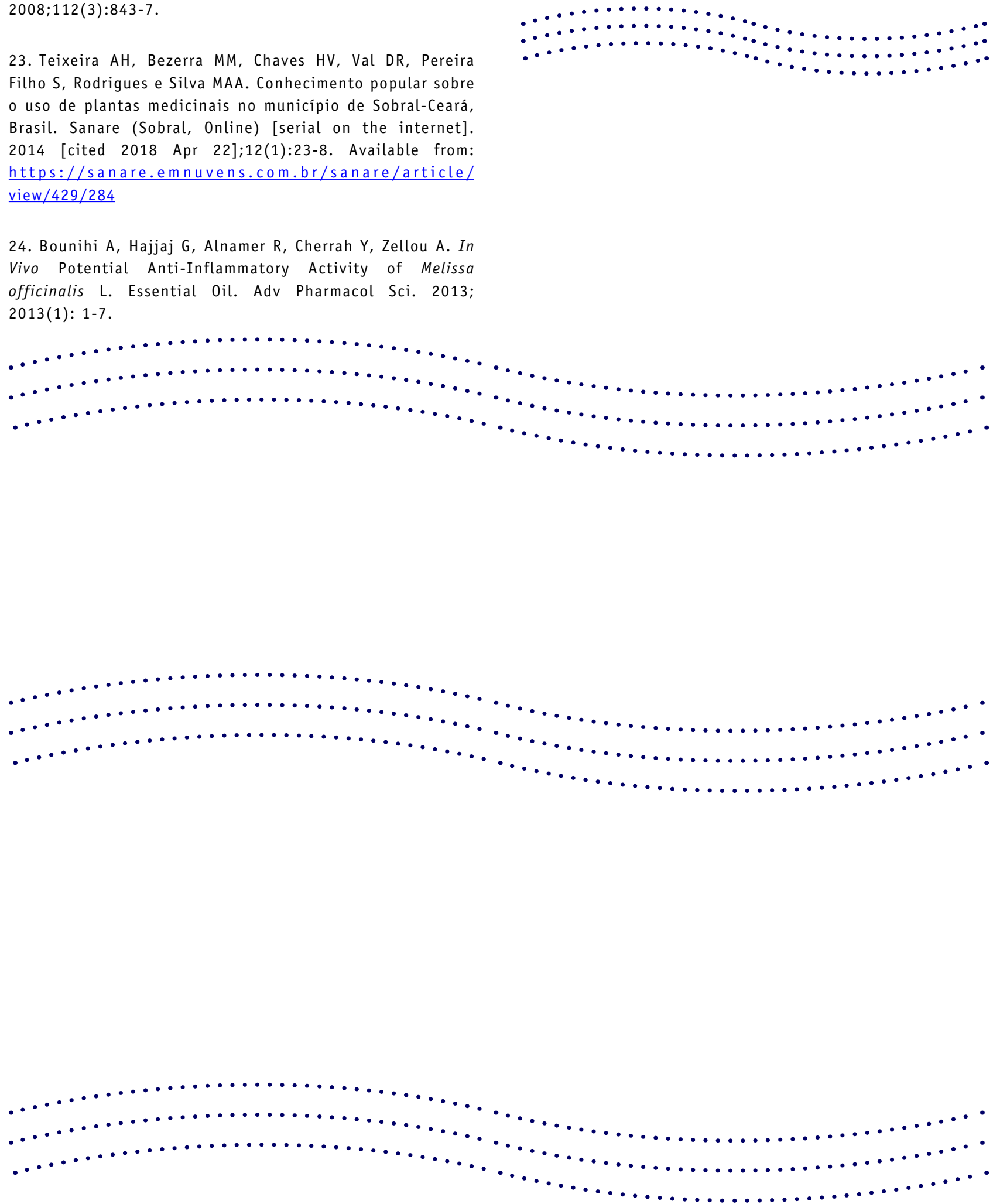


\title{
PERFIL EPIDEMIOLÓGICO DOS CASOS DE LEISHMANIOSE VISCERAL EM SOBRAL-CE DE 2011 A 2015
}

\author{
EPIDEMIOLOGICAL PROFILE OF CASES OF VISCERAL LEISHMANIASIS IN
} SOBRAL, CEARÁ, BRAZIL, FROM 2011 TO 2015

PERFIL EPIDEMIOLÓGICO DE LOS CASOS DE LEISHMANIASIS VISCERAL EN SOBRAL, CEARÁ, BRASIL, DE 2011 A 2015

\author{
Natanael Aguiar de Sousa ${ }^{1}$ \\ Carlito Braga Linhares \\ Francisco Gustavo Barbosa Pires \\ Taynã Cesário Teixeira \\ Joab da Silva Lima \\ Maria do Livramento Oliveira Nascimento
}

Palavras-chave:

Leishmaniose Visceral; Epidemiologia; Saúde Pública.

Keywords:

Visceral Leishmaniasis; Epidemiology; Public Health.

Palabras clave:

Leishmaniasis Visceral; Epidemiología; Salud Pública.

Submetido: $10 / 09 / 2017$

Aprovado: 07/04/2018

Autor(a) para Correspondência: Natanael Aguiar de Sousa End: Rua Corina Dantas, 52, Bairro Derby - CEP: 62042-220, Sobral - CE E-mail:natan6521@gmail.com

\section{RESUMO}

A leishmaniose visceral (LV) é uma doença crônica causada por protozoário do gênero Leishmania. No Brasil, principalmente na região Nordeste, constitui um importante problema de saúde pública. Sobral-CE, em 2008, foi considerada área endêmica para transmissão dessa doença, por isso, o objetivo deste estudo foi descrever os aspectos e facetas epidemiológicas dos casos notificados de LV nesse município, no período de 2011 a 2015. A pesquisa foi desenvolvida com bases nos dados disponibilizados pelo Sistema de Informação de Agravos de Notificação (Sinan). As variáveis obtidas foram sexo, nivel de escolaridade e faixa etária, entre outras, que foram devidamente analisadas, organizadas, tabuladas e apresentadas em gráficos. Foi registrado um total de 161 casos no período. Adulto, homem, e com baixa escolaridade é o perfil dos mais afetados. Houve decréscimo no número absoluto de casos notificados, o que mostra que as medidas utilizadas em Sobral têm sido efetivas. Entretanto, mesmo com a redução do número de ocorrências, o município ainda é responsável por alta incidência no estado.

\footnotetext{
1. Aluno de Graduação em Medicina na Universidade Federal do Ceará (UFC). Sobral (CE), Brasil. E-mail: natan6521@gmail.com

2. Aluno de Graduação em Medicina na Universidade Federal do Ceará (UFC). Sobral (CE), Brasil. E-mail: carlitobraga22@gmail.com

3. Aluno de Graduação em Medicina na Universidade Federal do Ceará (UFC). Sobral (CE), Brasil. E-mail: gustavopires1322@gmail.com

4. Aluna de Graduação em Medicina na Universidade Federal do Ceará (UFC). Sobral (CE), Brasil. E-mail: tayteixeira14@gmail.com

5. Aluno de Graduação em Medicina na Universidade Federal do Ceará (UFC). Sobral (CE), Brasil. E-mail: jb.araticum@gmail.com

6. Bióloga graduada pela Universidade Estadual do Vale do Acaraú (UVA). Sobral (CE), Brasil. E-mail: mariaoliveeira2010@gmail.com
} 


\section{ABSTRACT}

Visceral leishmaniasis (VL) is a chronic disease caused by a protozoan of the genus Leishmania. In Brazil, mainly in the Northeastern region, this is a major public health issue. Sobral, Ceará, Brazil, in 2008, was regarded as an endemic area for transmission of the disease, so this study aimed to describe the aspects and epidemiological facets of reported cases of VL in this municipality, within the period from 2011 to 2015. The research was conducted having data provided by the Brazilian Information System for Notifiable Diseases (Sinan) as a basis. The variables obtained were sex, educational level, and age group, among others, which were duly analyzed, organized, tabulated, and presented in graphs. A total of 161 cases were registered within the period. Adult, man, and low educational level is the profile of the most affected individuals. There was a decrease in the absolute number of notified cases, something which shows that the measures used in Sobral have been effective. However, even with a decreased number of occurrences, the municipality is still responsible for a high incidence in the state.

\section{RESUMEN}

La leishmaniasis visceral (LV) es una enfermedad crónica causada por un protozoario del género Leishmania. En Brasil, principalmente en la región Nordeste, este es un importante problema de salud pública. Sobral, Ceará, Brasil, en 2008, fue considerada como un área endémica para transmisión de esta enfermedad, por lo que este estudio tuvo como objetivo describir los aspectos y las facetas epidemiológicas de los casos notificados de LV en este municipio, en el período de 2011 a 2015. La investigación se realizó teniendo como base los datos provistos por el Sistema Brasileño de Información de Enfermedades de Notificación (Sinan). Las variables obtenidas fueron sexo, nivel educativo y franja etaria, entre otras, que fueron debidamente analizadas, organizadas, tabuladas y presentadas en gráficos. Un total de 161 casos fueron registrados dentro del período. Adulto, hombre y bajo nivel educativo es el perfil de las personas más afectadas. Hubo una disminución en el número absoluto de casos notificados, algo que muestra que las medidas utilizadas en Sobral han sido efectivas. Sin embargo, incluso con un número reducido de ocurrencias, el municipio sigue siendo responsable por una alta incidencia en el estado.

\section{INTRODUÇÃO}

A leishmaniose visceral (LV), conhecida popularmente como calazar, é uma doença sistêmica, crônica, grave que pode acometer pele, mucosas e vísceras, dependendo da espécie do parasita e da resposta imune do hospedeiro. Causada por protozoário do gênero Leishmania, pertencente ao complexo Leishmania donovani, pode afetar o homem e outras espécies. No Brasil, o agente etiológico encontrado é a L. chagasi e o vetor da LV é o mosquito flebotomíneo fêmea da espécie Lutzomyia longipalpis, conhecido como mosquito palha. 0 parasita possui ciclo heteroxêmico, vivendo na forma promastigota no hospedeiro invertebrado (mosquito) e na forma amastigota no sistema monócito fagocitário do hospedeiro vertebrado (mamíferos). A infecção se inicia quando o flebotomíneo, regurgita no local da picada formas promastigotas presentes em sua faringe e seu esôfago, que são fagocitadas por células do sistema monocítico fagocitário do homem e transformadas em amastigotas (aflageladas) que se multiplicam no interior do vacúolo fagocitário do macrófago ${ }^{1}$.

Trata-se de uma doença espectral, cuja apresentação clínica varia de formas assintomáticas até o quadro clássico da parasitose, evidenciado pela presença de febre, anemia, hepatoesplenomegalia, além de tosse seca, leucopenia, pancitopenia, hipoalbuminemia e hipergamaglobulinemia. Outras manifestações clínicas se desenvolvem com a progressão da doença, em especial diarreia, icterícia, emagrecimento, vômito e edema periférico, que dificultam o diagnóstico diferencial com outras patologias, retardando sua identificação ${ }^{2,3}$.

0 diagnóstico pode ser feito pela clínica ou por pesquisa das formas amastigotas no interior de macrófagos ou monócitos, mediante exames de esfregaço de sangue periférico, aspirado de medula óssea (padrão ouro), aspirado esplênico (mais agressivo para o paciente), cultura da Leishmania e exames sorológicos, como ELISA e $\mathrm{K} 39^{1}$.

0 primeiro relato de LV no Brasil é de 1934, quando foram encontradas amastigotas de Leishmania em cortes histológicos de fígados de pessoas que morreram com suspeita de febre amarela. Somente 20 anos depois é que se registrou o primeiro surto da doença, em Sobral-CE, município do norte do Ceará. Em meados dos anos 1980, constatou-se uma transformação drástica na distribuição geográfica da 


\section{...Sobral se apresenta como o segundo município com maior número de casos notificados...}

LV. A doença, antes restrita às áreas rurais do Nordeste, avançou para outras regiões indenes, alcançando inclusive a periferia de grandes centros urbanos ${ }^{4}$.

Segundo os dados do Ministério da Saúde, de 2011 a 2015 foram notificados 16.927 casos no Brasil, sendo o Nordeste a região com o maior número de casos (8.714 no total), seguido pelo Norte (2.839), Sudeste (2.545), Centro-0este (1.302) e Sul (14); as regiões ignoradas nas fichas de notificação totalizaram 1.513 casos. No Nordeste, o Ceará foi o segundo em número de casos (2.146 notificações), ficando atrás somente do Maranhão (2.519 notificações). 0 coeficiente de incidência no Brasil ficou entre 1,6 a 2,0 por 100 mil habitantes no período, já o Ceará ficou com 3,8/100 mil habitantes em 2012 (menor incidência) e 6,3/100 mil habitantes em 2011 (maior incidência). A letalidade no Brasil ficou entre 6,6 e 7,8\%; já no Ceará foi de 5,8\% em 2013 e $8,7 \%$ em 2014, a menor e a maior taxa de letalidade no período, respectivamente. 0 número de óbitos nesse mesmo intervalo de tempo foi de 1.220 no Brasil e de 178 no Ceará ${ }^{\text {. }}$

No período de 2001 a 2010 foram registrados 173 casos desse agravo patológico em Sobral. Durante esse período, observou-se um crescimento do número de casos, com os primeiros notificados a partir do ano de 2002, 5 casos, alcançando um total de 40 em $2010^{6}$. 0 município foi considerado pelo Ministério da Saúde uma área endêmica para transmissão da LV7.

De acordo com o Informe Epidemiológico do Governo do Estado do Ceará, de 2014, Sobral se apresenta como o segundo município com maior número de casos notificados, ficando atrás apenas de Fortaleza (capital cearense), e classificado como município com transmissão intensa, segundo a estratificação de risco $^{8}$.

A LV afeta diferentes classes sociais e graus de escolaridade. Há relatos de casos em todas as faixas etárias, com destaque para o aumento proporcional de casos na população de 20 a 39 anos e, historicamente, ocorre maior proporção de casos no sexo masculino ${ }^{9}$.

Diversos fatores contribuíram para a expansão de áreas endêmicas com aparecimento de novos focos em consequência das transformações no ambiente, provocadas pelo intenso processo migratório, por agressões ao ambiente, por pressões econômicas ou sociais, a pauperização decorrente de distorções na distribuição de renda, o crescente processo de urbanização, o esvaziamento rural e as secas periódicas ${ }^{6}$.

A estratégia de controle está centrada na identificação e eliminação dos reservatórios, principalmente o cão, aplicação de inseticidas para eliminação do vetor, e diagnóstico e tratamento adequados dos casos notificados. Maior conhecimento científico sobre o papel específico de cada elemento da cadeia de transmissão (agente etiológico, inseto transmissor, homem e reservatórios silvestres e domésticos) representa um dos maiores desafios para o aprimoramento das estratégias de controle ${ }^{8}$.

0 conhecimento acerca das características epidemiológicas da LV em Sobral, município com elevado número de casos notificados e de óbitos, pode ajudar as autoridades governamentais e as unidades de saúde na elaboração de estratégias para prevenção, controle e tratamento do agravo. Logo, o objetivo deste estudo foi descrever os aspectos epidemiológicos dos casos de LV notificados em Sobral, no período de 2011 a 2015.

\section{METODOLOGIA}

A pesquisa documental foi fundamentada nos dados sobre os casos de LV disponiveis no Sistema Nacional de Notificações e Agravos (Sinan) para o município de Sobral de 2011 a 2015.

Sobral, localiza-se a $235 \mathrm{~km}$ de Fortaleza e liga-se à capital do estado pela BR- 222 - que também liga o Ceará ao Piauí, ao Maranhão e ao Pará. Suas coordenadas geográficas são $3^{\circ} 41^{\prime} 10^{\prime \prime}$ de latitude e $40^{\circ} 10^{\prime} 59^{\prime \prime}$ de longitude. Segundo o Instituto Brasileiro de Geografia e Estatística (IBGE), em 2016, a área de unidade territorial era de $2.122,897 \mathrm{~km}^{2}$ e a população estimada para o ano de 2017 foi de 205.529 habitantes. Localizado no norte do Ceará, o município faz limite ao norte com Massapê, Santana do Acaraú e Meruoca; ao sul faz limite com Santa Quitéria, Groaíras e Cariré; a leste faz limite com Itapipoca, Irauçuba e Canindé; e a oeste faz limite com Coreaú, Mucambo e Alcântaras. Seu clima é quente e seco, com temperatura média de $30^{\circ} \mathrm{C}^{10,11}$. 
Foram analisadas as informações referentes aos indivíduos que contraíram LV, registrados na base de dados do Sinan, como já citado, disponível para consulta gratuita em seu site. As principais variáveis obtidas para as informações epidemiológicas foram: faixa etária, sexo, nível de escolaridade, tipo de entrada no sistema de saúde, evolução da doença em cada indivíduo para traçar o perfil epidemiológico da doença e incidência da doença em Sobral de 2011 a 2015.

0 Sinan é suprido, principalmente, pela notificação e investigação de casos de doenças e agravos que constam da lista nacional de doenças de notificação compulsória ${ }^{12}$, mas é facultado a estados e municípios incluir outros problemas de saúde de sua região e tem por objetivo o registro e processamento dos dados sobre agravos de notificação em todo o território nacional, fornecendo informações para análise do perfil da morbidade e contribuindo, dessa forma, para a tomada de decisões em nível municipal, estadual e federal ${ }^{13}$.

Segundo o Sinan, os dados obtidos para o ano de 2011 foram atualizados em 29/08/2012, os de 2012 em 12/08/2013, os de 2013 em 25/08/2014, os de 2014 em 19/08/2015 e os de 2015 ainda são parciais (sujeitos a revisão) ${ }^{14}$.

Os resultados foram tabulados e convertidos em gráficos para sintetizar e reunir informações de modo organizado e conciso, facilitando a investigação. Essa ferramenta proporciona uma análise mais complexa, incluindo a estatística descritiva, o teste da significância e a análise da variância. 0s dados foram organizados e processados no programa computacional Microsoft Excel, versão 2007.

\section{RESULTADOS E DISCUSSÃO}

Segundo os dados coletados no Sinan, um total de 161 casos de LV foram notificados no período de 2011 a 2015 em Sobral. Ao contrário da epidemiologia registrada na década anterior, quando os dados apontavam um tendência crescente, com aumento no número de casos a cada ano, no período em estudo, os dados indicam uma tendência decrescente, com diminuição no número de casos notificados, tendo ápice em 2011, com 53 casos (32,9\% do total); 2012 apresentou 38 casos $(23,6 \%)$, ao passo que 2013 teve $28(17,3 \%), 2014$ teve $25(15,5 \%)$ e 2015 teve 17 casos $(10,5 \%)^{6}$.

Essa diminuição pode demonstrar que as medidas de prevenção da doença, principalmente contra o vetor, têm mostrado resultados satisfatórios. Acredita-se, ainda, que esses números possam ser mais elevados ao considerar a subnotificação de casos.

Em comparação com o estado do Ceará, Sobral mostrou taxas de incidência bem mais elevadas, com $27,8 / 100$ mil habitantes em 2011, subindo para $8,4 / 100$ mil habitantes em 2015. Já o estado permaneceu com seus números seguindo um padrão linear, sem decréscimo acentuado, com 7,2/100 mil habitantes em 2011 e 6,4/100 mil habitantes em 2015 (Figura 1). Percebe-se que o município contribuiu de modo significativo para o aumento da incidência de LV no estado dentro do período em estudo.

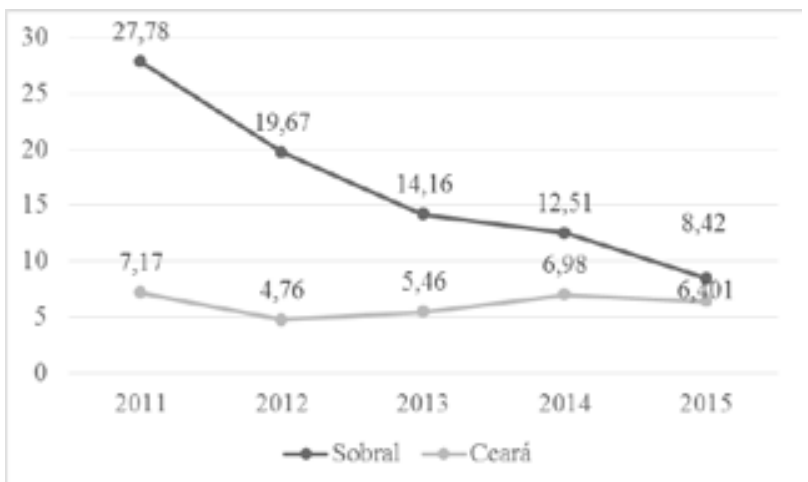

Figura 1. Coeficientes de incidência (por $100 \mathrm{mil}$ habitantes) de leishmaniose visceral no município de Sobral e no estado do Ceará, de 2011 a 2015. Fonte: Elaborada pelos autores.

Analisando a variável faixa etária (Figura 2), entre os adultos predomina a faixa dos 20 aos 39 anos (41 casos) e entre as crianças predomina a faixa de 1 a 4 anos (38 casos). Isso indica que são esses os grupos mais vulneráveis à afecção.

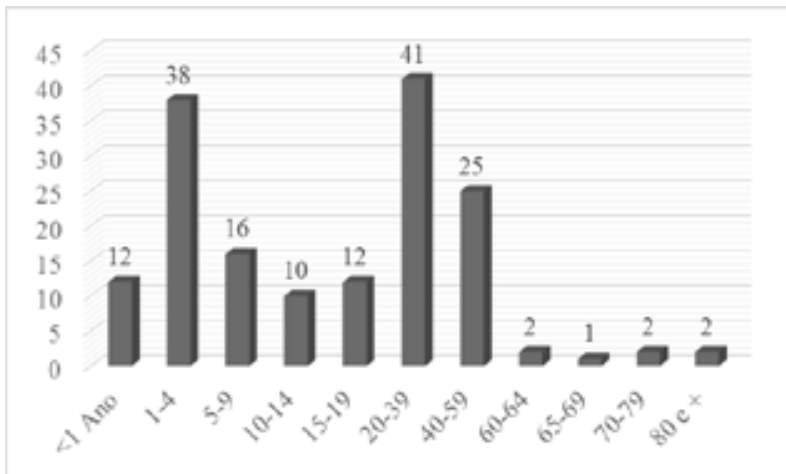

Figura 2. Número de casos notificados de leishmaniose visceral, segundo faixa etária, em Sobral, de 2011 a 2015.

Fonte: Elaborada pelos autores. 
A ocorrência da doença em adultos pode ser justificada por sua maior exposição aos flebotomíneos vetores, por serem considerados pertencentes ao grupo dos indivíduos economicamente ativos. Já a frequência em crianças apontada neste estudo também foi observada em um estudo realizado no Rio de Janeiro, que associou tal achado ao contato mais frequente das crianças com animais, além de sua maior carência nutricional e de seu estado imunológico ainda em formação ${ }^{15}$. Um resultado semelhante foi encontrado em um estudo realizado no Ceará, referente ao período de 2007 a 2011, e em outro estudo semelhante realizado em Sobral, referente ao período de 2001 a $2010^{6,16}$.

No que se refere ao sexo (Figura 3), em Sobral, a LV acomete com maior frequência a população masculina em todos os anos do período em estudo: $68,9 \%$ dos acometidos no período são homens. A doença pode atingir todas as idades e ambos os sexos, porém, a prevalência da doença nos homens pode ser justificada pela maior exposição aos vetores flebotomíneos e não por maior suscetibilidade ${ }^{17}$.

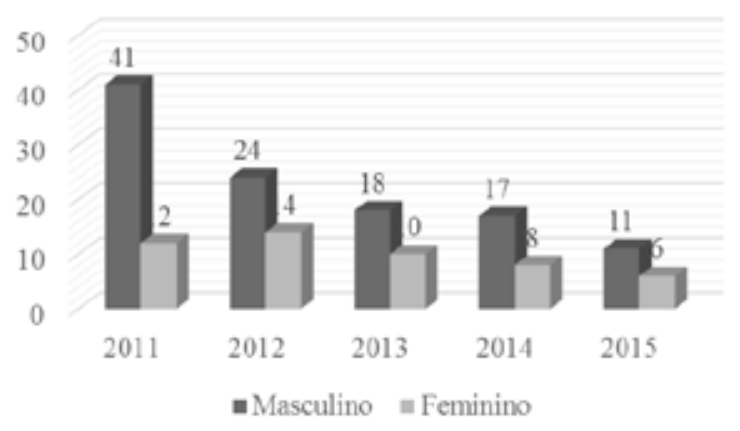

Figura 3. Número de casos notificados de leishmaniose visceral, segundo sexo, em Sobral, de 2011 a 2015. Fonte: Elaborada pelos autores.

Em relação ao grau de instrução (Figura 4), percebe-se que o número de indivíduos com alta escolaridade (Ensino Médio completo e Ensino Superior completo) e acometidos pela doença é baixo $(4,9 \%$ do total) - provavelmente, isso se deve ao maior acesso às informações sobre medidas preventivas. Já os indivíduos com baixa escolaridade e os analfabetos compõem a maioria dos doentes, evidenciando que a alta prevalência da LV nesse grupo pode estar associada a menor educação em saúde e menor potencial de controle epidemiológico. No entanto, os graus de instrução considerados ignorados ou em branco e os que não se aplicam, neste estudo, que juntos correspondem a $63,3 \%$ do total, podem ser justificados, em parte, pelo fato de que $31 \%$ dos casos de acometidos pela LV notificados correspondem a menores de 4 anos de idade, os quais ainda não frequentam o ambiente escolar. Resultados semelhantes a esses foram obtidos por estudos realizados em Sobral, no período de 2001 a 2010, e em Paracutu-MG, de 2007 a $2010^{6,17}$.

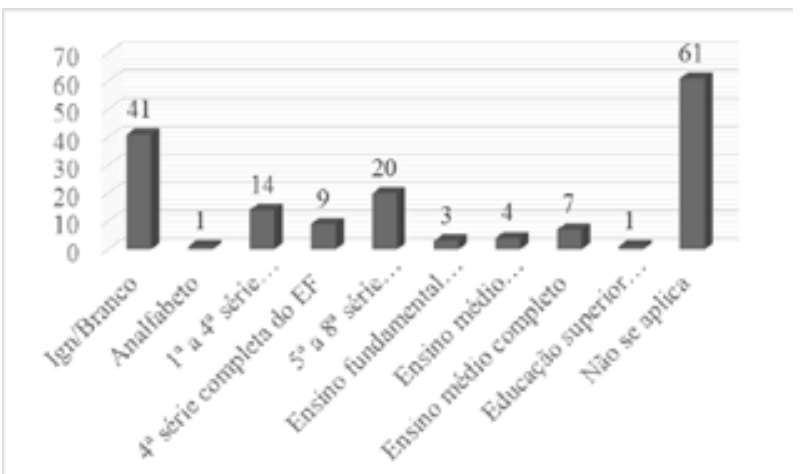

Figura 4. Número de casos notificados de leishmaniose visceral, segundo nível de escolaridade, em Sobral, de 2011 a 2015.

Fonte: Elaborada pelos autores.

Dentre os indivíduos com LV no período em estudo, $128(79,5 \%)$ obtiveram a cura como desfecho, 10 evoluíram para óbito e a letalidade observada nesse período variou de $3,5 \%$ a $8,0 \%$, com média de $6,2 \%$, ficando abaixo da média tanto do país $(6,8 \%)$ como do estado $(7,8 \%)$ no mesmo intervalo de tempo. Dentre os acometidos, $3(1,8 \%)$ evoluíram para óbito por outras causas, $3(1,8 \%)$ abandonaram o tratamento e o vínculo com o sistema de saúde, 16 (9,9\%) foram transferidos do município e $1(0,6 \%)$ foi considerado ignorado ou branco.

Essa grande proporção de cura nos casos notificados pode ser justificada pelo início precoce do tratamento e pelo bom preparo dos serviços de saúde do município, com profissionais preparados, testes laboratoriais e medicamentos para melhor atender a toda a demanda.

Por outro lado, $6(3,7 \%)$ dos casos de 2011 a 2015 foram notificados como recidivas. Isso pode ser explicado por ineficácia do tratamento, abandono e diminuição da capacidade de resposta do sistema imunológico da pessoa doente, além de comorbidades associadas à $L^{5}$. Entretanto, $117(72,6 \%)$ foram casos novos e $38(23,6 \%)$ foram casos notificados como transferidos de outros municípios (Figura 5 ). 


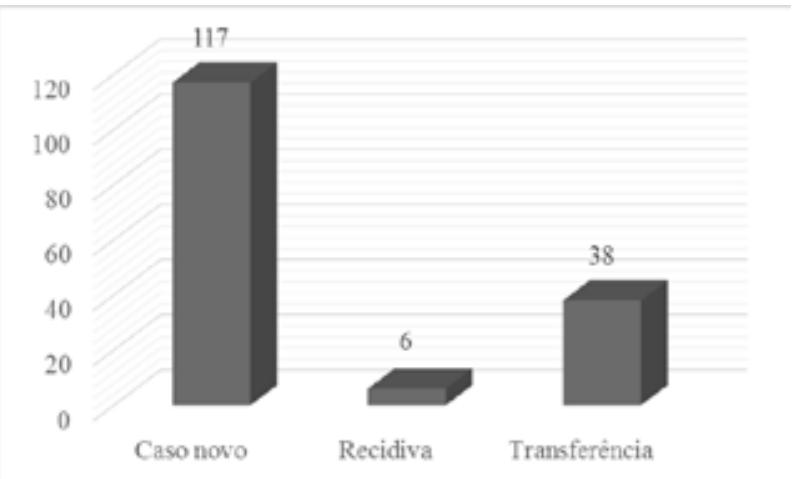

Figura 5. Número de casos notificados de leishmaniose visceral, segundo tipo de entrada, em Sobral, de 2011 a 2015.

Fonte: Elaborada pelos autores.

Considera-se que esses resultados apresentados, principalmente o decréscimo da taxa de incidência de LV e o aumento das taxas de cura, refletem a organização dos serviços na Atenção Primária à Saúde (APS) do município, principalmente com a implantação e expansão das ações das equipes da Estratégia Saúde da Família (ESF), que funcionam como porta de entrada do Sistema Único de Saúde (SUS). Entretanto, quando se compara ao estado e a outras cidades, os índices ainda se mostram elevados, sendo necessária a continuação e o aperfeiçoamento do acompanhamento dos acometidos e do trabalho de prevenção e de promoção da saúde já adotados.

\section{CONCLUSÃO}

Este estudo possibilitou a avaliação epidemiológica da incidência de LV em Sobral, no período de 2011 a 2015. Os dados que embasaram esta pesquisa avaliaram diferentes características da populaçãoalvo, comparando-as com períodos anteriores.

0 s resultados obtidos indicaram uma significativa redução do número de casos notificados anualmente, seguindo uma tendência de aproximação à média estadual e nacional. Observou-se, ainda, predominância do surgimento de casos em grupos específicos, como sexo masculino, classes socioeconômicas mais baixas e menores graus de escolaridade.

Assim, esta pesquisa possibilitou observar que, com o decréscimo no número de casos a cada ano, as medidas que têm sido adotadas no combate à doença no município se mostram efetivas. Ainda assim, sua média segue superior tanto ao nível estadual como nacional, o que indica a necessidade de manter e até intensificar tais medidas.

Percebe-se, também, que algumas características relacionadas à incidência no perfil da população ainda persistem, com alguns grupos se mostrando mais suscetíveis. Tal fato reforça a necessidade de uma abordagem mais direcionada e diferenciada a esses grupos, por parte do município, de modo a acentuar a redução dos índices de contração da doença.

\section{CONTRIBUIÇÃO DOS AUTORES}

Natanael Aguiar de Sousa contribuiu com 0 delineamento e a realização da pesquisa e a estruturação e redação do manuscrito. Carlito Braga Linhares e Francisco Gustavo Barbosa Pires contribuíram com a redação do manuscrito. Taynã Cesário Teixeira contribuiu com a realização da pesquisa. Joab da Silva Lima e Maria do Livramento Oliveira Nascimento contribuíram com a revisão crítica do manuscrito.

\section{REFERÊNCIAS}

1. Neves DP. Parasitologia humana. 13. ed. São Paulo: Atheneu; 2016.

2. Pastorino AC, Jacob CMA, Oselka GW, Carneiro-Sampaio MMS. Leishmaniose visceral: aspectos clínicos e laboratoriais. J Pediatr [serial on the internet]. 2002 [cited 2018 May 14];78(2):120-7. Available from: http://www. scielo.br/pdf/\%0D/jped/v78n2/v78n2a10.pdf

3. Pedrosa CMS, Rocha EMM. Aspectos clínicos e epidemiológicos da leishmaniose visceral em menores de 15 anos procedentes de Alagoas, Brasil. Rev Soc Bras Med Trop [serial on the internet]. 2004 [cited 2018 May 14];37(4):3004. Available from: http://www.scielo.br/pdf/rsbmt/ v37n4/21183.pdf

4. Gontijo CMF, Melo NM. Leishmaniose visceral no Brasil: quadro atual, desafios e perspectivas. Rev Bras Epidemiol [serial on the internet]. 2004 [cited 2017 Jul 17];7(3):33849. Available from: http://www.scielo.br/pdf/rbepid/ v7n3/11.pdf

5. Portal da Saúde [homepage on the internet]. Leishmaniose visceral: situação epidemiológica/dados. c2017 [cited 2017 Jul 17]. Available from: http:// portalsaude.saude.gov.br/index.php/o-ministerio/ principal/leia-mais-o-ministerio/726-secretaria-svs/ vigilancia-de-a-a-z/leishmaniose-visceral-lv/11334situacao-epidemiologica-dados

6. Silva OI, Vieira RDN, Timbó PEB. Perfil epidemiológico dos casos de leishmaniose visceral em Sobral, Ceará no período de 2001 a 2010. Sanare (Sobral, Online) [serial on 
the internet]. 2013 [cited 2017 Jul 17];12(1):13-9. Available from: file:///D:/323-624-1-SM\%20(2).pdf

7. Diário do Nordeste [homepage on the internet]. Cidade de Sobral é área endêmica para o calazar. 2008 [cited 2017 Jul 17]. Available from: http://diariodonordeste. verdesmares.com.br/cadernos/regional/cidade-de-sobral-earea-endemica-para-o-calazar-1.497175

8. Ceará (Estado). Informe epidemiológico: leishmaniose [document on the internet]. 2014 [cited 2017 Jul 17]. Available from: www.saude.ce.gov.br/index.php/boletins $\% 2$ 53Fdownload\%253D1559\%25253Ainforme-epidemiologicoleishmaniose-agosto-de-2014\%

9. Ceará (Estado). Boletim epidemiológico: leishmaniose visceral [document on the internet]. 2016 [cited $2017 \mathrm{Jul}$ 17]. Available from: http://www.saude.ce.gov.br/index. php/boletins?download $=2750 \% 3$ Aboletim-epidemiologicoleishmaniose-visceral-20-de-outubro-de-2016

10. Sobral (Município). A cidade: história [document on the internet]. c2017 [cited 2017 Jul 19]. Available from: http:// www.sobral.ce.gov.br/site novo/index.php/a-cidade/ historia

11. Instituto Brasileiro de Geografia e Estatística [homepage on the internet]. Cidades: Sobral c2017 [cited 2017 Sep 8]. Available from: http://cidades.ibge.gov.br/xtras/perfil. php? codmun $=231290$

12. Brasil. Portaria n. 204, de 17 de fevereiro de 2016. Define a Lista Nacional de Notificação Compulsória de doenças, agravos e eventos de saúde pública nos serviços de saúde públicos e privados em todo o território nacional, nos termos do anexo, e dá outras providências [document on the internet]. 2016 [cited 2018 May 14]. Available from: http:// bvsms.saude.gov.br/bvs/saudelegis/gm/2016/ prt0204 1702 2016.html

13. Instituto Brasileiro de Geografia e Estatística [homepage on the internet]. Comitê de Estatísticas Sociais: Sistema de Informação de Agravos de Notificação - Sinan. c2017 [cited $2017 \mathrm{Jul}$ 19]. Available from: http://ces.ibge.gov.br/basede-dados/metadados/ministerio-da-saude/sistema-deinformacoes-de-agravos-de-notificacao-sinan.html

14. Sistema de Informação de Agravos de Notificação [homepage on the internet]. Sinan. c2017 [cited 2017 Jul 19]. Available from: http://tabnet.datasus.gov.br/cgi/ deftohtm.exe?sinannet/cnv/leishvce.def

15. Marzochi MCA, Fagundes A, Andrade MV, Souza MB, Madeira MF, Mouta-Confort E, et al. Visceral leishmaniasis in Rio de Janeiro, Brazil: ecoepidemiological aspects and control. Rev Soc Bras Med Trop [serial on the internet] 2009 [cited 2017 Jul 18];42(5):52-63. Available from: http:// www.scielo.br/pdf/rsbmt/v42n5/17.pdf

16. Calvacante IJM, Vale MR. Aspectos epidemiológicos da leishmaniose visceral (calazar) no Ceará no período de 2007 a 2011. Rev Bras Epidemiol [serial on the internet]. 2014 [cited 2017 Jul 20];17(4):911-24. Available from: https:// pdfs.semanticscholar.org/d5f8/3434a00c3bc78c36149db476 b85a18f4ff5f.pdf

17. Oliveira EN, Pimenta AM. Perfil epidemiológico da leishmaniose visceral no município de Paracatu, MG no período de 2007 a 2010. REME Rev Min Enferm [serial on the internet]. 2014;18(2):365-75. Available from: file:///D:/ v18n2a09.pdf
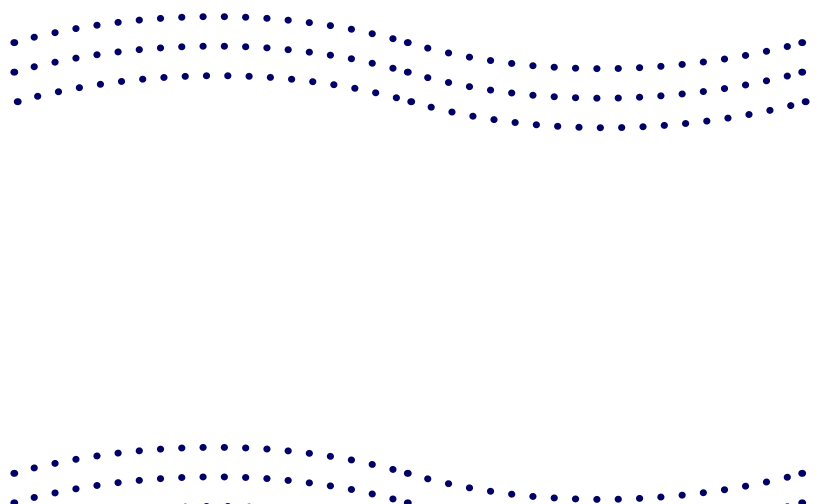
$\ldots \ldots \ldots \ldots \ldots \ldots \ldots \ldots$ $\ldots \ldots \ldots \ldots \ldots \ldots \ldots$ $\cdots \ldots \ldots \ldots \ldots$
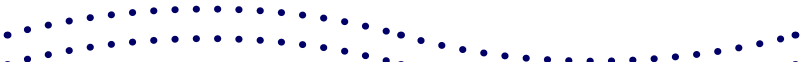
$\ldots \ldots \ldots \ldots \ldots \ldots \ldots$ $\ldots \ldots \ldots \ldots \ldots$
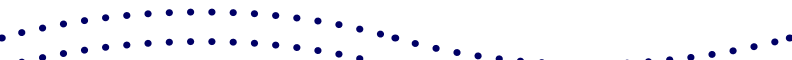
$\ldots \ldots \ldots \ldots \ldots \ldots \ldots \ldots$ $\ldots \ldots \ldots \ldots \ldots \ldots \ldots$

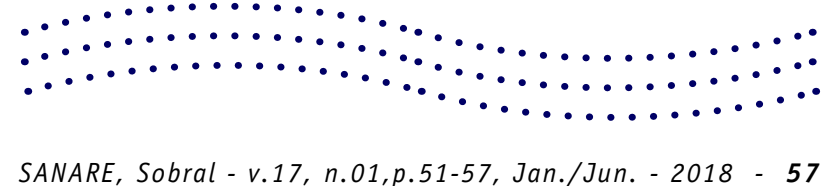




\section{O PODER DO PODER DE POLÍCIA À LUZ DO DIREITO SANITÁRIO E DA VIGILÂNCIA SANITÁRIA}

THE POWER OF POLICE POWER IN THE LIGHT OF HEALTH LAW AND HEALTH SURVEILLANCE

EL PODER DEL PODER DE POLICÍA A LA LUZ DEL DERECHO SANITARIO Y DE LA VIGILANCIA SANITARIA

Antônio Augusto Vieira de Aragão ${ }^{1}$

Sydia Rosana de Araújo Oliveira ${ }^{2}$

Palavras-chave: Vigilância Sanitária; Poder de Polícia; Saúde Pública.

Keywords: Health Surveillance; Police Power; Public Health.

Palabras clave: Vigilancia Sanitaria; Poder de Policía; Salud Pública.

Submetido: $14 / 12 / 2017$

Aprovado: 26/04/2018

Autor(a) para Correspondência: Antônio Augusto Vieira de Aragão End: Rua das Acácias SN, São Cristovão - CEP-56.512-380, Arcoverde-PE E-mail:augustoapevisa@gmail.com

\section{RESUMO}

Em virtude da vigilância sanitária (Visa) assumir caráter prioritário e compreender um conjunto de instituições do setor saúde cuja finalidade é controlar riscos provenientes dos processos produtivos, este artigo discorre sobre suas atribuições quando dotada do chamado poder de polícia, à luz do direito sanitário. Apresentam-se definições de poder, direito sanitário, poder de polícia e a abrangência desses termos, além de indicar a função do Poder Judiciário como mecanismo de controle da atividade pública. Aborda-se a inter-relação do poder de polícia com a saúde pública, porém, é na execução de suas funções na Visa que recebe seu direcionamento e suas responsabilidades. Observa-se que a Visa busca executar suas ações com ética e eficácia, com vistas à construção de uma sociedade dimanante e justa. Por ser um tema de natureza complexa, mostra-se imperativo apontar que o pleno exercício do poder de polícia, por ser de interesse público, demanda compartilhamento e transparência em suas ações, bem como compromisso e responsabilidade social, para gerar credibilidade diante da população.

1. Médico veterinário graduado pela Universidade Federal Rural de Pernambuco (UFRPE). Especialista em Saúde Pública pela Universidade de Pernambuco (UPE). Mestre em Saúde Pública pelo Instituto Aggeu Magalhães da Fundação 0swaldo Cruz (IAM/Fiocruz). Aluno de Doutorado em Saúde Pública no IAM/Fiocruz. Fiscal sanitário da Agência Pernambucana de Vigilância Sanitária (Apevisa). Recife (PE), Brasil. E-mail: augustoapevisa@ gmail.com

2. Dentista. Mestre em Saúde Comunitária. Doutora em Saúde Pública. Analista de Gestão em Saúde no IAM/ Fiocruz. Recife (PE), Brasil. E-mail: sydia@cpqam.fiocruz.br 


\section{ABSTRACT}

Since the Brazilian health surveillance (VISA) is a priority and a set of institutions in the health sector whose purpose is to control risks arising from productive processes, this article discusses its attributions when endowed with the so-called police power in the light of health law. Definitions of power, health law, and police power, and the scope of these terms are presented, as well as the Judiciary's role as a mechanism for controlling the public activity is indicated. We address the interrelationship between police power and public health, however, it is in the execution of its functions within the VISA that its direction and its responsibilities are received. It is noticed that the VISA seeks to carry out its actions ethically and effectively, with a view to building a fair and forthcoming society. Because this is a complex theme, it is imperative to point out that the full exercise of police power, as an issue of public interest, requires sharing and transparency in its actions, as well as commitment and social responsibility, in order to generate credibility vis-à-vis the population.

\section{RESUMEN}

Dado que la vigilancia sanitaria brasileña (VISA) es una prioridad y un conjunto de instituciones en el sector salud cuyo objetivo es controlar riesgos derivados de los procesos productivos, este artículo discurre acerca de sus atribuciones cuando está dotada del llamado poder de policía a la luz del derecho sanitario. Se presentan las definiciones de poder, derecho sanitario y poder de policía, y el alcance de estos términos, además de indicar la función del Poder Judicial como mecanismo de control de la actividad pública. Se aborda la interrelación entre el poder de policía y la salud pública, sin embargo, es en la ejecución de sus funciones dentro de la VISA donde se reciben su dirección y sus responsabilidades. Se observa que la VISA busca llevar a cabo sus acciones de manera ética y efectiva, con el objetivo de construir una sociedad dimanante y justa. Debido a que este es un tema complejo, es imperativo señalar que el pleno ejercicio del poder de policia, como cuestión de interés público, requiere compartición y transparencia en sus acciones, así como compromiso y responsabilidad social, a fin de generar credibilidad ante la población.

\section{INTRODUÇÃO}

Este artigo discorre sobre as atribuições da vigilância sanitária (Visa) quando dotada do chamado poder de polícia, à luz do direito sanitário. Apresentam-se definições de poder, direito sanitário, poder de polícia e a abrangência desses termos, além de indicar a função do Poder Judiciário como mecanismo de controle da atividade pública. A Visa, de caráter prioritário, compreende um conjunto de instituições do setor saúde cuja finalidade é controlar riscos provenientes dos processos produtivos.

0 poder é um conceito amplo, que envolve a capacidade de produzir ou contribuir para resultados que influenciam de modo considerável o(s) outro(s) por meio de relações sociais ${ }^{1}$. É intercambiável e utilizável como recurso para viabilizar planos. Consequentemente, o homem coletivo, como ator desses planos, deve expressar a consciência social do indivíduo - cada homem é um legatário e governante de seus atos, o que edifica sua liberdade ${ }^{2}$.

0 desenvolvimento dos centros urbanos, junto com a crescente complexidade cultural, religiosa e econômica das sociedades, trouxe a lume uma forma de organização social e política: o Estado. Neste, o direito assumiu relevância estratégica: ele ordena 0 jogo político das populações, as estruturas de organização do aparato estatal e as condições de exercício do poder. 0 Estado sistematiza suas ação e detém o monopólio do uso da força, condicionando todos os indivíduos a uma miríade pré-determinada de normas (e as respectivas sanções se não forem cumpridas) ${ }^{3}$.

Definir o termo saúde é algo de uma importância nesse contexto. 0 conceito de saúde é pauta de discussão desde os filósofos da Grécia Antiga, quando estava relacionado ao meio ambiente habitado pelo homem e à ausência de doenças. Em meados do século $X X$, com a organização política internacional pósSegunda Guerra Mundial e com a criação da Organização Mundial da Saúde (OMS), em 1946, a saúde foi reconhecida como direito fundamental de todo ser humano, sem diferenciação de raça, credo religioso, posição política ou condição econômica ou social - refere-se ao bem-estar físico, mental e social como um todo e não se limita à ausência de doenças ou outros agravos ${ }^{4}$.

A saúde constitui um ramo didaticamente autônomo do direito positivo, com diretrizes que aludem, direta ou indiretamente, à relação triádica entre Estado, sociedade e saúde pública ${ }^{5}$.

Duas designações são atribuídas a essa disciplina 
jurídica: direito sanitário e direito da saúde. 0 vocábulo sanitário provém do francês sanitaire, relativo a saúde e higiene. E a expressão da saúde aponta o objeto ou bem jurídico tutelado. No Brasil, predomina o termo direito sanitário, entendido como o conjunto de normas jurídicas reguladoras do poder de polícia voltado à promoção, proteção e recuperação da saúde, bem como à organização e ao funcionamento dos serviços de saúde ${ }^{4}$.

Assim, diferencia-se o direito sanitário do direito da saúde, cujo objeto é mais amplo e complexo. Nessa lógica, o direito da saúde constitui uma intersecção entre o direito positivo e o setor saúde (com serviços públicos e privados) - que engloba todos os aspectos relacionados à vida, ao bem-estar físico e mental e ao controle das doenças. 0 direito sanitário tem um objeto mais restrito: consiste no controle, viabilizado pelo poder de polícia, de todas as atividades públicas e privadas com potencial repercussão na saúde pública ${ }^{5}$.

$\mathrm{Na}$ Constituição Federal de 1988 (CF/1988), o direito da saúde é reconhecido como direito social (artigo $6^{\circ}$ ) e direito de todos (artigo 196), dotado de normas jurídicas que disciplinam as circunstâncias que têm a saúde por objeto mediato ou imediato; tais normas regulam a organização e o funcionamento das instituições destinadas à promoção da saúde ${ }^{6}$. Vale enfatizar que o vocábulo direito não denota apenas o ordenamento jurídico, podendo referir-se ao caminho para constatar a legitimidade dos atos e às permissões derivadas de normas jurídicas (o chamado direito subjetivo $)^{7}$.

0 Poder Judiciário tem assumido papel de destaque no Brasil quanto à garantia do direito à saúde, o que propicia uma análise complexa e fundamentada por parte de juristas, por afetar a operacionalização das políticas de saúde ${ }^{8}$.

Este artigo tem por objetivo demonstrar que 0 exercício do poder de polícia sempre deve ter o interesse público como razão.

\section{METODOLOGIA}

Este estudo descritivo adotou a revisão de literatura como técnica e baseia-se em material bibliográfico, como: obras de doutrina jurídica, legislação e jurisprudência; e periódicos científicos disponiveis nas bases eletrônicas SciELO e BVS (buscas no período de abril de 2017 a abril de 2018).

Apresentam-se concepções, características, competências e limites do poder de polícia, abordando

\section{A policia materializa \\ a prerrogativa de que \\ a administração \\ pública pode \\ restringir e \\ condicionar o uso e \\ gozo de bens...}

sua inter-relação com a saúde pública, bem como seu direcionamento e suas responsabilidades com base na Visa, com a finalidade de destacar sua abrangência em prol do exercício dos direitos individuais e do bem-estar social.

\section{RESULTADOS E DISCUSSÃO}

\section{Concepções e abrangência do poder de polícia}

0 ordenamento jurídico brasileiro, desde a CF/1988 até as leis infraconstitucionais, concede, confere e outorga uma série de direitos relacionados à propriedade e é uníssono na doutrina jurídica que o uso, o gozo e a disposição da propriedade estão vinculados precisamente à função social da propriedade - instrumento adequado para restringir os abusos da propriedade e do gozo, da disposição e do exercício da liberdade. Assim, o exercício do poder de polícia não pode afrontar o direito, porque comumente é um ato infraconstitucional mediado por um ato administrativo ${ }^{9}$.

A polícia é uma organização administrativa derivada do vocábulo latino politia, refere-se a "governo de uma cidade", "cidadania”, "administração pública" ou "política civil". Sua responsabilidade é impor limitações à liberdade (individual ou coletiva), na exata medida necessária à salvaguarda e manutenção da ordem pública (mais do que o considerado necessário constitui abuso do poder de polícia $)^{10}$. Pode-se dizer que a polícia é a instituição com legitimidade para o uso da força quando algo afronta a ordem pública e há necessidade de uma resposta do poder público ${ }^{11}$.

No Brasil, a polícia age em cumprimento do que dispõe a lei - de forma discricionária, segundo o entendimento do agente público, cabendo ao Poder Judiciário analisar os casos de abuso do poder de polícia. A polícia materializa a prerrogativa de que a administração pública pode restringir e condicionar o 
uso e gozo de bens, atividades e direitos individuais em benefício da coletividade ${ }^{12}$.

A administração pública atribui a serviços e corporações com legitimidade e capacitação específicas a manutenção da ordem pública, em conformidade com a legislação aplicável, em todas as áreas que demandem ação nesse sentido, com uso de meios e instrumentos legais, aplicados na defesa do que for individual, particular ou coletivo, corporal ou patrimonial ${ }^{13}$. 0 objetivo é preservar a ordem pública com medidas restritivas aos direitos individuais que se mostrem necessárias à salvaguarda da moralidade, da propriedade, da saúde pública e do exercício da liberdade em conformidade com a legislação aplicável ${ }^{14}$.

Polícia é o termo genérico que designa a força organizada que ampara a sociedade livrando-a da chamada vis inquietativa. Sua finalidade é assegurar a tranquilidade, a segurança e a salubridade no âmbito da sociedade ${ }^{15}$.

Atualmente, todo o sistema de proteção de um Estado de direito tem o tríplice objetivo de assegurar a tranquilidade, a segurança e a salubridade pública e caracteriza-se pela competência de adotar medidas que visem a tal desideratum. Trata-se da faculdade discricionária da administração pública de limitar as liberdades individuais em prol do interesse coletivo - nos termos da lei ${ }^{16}$.

Somente o Estado, como legislador, pode limitar e condicionar liberdades e direitos; assim, o poder de polícia, como aplicação da lei, é exercido pelo Estado, como administrador ${ }^{17}$.

Adotando uma conotação ampla, o termo polícia também pode ser definido como ação da administração pública que, ao limitar ou disciplinar liberdades e direitos, regulamenta a prática de ato ou a abstenção de fato em prol do interesse público relativo a segurança e tranquilidade pública, higiene, costumes, propriedade, produção e mercado e direitos individuais ou coletivos. 0 exercício do poder de polícia é considerado regular quando executado pelo órgão competente nos limites da lei aplicável, com observância do processo legal e sem abuso ou desvio de finalidade ${ }^{18}$.

São atributos gerais da polícia: a) discricionariedade; b) autoexecutoriedade; e c) coercibilidade ${ }^{11}$. A polícia tem um atributo específico; trata-se de uma atividade negativa, no sentido de que a atividade positiva proporciona um benefício material ou objetivo aos cidadãos - por exemplo, a energia elétrica ${ }^{19}$. Em outras palavras, com o poder de

\section{...o poder de \\ polícia, como \\ aplicação da lei, é \\ exercido pelo \\ Estado, como \\ administrador.}

polícia, a administração pública coíbe a prática de determinados atos contrários ao interesse público como determina a obrigação de não fazer, constitui uma atividade negativa ${ }^{11,20}$.

0 poder de polícia cabe àqueles que detêm efetivamente a competência para seu exercício, constituindo um ato administrativo. Mesmo que o poder de polícia não possa ter sua ilegalidade aferida diretamente pela letra da lei constitucional ou infraconstitucional, deve-se submetê-lo objetivamente a outros princípios quanto à sua razoabilidade para avaliar uma tutela indireta ou oblíqua da ilegalidade 9 . 0 poder de polícia encontra limites na legislação que tem por objeto a atividade policial (em especial na CF/1988) e não se descarta o exame de casos concretos para determinar se seu exercício é razoável.

Assim, nos termos da CF/1988, a competência limita o exercício do poder de polícia. Como não existe hierarquia entre as entidades componentes da Federação, exceto em campos diferentes de atuação, dispõe-se a competência para o exercício do poder de polícia no âmbito territorial de cada esfera de governo - se o órgão não for competente, o ato não terá legitimidade ${ }^{18}$.

0 conceito atual de poder de polícia garante ao Estado um papel mais ativo na promoção do bemestar de todos. A legislação não dispõe apenas no tocante à ordem pública, mas sobretudo no sentido da manutenção da ordem social e econômica, com normas limitadoras da liberdade individual operacionalizadas predominantemente por meio do poder de polícia ${ }^{21}$. Mostra-se fundamental considerar que o exercício do poder de polícia deve acatar os seguintes limites ${ }^{22}$ :

1. Necessidade: como medida administrativa, a polícia deve ser adotada apenas para evitar ameaças prováveis ou reais ao interesse público. 0s interesses individuais não podem contrastar com o interesse público, sobretudo quando se trata da proteção à saúde pública ${ }^{22}$. Por exemplo: uma indústria emite poluentes em um de seus setores. 0 órgão de 
fiscalização define prazo para a colocação de filtros na primeira visita. Na segunda visita, aplica multa por meio de auto de infração - a ação é necessária, pois a empresa fere o interesse público.

2. Proporcionalidade: os meios utilizados têm a obrigação de ser proporcionais aos fins visados. Se não forem proporcionais, constituem abuso de poder ${ }^{22}$. Por exemplo: no mesmo episódio, não ocorrendo o pagamento da multa e persistindo a emissão de poluentes, o órgão de fiscalização interdita toda a empresa. Essa medida pode ser desproporcional no caso de ser possivel interditar apenas o setor da empresa responsável pela poluição. Então, caberá à autoridade sanitária estabelecer, discricionariamente, nos limites da lei, a medida pertinente.

3. Eficácia: a medida deve ser adequada para evitar o dano ao interesse público 22 . Por exemplo: no mesmo caso, em vez de interditar, o órgão fiscalizador aplica nova multa. Continuam a ser emitidos poluentes. Não adianta aplicar mais multas, pois elas não impedem o dano ao interesse público. Mostra-se oportuno adotar outra medida, como interditar o estabelecimento.

Como o poder é intercambiável, o homem coletivo deve reivindicar e estimular a consciência social de cada indivíduo para edificar e defender a liberdade. Tendo em vista que o princípio informador de poder é que autoriza a administração pública a condicionar ou restringir o exercício de direitos e atividades particulares, deve prevalecer o interesse público sobre o interesse privado². E o direito sanitário, parte do direito administrativo que disciplina o exercício da função sanitária dos entes públicos, tutela diretamente o interesse sanitário da coletividade.

Diante das concepções apresentadas e discutidas, conclui-se que o poder de polícia é a atividade do Estado que limita o exercício dos direitos individuais em benefício do interesse público. Para o exercício do poder de polícia, permite-se a utilização de medidas repressivas, desde que executadas com a finalidade de ajustar o comportamento individual à legislação pertinente.

\section{Inter-relação do poder de polícia com a saúde pública}

0 poder de polícia está presente em diversas áreas da saúde pública, mas é na execução de suas funções no âmbito da Visa que recebe seu direcionamento e suas responsabilidades. Há uma miríade de níveis que

\section{...o homem \\ coletivo \\ deve reivindicar e \\ estimular a \\ consciência \\ social...}

conferem características próprias à Visa, como a dimensão política, técnica, ideológica e jurídica. $0 \S$ $1^{\circ}$ do artigo $6^{\circ}$ da Lei n. 8.080/1990 dispõe sobre 0 conceito de Visa:

$\S 1^{\circ}$ Entende-se por vigilância sanitária um conjunto de ações capaz de eliminar, diminuir ou prevenir riscos à saúde e de intervir nos problemas sanitários decorrentes do meio ambiente, da produção e circulação de bens e da prestação de serviços de interesse da saúde ${ }^{23}$.

Verifica-se uma nítida ampliação da Visa nas três décadas de vigência da Lei n. 8.080/1990, passando a ter inter-relações com toda a cadeia de serviços de saúde e com o meio ambiente ${ }^{24}$.

Em geral, os Estados de direito organizam serviços no âmbito da Visa considerando o princípio da livre iniciativa e o motor da produção capitalista, ou seja, o lucro. É forçoso admitir a dificuldade de atuação no mercado por parte de todos os interessados em relação aos direitos uns dos outros e aos direitos dos cidadãos e consumidores. Assim, a Visa assume vital importância como instrumento de organização econômica da sociedade, pois sua função protetora abarca não só os cidadãos e consumidores, mas também os produtores, uma vez que agrega valor à produção ${ }^{3}$.

Destarte, as ações da Visa estão dispostas em um contexto mais abrangente, qual seja, o das ações de saúde, buscando a promoção, a prevenção e a recuperação da saúde - um dos direitos fundamentais dos indivíduos ${ }^{24}$.

A Visa faz parte do Sistema Único de Saúde (SUS), em cumprimento da CF/1988, assume caráter prioritário e suas ações têm natureza fundamentalmente econômica ${ }^{25-27}$. 0 trabalho desenvolvido em nível nacional pela Visa tem tornado - Brasil uma referência em regulação sanitária e econômica na América Latina, englobando produtos e serviços de saúde que representam $25 \%$ do produto interno bruto (PIB) do país. 


\section{Direcionamento com as responsabilidades da vigilância sanitária}

A Visa compreende um conjunto de instituições do setor saúde com a finalidade de controlar riscos provenientes de processos produtivos e engloba a normatização, regulação e fiscalização de produtos e serviços relacionados à saúde. Trata-se da configuração mais complexa da saúde pública, pois suas ações, eminentemente preventivas, perpassam todas as práticas médico-sanitárias e são de grande relevância no contexto da promoção, proteção e recuperação da saúde ${ }^{26,27}$.

Ressalta-se que as ações da Visa são educativas e normativas (exercício do poder regulamentar), contudo, seu poder de polícia assume destaque perante a população. A Visa tem numerosas atribuições e todas, sob a ótica da população, envolvem alta complexidade.

A regulação sanitária é um exercício de poder, por isso a Visa detém o chamado poder de polícia, limitando o exercício dos direitos individuais em benefício do interesse público. 0 poder é um atributo para o cumprimento do dever do Estado de proteger a saúde da população. Em busca da segurança sanitária, a Visa, como braço especializado do Estado para a regulamentação em saúde, deve recorrer a tecnologias de intervenção, informações, metodologias e estratégias afinadas com o conhecimento científico atualizado e os princípios estabelecidos pela CF $/ 1988^{3}$.

Com isso, observa-se uma miríade de normas nos diferentes ramos da Visa. Algumas dessas normas são de complexa execução em determinadas circunstâncias históricas e tecnológicas de localidades específicas do nosso país 22 .

0 exercício do poder de polícia sempre visa ao interesse público e a saúde, um bem inalienável, não deve encontrar barreiras quando se trata de sua promoção, proteção e recuperação $0^{9}$. Nesse contexto, a Visa busca cumprir suas responsabilidades de modo ético e eficaz, com vistas à construção de uma sociedade dimanante e justa, em uma relação harmônica com diferentes atores sociais ${ }^{24}$. Vale ressaltar que o poder de polícia não pode afrontar 0 direito constitucional e as ações da Visa se compatibilizam plenamente com os princípios da CF/1988.

\section{CONCLUSÃO}

Este estudo abordou as atribuições da Visa quando dotada do poder de polícia, à luz do direito sanitário. Por ser um tema de natureza complexa, vale ressaltar que o poder do pleno exercício do poder de polícia, de interesse público, demanda compartilhamento e transparência nas ações, bem como compromisso e responsabilidade social para gerar credibilidade diante da população. Constatou-se que a inter-relação do poder de polícia com a saúde pública recebe seu direcionamento e suas responsabilidades na execução das funções da Visa, que age com ética e eficácia no Brasil do século XXI.

\section{CONTRIBUIÇÃO DOS AUTORES}

Antônio Augusto Vieira de Aragão contribuiu com o delineamento e a realização da pesquisa e a redação e revisão crítica do manuscrito. Sydia Rosana de Araújo Oliveira contribuiu com a redação e revisão crítica do manuscrito.

\section{AGRADECIMENTO}

Os autores agradecem a Álvaro Lazzarini (in memoriam), Desembargador de Justiça do Estado de São Paulo, por seu alto senso de compromisso e responsabilidade social.

\section{REFERÊNCIAS}

1. Lukes SM. El poder. Un enfoque radical. Madrid: Siglo XXI; 2007.

2. Matus C. Política, planejamento e governo. 2. ed. Brasília (DF): Ipea; 1996. t. 1.

3. Aith F, Minhoto LD, Costa EA. Poder de polícia e vigilância sanitária no Estado democrático de direito. In: Costa EA, organizer. Vigilância sanitária: temas para debate. Salvador: Ed. UFBA; 2009. p. 37-60.

4. Rocha JCS. Direito sanitário na perspectiva dos interesses difusos e coletivos. 2. ed. São Paulo: Atlas; 2011. 
5. Carvalho C, Machado RB, Timm LB. Direito sanitário brasileiro. São Paulo: Quartier Latin; 2004.

6. Correia S. Introdução ao direito da saúde. In: Oliveira A, Rocha N, Raposo M, Monteiro S, Correia S, Martinez S, et al. Direito da saúde e bioética. Lisboa: Lex; 1991. p. 39-53.

7. Dallari SG. 0 direito sanitário como campo fundamental para a vigilância sanitária. In: Marques MCC, Carvalho ML, Silveira D, Castro PC, Ibañez N, organizers. Vigilância sanitária: teoria e prática. São Carlos (SP): RiMa; 2006. p. 15-32.

8. Vasconcelos FJL, Dias MAS, Saraiva MJG, Silva MMS. Judicialização da saúde: análise de ações judiciais demandadas na comarca de Sobral, Ceará. Sanare (Sobral, Online) [serial on the internet]. 2017 [cited $2018 \mathrm{Apr}$ 25];6(2):6-13. Available from: https://sanare.emnuvens. com.br/sanare/article/view/1172/633

9. Dias HP. Flagrantes do ordenamento jurídico-sanitário. Brasília (DF): Anvisa; 2000.

10. Lazzarini A. Estudos de direito administrativo. 2. ed. São Paulo: Revista dos Tribunais; 2008.

11. Di Pietro MSZ. Direito administrativo. 14. ed. São Paulo: Atlas; 2002.

12. Meirelles HL. Direito administrativo brasileiro. 27. ed. São Paulo: Malheiros; 2002.

13. Cartana AP. Processo administrativo sanitário: teoria e prática. Porto Alegre: Alcance; 2000

14. Silva DP. Vocabulário jurídico. 2. ed. São Paulo: Forense; 2002.

15. 15. Medauar 0. Direito administrativo moderno. 11. ed. São Paulo: Revista dos Tribunais; 2007.

16. Cretella Júnior J. Curso de direito administrativo. Rio de Janeiro: Forense; 2006.

17. Moreira Neto DF. Curso de direito administrativo. Rio de Janeiro: Forense; 2003.

18. Brasil. Lei n. 5.172, de 25 de outubro de 1966. Dispõe sobre o Sistema Tributário Nacional e institui normas gerais de direito tributário aplicáveis à União, Estados e Municípios. Diário Oficial da União [serial on the internet], Brasília (1966 0ct 27 [cited 2018 Apr 25]);Sec.1. Available from: http://www.planalto.gov.br/ccivil 03/leis/15172.htm

19. Araújo AJB, Maciel TB. Curso de direito sanitário para inspetores da Apevisa. [S.l]: [s.n]; 2010. Não publicado.

20. Bandeira de Mello CA. Curso de direito administrativo. 26. ed. São Paulo: Malheiros; 2009.
21. Lazzarini A. Limites do poder de polícia. Justitia [serial on internet]. 1995 [cited 2018 Apr 25];57(170):73-85. Available from: http://www.revistajustitia.com.br/links/ revistas.php

22. Brasil. Manual de direito sanitário com enfoque na vigilância em saúde. Brasília (DF): Ministério da Saúde; 2006.

23. Brasil. Lei n. 8.080 , de 19 de setembro de 1990. Dispõe sobre as condições para a promoção, proteção e recuperação da saúde, a organização e o funcionamento dos serviços correspondentes e dá outras providências. Diário Oficial da União [serial on the internet], Brasília (1990 Sep 20 [cited 2018 apr 25]); Sec.1. Available from: http://www.planalto. gov.br/ccivil_03/leis/l8080.htm

24. Cordeiro RGF, Mello DR, Manso MEG, Nechio M, Carvalho W. Poder de polícia e as ações de vigilância sanitária. Integração [serial on internet]. 2006 [cited 2018 Apr 25];45:161-9. Available from: http://www.usjt.br/prppg/ revista/integracao/integracao_45.php. pdf

25. De Seta MH, Silva JAA. A gestão da vigilância sanitária. In: De Seta MH, Pepe VLE, Oliveira G0, organizers. Gestão e vigilância sanitária: modos de pensar e fazer. Rio de Janeiro: Fiocruz; 2006. p. 195-217.

26. Lucchesi G. A vigilância sanitária no Sistema Único de Saúde. In: De Seta MH, Pepe VLE, Oliveira GO, organizers. Gestão e vigilância sanitária: modos atuais do pensar e fazer. Rio de Janeiro: Fiocruz; 2006. p. 33-48.

27. Ferraro AHA, Costa EA, Vieira-da-Silva LM. Imagemobjetivo para a descentralização da vigilância sanitária em nível municipal. Cad Saúde Pública [serial on internet]. 2009 [cited 2018 Apr 25];25(10):2201-17. Available from: http://www.scielo.br/pdf/csp/v25n10/11.pdf
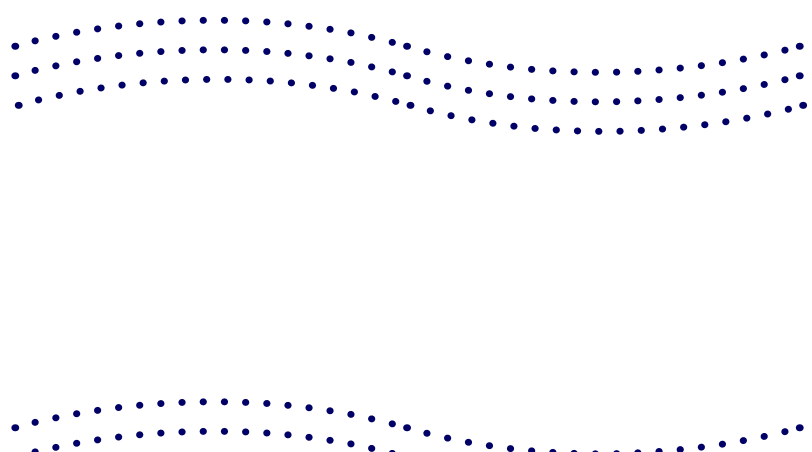
$\ldots \ldots \ldots \ldots \ldots \ldots \ldots \ldots \ldots$ $\ldots \ldots \ldots \ldots \ldots \ldots \ldots$ •..................

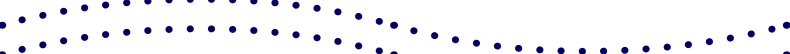
$\ldots \ldots \ldots \ldots \ldots \ldots \ldots \ldots$ ... 


\title{
AVALIAÇÃO DA RESOLUTIVIDADE E EFETIVIDADE DA ATENÇÃO PRIMÁRIA À SAÚDE: REVISÃO INTEGRATIVA DE LITERATURA
}

EVALUATING PROBLEM-SOLVING AND EFFECTIVENESS OF PRIMARY HEALTH CARE: INTEGRATIVE LITERATURE REVIEW

EVALUACIÓN DE LA RESOLUCIÓN DE PROBLEMAS Y LA EFECTIVIDAD DE LA ATENCIÓN PRIMARIA DE SALUD: REVISIÓN INTEGRADORA DE LITERATURA

\author{
Maristela Inês Osawa Vasconcelos 1 \\ Aparecida Lara Carlos Xavier ${ }^{2}$ \\ Maksoane Nobre do Nascimento ${ }^{3}$ \\ Yanka Alcântara Cavalcante ${ }^{4}$ \\ Sibele Pontes Rocha ${ }^{5}$ \\ Josiane da Silva Gomes 6
}

Palavras-chave: Efetividade; Atenção Primária à Saúde; Avaliação em Saúde; Resolutividade.

Keywords: Effectiveness; Primary Health Care; Health Evaluation; Problem-Solving.

Palabras clave: Efectividad; Atención Primaria de Salud; Evaluación en Salud; Resolución de Problemas.

Submetido: $17 / 03 / 2018$

Aprovado: 26/04/2018

\section{Autor(a) para Correspondência:} Josiane da Silva Gomes End: Rua Humberto Lopes, 258, Ap.A, Domingos Olímpio

Sobral-Ceará. CEP: 62.022-304 E-mail: josianegomes4@hotmail.com

\section{RESUMO}

Este artigo analisa métodos de avaliação da efetividade e resolutividade na atenção primária à saúde (APS). Trata-se de revisão integrativa de literatura considerando o período de 2008 a 2017, com buscas na Biblioteca Virtual em Saúde (BVS) e na Scientific Electronic Library Online (SCIELO) e uso dos descritores em ciências da saúde (DeCS) "efetividade", "atenção primária à saúde" e "avaliação em saúde", além do termo-chave "resolutividade". Por meio da aplicação dos critérios de inclusão e exclusão, 13 publicações foram selecionadas para compor a amostra do estudo, analisadas a partir das evidências científicas. Ao analisar essas publicações, identificou-se que a efetividade e resolutividade na APS estão interligadas à avaliação positiva por parte dos usuários acerca das ações realizadas pelos serviços de saúde. Constatou-se que uma assistência aos usuários de boa qualidade contribui com a boa gestão. Identificar os processos que necessitam de redirecionamento de gastos junto aos setores administrativo e financeiro do sistema de saúde possibilita a obtenção de resultados satisfatórios dos serviços de saúde.

1. Professora no Curso de Graduação em Enfermagem da Universidade Estadual Vale do Acaraú (UVA) e no Mestrado Acadêmico em Saúde da Família da Universidade Federal do Ceará (UFC). E-mail: maristela.osawa@ gmail.com

2. Aluna de Graduação em Enfermagem na UVA. Bolsista do Programa de Bolsas de Produtividade em Pesquisa. E-mail: laraxavier5@gmail.com

3. Aluna de Graduação em Enfermagem na UVA. Bolsista do Programa de Bolsas de Produtividade em Pesquisa. E-mail: maksoane@gmail.com

4. Aluna de Graduação em Enfermagem na UVA. Bolsista do Programa de Bolsas de Produtividade em Pesquisa.

E-mail: yanka-AC2010@hotmail.com

5. Aluna do Mestrado Acadêmico em Saúde da Família da UFC. E-mail: sibelepontes63@gmail.com

6. Aluna do Mestrado Acadêmico em Saúde da Família da UFC. E-mail: josianegomes4@hotmail.com 


\section{ABSTRACT}

This article analyzes methods for evaluating effectiveness and problem-solving of primary health care (PHC). This is an integrative literature review considering the period from 2008 to 2017, with search in the Virtual Health Library (VHL) and the Scientific Electronic Library Online (SciELO) and use of the health sciences descriptors (DeCS) 'effectiveness,' 'primary health care,' and 'health evaluation,' in addition to the key term 'problem-solving.' By applying the inclusion and exclusion criteria, 13 publications were selected to be in the study sample, analyzed through scientific evidence. When analyzing these publications, we identified that effectiveness and problemsolving in the PHC are intertwined with positive assessment by users about the actions taken by the health services. We found out that good-quality care for users contributes to good management. Identifying the processes that need to redirect spending along with the administrative and financial sectors of the health system makes it possible to obtain satisfactory outcomes from health services.

\section{RESUMEN}

Este artículo analiza los métodos de evaluación de la efectividad y la resolución de problemas en la atención primaria de salud (APS). Esta es una revisión integradora de literatura considerando el período de 2008 a 2017 , con búsqueda en la Biblioteca Virtual en Salud (BVS) y la Scientific Electronic Library Online (SCiELO) y uso de los descriptores en ciencias de la salud (DeCS) "efectividad", "atención primaria de salud" y "evaluación en salud", además del término clave "resolución de problemas". Mediante la aplicación de los criterios de inclusión y exclusión, se seleccionaron 13 publicaciones para componer la muestra del estudio, analizadas a través de las evidencias científicas. Al analizar estas publicaciones, se identificó que la efectividad y resolución en la APS están interconectadas a la evaluación positiva por parte de los usuarios sobre las acciones realizadas por los servicios de salud. Se constató que una asistencia a los usuarios de buena calidad contribuye a la buena gestión. Identificar los procesos que necesitan redirigir el gasto junto con los sectores administrativo y financiero del sistema de salud permite obtener resultados satisfactorios de los servicios de salud.

\section{INTRODUÇÃO}

A atenção primária à saúde (APS) representa 0 primeiro nível de acesso dos usuários ao sistema de saúde e desenvolve ações de prevenção, promoção, proteção e reabilitação da saúde, visando ao atendimento das demandas de saúde dos indivíduos, das famílias e das comunidades. A APS é considerada uma estratégia fundamental para aumentar a efetividade e resolutividade dos serviços, constituindo referência no cenário mundial para reduzir as iniquidades existentes no setor saúde ${ }^{1}$.

É importante esclarecer que a efetividade é o grau em que determinada intervenção ou tecnologia traz benefícios aos indivíduos de uma população; na APS, a efetividade se refere à atenção capaz de prevenir doenças ou controlar episódios agudos decorrentes de condições crônicas ${ }^{2}$. Por sua vez, a resolutividade é a capacidade de solucionar problemas de saúde de indivíduos em situação de vulnerabilidade social e biológica, norteada pelos seguintes atributos: a) acesso; b) longitudinalidade; c) integralidade; e d) coordenação ${ }^{3}$.

As pesquisas de avaliação em saúde que monitoram a qualidade e capacidade resolutiva dos serviços ofertados pela APS no Brasil alcançaram maior destaque a partir de iniciativas federais em 2004, com foco especial na Estratégia Saúde da Família $(E S F)^{4}$ - considerada a porta de entrada do usuário no Sistema Único de Saúde (SUS). A avaliação nesse nível de atenção se mostra relevante para identificar as fragilidades que dificultam sua organização e operacionalização $0^{5}$.

Desse modo, a avaliação em saúde tem configurado um importante instrumento para a avaliação da qualidade dos serviços da APS, possibilitando discussões sobre sua capacidade resolutiva e sua efetividade, além de fornecer respostas sobre as políticas e os programas, para abrir espaço a reestruturações alinhadas às reais necessidades dos indivíduos e da coletividade ${ }^{6}$.

Diante do exposto, compreende-se que houve muitos avanços na APS, principalmente devido às políticas e aos programas criados com o intuito de garantir o direito à saúde dos diferentes grupos populacionais atendidos pela ESF. No entanto, questiona-se se tais projetos atingem seus objetivos, pois se observa que esse nível de atenção tem vivenciado problemas relativos à estrutura física dos serviços, à escassez de recursos e à insuficiência de profissionais, o que reforça as dúvidas quanto à efetividade da APS para atender às demandas de 
saúde da população ${ }^{7}$.

Este estudo se justifica pela necessidade de compreender os processos implantados na APS, com vistas à garantia de sua efetividade e resolutividade, a partir da identificação das estratégias de avaliação das ações desenvolvidas pela ESF. Nesse sentido, o estudo levantou na literatura científica produções relacionadas aos métodos de avaliação da efetividade e resolutividade na APS.

\section{METODOLOGIA}

Este estudo se caracteriza como uma revisão integrativa - método que reúne, analisa e sintetiza a produção científica sobre uma temática específica, a fim de obter uma compreensão completa do fenômeno que se almeja estudar ${ }^{8}$. A construção de uma revisão integrativa contempla as seguintes fases: a) identificação do tema e elaboração da pergunta norteadora; b) busca ou amostragem na literatura (definindo os critérios de inclusão e exclusão); c) categorização dos estudos; d) análise crítica dos estudos incluídos; e) interpretação dos resultados e síntese do conhecimento (apresentação da revisão) ${ }^{9}$.

Para seguir o padrão metodológico proposto, buscou-se responder a seguinte pergunta norteadora:

- Quais métodos vêm sendo utilizados para a avaliação da efetividade e resolutividade na APS?

As buscas, considerando o período de 2008 a 2017, foram realizadas em junho e julho de 2017 na Biblioteca Virtual em Saúde (BVS) e na Scientific Electronic Library Online (SciELO), com uso dos descritores em ciências da saúde (DeCS) "efetividade", "atenção primária à saúde" e "avaliação em saúde", além do termo-chave "resolutividade".

Recorremos a 5 cruzamentos entre os descritores e a palavra-chave em questão, mediados pelo operador booleano "and": a) "atenção primária à saúde" and "resolutividade"; b) "atenção primária à saúde" and "efetividade"; c) "atenção primária à saúde" and "resolutividade" and "efetividade"; d) "efetividade" and "atenção primária à saúde" and "avaliação em saúde"; e e) "resolutividade" and "atenção primária à saúde" and "avaliação em saúde".

Os critérios de inclusão foram: a) artigos nacionais disponiveis em texto integral; b) artigos em língua portuguesa; c) artigos publicados entre 2008 a 2017; e d) artigos que discutem as formas de avaliação da efetividade e resolutividade na APS.

Já os critérios de exclusão foram: a) artigos não disponiveis em texto integral; b) artigos duplicados

\section{Quais métodos vêm sendo utilizados para a avaliação da efetividade $e$ resolutividade na APS?}

nas bases BVS e SciELO; e c) artigos que não abordam a temática proposta.

A coleta de dados foi mediada por um instrumento validado e adaptado pelas autoras, para sistematizar e organizar os estudos, minimizando o risco de erros ou omissão de informações ${ }^{10}$. 0 s estudos foram selecionados por: a) título; b) autor(es); c) ano de publicação; d) métodos; e e) nível de evidência científica.

Há 6 níveis de evidência científica:

- Nivel 1: evidências resultantes da metanálise de múltiplos estudos clínicos controlados e randomizados;

- Nivel 2: evidências obtidas em estudos individuais com delineamento experimental;

- Nivel 3: evidências de estudos quase experimentais;

- Nivel 4: evidências de estudos descritivos (não experimentais) ou com abordagem qualitativa;

- Nivel 5: evidências provenientes de relatos de caso ou relatos de experiência; e

- Nível 6: evidências baseadas em opiniões de especialistas ${ }^{8}$.

As publicações foram selecionadas com base na leitura de títulos e resumos, considerando os critérios de inclusão e exclusão. Os artigos pré-selecionados foram lidos na íntegra e analisados segundo os níveis de evidência, sendo sistematizados para estabelecer a amostra da revisão. Os artigos selecionados foram sintetizados e discutidos a partir da literatura pertinente.

\section{RESULTADOS}

As buscas na BVS identificaram 269 publicações; a leitura dos títulos e resumos levou à exclusão de 240 publicações (221 não tinham relação com o tema e 19 estavam duplicadas). Após essa pré-seleção, restaram 29 artigos, dos quais foram excluídos 19 após a leitura integral (por não abordarem métodos de 
avaliação da resolutividade e efetividade especificamente). Restaram, portanto, 10 artigos para compor a amostra deste estudo.

As buscas na SciELO foram realizadas com os mesmos cruzamentos, resultando em 159 publicações; 136 publicações foram excluídas após a leitura dos títulos e resumos por não abordarem diretamente a temática investigada e 20 foram excluídas por estar duplicadas, restando 3 artigos.

A Figura 1 resume a amostra final desta revisão integrativa.

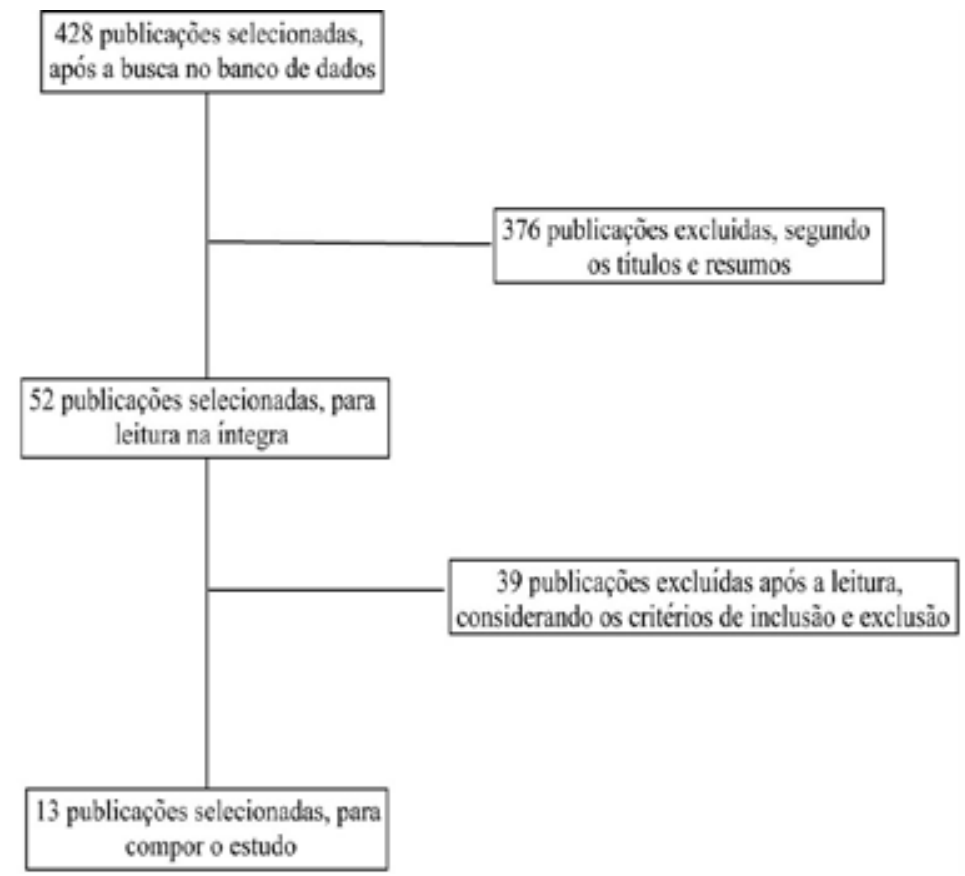

Figura 1. Distribuição dos artigos incluídos na amostra final da revisão integrativa. Fonte: Elaborada pelas autoras.

A Tabela 1 sistematiza os 13 estudos selecionados para a amostra final desta revisão integrativa.

Tabela 1 - Caracterização dos artigos incluídos na amostra final da revisão integrativa.

\begin{tabular}{llll}
\hline Titulo Autores Ano & Métodos Nivel de \\
evidência
\end{tabular}

1. Resolutividade dos serviços de saúde por inquérito domiciliar: percepção do usuário ${ }^{22}$
Turrini RNT, Lebrão $M L$, Cesar CLG
Tipo de estudo: descritivo.

Coleta: banco de dados do

2008 inquérito domiciliar, morbidade referida e utilização de serviços de saúde no ERSA-12.

2. Avaliação de efetividade da Atenção Básica à Saúde em municípios das regiões Sul e Nordeste do Brasil: contribuições metodológicas $^{16}$

3. Câncer cérvico-uterino como condição marcadora: uma proposta de avaliação da atenção básica ${ }^{17}$

Facchini LA, Piccini RX, Tomasi E, Thumé $E$, Teixeira VA, Silveira DS, et al.

Bottari CMS, Vasconcellos MM, Mendonça MHM
Tipo de estudo: transversal.

2008 Coleta: grupos de comparação e avaliações em saúde pública.
4. Resolutividade da assistência e satisfação de usuários da Estratégia Saúde da Família ${ }^{19}$
Rosa RB, Pelegrini AHW, Lima MADS
Tipo de estudo: qualiquantitativo.

Coleta: ELB-PROESF em municípios com população acima de 100 mil habitantes no estado do Rio de Janeiro.

Tipo de estudo: quantiqualitativo.

2011

Coleta: formulário estruturado e entrevista semiestruturada. 
5. Regulação do acesso ao cuidado na atenção primária: percepção dos usuários ${ }^{18}$
Clares JWB, Silva LMS, Dourado HHM, Lima LL
Tipo de estudo: exploratóriodescritivo, com abordagem qualitativa.

2011

Coleta: entrevista

semiestruturada e análise de conteúdo.

Tipo de estudo: avaliativo, qualitativo, participativo, com

triangulação de métodos e referencial teórico da
6. Avaliação de estratégias inovadoras na organização da atenção primária à saúde ${ }^{20}$
Campos RT0, Campos

GWS, Ferrer AL, Corrêa CRS, Madureira PR, Gama CAP, et al.
2012

Coleta: divisão de grupos para análise e comparação da aplicação de escalas nos 2 distritos de saúde mais populosos de Campinas (SP).

Tipo de estudo: revisão conceitual.

7. Avaliação de desempenho de sistemas de Viacava F, Ugá MAD, Paúdo S, Laguardia J, análise ${ }^{2}$
2012

Coleta: indicadores sugeridos

na segunda etapa do PROADESS

e sintese dos resultados obtidos.
8. Acessibilidade aos serviços de saúde: uma análise a partir da atenção básica em Pernambuco ${ }^{23}$
Albuquerque MSV, Lyra TM, Farias SF, Mendes MFM, Martelli PJL
Tipo de estudo: quantitativo 2014 descritivo, de corte transversal. 4 Coleta: dados do PMAQ-AB.
9. 0 acesso e a dificuldade na resolutividade do cuidado da criança na atenção primária à saúde ${ }^{21}$

10. A resolutividade em saúde bucal na atenção básica como instrumento para avaliação dos modelos de atenção ${ }^{3}$
Finkler AL, Viera CS, Tacla MTGM, Toso BRGO
Tipo de estudo: qualitativo.

Coleta: hermenêutica e observação não participante.

Tipo de estudo: ecológico, retrospectivo.

Coleta: indicadores de acesso ulgareli J, Cortellazzi KL, Ambrosano GMB, Meneghim MC, Faria $\mathrm{ET}$, Mialhe $\mathrm{FL}$, et al.
2014

ao tratamento odontológico e percentual de cobertura populacional em tratamento completado inicial (TCI).
11. Avaliação da longitudinalidade em unidades de atenção primária à saúde ${ }^{12}$
Frank BRB, Viera CS, Ross C, Obregón PL, Toso BRG0

Tipo de estudo: quantitativo.

Coleta: Primary Care Assessment

Tool (PCATool), versão criança,

validado no Brasil em 2010.

Tipo de estudo: avaliativo, transversal, com abordagem quantitativa.

12. Avaliação do desempenho da atenção básica nos municípios brasileiros com indicador

Miclos PV, Calvo MCM, Colussi CF

2015

Coleta: indicador sintético

desenvolvido pelo Núcleo de

Extensão e Pesquisa em

Avaliação em Saúde da

Universidade Federal de Santa

Catarina (Nepas/UFSC).
13. Estratégias para consolidação da coordenação do cuidado pela atenção básica ${ }^{4}$
Almeida PF, Marin J, Casotti $\mathrm{E}$
2017
Tipo de estudo: avaliativo e descritivo.

Coleta: questionários aplicados a 1.313 usuários e 324 equipes de atenção básica no município do Rio de Janeiro.

Fonte: Elaborada pelas autoras. 
A partir da análise dessa amostra bibliográfica, observou-se que algumas profissões do setor saúde estavam mais presentes nas discussões sobre as avaliações da resolutividade e efetividade na APS, dentre elas: Enfermagem (artigos n. 1, 3-5, 9 e 10); Medicina (artigos n. 2, 6 e 7); 0dontologia (artigos n. 11 e 12); Serviço Social (artigo n. 8); e Psicologia (artigo n. 13).

Quanto ao grau de evidência, a Tabela 1 indica $61,53 \%$ de estudos com nível 4 de evidência (artigos n. 4, 5, 7-10, 12 e 13), divididos entre estudos descritivos e estudos com abordagem qualitativa; $30,76 \%$ de estudos com nível 3 (artigos n. 1, 3, 6 e 11), onde se situam os estudos quase experimentais; e $7,6 \%$ de estudos com nível 2 (artigo n. 1) - de delineamento experimental.

No que tange ao recorte temporal das publicações, foram identificados 3 publicações de 2008 (artigos $n$. 1-3), 3 publicações de 2011 (artigos n. 4-6), 1 publicação de 2012 (artigo n. 7), 3 publicações de 2014 (artigos n. 8-10), 2 publicações de 2015 (artigos n. 11 e 12) e 1 publicação de 2017 (artigo n. 13).

No que se refere ao delineamento metodológico dos artigos analisados, 8 estudos eram quantitativos, 6 estudos eram qualitativos, 5 apresentavam abordagem descritiva, 4 tinham abordagem avaliativa, 2 estudos eram exploratórios, 1 estudo era transversal e havia 1 revisão conceitual e 1 estudo ecológico retrospectivo.

\section{DISCUSSÃO}

Constatou-se a relevância do tema em relação ao cenário nacional e às modificações das práticas em saúde, pois tais estudos contribuem para 0 fortalecimento do SUS na busca por soluções para ampliar a efetividade e resolutividade dos serviços ofertados pela APS ${ }^{11}$.

0s resultados demonstram que a APS requer compromisso político para responder de modo efetivo e resolutivo às demandas de saúde dos indivíduos e as práticas assistenciais devem ser de boa qualidade e inovadoras ${ }^{12}$. Entretanto, a APS enfrenta vários desafios, como: a) oferta de serviços e infraestrutura inadequadas; e b) desarticulação entre acolhimento dos usuários e coordenação da atenção. Isso interfere no processo de trabalho capaz de satisfazer as reais necessidades dos usuários ${ }^{13}$.

Dentre os estudos que integram a revisão, 6 publicações provêm da enfermagem - área de vital importância para as atribuições da APS com grande

\section{... a APS requer compromisso político para responder de modo efetivo $e$ resolutivo às demandas de saúde...}

repercussão na realidade desse nível de atenção em âmbito nacional ${ }^{14}$.

Notou-se um aumento do número de publicações que abordam a avaliação dos serviços de saúde com foco na APS em 2014. Sugere-se que tal aumento se deve à criação do Programa de Melhoria do Acesso e da Qualidade da Atenção Básica (PMAQ-AB), em 2011, que possibilita avaliar os serviços de saúde segundo a Política Nacional da Atenção Básica (PNAB), criada em $2006^{15}$.

Outro aspecto analisado se refere ao nível de evidência científica - a maioria dos artigos foi considerada de média qualidade, pois seu delineamento metodológico se pautou em estudos descritivos (não experimentais) ou em abordagens qualitativas, o que os levou a não apresentar um alinhamento que permita sua aplicação em diferentes realidades e contextos; entretanto, proporcionam informações importantes acerca da efetividade e resolutividade da APS.

Vale ressaltar que os estudos selecionados trazem diversas abordagens metodológicas para avaliação dos resultados no setor saúde, desde a utilização de escalas, indicadores e instrumentos, em sua maioria criados e validados pelos próprios autores; todavia, esses estudos têm em comum os resultados obtidos por meio do PMAQ-AB.

Ao analisar o conteúdo da amostra foram identificadas 9 estratégias metodológicas.

Algumas pesquisas apresentam como semelhança o chamado estudo de linha de base (ELB), que avalia o desempenho da APS na implementação do Projeto de Expansão e Consolidação do Saúde da Família (PROESF), utilizando dados secundários do DataSUS. As questões dos formulários englobam gestão, controle social, estrutura, profissionais e usuários dos serviços de saúde ${ }^{16,17}$.

Outras publicações desenvolveram questionários com aplicação de entrevistas semiestruturadas, com o objetivo de avaliar a efetividade e resolutividade das 
ações inerentes à APS com base no discurso da população atendida nos serviços de saúde ${ }^{18,19}$. Também se identificou nessas pesquisas a elaboração de escalas e diários de campo e o uso dos métodos de análise temática e triangulação hermenêutica - com abordagem sócio-histórica para interpretação/ reinterpretação dos dados ${ }^{20,21}$.

observou-se que a maioria dos estudos com aplicação de questionários e formulários avaliou as variáveis direcionadas efetividade e resolutividade dos serviços por meio dos módulos I, II e III do $P M A Q-A B^{4,22,23}$. Alguns pesquisadores apresentam métodos diferenciados para análise da resolutividade, com uso de registros do escritório regional de saúde combinados ao inquérito domiciliar de morbidade referida, englobando 14 variáveis inerentes ao objeto de estudo 22 .

Um estudo do tipo revisão conceitual, realizado a partir da proposta formulada pelo Projeto de Avaliação de Desempenho de Sistemas de Saúde (PROADESS), elencou subdimensões de avaliação do desempenho dos serviços de saúde: a) efetividade; b) acesso; c) eficiência; e d) adequação. No que se refere à efetividade, esse estudo reuniu os indicadores em 3 grupos: a) mortes evitáveis; b) morbidade evitável; e c) internações evitáveis - cada um desses indicadores tem seu subgrupo de taxas epidemiológicas, que foram utilizadas para mensurar a efetividade da APS 2 .

Outro estudo adotou abordagem distinta, com uso da base de dados do Sistema de Informação em Saúde para a Atenção Básica (SISAB) e do relatório de avaliação de saúde bucal, para analisar a resolutividade dos serviços de tratamento bucal ${ }^{21}$.

E outra publicação recorreu a um instrumento de coleta de dados internacional, adaptado e validado para o Brasil, denominado PrimaryCare Assessment Tool (PCATool-Brasil); por meio dele foram investigadas as variáveis de um atributo quanto à distribuição de suas frequências absolutas e relativas e de suas médias e medianas.

Nesta revisão, pôde-se verificar que, apesar dos desafios para atingir bons níveis de efetividade e resolutividade na APS, os avanços se sobrepõem às dificuldades, resultando em maior número de ações integradas na APS, por meio da implantação de programas como a Política Nacional de Atenção Integral à Saúde da Mulher (PNAISM) e a Política Nacional de Saúde Bucal (PNSB) 24,25.

A integração de ações na APS pode ser mencionada a partir de experiências relatadas em estudos realizados nos estados de São Paulo e do Rio de

\section{...os avanços se \\ sobrepõem às \\ dificuldades, \\ resultando em maior \\ número de ações integradas na APS...}

Janeiro - a introdução dessas políticas na APS contribui para a expansão da cobertura da ESF e, consequentemente, para a garantia do direito à saúde do usuário ${ }^{3,17}$.

Nos estudos incluídos nesta revisão, observou-se que a ideia de efetividade na APS se relaciona aos resultados das ações em saúde, sendo imprescindível que estas tragam benefícios para o indivíduo de determinada população e mostrem-se adequadas para avaliar o cumprimento de objetivos, metas e funções de ações programáticas na ESF2,16. A compreensão da resolutividade na APS mediada pela literatura envolve 4 fatores: a) oferta de serviços; b) infraestrutura; c) acolhimento; e d) coordenação da atenção. Nesse sentido, é imprescindivel que os serviços correspondam às demandas dos usuários ${ }^{19,21,22,26}$ e os estudos indicam que a APS efetiva e resolutiva está interligada à avaliação positiva de ações e serviços de saúde por parte dos usuários.

Os estudos selecionados apontaram as possiveis medidas a ser implementadas para garantir a resolutividade e efetividade na APS, sendo fundamental ampliar os recursos profissionais, assistenciais e tecnológicos e a infraestrutura dos serviços ${ }^{11}$. Apesar das diferenças locais dos estados brasileiros, eles seguem as mesmas diretrizes e a mesma legislação para a estruturação da APS; contudo, as ações definidas pelos gestores diferem de um lugar para o outro, constituindo distintas formas de organização, que, por sua vez, produzem resultados distintos no setor saúde ${ }^{26}$.

Assim, os resultados dos estudos incluídos na amostra desta revisão podem proporcionar apoio a outras localidades, levando em consideração as peculiaridades dos sistemas locais para avaliar os modelos de atenção operantes $3,19,20,26$. As metodologias de avaliação adotadas pelos estudos em questão apresentam impacto significativo na saúde da comunidade ao identificar a melhoria da qualidade dos serviços ofertados pela APS, assim como seus problemas e suas falhas, levando à necessidade de 
buscar estratégias para correção e novos planejamentos ${ }^{27}$.

\section{CONCLUSÃO}

Este estudo constatou que, para a avaliação da efetividade e resolutividade na APS, mostra-se necessária a adoção de um processo criterioso e organizado - com metodologias claras e bem definidas -, que possibilite o levantamento da real situação de saúde em análise, pois o uso de diferentes métodos pode levar ao distanciamento dos objetivos da avaliação.

Também se identificou que a qualidade da assistência aos usuários colabora com a gestão, ao identificar os processos que necessitam de redirecionamento de gastos junto ao setor administrativo e financeiro do setor saúde, contribuindo para um resultado satisfatório dos serviços de saúde.

Pode-se apontar como limitação deste estudo a adoção de diversas abordagens metodológicas para avaliação dos serviços de saúde, uma vez que os métodos apresentam restrições ao analisar as ações em saúde na APS, pois os dados apresentados não refletem a realidade dos serviços de saúde considerando as especificidades locais. Nesse sentido, faz-se necessária a realização de estudos que mensurem com maior precisão a efetividade e resolutividade, com uso de parâmetros nacionais e regionais que avaliem todas as diretrizes e todos os fundamentos da PNAB.

As autoras esperam que este artigo contribua com os esforços de outros pesquisadores interessados em analisar as diversas metodologias adotadas na avaliação da efetividade e resolutividade na APS. A literatura ainda se mostra escassa nesse área do conhecimento, tendo em vista o reduzido número de publicações identificadas e selecionadas para esta revisão integrativa.

\section{CONTRIBUIÇÃO DAS AUTORAS}

Maristela Inês 0 sawa Vasconcelos contribuiu com a concepção, realização da pesquisa, e redação e revisão crítica do manuscrito. Aparecida Lara Carlos Xavier contribuiu com a concepção e realização da pesquisa e a redação do manuscrito. Maksoane Nobre do Nascimento e Yanka Alcântara Cavalcante contribuíram com a estruturação e redação do manuscrito. Sibele Pontes Rocha e Josiane da Silva Gomes contribuíram com a redação do manuscrito.

\section{REFERÊNCIAS}

1. Carrer A, Toso BRG0, Guimarães ATB, Conterno JR, Minosso KC. Efetividade da Estratégia Saúde da Família em unidades com e sem Programa Mais Médicos em município no oeste do Paraná, Brasil. Ciênc Saúde Colet [serial on the internet]. 2016 [cited 2018 Apr 11];21(9):2849-60. Available from: http://www.scielo.br/pdf/csc/v21n9/14138123-csc-21-09-2849.pdf

2. Viacava F, Ugá MAD, Porto S, Laguardia J, Moreira RS. Avaliação de desempenho de sistemas de saúde: um modelo de análise. Ciênc Saúde Colet [serial on the internet]. 2012 [cited $2018 \mathrm{Apr} 9$ ];17(4):921-34. Available from: http:// www.scielo.br/pdf/csc/v17n4/v17n4a14.pdf

3. Bulgareli J, Cortellazzi KL, Ambrosano GMB, Meneghim MC, Faria ET, Mialhe FL, et al. A resolutividade em saúde bucal na atenção básica como instrumento para avaliação dos modelos de atenção. Ciênc Saúde Colet [serial on the internet]. 2014 [cited 2018 Apr 11];19(2):383-91. Available from: http://www.scielo.br/pdf/csc/v19n2/1413-8123csc-19-02-00383.pdf

4. Almeida PF, Marin J, Casotti E. Estratégias para consolidação da coordenação do cuidado pela atenção básica. Trab Educ Saúde [serial on the internet]. 2017 [cited 2018 Apr 9];15(2):373-98. Available from: http://www. scielo.br/pdf/tes/v15n2/1678-1007-tes-1981-7746sol00064.pdf

5. Miclos PV, Calvo MCM, Colussi CF. Avaliação do desempenho da atenção básica nos municípios brasileiros com indicador sintético. Saúde Debate [serial on the internet]. 2015 [cited 2018 Apr 11];39(107):984-96. Available from: http://www.scielo.br/pdf/sdeb/ v39n107/0103-1104-sdeb-39-107-00984.pdf

6. Sancho LG, Dain S. Avaliação em saúde e avaliação econômica em saúde: introdução ao debate sobre seus pontos de interseção. Ciênc Saúde Colet [serial on the internet]. 2012 [cited 2018 Apr 9];17(Suppl 3):765-74. Available from: http://www.scielo.br/pdf/csc/v17n3/ v17n3a24.pdf

7. Braga LM, Torres LM, Ferreira VM. Condições de trabalho e fazer em enfermagem. Revista de Enfermagem da UFJF [serial on the internet]. 2015 [cited 2018 Apr 10];1(1):5563. Available from: http://www.ufjf.br/ revistadeenfermagem/files/2015/05/10-Revista-deEnfermagem-C07.pdf

8. Souza MT, Silva MD, Carvalho R. Revisão integrativa: o que é e como fazer. Einstein [serial on the internet]. 2010 [cited 2017 Aug 8];8(1):102-6. Available from: http://www. scielo.br/pdf/eins/v8n1/pt 1679-4508-eins-8-1-0102.pdf

9. Mendes KDS, Silveira RCCP, Galvão CM. Revisão integrativa: método de pesquisa para a incorporação de evidências na saúde e na enfermagem. Texto \& Contexto Enferm [serial on the internet]. 2008 [cited 2017 Aug 8];17(4):758-64. Available from: http://www.scielo.br/pdf/ tce/v17n4/18.pdf 
10. Ursi ES. Prevenção de lesões de pele no perioperatório: revisão integrativa da literatura. Ribeirão Preto (SP): Universidade de São Paulo; 2005.

11. Rodrigues LBB, Silva PCS, Peruhype RC, Palha PF, Popolin $M P$, Crispim JA, et al. A atenção primária à saúde na coordenação das redes de atenção: uma revisão integrativa. Ciênc Saúde Colet [serial on the internet]. 2014 [cited 2018 Apr 9];19(2):343-52. Available from: http://www.scielo.br/ $\mathrm{pdf} / \mathrm{csc} / \mathrm{v} 19 \mathrm{n} 2 / 1413-8123-c s c-19-02-00343 . \mathrm{pdf}$

12. Frank BRB, Viera CS, Ross C, Obregón PL, Toso BRG0. Avaliação da longitudinalidade em unidades de atenção primária à saúde. Saúde Debate [serial on the internet]. 2015 [cited 2018 Apr 9];39(105):400-10. Available from: http://www.scielo.br/pdf/sdeb/v39n105/0103-1104sdeb-39-105-00400.pdf

13. Cubas MR, Faoro NT, Moysés ST, Carvalho DR. Avaliação da atenção primária à saúde: validação de instrumento para análise de desempenho dos serviços. Saúde Debate [serial on the internet]. 2017 [cited 2018 Apr 11];41(113): 47185. Available from: http://www.scielo.br/pdf/sdeb/ v41n113/0103-1104-sdeb-41-113-0471.pdf

14. Toso BRG0, Filippon J, Giovanella L. Atuação do enfermeiro na atenção primária no Serviço Nacional de Saúde da Inglaterra. Rev Bras Enferm [serial on the internet]. 2016 [cited 2018 Apr 11];69(1):182-91.Available from: http://www.scielo.br/pdf/reben/v69n1/0034-7167reben-69-01-0182.pdf

15. Brasil. Programa Nacional de Melhoria do Acesso e da Qualidade da Atenção Básica (PMAQ): manual instrutivo. Brasília (DF): Ministério da Saúde; 2012.

16. Facchini LA, Piccini RX, Tomasi E, Thumé E, Teixeira VA, Silveira DS, et al. Avaliação de efetividade da atenção básica à saúde em municípios das regiões Sul e Nordeste do Brasil: contribuições metodológicas. Cad Saúde Pública [serial on the internet]. 2008 [cited 2018 Apr 13];24(Suppl 1):159-72. Available from: http://www.scielo.br/pdf/csp/ v24s1/20.pdf

17. Bottari CMS, Vasconcellos MM, Mendonça MHM. Câncer cérvico-uterino como condição marcadora: uma proposta de avaliação da atenção básica. Cad Saúde Pública [serial on the internet]. 2008 [cited 2018 Apr 13];24(Suppl 1):S111-S122. Available from: https://www.scielosp.org/ $\mathrm{pdf} / \mathrm{csp} / \mathrm{v} 24 \mathrm{~s} 1 / 16 . \mathrm{pdf}$

18. Clares JWB, Silva LMS, Dourado HHM, Lima LL. Regulação do acesso ao cuidado na atenção primária: percepção dos usuários. Rev Enferm UERJ [serial on the internet]. 2011 [cited 2018 Apr 14];19(4):604-9. Available from: http:// www.facenf.uerj.br/v19n4/v19n4a17.pdf

19. Rosa RB, Pelegrini AHW, Lima MADS. Resolutividade da assistência e satisfação de usuários da Estratégia Saúde da Família. Rev Gaúch Enferm [serial on the internet]. 2011 [cited 2018 Apr 2014];32(2):345-51. Available from: http:// seer.ufrgs.br/index.php/RevistaGauchadeEnfermagem/ article/view/18574/12782
20. Campos RT0, Campos GWS, Ferrer AL, Corrêa CRS, Madureira PR, Gama CAP, et al. Avaliação de estratégias inovadoras na organização da atenção primária à saúde. Rev Saúde Pública [serial on the internet]. 2012 [cited $2018 \mathrm{Apr}$ 14];46(1):43-50. Available from: http://www.scielo.br/pdf/ rsp/v46n1/2502.pdf

21. Finkler AL, Viera CS, Tacla MTGM, Toso BRGO. 0 acesso e a dificuldade na resolutividade do cuidado da criança na atenção primária à saúde. Acta Paul Enferm [serial on the internet]. 2014 [cited $2018 \mathrm{Apr} 12$ ];27(6):548-53. Available from: http://www.scielo.br/pdf/ape/v27n6/1982-0194ape-027-006-0548.pdf

22. Turrini RNT, Lebrão ML, Cesar CLG. Resolutividade dos serviços de saúde por inquérito domiciliar: percepção do usuário. Cad Saúde Pública [serial on the internet]. 2008 [cited 2018 Apr 11];24(3):663-74. Available from: http:// www.scielo.br/pdf/csp/v24n3/20.pdf

23. Albuquerque MSV, Lyra TM, Farias SF, Mendes MFM, Martelli PJL. Acessibilidade aos serviços de saúde: uma análise a partir da atenção básica em Pernambuco. Saúde Debate [serial on the internet]. 2014 [cited 2018 Apr 12];38(Spec):182-94. Available from: http://www.scielo.br/ pdf/sdeb/v38nspe/0103-1104-sdeb-38-spe-0182.pdf

24. Ramos AL, Silva DP, Machado GMO, Oliveira EN, Lima DS. A atuação do enfermeiro da Estratégia Saúde da Família na prevenção do câncer de colo de útero. Sanare (Sobral, Online) [serial on the internet]. 2014 [cited $2018 \mathrm{Apr}$ 12];13(1):84-91. Available from: https://sanare.emnuvens. com.br/sanare/article/view/437/292

25. Carvalho TGS, Almeida AMB, Bezerra MIC. Percepção dos profissionais de saúde da atenção primária sobre educação permanente em saúde. Sanare (Sobral, Online) [serial on the internet]. 2016 [cited $2018 \mathrm{Apr} 12$ ];15(2):94-103. Available from: https://sanare.emnuvens.com.br/sanare/article/ view/1043/589

26. Miclos PV, Calvo MCM, Colussi CF. Avaliação do desempenho da atenção básica nos municípios brasileiros com indicador sintético. Saúde Debate [serial on the internet]. 2015 [cited 2018 Apr 13];39(107):984-96. Available from: http://www.scielo.br/pdf/sdeb/ v39n107/0103-1104-sdeb-39-107-00984.pdf

27. Ferreira VD, Oliveira JM, Maia MAC, Santos JS, Andrade RD, Machado GAB. Avaliação dos atributos da atenção primária à saúde em um município mineiro. Esc. Anna Nery Rev Enferm [serial on the internet]. 2016 [cited 2018 Apr 13];20(4):e20160104. Available from: http://www.scielo. br/pdf/ean/v20n4/en 1414-8145-ean-20-04-20160104.pdf
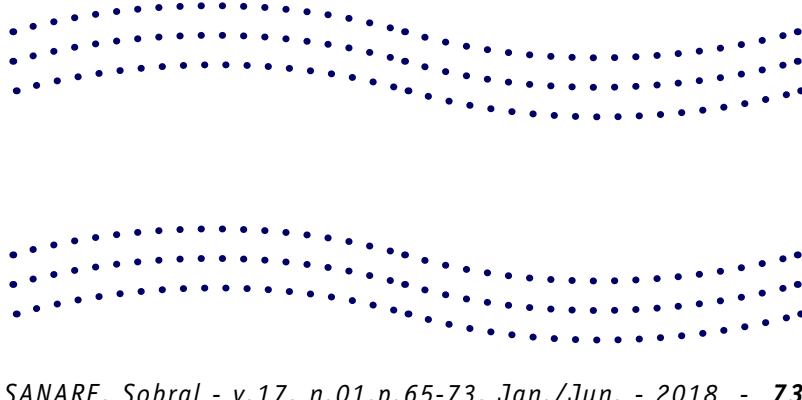


\title{
INCLUSÃO DO EDUCADOR FÍSICO NA ATENÇÃO PRIMÁRIA À SAÚDE: REVISÃO INTEGRATIVA
}

\author{
INCLUDING THE PHYSICAL EDUCATOR IN PRIMARY HEALTH CARE:
} INTEGRATIVE REVIEW

INCLUSIÓN DEL EDUCADOR FÍSICO EN LA ATENCIÓN PRIMARIA DE SALUD: REVISIÓN INTEGRADORA

Jefferson Carlos Araujo Silva ${ }^{1}$

Kamila Santos da Silva ${ }^{2}$

Carlos Martins Neto ${ }^{3}$

Thalita Cristinny Araujo Silva ${ }^{4}$

Alexandre Soares de Campos ${ }^{5}$

Palavras-chave:

Educação Física; Atenção Primária à Saúde; Promoção da Saúde.

Keywords:

Physical Education; Primary Health Care; Health Promotion.

Palabras clave: Educación Física; Atención Primaria de Salud; Promoción de la Salud.

Submetido: 04/12/2017

Aprovado:

04/05/2018

Autor(a) para Correspondência: Jefferson Carlos Araujo Silva End: Centro Metropolitano, Conj. A, Lote 1 - CEP: 72220-275, Brasília-DF E-mail: jeffcasilva@gmail.com

\section{RESUMO}

O objetivo deste estudo foi analisar a inclusão do profissional de educação física (PEF) na atenção primária à saúde (APS). Trata-se de uma revisão integrativa de literatura, realizada com publicações do periodo entre 2008 e 2018 e buscas nas bases MedLine, SciELO, Lilacs, PubMed e Google Acadêmico, por meio dos seguintes descritores em ciências da saúde (DeCS): educação física, atenção primária à saúde, inclusão e promoção da saúde. A palavra-chave atenção básica foi considerada sinônimo do DeCS atenção primária à saúde. Foram identificados 67 artigos com a temática desta revisão; após a aplicação dos critérios de inclusão e exclusão, foram selecionados 10 artigos. Os estudos revelaram deficiência na formação do PEF em relação às temáticas da APS. Ressaltou-se o estímulo a estratégias como o Programa de Educação pelo Trabalho para a Saúde (PET-Saúde), que visam a suprir a carência de disciplinas específicas nos currículos de graduação em Educação Física, colocando o PEF em contato com a promoção da saúde desde esse nível de formação. Constatou-se que a atuação do PEF na APS deve abranger a prevenção de doenças crônico-degenerativas não transmissíveis e as ações de educação em saúde.

\footnotetext{
1. Fisioterapeuta. Aluno de Mestrado em Ciências da Reabilitação na Universidade de Brasília (UnB). Brasília (DF), Brasil. E-mail: jeffcasilva@gmail.com

2. Fisioterapeuta. Aluno de Mestrado em Ciência Biomédicas na Universidade Federal do Piauí (UFPI). Parnaíba (PI), Brasil. E-mail: kamilasantoskss@outlook.com

3. Fisioterapeuta. Residente em Terapia Intensiva no Hospital Universitário da Universidade Federal do Maranhão (HU-UFMA). São Luís (MA), Brasil. E-mail: carlosneto91@hotmail.com

4. Aluna de Graduação em Enfermagem no Centro Universitário Maurício de Nassau (Uninassau). Parnaíba (PI), Brasil. E-mail: cristinny.thalita@gmail.com

5. Educador Físico. Residente em Saúde Renal no HU-UFMA. São Luís (MA), Brasil. E-mail: alexandresoaresef@ gmail.com
} 


\section{ABSTRACT}

This study aimed to analyze the inclusion of the physical education professional (PEP) in primary health care $(P H C)$. This is an integrative literature review, conducted with publications from the period within 2008 and 2018 and searches in the databases MedLine, SciELO, LILACS, PubMed, and Google Academic, by means of the following descriptors in health sciences (DeCS): physical education, primary health care, inclusion, and health promotion. The keyword primary care was considered as a synonym of the DeCS primary health care. Sixty-seven articles were identified as having the theme of this review; after applying the inclusion and exclusion criteria, 10 articles were selected. The studies revealed a deficiency in the education of a PEP in relation to the themes of PHC. Emphasis was given to strategies such as the Program Education through Work for Health (PEW-Health), which aim to overcome the lack of specific subjects in undergraduate curricula in Physical Education, putting the PEP in contact with health promotion from this educational level onwards. It was found that the work of the PEP in PHC should cover the prevention of non-transmissible chronic-degenerative diseases and health education actions.

\section{RESUMEN}

Este estudio tuvo como objetivo analizar la inclusión del profesional de educación física (PEF) en la atención primaria de salud (APS). Se trata de una revisión integradora de la literatura, realizada con publicaciones del período entre 2008 y 2018 y búsquedas en las bases de datos MedLine, SciELO, LILACS, PubMed y Google Académico, mediante los siguientes descriptores en ciencias de la salud (DeCS): educación física, atención primaria de salud, inclusión y promoción de la salud. La palabra clave atención primaria se consideró como un sinónimo del DeCS atención primaria de salud. Se identificaron 67 artículos con el tema de esta revisión; después de aplicar los criterios de inclusión y exclusión, se seleccionaron 10 artículos. Los estudios revelaron una deficiencia en la formación del PEF con relación a los temas de la APS. Se resaltó el estímulo a estrategias como el Programa de Educación a través del Trabajo para la Salud (PET-Salud), que tienen como objetivo superar la falta de asignaturas específicas en los currículos de pregrado en Educación Física, poniendo al PEF en contacto con la promoción de la salud desde este nivel de formación. Se encontró que el trabajo del PEF en la APS debe cubrir la prevención de enfermedades crónico-degenerativas no transmisibles y las acciones de educación en salud.

\section{INTRODUÇÃO}

A reforma sanitária brasileira, de meados da década de 1980, culminou na criação do Sistema Único de Saúde (SUS) - instituído pela Constituição Federal de 1988 (CF/1988) - e levou à adoção de um novo modelo de atenção à saúde ${ }^{1,2}$. 0 paradigma vigente até então, denominado biomédico, já não se mostrava eficiente e envolvia altos custos, além de não atender à população brasileira como um todo ${ }^{3}$.

A CF/1988 dispõe em seu artigo 198, caput e incisos I a IIII:

Art. 198. As ações e serviços públicos de saúde integram uma rede regionalizada e hierarquizada e constituem um sistema único, organizado de acordo com as seguintes diretrizes:

I - descentralização, com direção única em cada esfera de governo;

II - atendimento integral, com prioridade para as atividades preventivas, sem prejuízo dos serviços assistenciais;

III - participação da comunidade ${ }^{4}$.

Assim, no Brasil, a saúde é um direito de todos e um dever do Estado ${ }^{2,4}$ e assume destaque a adoção de um modelo assistencial com vistas à promoção da saúde ${ }^{5}$.

Para sua efetivação, o SUS recorre a medidas ou estratégias, como o Programa de Agentes Comunitários de Saúde (Pacs) e a Estratégia Saúde da Família $(E S F)^{6}$, que buscam substituir o paradigma biomédico e reorganizar a atenção primária à saúde (APS) sobre novas bases, com a família como foco das políticas voltadas à promoção da saúde populacional?

A aprovação da Política Nacional da Atenção Básica (PNAB) pelo Ministério da Saúde (MS) reestruturou a $\mathrm{APS}^{8}$ e caracterizou a ESF como sua base de expansão, qualificação e consolidação, além de eixo estruturante do SUS. A ESF favorece a reorientação do processo de trabalho no sentido de aprofundar os princípios, as diretrizes e os fundamentos da APS 9 .

0 núcleo de apoio à saúde da família (Nasf) foi criado para aumentar a abrangência e a resolutividade da ESF ${ }^{10}$. 0 Nasf aumenta o escopo de ações da APS e a capacidade clínica das equipes de saúde, pois consiste em uma equipe com profissionais de diferentes áreas do conhecimento que atuam em conjunto com profissionais de equipes da ESF, 
compartilhando e apoiando as práticas em saúde nos territórios sob responsabilidade dessas equipes da $\mathrm{ESF}^{11}$.

0 profissional de educação física (PEF) faz parte da equipe do Nasf e atua por meio de práticas corporais e de atividade física sistematizada, seguindo a concepção de saúde coletiva em vez da individual ${ }^{12}$. 0 SUS indica que a prática regular de exercício físico, determinante para a saúde integral, deve ser estimulada e orientada por profissional capacitado ${ }^{13}$.

Sendo fundamental a inserção do PEF na APS com vistas à promoção à saúde e à prevenção e reabilitação de doenças - e por ser a ESF uma área relativamente nova de atuação do PEF, mostra-se importante reconhecer seu processo de trabalho e sua inserção nesse contexto. Diante do exposto, este artigo analisa a inclusão do PEF na APS.

\section{MATODOLOGIA}

Trata-se de uma revisão integrativa de literatura ${ }^{14}$, realizada com buscas nas bases MedLine, SciELO, Lilacs, PubMed e Google Acadêmico, por meio dos seguintes descritores em ciências da saúde (DeCS): educação física, atenção primária à saúde, inclusão e promoção da saúde. A palavra-chave atenção básica foi considerada sinônimo do DeCS atenção primária à saúde. Os termos de busca foram aplicados de modo individual e cruzado. 0s cruzamentos adotados foram: educação física e atenção básica (36 artigos); educação física e inclusão (12 artigos); e educação física e promoção da saúde (19 artigos). 0 período definidos para a inclusão de publicações foi entre 2008 e 2018, pois a inclusão do PEF na APS ocorreu mediante a Portaria GM n. 154, de 24 de janeiro de 2008, que criou os $\mathrm{Nasf}^{10}$.

Os critérios de inclusão adotados foram: a) artigos disponíveis na íntegra nas bases de dados em questão; b) publicações em português no período entre 2008 e 2018; e c) publicações sobre o processo de trabalho do PEF e sua inclusão na APS. Já os critérios de exclusão foram: a) publicações que não versavam sobre o processo de trabalho do PEF e sua inclusão na APS; b) resumos publicados em anais de congresso; e c) publicações duplicadas nas bases de dados em questão.

\section{RESULTADOS}

Foram identificados 67 artigos com a temática desta revisão integrativa de literatura. Após a aplicação dos critérios de inclusão e exclusão, foram selecionados 10 artigos - lidos na íntegra e caracterizados na Tabela 1.

Tabela 1 - Categorização dos artigos selecionados com base na aplicação dos critérios de inclusão e exclusão adotados.

\begin{tabular}{|c|c|c|c|c|}
\hline $\mathbf{N}$ & Autor(es)/ano & Título & Objetivo & $\begin{array}{l}\text { Tipo de } \\
\text { estudo }\end{array}$ \\
\hline 1 & $\begin{array}{l}\text { Anjos, Duarte } \\
\quad(2009)^{15}\end{array}$ & $\begin{array}{l}\text { A educação física e a } \\
\text { Estratégia Saúde da } \\
\text { Família: formação e } \\
\text { atuação profissional }\end{array}$ & $\begin{array}{l}\text { Analisar currículos de cursos de } \\
\text { graduação em Educação Física. }\end{array}$ & Descritivo \\
\hline 2 & $\begin{array}{l}\text { Santos et al. } \\
\qquad(2011)^{16}\end{array}$ & $\begin{array}{l}\text { Educação física e o } \\
\text { PET-Saúde: uma } \\
\text { estratégia } \\
\text { complementar na } \\
\text { formação para o SUS }\end{array}$ & $\begin{array}{l}\text { Salientar a importância do Programa de } \\
\text { Educação pelo Trabalho para a Saúde } \\
\text { (PET-Saúde) como formação } \\
\text { complementar do profissional de } \\
\text { educação física (PEF) para o Sistema } \\
\text { Único de Saúde (SUS). }\end{array}$ & $\begin{array}{l}\text { Qualitativo/ } \\
\text { descritivo }\end{array}$ \\
\hline 3 & $\begin{array}{l}\text { Santos, } \\
\text { Benedetti } \\
(2012)^{17}\end{array}$ & $\begin{array}{l}\text { Cenário de implantação } \\
\text { do núcleo de apoio à } \\
\text { saúde da família e a } \\
\text { inserção do profissional } \\
\text { de educação física }\end{array}$ & $\begin{array}{l}\text { Caracterizar a implantação do núcleo } \\
\text { de apoio à saúde da família (Nasf) e a } \\
\text { inserção do PEF no Brasil, tendo como } \\
\text { referência o mês de janeiro de } 2011 \text {. }\end{array}$ & $\begin{array}{l}\text { Descritivo/ } \\
\text { epidemiológico }\end{array}$ \\
\hline 4 & $\begin{array}{l}\text { Falci, Belisário } \\
\qquad(2013)^{18}\end{array}$ & $\begin{array}{c}\text { A inserção do } \\
\text { profissional de } \\
\text { educação física na } \\
\text { atenção primária à } \\
\text { saúde e os desafios em } \\
\text { sua formação }\end{array}$ & $\begin{array}{c}\text { Analisar a formação do PEF para sua } \\
\text { inserção na atenção primária à saúde } \\
\text { (APS). }\end{array}$ & $\begin{array}{l}\text { Qualitativo/ } \\
\text { exploratório }\end{array}$ \\
\hline
\end{tabular}




\begin{tabular}{|c|c|c|c|c|}
\hline N & Autor(es)/ano & Título & Objetivo & $\begin{array}{l}\text { Tipo de } \\
\text { estudo }\end{array}$ \\
\hline 5 & $\begin{array}{l}\text { Guarda et al. } \\
\qquad(2014)^{19}\end{array}$ & $\begin{array}{l}\text { A atividade física como } \\
\text { ferramenta de apoio às } \\
\text { ações da atenção } \\
\text { primária à saúde }\end{array}$ & $\begin{array}{c}\text { Apresentar as ações de atividades } \\
\text { físicas desenvolvidas pela equipe dos } \\
\text { Nasf em Igarassu (PE). }\end{array}$ & Descritivo \\
\hline 6 & $\begin{array}{l}\text { Lima et al. } \\
(2015)^{20}\end{array}$ & $\begin{array}{l}\text { Representações sociais } \\
\text { sobre o trabalho do } \\
\text { profissional de } \\
\text { educação física na } \\
\text { atenção primária à } \\
\text { saúde pelas equipes de } \\
\text { saúde da família }\end{array}$ & $\begin{array}{c}\text { Analisar as representações sociais } \\
\text { acerca do trabalho do PEF na APS pelos } \\
\text { profissionais das equipes da Estratégia } \\
\text { Saúde da Família (ESF). }\end{array}$ & Qualitativo \\
\hline 7 & $\begin{array}{l}\text { Silva, } \\
\text { Figueiredo } \\
\text { Júnior }(2015)^{21}\end{array}$ & $\begin{array}{l}\text { A atuação da educação } \\
\text { física no âmbito da } \\
\text { saúde pública: uma } \\
\text { revisão sistemática }\end{array}$ & $\begin{array}{c}\text { Mostrar a importância da inserção do } \\
\text { PEF nas ações desenvolvidas no âmbito } \\
\text { da saúde pública. }\end{array}$ & $\begin{array}{l}\text { Revisão } \\
\text { sistemática de } \\
\text { literatura }\end{array}$ \\
\hline 8 & $\begin{array}{l}\text { Carvalho, } \\
(2016)^{22}\end{array}$ & $\begin{array}{l}\text { Práticas corporais e } \\
\text { atividades físicas na } \\
\text { atenção básica do } \\
\text { sistema único de saúde: } \\
\text { ir além da prevenção } \\
\text { das doenças crônicas } \\
\text { não transmissíveis } \\
\text { (DCNT) é necessário }\end{array}$ & $\begin{array}{c}\text { Defender que as práticas corporais e } \\
\text { atividades físicas ofertadas na APS do } \\
\text { SUS não se resumam a atividades de } \\
\text { prevenção das DCNT. }\end{array}$ & $\begin{array}{l}\text { Revisão de } \\
\text { literatura não } \\
\text { sistematizada }\end{array}$ \\
\hline 9 & $\begin{array}{l}\text { Ferreira et al. } \\
\qquad(2016)^{23}\end{array}$ & $\begin{array}{c}\text { A inserção do } \\
\text { profissional de } \\
\text { educação física nos } \\
\text { núcleos de apoio a } \\
\text { saúde da família: visão } \\
\text { dos profissionais }\end{array}$ & $\begin{array}{c}\text { Analisar a percepção do PEF inserido } \\
\text { no Nasf sobre as funções e a } \\
\text { efetividade da intervenção } \\
\text { multiprofissional nas equipes em São } \\
\text { Paulo (SP). }\end{array}$ & $\begin{array}{l}\text { Qualitativo/ } \\
\text { descritivo }\end{array}$ \\
\hline 10 & $\begin{array}{l}\text { Santos et al. } \\
\qquad(2016)^{24}\end{array}$ & $\begin{array}{c}\text { Representações sociais } \\
\text { dos usuários do Sistema } \\
\text { Único de Saúde do } \\
\text { Brasil acerca das } \\
\text { práticas corporais/ } \\
\text { atividades físicas na } \\
\text { atenção primária à } \\
\text { saúde }\end{array}$ & $\begin{array}{c}\text { Conhecer as representações sociais dos } \\
\text { usuários do SUS acerca das práticas } \\
\text { corporais e das atividades físicas } \\
\text { realizadas na APS. }\end{array}$ & $\begin{array}{l}\text { Qualitativo/ } \\
\text { descritivo }\end{array}$ \\
\hline
\end{tabular}

Fonte: Elaborada pelos autores.

A Tabela 2 apresenta a síntese dos estudos selecionados em relação às características de sua amostra, aos seus principais resultados e à sua conclusão.

Tabela 2 - Síntese dos artigos selecionados com base na aplicação dos critérios de inclusão e exclusão adotados.

\begin{tabular}{|c|c|c|c|c|}
\hline N & Autor(es)/ano & Amostra & Principais resultados & Conclusão \\
\hline 1 & $\begin{array}{c}\text { Anjos, Duarte } \\
(2009)^{15}\end{array}$ & $\begin{array}{c}\text { Grade curricular } \\
\text { de } 4 \text { faculdades } \\
\text { de Educação } \\
\text { Física. }\end{array}$ & $\begin{array}{l}\text { 0s cursos apresentam } \\
\text { atividades direcionadas ao } \\
\text { campo da saúde, mas não } \\
\text { de forma específica. }\end{array}$ & $\begin{array}{c}\text { Há carência de informações } \\
\text { sobre os serviços públicos de } \\
\text { saúde e a atuação do } \\
\text { profissional de educação física } \\
\text { (PEF) em sua formação. Sugere- } \\
\text { se que repensem e incluam } \\
\text { formas de capacitação, para que } \\
\text { a Educação Física assuma com } \\
\text { propriedade seu novo campo de } \\
\text { atuação. }\end{array}$ \\
\hline
\end{tabular}




\begin{tabular}{|c|c|c|c|c|}
\hline $\mathbf{N}$ & Autor(es)/ano & Amostra & Principais resultados & Conclusão \\
\hline 2 & $\begin{array}{l}\text { Santos et al. } \\
\qquad(2011)^{16}\end{array}$ & $\begin{array}{c}\text { Diálogos } \\
\text { registrados nos } \\
\text { diários de campo } \\
\text { do Programa de } \\
\text { Educação pelo } \\
\text { Trabalho para a } \\
\text { Saúde (PET- } \\
\text { Saúde). } \\
\text { Acadêmicos, } \\
\text { preceptores, } \\
\text { tutores e } \\
\text { profissionais do } \\
\text { campo de atuação } \\
\text { que registravam } \\
\text { suas atividades } \\
\text { nos diários. }\end{array}$ & $\begin{array}{l}\text { A maioria dos currículos dos } \\
\text { cursos de Educação Física } \\
\text { não trabalha a inserção } \\
\text { desse profissional na } \\
\text { atenção primária à saúde } \\
\text { (APS). O estudante de } \\
\text { Educação Física deve buscar } \\
\text { referências que apoiem essa } \\
\text { prática e inserir-se em } \\
\text { campo de estágio para que } \\
\text { haja maior interação no } \\
\text { processo de serviço na } \\
\text { saúde coletiva. }\end{array}$ & $\begin{array}{c}\text { 0 PET-Saúde realiza a } \\
\text { integração ensino-serviço- } \\
\text { comunidade e capacita o } \\
\text { estudante universitário para a } \\
\text { vivência no âmbito da saúde } \\
\text { coletiva, de modo } \\
\text { interdisciplinar. }\end{array}$ \\
\hline 3 & $\begin{array}{c}\text { Santos, } \\
\text { Benedetti } \\
(2012)^{17}\end{array}$ & $\begin{array}{l}\text { Dados } \\
\text { secundários do } \\
\text { Departamento de } \\
\text { Informática do } \\
\text { Sistema Único de } \\
\text { Saúde (DataSUS), } \\
\text { em específico no } \\
\text { Cadastro Nacional } \\
\text { dos } \\
\text { Estabelecimentos } \\
\text { de Saúde (CNES). }\end{array}$ & $\begin{array}{l}\text { A Educação Física está } \\
\text { entre as } 5 \text { profissões mais } \\
\text { recrutadas para atuação no } \\
\text { núcleo de apoio à saúde da } \\
\text { família (Nasf). } 0 \\
\text { coeficiente de PEF por } \\
\text { população coberta pela } \\
\text { Estratégia Saúde da Família } \\
\text { (ESF) é inferior a } 1 \\
\text { profissional por } 100 \text { mil } \\
\text { habitantes. A estimativa foi } \\
\text { de } 0,25 \text { ou menos } \\
\text { profissionais por } 100 \text { mil } \\
\text { habitantes cobertos pela } \\
\text { ESF. }\end{array}$ & $\begin{array}{l}\text { Nota-se a necessidade de } \\
\text { investimento político e } \\
\text { acadêmico para definição de } \\
\text { estratégias coletivas que } \\
\text { contribuam para a consolidação } \\
\text { do Nasf e a integração do PEF } \\
\text { na rede de assistência pública } \\
\text { de saúde. }\end{array}$ \\
\hline 4 & $\begin{array}{c}\text { Falci, Belisário } \\
(2013)^{18}\end{array}$ & $\begin{array}{l}\text { Dois grupos, de } 7 \\
\text { e } 8 \text { pessoas, } \\
\text { compostos por } \\
\text { PEF que cursam } \\
\text { especialização em } \\
\text { APS, com } \\
\text { experiência na } \\
\text { APS e próximos } \\
\text { de finalizar esse } \\
\text { curso. }\end{array}$ & $\begin{array}{c}\text { A inserção do PEF na APS } \\
\text { foi vista como ampliação do } \\
\text { mercado de trabalho e } \\
\text { deve-se ao crescimento das } \\
\text { doenças crônicas não } \\
\text { transmissíveis (DCNT) e ao } \\
\text { incentivo às políticas } \\
\text { públicas de saúde. } \\
\text { Entretanto, ressaltam-se } \\
\text { déficits na formação para a } \\
\text { inserção do profissional na } \\
\text { APS. }\end{array}$ & $\begin{array}{l}\text { A inserção do PEF na APS reflete } \\
\text { de modo positivo nos serviços e } \\
\text { na comunidade. Deve-se atentar } \\
\text { para a formação, a fim de } \\
\text { promover maior inserção do } \\
\text { estudante universitário nesse } \\
\text { novo âmbito de trabalho. }\end{array}$ \\
\hline 5 & $\begin{array}{l}\text { Guarda et al. } \\
\qquad(2014)^{19}\end{array}$ & $\begin{array}{l}\text { Registro das } \\
\text { ações } \\
\text { desenvolvidas } \\
\text { pelo PEF } \\
\text { integrante do } \\
\text { Nasf. }\end{array}$ & $\begin{array}{c}\text { As atividades são } \\
\text { desenvolvidas por } 2 \\
\text { profissionais. São } \\
\text { executadas aulas de } \\
\text { ginástica, atividades em } \\
\text { grupos, danças de salão e } \\
\text { apoio às atividades de } \\
\text { promoção à saúde } \\
\text { desenvolvidas pelas equipes } \\
\text { da ESF. }\end{array}$ & $\begin{array}{c}0 \text { Nasf atua promovendo } \\
\text { integralidade, participação } \\
\text { social e intersetorialidade. Visa } \\
\text { a desenvolver ações no } \\
\text { território que capacitem os } \\
\text { sujeitos a intervir em aspectos } \\
\text { individuais e coletivos da } \\
\text { saúde. }\end{array}$ \\
\hline
\end{tabular}




\begin{tabular}{|c|c|c|c|c|}
\hline $\mathbf{N}$ & Autor(es)/ano & Amostra & Principais resultados & Conclusão \\
\hline 6 & $\begin{array}{l}\text { Lima et al. } \\
\qquad(2015)^{20}\end{array}$ & $\begin{array}{l}12 \text { profissionais } \\
\text { de saúde que } \\
\text { atuam na ESF e } \\
\text { que contam com } \\
\text { o trabalho do PEF } \\
\text { no Nasf. }\end{array}$ & $\begin{array}{l}0 \text { PEF foi reconhecido como } \\
\text { atuante em grupos } \\
\text { específicos. Alguns } \\
\text { profissionais da saúde } \\
\text { afirmaram desconhecer o } \\
\text { trabalho do PEF. Houve } \\
\text { relação entre atividade } \\
\text { física/prática corporal e } \\
\text { prevenção de doenças e/ou } \\
\text { sedentarismo. }\end{array}$ & $\begin{array}{l}\text { Há boa visibilidade das } \\
\text { atividades desenvolvidas pelo } \\
\text { PEF, mesmo que alguns } \\
\text { profissionais da saúde } \\
\text { desconheçam seu trabalho. } \\
\text { Salienta-se o déficit do curso } \\
\text { de graduação no preparo para } \\
\text { esse campo de trabalho. }\end{array}$ \\
\hline 7 & $\begin{array}{l}\text { Silva, Figueiredo } \\
\text { Júnior }(2015)^{21}\end{array}$ & $\begin{array}{l}8 \text { artigos que } \\
\text { discorrem sobre a } \\
\text { atuação do PEF } \\
\text { no âmbito da } \\
\text { saúde pública. }\end{array}$ & $\begin{array}{l}0 \text { PEF atuante na saúde } \\
\text { pública pode contribuir } \\
\text { substancialmente para } \\
\text { melhorar a qualidade de } \\
\text { vida da população. }\end{array}$ & $\begin{array}{l}\text { A inserção do PEF na APS se } \\
\text { mostrou necessária e seu } \\
\text { trabalho sempre absorve um } \\
\text { caráter multidisciplinar. Há } \\
\text { déficits na formação desse } \\
\text { profissional em relação a esse } \\
\text { campo de atuação. }\end{array}$ \\
\hline 8 & $\begin{array}{l}\text { Carvalho, } \\
(2016)^{22}\end{array}$ & $\begin{array}{l}\text { Informações } \\
\text { coletadas em } \\
\text { periódicos, livros } \\
\text { e documentos } \\
\text { oficiais. }\end{array}$ & $\begin{array}{c}\text { A atividade física } \\
\text { proporciona, além dos } \\
\text { benefícios biológicos } \\
\text { individuais, a inserção em } \\
\text { grupos com objetivos em } \\
\text { comum. }\end{array}$ & $\begin{array}{l}\text { As práticas corporais e as } \\
\text { atividades físicas na APS devem } \\
\text { ampliar e garantir a } \\
\text { integralidade do cuidado e não } \\
\text { só os benefícios } \\
\text { biopsicossociais. }\end{array}$ \\
\hline 9 & $\begin{array}{l}\text { Ferreira et al. } \\
\qquad(2016)^{23}\end{array}$ & $\begin{array}{l}8 \text { PEF com } \\
\text { experiência de } \\
\text { trabalho no Nasf. }\end{array}$ & $\begin{array}{l}\text { Os profissionais tinham } \\
\text { conhecimento sobre o } \\
\text { processo de trabalho no } \\
\text { Nasf e afirmaram que o PEF } \\
\text { é responsável pela } \\
\text { realização de atividades } \\
\text { física em grupo, avaliação } \\
\text { física, orientação de } \\
\text { hábitos saudáveis, auxílio } \\
\text { na saúde mental etc. }\end{array}$ & $\begin{array}{l}\text { Os PEF detêm conhecimento } \\
\text { sobre seu papel de atuação no } \\
\text { Nasf, porém, com limitações que } \\
\text { não devem ser ignoradas. }\end{array}$ \\
\hline 10 & $\begin{array}{l}\text { Santos et al. } \\
\qquad(2016)^{24}\end{array}$ & $\begin{array}{l}5 \text { praticantes e } 5 \\
\text { não praticantes } \\
\text { de atividade } \\
\text { física. }\end{array}$ & $\begin{array}{c}\text { 0s individuos que } \\
\text { praticavam atividade física } \\
\text { buscavam melhorar suas } \\
\text { condições de saúde. 0s não } \\
\text { praticantes alegaram } \\
\text { desconhecimento das } \\
\text { atividades promovidas pelo } \\
\text { Nasf. }\end{array}$ & $\begin{array}{l}\text { A comunidade, ao participar da } \\
\text { construção de meios para } \\
\text { melhoria da saúde, apropria-se } \\
\text { do empoderamento. O PEF } \\
\text { apresenta formação voltada ao } \\
\text { Sistema Único de Saúde (SUS) } \\
\text { por meio da residência } \\
\text { multiprofissional. }\end{array}$ \\
\hline
\end{tabular}

Fonte: Elaborada pelos autores.

\section{DISCUSSÃO}

A inclusão do PEF na APS visa a coordenar, planejar e realizar treinamentos especializados, com ênfase nas práticas corporais e nas atividades físicas sistematizadas. 0 PEF tem um trabalho voltado à promoção da saúde, prevenindo e tratando, de modo não farmacológico, as doenças crônicas não transmissíveis $(D C N T)^{15}$. A atuação do PEF no Nasf visa a oferecer suporte especializado para que a população realize atividade física sistematizada sob supervisão de profissional capacitado ${ }^{16}$.
Um estudo ${ }^{15}$, ao analisar o currículo dos cursos de graduação em Educação Física, observou que nenhuma das instituições em questão apresentava direcionamento dos cursos à APS. Quando comparados os cursos de bacharelado aos de licenciatura, observase nos primeiros melhor preparo para trabalhar na APS, por possuírem maior número de disciplinas relacionadas ao tema. Esse fato evidencia carência desde o processo de formação do PEF, que não é voltado à atuação na APS.

0 Programa de Educação pelo Trabalho para a Saúde (PET-Saúde) foi criado para suprir tais carências 
dos cursos de graduação no setor saúde, visando a fomentar a formação, em nível de graduação, voltada à ESF por meio de educação tutorial ${ }^{17}$. Uma pesquisa ${ }^{16}$ procurou analisar a importância do PET-Saúde como parte complementar da formação do PEF para sua inclusão no SUS e na APS. Os autores concluíram que as experiências vivenciadas no PET-Saúde serviram de base para a atuação na APS e muniram o PEF de conhecimentos adequados acerca do SUS.

A criação do Nasf ${ }^{10}$ efetivou o PEF como profissional atuante na APS. Uma pesquisa ${ }^{17}$ realizada com dados secundários do SUS e do cadastro das equipes do Nasf caracterizou a implantação deste e a inserção do PEF nele e observou-se que tal implantação não havia ocorrido na maioria dos municípios brasileiros na época do estudo. A região Sudeste apresentou o maior número de equipes, ao passo que a região Norte apresentou o menor número de equipes. Ao analisar a inserção do PEF na APS, os autores observaram que ele foi o quinto profissional mais recrutado para os Nasf. Quanto à inserção do PEF no Nasf, verificou-se que $49,2 \%$ das equipes possuíam profissional em seu quadro, porém, os valores diferenciam entre os vários estados do país, apresentando proporções desiguais.

Pesquisadores selecionaram alunos de um curso de especialização em APS em Minas Gerais e avaliaram o processo de formação do PEF e sua inserção na APS. Concluiu-se que a inserção do PEF no Nasf proporcionou maior interdisciplinaridade na promoção à saúde, qualificando esse profissional da saúde, ao aumentar o escopo de suas ações e seu mercado de trabalho. Dentre as dificuldades identificadas, a formação do PEF foi considerada insuficiente para sua atuação na APS - pois ainda é focada em treinamento esportivo ${ }^{18}$.

A inserção do PEF no SUS é pouco explorada diante da significativa contribuição que pode proporcionar atuando na prevenção e no controle das DCNT, com base na prática regular de exercício físico planejando e na execução de atividades voltadas à promoção à saúde, com vistas ao caráter educativo. 0 PEF também pode orientar a construção de ciclovias e pistas de caminhada ${ }^{18}$. A prática regular de exercício físico em grupos especiais ${ }^{19}$, como os idosos, os hipertensos, os diabéticos, as gestantes e os portadores de transtornos mentais, entre outros, é um meio de intercâmbio de saberes com outras áreas da saúde, incorporando o PEF ao caráter interdisciplinar que a ESF propõe $\mathrm{e}^{19}$.

Alguns estudos apontaram que membros da equipe multidisciplinar não apresentam conhecimento

\section{...a formação dos grupos de atividade física promovem 0 fortalecimento das relações sociais...}

adequado sobre o trabalho do PEF na APS ${ }^{18,19}$. Uma pesquisa realizada em Limoeiro do Norte (CE ${ }^{20}$ analisou as representações sociais acerca do trabalho do PEF na APS por parte dos profissionais que compõem as equipes da ESF do município. 0s profissionais da ESF declararam que a atuação do PEF se mostra importante no que tange aos grupos de idosos e gestantes, no desenvolvimento de atividades físicas e práticas corporais. Constatou-se reconhecimento em relação ao trabalho interprofissional, por meio de atividades realizadas em conjunto com outros membros da equipe de saúde. Algumas dificuldades foram enumeradas, como a não valorização da categoria nas políticas públicas, o desconhecimento do trabalho do PEF por parte de alguns membros da equipe de saúde e a não capacitação, enquanto aluno de graduação, para desenvolver atividades na APS e inserir-se no Nasf.

Uma revisão sistemática de literatura ${ }^{21}$ destacou que o PEF não atua somente na promoção da prática de atividade física sistematizada, mas também na elaboração de projetos voltados ao caráter educativo da população. Outro ponto recorrente nessa revisão foi a interdisciplinaridade, visto que, inserido em uma equipe, participa conjuntamente na tomada de decisões para a prevenção, o tratamento e a reabilitação de usuários da ESF. 0 entendimento de que o exercício físico promove melhora da qualidade de vida - não somente visando à perda de peso, mas também à redução dos riscos de desenvolver DCNT e à prevenção do quadro de osteoporose, bem como dos efeitos adversos do processo natural de envelhecimento ${ }^{15-17}$ - levou a maior adoção da prática regular de exercício físico e maior visibilidade do PEF.

Uma pesquisa ${ }^{22}$ indicou que a atividade física estruturada ofertada no âmbito da APS não é exclusivamente voltada à prevenção de DCNT, mas também para alcançar objetivos socioafetivos, biológicos e cognitivos. A convivência e a formação dos grupos de atividade física promovem 0 fortalecimento das relações sociais, a prática de 
atividade física faz parte de um contexto maior, onde seu objetivo é a garantia da integralidade do cuidado, trazendo não só benefícios biológicos, mas também aumento do círculo social de convivência ${ }^{23}$.

Um estudo de abordagem qualitativa observou certo distanciamento do PEF em relação aos outros profissionais do Nasf e a principal função atribuída ao PEF foi a promoção da saúde, porém, destacou-se em alguns discursos o trabalho com a gestão, as políticas de saúde e o diagnóstico, entre outros aspectos ${ }^{23}$. Outro estudo qualitativo, realizado no norte do Paraná, constatou que houve resistência inicial por parte de alguns profissionais da ESF quanto à inclusão do PEF na APS. Os autores concluíram que a inserção do PEF na APS carece de maior preparo nos cursos de graduação, pois ainda é bastante voltada à prática esportiva generalista ${ }^{24-31}$.

Um estudo realizado em João Pessoa $(P B)^{32}$ identificou que todos os PEF possuíam diploma de Licenciatura Plena em Educação Física, visto que sua formação precedia a divisão dos cursos em bacharelado e licenciatura, e a maioria estava inserida em atividades de educação permanente. Um trabalho ${ }^{20}$ desenvolvido em Sobral (CE) analisou a visão do usuário acerca da inserção do PEF na APS; os usuários expressaram em seus discursos que o PEF contribui para a manutenção da saúde, porém, destacou-se a deficiência da divulgação das atividades promovidas pelo Nasf.

\section{CONCLUSÃO}

Este artigo evidenciou a importância do PEF na APS por meio dos Nasf e sua atuação não deve resumir-se à prevenção das DCNT; também se deve buscar a promoção da saúde por meio de palestras educativas.

0 PEF atua com maior destaque em grupos específicos, como os idosos ou as gestantes, mas não deve restringir-se a tais grupos. Destacou-se carência na formação do PEF quanto ao seu direcionamento para a atuação na APS; para superar esse desafio foram criadas medidas como o PET-Saúde e a residência multiprofissional em saúde.

Em suma, pode-se dizer que a atuação do PEF é considerada importante e complementar tanto por outros membros da equipe como pelos usuários.

\section{CONTRIBUIÇÃO DOS AUTORES}

Jefferson Carlos Araujo Silva contribuiu com o delineamento e a realização da pesquisa e a estruturação e redação do manuscrito. Kamila Santos da Silva, Carlos Martins Neto e Thalita Cristinny Araujo Silva contribuíram com a redação do manuscrito. Alexandre Soares de Campos contribuiu com a revisão crítica do manuscrito.

\section{REFERÊNCIAS}

1. Brasil. Histórico: do sanitarismo à municipalização. Brasília (DF): Ministério da Saúde; 2013.

2. Santos NR. Desenvolvimento do SUS, rumos estratégicos e estratégias para visualização dos rumos. Ciênc Saúde Colet [serial on the internet]. 2007 [cited 2018 May 7];12(2):42935. Available from: http://www.scielo.br/pdf/csc/v12n2/ a19v12n2.pdf

3. Oliveira DC, Sá CP, Gomes AMT, Ramos RS, Pereira NA, Santos WCR. A política pública de saúde brasileira: representação e memória social dos profissionais. Cad Saúde Pública. 2008;24(1):197-206.

4. Brasil. Constituição 1988. Constituição da República Federativa do Brasil. Brasília (DF): Senado; 1988.

5. Paim JS, Teixeira CF. Configuração institucional e gestão do Sistema Único de Saúde: problemas e desafios. Ciênc Saúde Colet [serial on the internet]. 2007 [cited 2018 May 7];12(Suppl):1819-29. Available from: http://www.scielo. $\mathrm{br} / \mathrm{pdf} / \mathrm{csc} / \mathrm{v} 12 \mathrm{~s} 0 / 05 . \mathrm{pdf}$

6. Brasil. Portal da Saúde [homepage on the internet]. 2017 [cited 2018 May 7]. Available from: http://u.saude.gov.br/ index.php/cidadao/acoes-e-programas

7. Ronzani TM, Silva CM. O Programa Saúde da Família segundo profissionais de saúde, gestores e usuários. Ciênc Saúde Colet [serial on the internet]. 2008 [cited 2018 May 7];13(1): 23-34. Available from: http://www.scielo.br/pdf/ csc/v13n1/06.pdf

8. Brasil. Política Nacional de Atenção Básica. Brasília (DF): Ministério da Saúde; 2012.

9. Piovesan LR, Schimith MD, Simon BS, Budó MLD, Weiller TH, Brêtas ACP. Promoção da saúde na perspectiva de enfermeiros de atenção básica. Rev Enferm UERJ [serial on the internet]. 2016 [cited 2018 May 7];24(3):e5816. Available from: http://www.e-publicacoes.uerj.br/index. php/enfermagemuerj/article/view/5816/19396

10. Brasil. Portaria GM n. 154, de 24 de janeiro de 2008. Cria Núcleos de Apoio à Saúde da Família - NASF. Diário Oficial da União [serial on the internet], Brasília (2008 Jan 25 [cited 2018 May 7]); Sec 1. Available from: http://189.28.128.100/dab/docs/legislacao/ portaria154_24_01_08.pdf 
11. Ribeiro MDA, Bezerra EMA, Costa MS, Branco CEC, Araújo Neto JD, Moreira AKF, et al. Avaliação da atuação do núcleo de apoio à saúde da família. Rev Bras Promoç Saúde [serial on the internet]. 2014 [cited 2018 May 7];27(2):224-31. Available from: http://periodicos.unifor.br/RBPS/article/ view/2426/pdf

12. Brasil. Núcleo de Apoio à Saúde da Família. Brasília (DF): Ministério da Saúde; 2014.

13. Fraga AB, Carvalho YM, Gomes IM. Políticas de formação em educação física e saúde coletiva. Trab Educ Saúde [serial on the internet]. 2012 [cited 2018 May 7];10(3):367-86. Available from: http://www.scielo.br/pdf/tes/v10n3/ a02v10n3.pdf

14. Botelho LLR, Cunha CCA, Macedo M. 0 método da revisão integrativa nos estudos organizacionais. Gestão e Sociedade [serial on the internet]. 2011 [cited 2018 May 7];5(11):12136. Available from: https://www.gestaoesociedade.org/ gestaoesociedade/article/view/1220/906

15. Anjos TC, Duarte ACGO. A educação física e a Estratégia Saúde da Família: formação e atuação profissional. Physis (Rio J). 2009;19(4):1127-44.

16. Santos ALB, Maia Neto JP, Souza Neto FCV, Oliveira BN, Rui EM, Sá MEG. Educação física e o PET-Saúde: uma estratégia complementar na formação para o SUS. Sanare (Sobral, Online) [serial on the internet]. 2011 [cited 2018 May 7];10(2):75-8. Available from: https://sanare. emnuvens.com.br/sanare/article/view/259/232

17. Santos SFS, Benedetti TRB. Cenário de implantação do núcleo de apoio à saúde da família e a inserção do profissional de educação física. Rev Bras Ativ Fís Saúde. 2012;17(3):188-94.

18. Falci DM, Belisário SA. A inserção do profissional de educação física na atenção primária à saúde e os desafios em sua formação. Interface Comun Saúde Educ [serial on the internet]. 2013 [cited 2018 May 7];17(47):885-99. Available from: http://www.scielo.br/pdf/icse/v17n47/aop3913.pdf

19. Guarda FRB, Silva RN, Silva SM, Santana PR. A atividade física como ferramenta de apoio às ações da atenção primária à saúde. Rev Bras Ativ Fís Saúde [serial on the internet]. 2014 [cited 2018 May 7];19(2):265-270. Available from: http://rbafs.emnuvens.com.br/RBAFS/article/ view/2756/pdf168

20. Lima LJR, Oliveira BN, Oliveira BN. Representações sociais sobre o trabalho do profissional de educação física na atenção primária à saúde pelas equipes de saúde da família. Educação Física em Revista [serial on the internet]. 2015 [cited 2018 May 7];9(2):12-22. Available from: https://portalrevistas.ucb.br/index.php/efr/article/ view/6575/4724

21. Silva JM, Figueiredo Júnior JM. A atuação da educação física no âmbito da saúde pública: uma revisão sistemática. Revista Brasileira de Educação e Saúde [serial on the internet]. 2015 [cited 2018 May 7];5(1):75-86. Available from: http://www.gvaa.com.br/revista/index.php/REBES/ article/view/3208/2703

22. Carvalho FFB. Práticas corporais e atividades físicas na atenção básica do Sistema Único de Saúde: ir além da prevenção das doenças crônicas não transmissiveis é necessário. Movimento (Porto Alegre) [serial on the internet]. 2016 [cited 2018 May 7];22(2):647-58. Available from: $\quad$ http://www.seer.ufrgs.br/index.php/Movimento/ article/view/58174/37391

23. Ferreira TB, Cipolotti MD, Marques BG, Miranda MLJ. A inserção do profissional de educação física nos núcleos de apoio a saúde da família: visão dos profissionais. Rev Bras Ativ Fís Saúde [serial on the internet]. 2016 [cited 2018 May 7];21(3):228-36. Available from: http://rbafs. emnuvens.com.br/RBAFS/article/view/5703/6025

24. Santos ALB, Aguiar JB, Gurgel LA, Silveira MAA, Catunda KC, Souza Neto FCV. Representações sociais dos usuários do Sistema Único de Saúde do Brasil acerca das práticas corporais/atividades físicas na atenção primária à saúde. $V$ Congresso Ibero-Americano em Investigação Qualitativa. Atas [document on the internet]. Porto: [s.n]; 2016 [cited 2018 May 7]. Available from: http://proceedings.ciaiq.org/ index.php/ciaiq2016/article/view/901/885

25. Corrêa LQ, Valério MP, Teixeira A0, Guerreiro LF, Silveira DF, Machado PT, et al. A atuação da educação física nas residências multiprofissionais em saúde. Rev Bras Promoç Saúde [serial on the internet]. 2014 [cited 2018 May 7];27(3):428-33. Available from: http://periodicos.unifor. br/RBPS/article/view/2863/pdf

26. Lopes ACS, Ferreira AD, Mendonça RD, Dias MAS, Rodrigues RCLC, Santos LC. Estratégia de promoção à saúde: programa academia da cidade de Belo Horizonte. Rev Bras Ativ Fís Saúde [serial on the internet]. 2016 [cited 2018 May 7];21(4):379-84. Available from: http://rbafs. emnuvens.com.br/RBAFS/article/view/7582/pdf

27. Souza FL, Silva MMS, Dias MSA, Vasconcelos MI0, Aguiar $C P$, Evangelista $A R$, et al. Formação dos monitores do PRÓPET-SAÚDE a partir das necessidades de aprendizagem vivenciadas no PSE. Tempus (Brasília) [serial on the internet]. 2015 [cited 2018 May 7];9(1):79-89. Available from: http://www.tempusactas.unb.br/index.php/tempus/ article/view/1693/1400

28. Guarda FB, Silva RN, Araújo Júnior JL, Santana PR, Santos Neto PM. Incorporação e contribuições dos profissionais de educação física ao Sistema Único de Saúde do Brasil. Tempus (Brasília) [serial on the internet]. 2014 [cited 2018 May 7];8(3):185-96. Available from: http:// tempusactas.unb.br/index.php/tempus/article/view/1573

29. Vieira ELS. Investigando a atuação dos profissionais de educação física das equipes do núcleo de apoio à saúde da família do município de Natal-RN. Natal: Universidade Federal do Rio Grande do Norte; 2016. 
30. Oliveira FA, Pirajá WC, Silva AP, Primo CPF. Benefícios da prática de atividade física sistematizada no lazer de idosos: algumas considerações. Licere [serial on the internet]. 2015 [cited 2018 May 7];18(2):262-304. Available from: $\quad$ https://seer.ufmg.br/index.php/licere/article/ view/1052/761

31. Souza SC, Loch MR. Intervenção do profissional de educação física nos núcleos de apoio à saúde da família em municípios do norte do Paraná. Rev Bras Ativ Fís Saúde [serial on the internet]. 2011 [cited 2018 May 7];16(1):510. Available from: http://rbafs.emnuvens.com.br/RBAFS/ article/view/549/547

32. Rodrigues JD, Ferreira DKS, Junior JCF, Caminha I0, Florindo AA, Loch MR. Perfil e atuação do profissional de educação física nos núcleos de apoio à saúde da família na região metropolitana de João Pessoa-PB. Rev Bras Ativ Fís Saúde [serial on the internet]. 2015 [cited 2018 May 7];20(4):352-65. Available from: http://rbafs.emnuvens. com.br/RBAFS/article/view/5098/4970

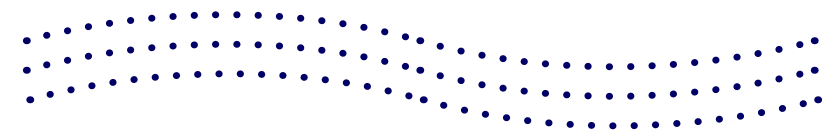

$\ldots \ldots \ldots \cdots \cdots$

$\ldots \ldots \ldots \ldots \ldots \ldots \ldots \ldots \ldots$ $\ldots \ldots \ldots \ldots \ldots \ldots \ldots$

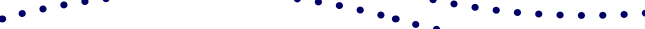
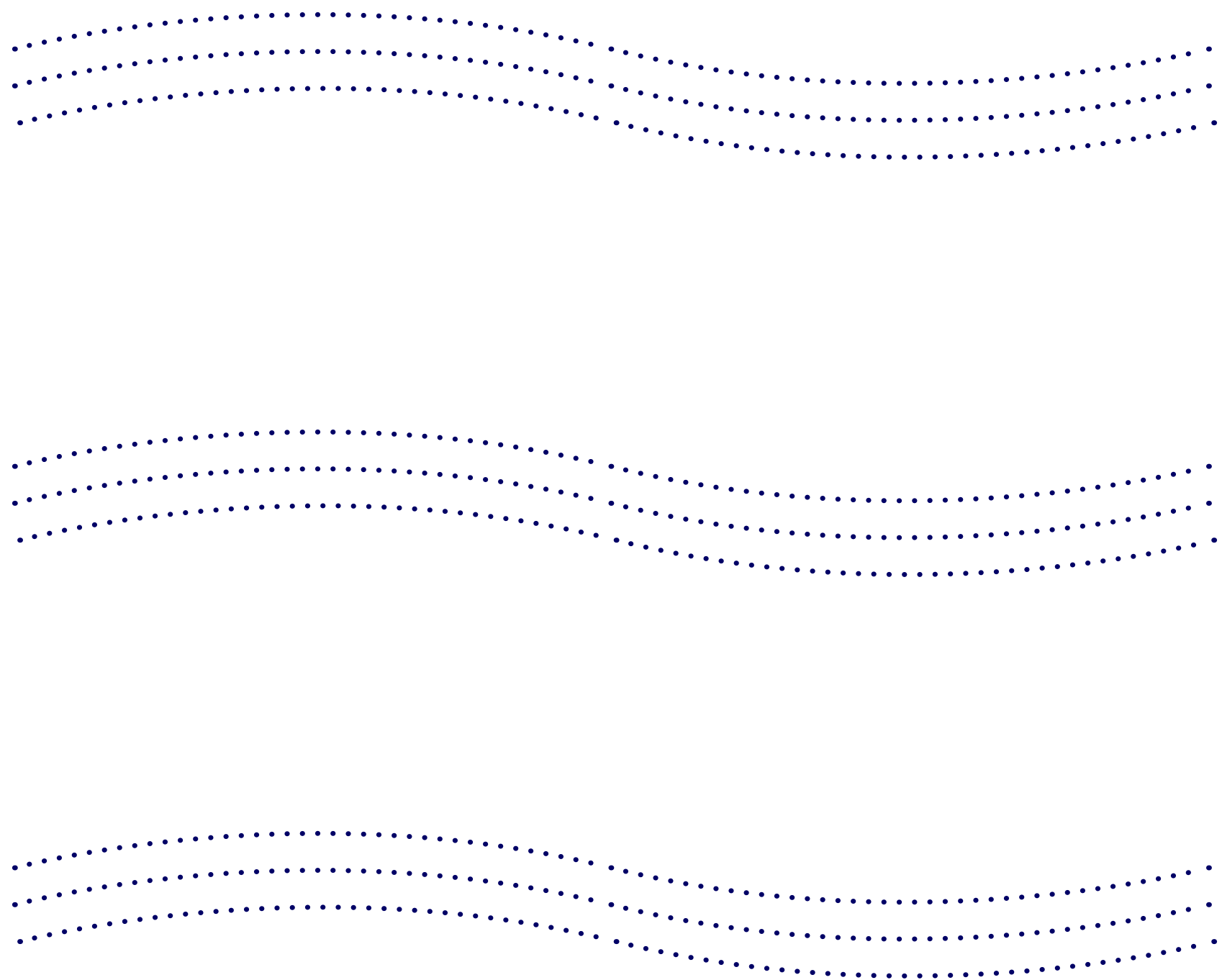


\title{
PRODUÇÃO DO CUIDADO NA REDE DE ATENÇÃO AO CÂNCER DE MAMA: REVISÃO INTEGRATIVA
}

\author{
PRODUCTION OF CARE IN THE BREAST CANCER CARE NETWORK:
} INTEGRATIVE REVIEW

PRODUCCIÓN DEL CUIDAdO EN LA RED DE ATENCIÓN AL CÁNCER DE MAMA: REVISIÓN INTEGRADORA

Francisca Alanny Rocha Aguiar 1

Thaianny Cordeiro de Sousa ${ }^{2}$

July Grassiely de Oliveira Branco 3

Francisca Bertilia Chaves Costa ${ }^{4}$

Amelia Romana Almeida Torres ${ }^{5}$

Lidyane Parente Arruda 6

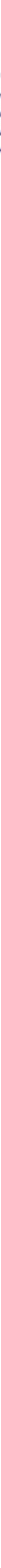

84 - SANARE, Sobral - v.17, n.01,p.84-92, Jan./Jun. - 2018 


\section{ABSTRACT}

Breast cancer has been chosen as a directive condition for this study because it is one of the most prevalent health issues in Brazil. From this perspective, interprofessional collaboration is a measure to be considered in order to ensure good-quality care. The aim was analyzing how production of care occurs in the breast cancer care network. This is an integrative review with search conducted in October 2016, on the Virtual Health Library (VHL), using the databases SCIELO, LILACS, and Coleciona SUS. The descriptors 'breast neoplasms,' 'cooperative behavior,' 'health services,' and 'Unified Health System' were cross-referenced. In view of the findings, the user's itinerary in the health system was identified, since her first appointment in the Primary Health Care (PHC) until the diagnosis was established. The difficulties of this system for effecting this line of care in the health service showed that lengthy waiting times can have serious consequences. It is worth emphasizing the importance of creating devices that increase interprofessional collaboration and the line of care in the breast cancer care network, enabling the provision of comprehensive and problem-solving actions.

\section{RESUMEN}

El cáncer de mama ha sido elegido como una condición directiva para este estudio porque es uno de los problemas de salud más prevalentes en Brasil. Desde esta perspectiva, la colaboración interprofesional es una medida a considerar para garantizar una atención de buena calidad. Se objetivó analizar cómo ocurre la producción del cuidado en la red de atención al cáncer de mama. Esta es una revisión integradora con búsqueda realizada en octubre de 2016, en la Biblioteca Virtual en Salud (BVS), utilizando las bases de datos SciELO, LILACS y Coleciona SUS. Se han cruzado los descriptores "neoplasias de la mama", "conducta cooperativa", "servicios de salud" y "Sistema Único de Salud". En vista de los hallazgos, se identificó el itinerario de la usuaria en el sistema de salud, desde su primera consulta en la Atención Primaria de Salud (APS) hasta que se establezca el diagnóstico. Las dificultades de este sistema para llevar a cabo esta linea de cuidado en el servicio de salud mostraron que los largos tiempos de espera pueden tener graves consecuencias. Vale la pena enfatizar la importancia de crear dispositivos que aumenten la colaboración interprofesional y la línea de cuidado en la red de atención al cáncer de mama, permitiendo la provisión de acciones integrales y resolutorias.

\section{INTRODUÇÃO}

A relação do homem ou das populações com sua história, seus padrões de desenvolvimento, suas interações com o mundo e com o ambiente sociocultural, suas necessidades, direitos e condições de vida reflete uma transição demográfica acelerada que acumula doenças infecciosas e parasitárias, problemas de saúde materno-infantis, causas externas e condições crônicas. Essa situação requer respostas sociais deliberadas às demandas de saúde da população $0^{1,2}$.

Observa-se a necessidade de cuidado longitudinal a ser prestado nas Redes de Atenção à Saúde (RAS), as quais atuam na prestação de serviços com diferentes densidades tecnológicas ao longo do sistema de saúde. Para garantir o cuidado integral, cada nível de atenção assume um papel específico com vistas à resolução dos problemas de saúde da população ${ }^{3}$.

Nesse contexto, manifestam-se especificidades nos campos de trabalho no setor saúde, revelando a urgência de uma interlocução entre os atores envolvidos nesses espaços de atenção que sejam capazes de desenvolver uma lógica de atendimento que se adapte à nova realidade. Essa lógica renovada cede à hegemonia da atenção aos eventos agudos para adoção de uma abordagem contínua que integre as dimensões biopsicossociais.

Destarte, o uso de práticas colaborativas pode assumir um papel importante no enfrentamento de muitos desafios do sistema de saúde; um deles seria a inclusão da rede de atenção à pessoa com condição crônica nas ações de prevenção e controle do câncer ${ }^{4,5}$. No Brasil, tem-se visto a ascensão das Doenças Crônicas Não Transmissíveis (DCNT), consideradas sério problema de saúde pública, que demandam ações de maior abrangência do sistema de saúde, além de maior promoção da saúde e prevenção de doenças, com vistas a qualificar a atenção às pessoas com doenças crônicas ${ }^{5}$.

Dentre as DCNT se destaca o câncer, definido como um conjunto de mais de 100 doenças que tem em comum o crescimento descontrolado de células anormais e sua disseminação, resultando em alterações morfológicas distintas e em anomalias nos padrões histológicos, podendo espalhar-se por diversas regiões do corpo $0^{6,7}$. 
Em 2011 se verificou aumento da incidência do câncer de mama na população brasileira, que ocupa o segundo lugar em número de mulheres afetadas no mundo, correspondendo a $25 \%$ de todos os casos de câncer diagnosticados em 2012 e apresentando a estimativa de 1,67 milhão de casos novos nesse ano. Tal agravo, dentre os cânceres, estabeleceu-se como o mais comum em mulheres, classificado como a quinta causa de morte mais frequente por câncer (522 mil óbitos) ${ }^{8}$.

No Brasil, de acordo com as estimativas para 2016/2017, esperava-se um registro próximo a 596 mil casos de câncer. Entre os homens são esperados 295.200 casos e entre as mulheres, 300.800 casos. 0 número de casos novos de câncer de mama estimado para 2016 foi de 57.960, excluindo os tumores de pele não melanoma. Trata-se do tipo mais incidente em mulheres de todas as regiões, exceto no Norte, onde o câncer do colo do útero ocupa a primeira posição $0^{9}$.

Existem diversas causas para o desenvolvimento do câncer de mama, internas ou externas ao organismo, que estão inter-relacionadas. As causas externas se relacionam ao meio ambiente e aos hábitos ou costumes próprios de um ambiente social e cultural. As causas internas são, na maioria das vezes, geneticamente determinadas e estão ligadas à capacidade do organismo se defender das agressões externas ${ }^{10}$.

Entretanto, considerando a gravidade desse tipo de câncer, o profissional da saúde tem assumido um papel cada vez mais decisivo e proativo diante das necessidades de cuidados básicos das mulheres em suas diferentes dimensões, ou seja, a implementação de estratégias eficazes que incentivem métodos preventivos e a conscientização da população para a adoção de práticas voltadas ao diagnóstico precoce, aumentando as chances de tratamento bemsucedido ${ }^{11}$.

Diante dessas considerações, o que se têm observado é que se um sistema de saúde funciona com base em uma lógica de rede, seus processos dependem especialmente de relações estabelecidas em parceria ${ }^{12}$. Assim, objetivou-se analisar na literatura científica como ocorre a produção do cuidado na rede de atenção ao câncer de mama.

\section{METODOLOGIA}

Trata-se de revisão integrativa, realizada por meio das seguintes etapas: a) identificação do tema; b) elaboração da questão norteadora; c) estabelecimento dos critérios de inclusão e exclusão de estudos; d) identificação dos estudos pré-selecionados e selecionados; e) categorização dos estudos selecionados; f) análise e interpretação dos resultados; e g) apresentação da síntese da revisão $0^{13}$.

Para consolidar os objetivos propostos, elaborouse a seguinte questão norteadora:

- Como se dá a produção do cuidado na rede de atenção ao câncer de mama?

Busca-se, a partir de busca na literatura, desvelar o trabalho em equipe $e$ as interfaces para 0 acompanhamento em rede de atenção para pacientes com câncer de mama.

0 cruzamento dos descritores ocorreu na Biblioteca Virtual em Saúde (BVS), utilizando as bases de dados SciELO, Lilacs e Coleciona SUS. As buscas foram realizadas em outubro de 2016 e tiveram a finalidade de identificar estudos publicados no período de 2012 a 2016.

Para a busca dos artigos foram adotados os seguintes descritores em ciências da saúde (DeCS): "neoplasias de mama", "comportamento cooperativo", "serviços de saúde" e "Sistema Único de Saúde" mediados pelo operador booleano "AND".

Os critérios de inclusão adotados foram: a) artigos de livre acesso; b) publicações em português; e c) artigos que apresentavam referências a cuidado em saúde, estratégias e/ou manejo de pacientes com câncer de mama, acesso/barreiras de acesso a serviços e conduta profissional (inclusive colaboração interprofissional e trabalho em equipe).

Já os critérios de exclusão foram: a) artigos com duplicidade de inclusão nas bases de dados; e b) artigos sem elementos relevantes quanto ao escopo da pesquisa.

Após leitura integral de cada artigo identificado, constatou-se que 9 publicações científicas deveriam ser selecionadas como fontes de dados para esta pesquisa (Figura 1).

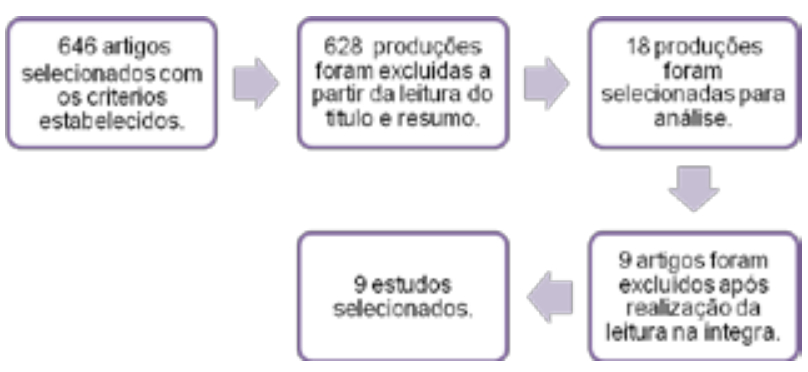

Figura 1. Seleção de artigos nas bases da Biblioteca Virtual em Saúde.

Fonte: Elaborada pelas autoras. 
Os dados foram obtidos mediante aplicação de um instrumento de coleta adaptado ${ }^{13}$ para análise de 4 variáveis: a) título do artigo; b) tipo de estudo; e c) base de dados. Tal análise gerou 2 categorias: a) Linha de cuidado ao câncer de mama na rede de atenção à saúde; e b) Desafios e potencialidades para a efetivação da linha de cuidado na atenção ao câncer de mama.

\section{RESULTADOS E DISCUSSÃO}

0 Quadro 1 caracteriza os artigos selecionados com base nas variáveis de análise.

Quadro 1 - Caracterização dos artigos selecionados.

\begin{tabular}{|c|c|c|}
\hline Título & Tipo de estudo & Base de dados \\
\hline $\begin{array}{l}\text { Assistência em mastologia em uma unidade de referência do } \\
\text { Sistema Único de Saúde no Ceará, Brasil }{ }^{14}\end{array}$ & $\begin{array}{l}\text { Estudo transversal e } \\
\text { quantitativo }\end{array}$ & Coleciona SUS \\
\hline $\begin{array}{l}\text { Atraso no diagnóstico e tratamento do câncer de mama e } \\
\text { estratégias para sua redução }{ }^{15}\end{array}$ & Revisão bibliográfica & Lilacs \\
\hline $\begin{array}{l}\text { Barreiras no rastreamento do câncer de mama e o papel da } \\
\text { enfermagem: revisão integrativa }{ }^{16}\end{array}$ & Revisão bibliográfica & SCIELO \\
\hline $\begin{array}{l}0 \text { retrato das políticas públicas no tratamento do câncer de } \\
\text { mama no Brasil }{ }^{17}\end{array}$ & Revisão bibliográfica & Lilacs \\
\hline $\begin{array}{l}\text { Conduta de profissionais durante a consulta de rastreio do } \\
\text { câncer de mama e útero }{ }^{18}\end{array}$ & Estudo descritivo & Lilacs \\
\hline $\begin{array}{l}\text { Acesso à detecção precoce do câncer de mama no Sistema } \\
\text { Único de Saúde: uma análise a partir dos dados do Sistema de } \\
\text { Informação em Saúde }{ }^{19}\end{array}$ & Estudo descritivo & SCIELO \\
\hline $\begin{array}{l}\text { Aspectos relacionados ao atraso no diagnóstico e tratamento } \\
\text { do câncer de mama em uma unidade hospitalar de Pernambuco }{ }^{20}\end{array}$ & $\begin{array}{l}\text { Estudo epidemiológico } \\
\text { observacional }\end{array}$ & Coleciona SUS \\
\hline $\begin{array}{l}\text { Os caminhos de cuidado das mulheres com diagnóstico de } \\
\text { câncer de mama }{ }^{21}\end{array}$ & Estudo descritivo & SCIELO \\
\hline $\begin{array}{l}\text { Demora no diagnóstico de câncer de mama de mulheres } \\
\text { atendidas no sistema público de saúde }{ }^{22}\end{array}$ & Estudo descritivo & SCIELO \\
\hline
\end{tabular}

Fonte: Elaborado pelas autoras.

Em relação à abordagem metodológica, prevalecem os estudos transversais descritivos (4), seguidos pelas revisões bibliográficas (3) e pelos estudos epidemiológicos observacionais (1) e transversais quantitativos (1). Com base na análise das publicações, a discussão englobou as categorias descritas a seguir.

\section{Linha de cuidado ao câncer de mama na rede de atenção à saúde}

0 aumento da incidência de câncer de mama no Brasil tem sido acompanhado pelo aumento da mortalidade - o que pode ser atribuído ao diagnóstico da doença em estágios avançados, sugerindo a dificuldade de acesso aos serviços de saúde ${ }^{22}$.

A detecção precoce abrange duas estratégias: a) o diagnóstico precoce; e b) o rastreamento. 0 diagnóstico precoce consiste na abordagem de pessoas com sinais e/ou sintomas da doença. Já o rastreamento é a aplicação de teste ou exame em uma população assintomática (aparentemente saudável), com a finalidade de identificar lesões sugestivas de câncer ${ }^{23}$.

No que tange à assistência, as ações de rastreamento para o diagnóstico precoce fazem parte das atribuições dos serviços de Atenção Primária à Saúde (APS), ao passo que a investigação para a efetivação do diagnóstico e o tratamento fazem parte do conjunto de ações dos serviços especializados da atenção secundária e terciária, respectivamente ${ }^{18,22}$.

A concentração das ações de rastreamento na APS ocorre não apenas por ser a principal porta de entrada no Sistema Único de Saúde (SUS), mas, fundamentalmente, em função da natureza da densidade tecnológica prevista para esse nível de atenção e da proximidade entre a equipe e os usuários dos serviços de saúde, estreitada à medida que o 
vínculo se estabelece no cotidiano da assistência ${ }^{22}$.

$\mathrm{Na}$ unidade de saúde, os profissionais que identificam uma paciente assintomática na faixa etária recomendada pelo Ministério da Saúde devem solicitar a "mamografia de rastreamento" por meio de formulário padronizado e providenciar seu encaminhamento. No caso das mulheres sintomáticas em qualquer faixa etária, o pedido deve ser feito com indicação clínica de "mamografia diagnóstica" 24 . 0 Quadro 2 ilustra o itinerário percorrido pela usuária no sistema de saúde.

Quadro 2 - Itinerário da usuária para realização de mamografia, biopsia e cirurgia para tratamento do câncer de mama.

\begin{tabular}{|c|c|}
\hline Nível de atenção & Percurso da usuária \\
\hline Unidade de saúde (atenção primária) & Recebimento de solicitação da mamografia. \\
\hline $\begin{array}{l}\text { Serviço de mamografia (atenção } \\
\text { secundária) }\end{array}$ & Realização da mamografia e recebimento do resultado. \\
\hline Unidade de saúde (atenção primária) & $\begin{array}{l}\text { Retorno ao médico solicitante com o laudo da mamografia. Se o } \\
\text { laudo da mamografia se enquadrar nas categorias BI-RADS } 4 \text { ou } 5 \text {, há } \\
\text { encaminhamento para unidade especializada. }\end{array}$ \\
\hline $\begin{array}{l}\text { Unidade especializada (atenção } \\
\text { secundária) }\end{array}$ & Recebimento da solicitação e realização da biopsia. \\
\hline Laboratório (atenção secundaria) & Emissão do resultado da biopsia. \\
\hline $\begin{array}{l}\text { Unidade especializada (atenção } \\
\text { secundaria) }\end{array}$ & $\begin{array}{l}\text { Se o laudo da biopsia indica doença benigna, há orientação médica } \\
\text { sobre a conduta terapêutica. Se o laudo da biopsia indica doença } \\
\text { maligna, há encaminhamento para cirurgia. }\end{array}$ \\
\hline Atenção terciária & Realização da cirurgia. Tratamento. \\
\hline
\end{tabular}

Fonte: Adaptado de Azevedo e Silva, Bustamante-Teixeira, Aquino, Tomazelli, Santos (2014) ${ }^{19}$.

Como mostra o Quadro 2, após a consulta na unidade de APS, a paciente é encaminhada ao serviço de atenção secundária para realização da mamografia. 0 laudo de mamografia padronizado com base no sistema de classificação BI-RADS é entregue à usuária, que deve retornar ao profissional que solicitou o exame para análise do resultado e indicação da conduta adequada. Por sua vez, o encaminhamento para conclusão do diagnóstico se apoia na interpretação das categorias BI-RADS ${ }^{19}$. Quando há confirmação do diagnóstico, havendo indicação de tratamento cirúrgico, a usuária é encaminhada ao nível terciário de atenção (hospital especializado em cirurgia mamária) ${ }^{19}$.

A linha de cuidado baseada na colaboração interprofissional pressupõe ações integradas dos recursos disponíveis - serviços, equipes de saúde e comunidade organizada -, voltados a atender às demandas de saúde dos usuários, a reduzir a morbimortalidade e a melhorar a qualidade de vida dos portadores de doenças. Tudo isso requer ações coordenadas que envolvam estratégias de prevenção, detecção precoce, tratamento oportuno e cuidados paliativos, complementadas por ações que perpassam os campos da educação e comunicação em saúde, da vigilância do câncer e dos fatores de risco à saúde ${ }^{22}$.

A linha de cuidado consiste na imagem pensada para expressar os fluxos assistenciais demandados em situações de saúde/doença, com vistas a garantir o atendimento às necessidades de saúde. Aplicada ao câncer de mama, a linha de cuidado é o itinerário que a usuária percorre para garantir acesso à assistência integral de que necessita, inclusive as ações oferecidas nos três níveis de atenção e de assistência à saúde, além daquelas ofertadas pelas entidades comunitárias e sem fins lucrativos, integradas à rede para proporcionar suporte social ao paciente e à família ${ }^{22}$.

A efetividade do cuidado dispensado depende de pactuação do fluxo entre os serviços e de reorganização dos processos de trabalho. A quebra do fluxo de serviços ou a inexistência de articulação entre eles costuma dificultar o percurso das usuárias na rede de saúde e atrasar a concretização das ações, retardando o diagnóstico, o início do tratamento ou mesmo as ações de natureza social, fundamentais em situações de vulnerabilidade social.

0 tempo gasto pelas mulheres em cada etapa da assistência expõe gargalos importantes na agenda de consulta em serviços especializados da atenção secundária e na biopsia. Esse período temporal ao longo do itinerário pode levar a um prognóstico desfavorável 22 . 


\section{Desafios e potencialidades para a efetivação da linha de cuidado na atenção ao câncer de mama}

A demora para estabelecer o diagnóstico e iniciar o tratamento pode trazer graves consequências às usuárias com câncer de mama - associadas a menor taxa de sobrevida ${ }^{20,22}$. Trata-se do tempo transcorrido entre o primeiro contato com o serviço que gerou a solicitação de exame de imagem até a efetivação do diagnóstico, além do tempo parcial entre cada evento, como o exame de mamografia e/ou a ultrassonografia, a consulta médica especializada e a biopsia ${ }^{22}$.

Quanto à diferença entre a demora de atendimento às usuárias que residem na capital cearense e àquelas provenientes do interior do estado em um centro de referência, a mediana do tempo de espera por consulta especializada foi de 15 dias para as usuárias da capital e 30 dias para as usuárias do interior do estado. Diante da solicitação de biopsia, seu resultado, além da realização e do resultado de mamografia, não se identificou diferença em relação ao tempo de espera, com média de 30 a 60 dias. Quanto ao procedimento cirúrgico, a média do tempo de espera para usuárias da capital foi de 39 dias e de 63 dias para as usuárias do interior ${ }^{14}$.

0 acesso ao diagnóstico e ao tratamento varia de região para região do país, dependendo de variáveis geográficas e sociais relativas à distância entre a residência e os serviços de saúde, do nível de informação das mulheres e da disponibilidade de serviços. 0 mapa da mortalidade por câncer de mama indica a influência desses fatores, que é maior nas regiões onde a incidência da doença é elevada e os recursos médicos para diagnóstico precoce e tratamento adequado são de difícil acesso ${ }^{22}$. Há, ainda, imensas desigualdades na oferta de assistência especializada ${ }^{19}$.

A média de demora entre o atendimento no serviço de saúde e a confirmação do diagnóstico pode atingir 120 a 180 dias de espera, com chance do diagnóstico se concretizar em 60 dias. Já os encaminhamentos podem apresentar uma média superior a 30 dias $^{22}$.

Destaca-se que a Lei Federal nº.12.732/2012 garante a todo usuário com neoplasia o direito de submeter-se ao primeiro tratamento dentro do prazo de 60 dias (contados a partir do dia em que for estabelecido o diagnóstico $)^{24}$.

0 principal fator de demora relatado foi a espera por consulta médica especializada no nível secundário de atenção, visto que ações desenvolvidas no âmbito

\section{...os resultados reforçam as potencialidades da APS como porta de entrada no SUS...}

da detecção precoce e do diagnóstico apresentaram enorme avanço; mas essa espera no itinerário das usuárias na busca pelo diagnóstico demonstra a fragilidade na efetivação da linha de cuidados oncológicos ${ }^{22}$.

Outro fator que dificulta essa rede de cuidados decorre do limitado número de casos com diagnóstico precoce. 0 rastreamento mamográfico ainda constitui o melhor método de prevenção, com medidas de intervenção, detecção precoce na fase assintomática e diminuição da morbimortalidade decorrente do diagnóstico tardio. No entanto, há diversas barreiras relacionadas ao rastreamento mamográfico que podem advir do sistema de saúde, da educação e da usuária ${ }^{16}$.

Assim, os resultados reforçam as potencialidades da APS como porta de entrada no SUS, tendo como responsabilidades na atenção ao câncer de mama seu rastreamento e o fortalecimento do vínculo entre as usuárias e o serviço de saúde, contribuindo para a criação de uma linha de cuidado dentro da rede de atenção oncológica ${ }^{25}$. Delineia-se, ainda, a importância de articular as ações de educação em saúde como produtoras de um saber coletivo que estimula 0 indivíduo quanto à sua autonomia e emancipação para o autocuidado e o cuidado voltado à sua família e ao seu ambiente.

Um estudo realizado no norte do Ceará apontou que atividades grupais com mulheres mastectomizadas em processo de reabilitação com ações de educação em saúde propiciou que as informações referentes ao câncer de mama e seu acompanhamento fossem mais acessiveis, proporcionando melhoria da qualidade de vida dessas usuárias ${ }^{26}$.

As estratégias também incluem promover 0 diagnóstico e tratamento precoce, minimizando qualquer atraso no itinerário da usuária, além da capacitação dos profissionais da saúde, sendo estes da APS ou não, além dos agentes comunitários de saúde $(A C S)^{15}$.

Desse modo, destaca-se a importância dos profissionais da saúde no processo saúde-doença suas orientações e condutas influenciam 
significativamente 0 percurso dos portadores de doença. 0 enfermeiro, em especial, pode desenvolver ações para esclarecer dúvidas e proporcionar maior segurança aos usuários.

Considerando que a precocidade do diagnóstico e do tratamento reduz os impactos das doenças, a demora pode ser minimizada pela implementação efetiva de uma linha de cuidados na rede de serviços oncológicos, com pactuação dos fluxos entre os serviços para agilizar o acesso das usuárias à assistência integral ${ }^{22}$.

A implantação de um programa que auxilie ao longo do percurso, do diagnóstico ao tratamento, mostrou grande relevância na redução do tempo tanto para o diagnóstico como para o tratamento, auxiliando a transposição das barreiras de acesso aos serviços de saúde e aumentando a compreensão das usuárias sobre o tratamento e a importância da adesão para um bom prognóstico ${ }^{15}$.

A maior proporção da redução da mortalidade por câncer de mama foi atribuída ao diagnóstico precoce associado à melhoria da gestão da assistência às usuárias ${ }^{15}$.

Como modo de solucionar os problemas apresentados, bem como para avançar rumo às potencialidades, sugere-se: a) ampliação do rastreamento mamográfico anual em todo o Brasil para as faixas etárias preconizadas; b) capacitação dos serviços de rastreamento e diagnóstico por imagem; e c) criação de novos centros de referência para o paciente oncológico. Além disso, há necessidade de melhor alocação dos recursos públicos na promoção da saúde e na prevenção e no tratamento de doenças ${ }^{17}$.

\section{CONCLUSÃO}

Compreende-se a importância da melhoria de acesso aos serviços de saúde e da qualidade do atendimento, vislumbrando o relacionamento interpessoal e o cuidado integral ao ser humano pondo em prática os princípios de universalidade, integralidade e equidade preconizados pelo SUS.

Assim, a linha de cuidado demonstra uma possibilidade de garantir a integralidade relacionada à organização dos serviços de saúde, mostrando o caminho a ser percorrido nas redes de atenção ao câncer de mama - desde a Estratégia Saúde da Família (ESF) e sempre levando em conta a colaboração interprofissional como recurso de fortalecimento dessa linha de cuidado.

\section{... a linha de cuidado demonstra uma possibilidade de garantir a integralidade relacionada à organização dos serviços de saúde...}

Quanto ao tempo de demora, as usuárias acometidas por câncer de mama precisam esperar além do que é recomendado; com isso, constata-se a necessidade de implantação efetiva da linha de cuidado na rede de atenção oncológica, com pactuação entre os serviços para agilizar o acesso à assistência integral.

É evidente que as ações desenvolvidas no âmbito da detecção precoce e do diagnóstico do câncer de mama no Brasil obtiveram enormes avanços. As leis sancionadas com vistas ao tratamento também representam conquistas importantes, no entanto, a falta de estrutura e investimento no setor saúde são fatores limitantes para o cumprimento dessas normativas e para a prestação de um atendimento adequado às usuárias com esse tipo de neoplasia.

Pode-se afirmar que os objetivos propostos neste estudo foram alcançados, visto que foi possível, por meio da análise dos artigos, descrever o processo colaborativo na atenção do câncer de mama, apesar da carência de estudos que abordam essa temática.

Enfatizamos a importância da criação de dispositivos que ampliem a colaboração interprofissional nos serviços de saúde, possibilitando a prestação de cuidados integrais e resolutivos e diminuindo as dificuldades no itinerário desde 0 diagnóstico até o tratamento do câncer de mama.

Esperamos que este estudo constitua ferramenta de apoio para garantir uma melhor atenção à mulher com câncer de mama, mediante organização dos fluxos assistenciais e fortalecimento das ações na rede de atenção oncológica. Sabemos que os desafios são diversos, mas também se mostram estimulantes e promovem o compromisso e a determinação dos profissionais da saúde.

\section{CONTRIBUIÇÃO DAS AUTORAS}

Francisca Alanny Rocha Aguiar e Thaianny Cordeiro de Sousa contribuíram com o delineamento 
da pesquisa e a estruturação e redação do manuscrito. July Grassiely de Oliveira Branco e Francisca Bertilia Chaves Costa contribuíram com a redação do manuscrito. Amelia Romana Almeida Torres e Lidyane Parente Arruda contribuíram com a revisão crítica do manuscrito.

\section{REFERÊNCIAS}

1. Moretti AC, Teixeira FF, Suss FMB, Lawder Juliana AC, Lima LSM, Bueno RE, et al. Intersetorialidade nas ações de promoção de saúde realizadas pelas equipes de saúde bucal de Curitiba (PR). Ciênc Saúde Colet [serial on the internet]. 2010 [cited 2018 May 4];15(Suppl 1):1827-34. Available from: http://www.scielo.br/pdf/csc/v15s1/095.pdf

2. Mendes EV. As redes de atenção à saúde. Brasília (DF): Organização Pan-Americana da Saúde; 2011.

3. Brasil. Diretrizes para a organização das RAS no âmbito do SUS. Portaria n. 4.279, de 30/12/2010. Brasília (DF): Ministério da Saúde; 2010.

4. Organização Mundial da Saúde. Marco para ação em educação interprofissional e prática colaborativa. Redes de profissões de saúde. Enfermagem e obstetrícia. Recursos humanos para a saúde. Brasília (DF): Organização Mundial da Saúde; 2010.

5. Brasil. Secretaria de Vigilância a Saúde [document on the internet]. Brasília (DF): Ministério da Saúde; 2014 [cited 2018 May 17]. Available from: http://portalms.saude.gov. $\underline{\mathrm{br} / \mathrm{svs}}$

6. Nettina SM. Prática de enfermagem. Rio de Janeiro: Guanabara Koogan; 2012.

7. Rodrigues JD, Cruz MS, Paixão AN. Uma análise da prevenção do câncer de mama no Brasil. Ciênc Saúde Colet [serial on the internet]. 2015 [cited 2018 May 17];20(10):3163-76. Available from: http://www.scielo.br/ $\mathrm{pdf} / \mathrm{csc} / \mathrm{v} 20 \mathrm{n} 10 / 1413-8123-\mathrm{csc}-20-10-3163 . \mathrm{pdf}$

8. World Health Organization. International Agency for Research on Cancer. Geneva: WH0; 2016.

9. Brasil. Estimativa 2016/2017. Estimativa por tipo de câncer. Rio de Janeiro: Instituto Nacional de Câncer; 2016.

10. Brasil. Doenças crônicas: câncer. Brasília (DF): Ministério da Saúde; 2014.

11. Arruda RL, Teles ED, Oliveira FJF, Fontoura IG, Ferreira AGN, Machado NS. Prevenção do câncer de mama em mulheres atendidas em unidades básicas de saúde. Rev Rene [serial on the internet]. 2015 [cited 2017 Jan 20];16(2):143-9. Available from: http://www.repositorio.ufc.br/bitstream/ riufc/12638/1/2015_art_rlarruda.pdf
12. Brouselle A, Champagne F, Contandriopoulos AP, Hartz $Z$, organizers. Avaliação: conceitos e métodos. Rio de Janeiro: Ed. Fiocruz; 2011.

13. Botelho LLR, Cunha CCA, Macedo M. 0 método da revisão integrativa nos estudos organizacionais. Gestão Sociedade [serial on the internet]. 2011 [cited 2018 May 17];5(11):12136. Available from: https://www.gestaoesociedade.org/ gestaoesociedade/article/view/1220/906

14. Cavalcanti LPG, Simões PSF, Silva MRR, Galdino PNR. Assistência em mastologia em uma unidade de referência do Sistema Único de Saúde no Ceará, Brasil. Rev Bras Cancerol. 2012;58(4):603-9. Available from: http://www.inca.gov.br/ $\mathrm{rbc} / \mathrm{n} 58 / \mathrm{v} 04 / \mathrm{pdf} / 05$-artigo-assistencia-mastologiaunidade-referencia-sistema-unico-saude-ceara-brasil.pdf

15. Barros AF, Uemura G, Macedo JLS. Atraso no diagnóstico e tratamento do câncer de mama e estratégias para sua redução. Femina. 2012;40(1):31-6.

16. Lourenço TS, Mauad EC, Vieira AC. Barreiras no rastreamento do câncer de mama e o papel da enfermagem: revisão integrativa. Rev Bras Enferm [serial on the internet]. 2013 [cited 2018 May 17];66(4):585-91. Available from: http://www.scielo.br/pdf/reben/v66n4/v66n4a18.pdf

17. Nicolaou PK, Padoin LV. 0 retrato das políticas públicas no tratamento do câncer de mama no Brasil. Rev Bras Mastologia [serial on the internet]. 2013 [cited 2018 May 17];23(3):92-4. Available from: http://www.rbmastologia. com.br/wp-content/uploads/2015/06/MAS_v23n3_92-94. $\underline{\mathrm{pdf}}$

18. Bertocchi FM, Fernandes BM, Almeida MIG, Freitas SC, Paiva CCN, Paula EA. Conduta de profissionais durante a consulta de rastreio do câncer de mama e útero. Rev Rene [serial on the internet]. 2014 [cited $2017 \mathrm{Jan} 20$ ];15(6):9739. Available from: http://www.revistarene.ufc.br/revista/ index.php/revista/article/viewFile/1803/pdf

19. Azevedo e Silva G, Bustamante-Teixeira MT, Aquino EML, Tomazelli JG, Santos SI. Acesso à detecção precoce do câncer de mama no Sistema Único de Saúde: uma análise a partir dos dados do Sistema de Informação em Saúde. Cad Saúde Pública [serial on the internet]. 2014 [cited 2018 May 17];30(7):1537-50. Available from: http://www.scielo. $\mathrm{br} / \mathrm{pdf} / \mathrm{csp} / \mathrm{v30n7/0102-311X-csp-30-7-1537.pdf}$

20. Paiva CJK, Cesse EAP. Aspectos relacionados ao atraso no diagnóstico e tratamento do câncer de mama em uma unidade hospitalar de Pernambuco. Rev Bras Cancerol [serial on the internet]. 2015 [cited 2018 May 17];61(1):23-30. Available from: http://www.inca.gov.br/rbc/n_61/v01/ pdf/05-artigo-aspectos-relacionados-ao-atraso-nodiagnostico-e-tratamento-do-cancer-de-mama-em-umaunidade-hospitalar-de-pernambuco.pdf

21. Feijó AM, Leon LC, Costa VA, Pozza SB. Os caminhos de cuidado das mulheres com diagnóstico de câncer de mama. Av Enferm [serial on the internet]. 2016 [cited 2018 May 17];34(1):58-68. Available from: http://www.scielo.org.co/ $\mathrm{pdf} / \mathrm{aven} / \mathrm{v} 34 \mathrm{n} 1 / \mathrm{v} 34 \mathrm{n} 1 \mathrm{a} 07 . \mathrm{pdf}$ 
22. Traldi MC, Galvão P, Morais SS, Fonseca MRCC. Demora no diagnóstico de câncer de mama de mulheres atendidas no sistema público de saúde. Cad Saúde Coletiva [serial on the internet]. 2016 [cited 2018 May 17];24(2):185-91. Available from: http://www.scielo.br/pdf/cadsc/v24n2/1414-462Xcadsc-24-2-185.pdf

23. Brasil. Controle do câncer de mama. Rio de Janeiro: Instituto Nacional de Câncer; 2016.

24. Brasil. Lei n. 12.732, de 22 de novembro de 2012. Dispõe sobre o primeiro tratamento de paciente com neoplasia maligna comprovada e estabelece prazo para seu início. Diário Oficial da União [serial on the internet], Brasília (2012 Nov 23 [cited 2018 May 17]); Sec 1. Available from: http://www.planalto.gov.br/ccivil_03/_ato20112014/2012/lei/l12732.htm

25. Brasil. Diretrizes para a detecção precoce do câncer de mama no Brasil. Rio de Janeiro: Instituto Nacional de Câncer; 2015.

26. Farias LMA, Aguiar VCF, Carvalho AMF, Linhares JM, Linhares AEMS, Sousa AMM. Grupo de mulheres mastectomizadas: construindo estratégias de cuidado. Sanare (Sobral, 0nline) [serial on the internet]. 2014 [cited 2018 May 17];14(2):91-7. Available from: https://sanare. emnuvens.com.br/sanare/article/view/831/502

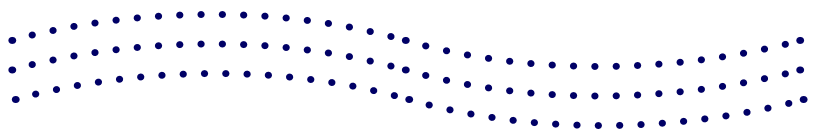
$\ldots . .$.

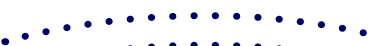

$\ldots \ldots \ldots \ldots \ldots \ldots$ $\ldots \ldots \ldots \ldots \ldots \ldots \ldots \ldots$ $\ldots \ldots \ldots \ldots \ldots \ldots$

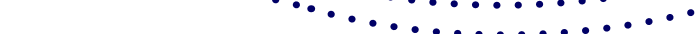




\title{
TIMEROSAL CONTIDO EM VACINAS E TRANSTORNOS DO ESPECTRO AUTISTA: REVISÃO DE LITERATURA
}

\author{
THIMEROSAL-CONTAINING VACCINES AND AUTISM SPECTRUM DISORDERS:
}

LITERATURE REVIEW

TIMEROSAL CONTENIDO EN VACUNAS Y TRASTORNOS DEL ESPECTRO AUTISTA: REVISIÓN DE LITERATURA

Vinicius da Silva Pires ${ }^{1}$

Palavras-chave:

Timerosal; Transtorno do Espectro Autista; Autismo.

Palabras clave: Timerosal; Trastorno del Espectro Autista; Autismo.

Submetido: $16 / 09 / 2017$

Aprovado: 10/04/2018

\section{Autor(a) para Correspondência:} Vinicius da Silva Pires End: Av. Roberto Silveira, 307-ap. 608, Icaraí-CE - CEP: 24.230-152, Niterói/RJ E-mail:viniciusdasilvapires@gmail.

com

\section{RESUMO}

O transtorno do espectro autista (TEA), antes considerado um distúrbio raro, passou a ter prevalência maior do que o câncer infantil, o diabetes $e$ a síndrome de Down. Nos últimos anos houve crescimento exponencial do número de pesquisas sobre fatores ambientais associados ao TEA, dentre os quais se destacam os estudos epidemiológicos de associação entre TEA $e$ timerosal contido em vacinas (TCV). O objetivo deste estudo foi analisar o progresso desses estudos e verificar se há consenso entre os pesquisadores. As bases MedLine e Scopus e a Biblioteca Virtual em Saúde (BVS) foram consultadas para identificar artigos publicados entre 2000 e 2017, adotando como termos de busca (em língua inglesa): "thimerosal"; "thiomersal"; "ethilmercury"; "autism spectrum disorder"; e "autism". Dezesseis artigos foram selecionados por meio da leitura de títulos e textos. Observou-se que não houve consenso entre os pesquisadores dos Estados Unidos da América (EUA) sobre a associação entre timerosal e TEA, entretanto, todos os autores dos demais paises concluíram não haver essa associação.

1. Engenheiro. Especialista em Segurança do Trabalho. Aluno de Mestrado em Engenharia Ambiental na Universidade do Estado do Rio de Janeiro (UERJ). Niterói (RJ),Brasil. E-mail: viniciusdasilvapires@gmail.com 


\section{ABSTRACT}

Autism spectrum disorder (ASD), formerly regarded as a rare disorder, has become more prevalent than childhood cancer, diabetes, and Down syndrome. In recent years, there has been an exponential increase in the number of scientific studies on environmental factors associated with ASD, among which we highlight the epidemiological studies of association between ASD and thimerosal-containing vaccines (TCV). This study aimed to analyze the progress of these studies and verify whether there is consensus among scholars. The MedLine and SCOPUS databases and the Virtual Health Library (VHL) were accessed in order to identify articles published between 2000 and 2017 , adopting as search terms (in English): 'thimerosal;' 'thiomersal;' 'ethilmercury;' 'autism spectrum disorder;' and 'autism.' Sixteen articles were selected by reading the titles and texts. It was observed that there was no consensus among scholars from the United States of America (USA) about the association between thimerosal and ASD, however, all authors from the other countries concluded that there was no such association.

\section{RESUMEN}

El trastorno del espectro autista (TEA), anteriormente considerado un trastorno raro, se ha vuelto más frecuente que el cáncer infantil, la diabetes y el síndrome de Down. En los últimos años, ha habido un aumento exponencial en el número de investigaciones sobre factores ambientales asociados con el TEA, entre los que destacamos los estudios epidemiológicos de asociación entre TEA y timerosal contenido en vacunas (TCV). Este estudio tuvo como objetivo analizar el progreso de estos estudios y verificar si existe consenso entre los investigadores. Se accedió a las bases de datos MedLine y SCOPUS y a la Biblioteca Virtual en Salud (BVS) para identificar artículos publicados entre 2000 y 2017, adoptando como términos de búsqueda (en inglés): "thimerosal"; "thiomersal"; "ethilmercury"; "autism spectrum disorder"; y "autism". Dieciséis artículos fueron seleccionados leyendo los títulos y los textos. Se observó que no hubo consenso entre los investigadores de los Estados Unidos (EE. UU.) acerca de la asociación entre el timerosal y el TEA, sin embargo, todos los autores de los otros países concluyeron que no existía tal asociación.

\section{INTRODUÇÃO}

0 transtorno do espectro autista (TEA) afeta cerca de $1 \%$ da população mundial e é 4 vezes mais frequente em homens do que em mulheres ${ }^{1}$. Em 2004, - Departamento de Saúde e Serviços Humanos da Academia Americana de Pediatria (AAP) emitiu um comunicado alarmante: 1 em cada 166 crianças apresentava um transtorno autista. Estudos epidemiológicos sobre transtornos autistas e transtornos globais do desenvolvimento (TGD) realizados em todo o mundo apontaram estimativa média de prevalência global para TEA de 0,62\%. 0 autismo, antes considerado um distúrbio raro, passou a ter prevalência maior do que o câncer infantil, o diabetes e a sindrome de Down ${ }^{2-5}$.

Ao longo dos últimos anos ocorreu um crescimento exponencial do número de fatores ambientais estudados em associação ao TEA. Embora em estágios iniciais, os estudos focados em períodos críticos de desenvolvimento sugeriram fatores promissores de risco e proteção, como vírus, medicamentos, produtos químicos, agentes físicos e influências sociais e culturais ${ }^{6}$.

Em relação aos produtos químicos, destaca-se 0 mercúrio, cuja toxicidade humana varia de acordo com a forma química, a dose e a exposição. Uma série de doenças, inclusive transtornos do sistema nervoso central (SNC), pode estar associada à exposição ao mercúrio ${ }^{7}$.

0 mercúrio está presente em algumas vacinas sob a forma de timerosal - que contém 49,55\% de mercúrio em massa e facilmente se decompõe em soluções salinas aquosas de hidróxido de etilmercúrio e cloreto de etilmercúrio. Houve muitos questionamentos quanto à segurança do mercúrio orgânico nesses produtos, principalmente quando foram descobertos os efeitos do metilmercúrio no organismo, devido a acidente ocorrido em Minamata (Japão), conhecido como Mal de Minamata8.

A discussão sobre timerosal contido em vacinas (TCV) começou em 1999, por meio da AAP e do Serviço de Saúde Pública dos Estados Unidos da América (EUA), que suspeitava que o etilmercúrio (EtHg) presente nas vacinas tivesse um efeito nocivo no desenvolvimento de crianças.

0 objetivo da pesquisa foi realizar uma análise dos estudos epidemiológicos mais recentes, publicados entre 2000 e 2017 sobre a relação entre a exposição ao TCV e aos TEA, bem como avaliar se há consenso entre os estudos analisados em todo o mundo. 


\section{METODOLOGIA}

Foram identificadas publicações originais que associam a exposição a TCV aos TEA nas bases MedLine e Scopus e na Biblioteca Virtual em Saúde (BVS), no período entre 2000 e 2017, adotando os termos de busca (em língua inglesa) thimerosal, thiomersal e autism para localização por meio da leitura de títulos e textos.

Adotou-se o ano 2000 como período inicial de pesquisa porque marcou o início do aumento da quantidade de estudos relacionados ao mercúrio e aos distúrbios do neurodesenvolvimento. A pesquisa se estendeu até 2017 para avaliar se houve evolução nos desenhos de estudo e se as conclusões convergiam para um mesmo desfecho.

Inicialmente, realizou-se a leitura dos títulos dos artigos; em seguida foram lidos os resumos, eliminando os artigos que não atendiam aos critérios de inclusão e exclusão; por fim foram lidos os textos completos dos artigos, extraindo os dados com base em: nome do(s) autor(es); título; ano de publicação; e conclusão. Os métodos de estudo foram avaliados segundo desenho, tipo e tamanho da população, exposição, resultados, validações de diagnósticos de desenvolvimento, discussão da potência do estudo e métodos estatísticos, inclusive técnicas para controlar as variáveis de confundimento.

Foram excluídos os artigos relacionados a eventos adversos com vacinas que não apresentavam associação a: timerosal; cobertura vacinal; conscientização sobre vacinação; associação com obesidade infantil e litígios sobre eventos adversos causados pela vacinação; e exposição ao timerosal por meio de outros medicamentos. Além disso, excluíram-se: notas de editores; estudos toxicológicos; revisões bibliográficas; estudos clínicos; assuntos regulatórios; relatórios; e comentários.

\section{RESULTADOS E DISCUSSÃO}

Do total de 198 artigos identificados, 16 artigos foram selecionados por consistirem em estudos epidemiológicos de associação entre o TCV e os TEA (Tabela 1).

Tabela 1 - Estudos epidemiológicos de associação entre timerosal contido em vacinas e transtorno do espectro autista.

\begin{tabular}{|c|c|c|c|}
\hline Autor/ano de publicação & Desenho/período de estudo & País & Base de dados \\
\hline Geier, Kern, Geier (2017) $)^{12}$ & Caso-controle (1991-2000) & EUA & VSD \\
\hline Geier, Kern, Homme, Geier (2017) & Caso-controle (1991-2000) & EUA & VSD \\
\hline Geier, Kern, Geier $(2016)^{16}$ & Caso-controle (1998-2003) & EUA & VAERS \\
\hline $\begin{array}{l}\text { Uno, Uchiyama, Kurosawa, Aleksic, Ozaki } \\
(2015)^{15}\end{array}$ & Caso-controle (1986-1992) & Japão & YPDC \\
\hline $\begin{array}{l}\text { Geier, Hooker, Kern, King, Sykes, Geier } \\
(2013)^{8}\end{array}$ & Caso-controle (1998-2000) & EUA & VAERS \\
\hline Gallagher, Goodman $(2010)^{18}$ & Caso-controle (1997-2002) & EUA & NHIS \\
\hline $\begin{array}{l}\text { Price, Thompson, Goodson, Weintraub, } \\
\text { Croen, Hinrichsen, et al. }(2010)^{14}\end{array}$ & Caso-controle (1994-1999) & EUA & MCO \\
\hline $\begin{array}{l}\text { Majewska, Urbanowicz, Rok-Bujko, } \\
\text { Namysłowska, Mierzejewski (2010) }{ }^{17}\end{array}$ & Caso-controle (2007-2009) & Polônia & $\begin{array}{l}\text { Clínicas e } \\
\text { escolas }\end{array}$ \\
\hline $\begin{array}{l}\text { Fombonne, Zakarian, Bennett, Meng, } \\
\text { McLean-Heywood }(2006)^{23}\end{array}$ & Coorte (1987-1998) & Canadá & LBPSB \\
\hline Geier, Geier $(2006)^{13}$ & Caso-controle (1994-1998) & EUA & VAERS \\
\hline Geier, Geier $(2005)^{28}$ & Coorte (1997-2001) & EUA & VAERS \\
\hline Geier, Geier $(2004)^{27}$ & Coorte (1997-2000) & EUA & VAERS \\
\hline $\begin{array}{l}\text { Andrews, Miller, Grant, Stowe, Osborne, } \\
\text { Taylor }(2004)^{24}\end{array}$ & Coorte (1988-1997) & UK & GPRD \\
\hline $\begin{array}{l}\text { Verstraeten, Davis, DeStefano, Lieu, } \\
\text { Rhodes, Black, et al. }(2003)^{25}\end{array}$ & Coorte (1991-2000) & EUA & HMO \\
\hline
\end{tabular}




\begin{tabular}{lccc}
\hline Autor/ano de publicação & Desenho/periodo de estudo & País & Base de dados \\
\hline Hviid, Stellfeld, Wohlfahrt, Melbye $(2003)^{26}$ & Coorte $(1990-1996)$ & Dinamarca & DNR \\
Geier, Geier $(2003)^{22}$ & Coorte $(1992-2000)$ & EUA & DNR \\
\hline
\end{tabular}

Legenda: EUA = Estados Unidos da América; UK = United Kingdom; VSD = Vaccine Safety Datalink; VAERS = Vaccine Adverse Event Reporting System; YPDC = Yokohama Psycho-Developmental Clinic; NHIS = National Health Interview Survey; MCO = Managed Care Organization; LBPSB = Lester Bowles Pearson School Board; GPRD = General Practitioner Research Database; $\mathrm{HMO}=$ Health Maintenance Organization; $\mathrm{DNR}=$ Danish National Registries.

Fonte: Elaborada pelo autor.

Dentre os 9 estudos de caso controle, 5 avaliaram a hipótese de que crianças-caso teriam recebido doses mais altas de timerosal do que os indivíduos de controle $8,11,12,15,16$. Com exceção do estudo japonês ${ }^{15}$, os demais autores utilizaram dados informatizados de registros médicos e/ou eventos adversos dos EUA, nos períodos em que crianças foram expostas ao timerosal, com aplicação de testes de hipóteses para determinar a razão de chances (RC) de possíveis doses recebidas por crianças com diagnósticos de TEA.

Quanto aos outros 4 artigos, um estudo dos EUA ${ }^{14}$ analisou as relações entre a exposição pré-natal e infantil ao EtHg e 2 subcategorias de TEA: transtorno autista e TEA com regressão, em 3 Managed Care Organization (MCO) em 256 crianças com TEA e 752 indivíduos de controle correspondentes ao ano de nascimento, gênero e MCO. Não se encontraram evidências de aumento de risco para qualquer dos 3 resultados. Outro estudo realizado no Japão ${ }^{15}$ concluiu não haver evidências de que a vacinação contra sarampo/caxumba/rubéola (SCR) causou aumento do timerosal - associado ao aumento do risco de TEA. A população de estudo consistiu em indivíduos não caucasianos, inclusive pessoas japonesas (consideradas altamente homogêneas), minimizando efeitos de fatores de risco específicos da população que possam interagir com exposições ambientais (imunização). Entretanto, a pesquisa não incluiu uma variedade de outros fatores, como estado psiquiátrico materno e medicamentos usados durante a gravidez,

\section{...crianças autistas apresentaram prevalência significativamente maior de reações adversas após vacinações...}

infecções, poluição do ar ou presença de metais, o que pode estar relacionado ao início de TEA e distúrbios de neurodesenvolvimento infantil.

Outro estudo, realizado na Polônia ${ }^{17}$, investigou a associação entre autismo e exposição inicial ao EtHg em 91 crianças autistas, de ambos os sexos, com idades entre 3-4 anos e 7-9 anos, comparadas a 75 crianças saudáveis com idade e sexo equivalentes em relação a medidas demográficas, perinatais, clínicas e de desenvolvimento, além de idade dos pais, ordem de nascimento, medidas morfométricas, histórico de vacinação e quantidade de mercúrio capilar. Como resultado, as crianças autistas apresentaram prevalência significativamente maior de reações adversas após vacinações e desenvolvimento anormal mais frequente do que o dos indivíduos de controle.

0 estudo não analisou em detalhe as fontes de exposição ao mercúrio dos participantes, no que diz respeito à exposição pré-natal ou pós-natal. Entretanto, avaliou outras fontes de mercúrio, como amálgamas dentários e tratamento de quelação. $\mathrm{Na}$ Polônia ainda são utilizadas vacinas pediátricas com timerosal. A utilização de entrevista semiestruturada e o diagnóstico infantil realizado pela mesma equipe de profissionais experientes - além da inspeção abrangente dos registros médicos dos pacientes e do uso de grupos diferenciados por idade e sexo constituem pontos fortes do estudo. Contudo, os autores relataram a incapacidade de avaliar com maior precisão as fontes de exposição ao mercúrio e a seleção uniforme dos participantes do estudo ${ }^{17,18}$.

Dentre os estudos de coorte, 3 encontraram associação entre TEA e exposição ao timerosal ${ }^{19-22}$, ao passo que os outros 4 não encontraram evidências que pudessem relacionar TEA e timerosal ${ }^{23-26}$.

Em outro estudo ${ }^{19}$, os autores alegam ter sido a primeira evidência epidemiológica, com base em dezenas de milhões de doses de vacina administradas nos EUA, que associa aumento da mortalidade por vacina com transtornos do desenvolvimento neurológico. Especificamente em relação ao TEA, uma 
análise do banco de dados do Vaccine Adverse Event Reporting System (VAERS) mostrou aumento estatístico da taxa de incidência de autismo ( $R C=$ $6,0)$ após as vacinas contra difteria, tétano e coqueluche acelular (DTaP) contendo timerosal, em comparação com as vacinas DTaP isentas de timerosal. A proporção masculino/feminino indicou que o TEA foi encontrado com maior frequência em crianças do sexo masculino do que feminino após as vacinas DTaP contendo timerosal.

Em continuidade ao estudo anterior ${ }^{20}$, os autores avaliaram novamente crianças que receberam vacinas contra a DTaP contendo timerosal e crianças que receberam vacinas DTaP isentas de timerosal, administradas entre 1997 e 2000, com base em avaliação de eventos adversos relatados no VAERS. Concluiu-se que houve aumentos de RC significativamente maiores para o TEA $R C=1,8(\mathrm{p}<$ $0,05)$ relatado ao VAERS com as vacinas DTaP contendo timerosal, em comparação com vacinas isentas de timerosal.

Novo estudo ${ }^{21}$ realizado pelo mesmo grupo de autores, em duas fases, avaliou os transtornos de neurodesenvolvimento notificados no VAERS, dentre eles o autismo - TEA - após vacinas DTaP contendo timerosal em comparação com vacinas DTaP isentas de timerosal administradas de 1997 a 2001 na fase 1 . E na fase 2 se avaliou a base de dados do Vaccine Safety Datalink (VSD) para exposição cumulativa ao mercúrio de TCV, em crianças com 1, 2, 3 e 6 meses de vida, nascidos de 1992 a 1997, e o eventual risco de desenvolver transtornos do neurodesenvolvimento.

A primeira fase mostrou riscos significativamente elevados para o TEA registrados no VAERS após vacinas DTaP que continham timerosal em comparação com vacinas DTaP isentas de timerosal. A fase 2 mostrou associações significativas entre exposições cumulativas ao timerosal e TEA, dentre outros transtornos, afirmando que a exposição ao timerosal administrado nos EUA foi significativo fator de risco para 0 desenvolvimento de transtornos do neurodesenvolvimento.

Três estudos $22-28$ mostram pesquisas com coincidência de período, base de dados e desenho de estudo. Apenas no segundo estudo os autores acrescentaram 1 ano em comparação ao estudo de 2004 e utilizaram outros eventos adversos para servir de controle e ajuste da composição demográfica. 0s estudos não apresentam garantias quanto à precisão dos dados obtidos. Vários fatores podem ter contribuído para uma subnotificação do número de

\section{...associações \\ significativas \\ entre exposições \\ cumulativas ao \\ timerosal e TEA...}

eventos adversos, uma vez que o VAERS é um sistema de relatório passivo, monitorado pelo Center for Disease Control (CDC) e pela Food and Drug Administration (FDA), no qual profissionais da saúde ou mesmo pais podem notificar um evento adverso após a vacinação. Além disso, os autores não revelaram quais termos de diagnóstico ou sintomas foram extraídos do VAERS ou como eles lidaram com sobreposições de diagnóstico ou registros incomuns. Outro problema que afeta os estudos é a insuficiência de dados para definir com precisão a exposição total ao timerosal, bem como estimar quantidades de uma variedade tão grande de fabricantes.

Um estudo realizado no Canadá ${ }^{23}$ analisou a prevalência de transtornos do neurodesenvolvimento em Montreal, com 27.749 crianças nascidas entre 1987 e 1998, que frequentavam 55 escolas do conselho escolar de língua inglesa, e avaliou 0 comportamento das taxas de TEA, por meio de mudanças no cronograma de vacinação infantil contra SCR. Crianças com TEA foram identificadas por equipes preparadas para atender crianças com necessidades especiais, que verificaram a exposição acumulada aos 2 anos de idade ao timerosal. A exposição ao EtHg variou de média (100-125 $\mu \mathrm{g})$ de 1987 a 1991 para alta (200-225 $\mu \mathrm{g})$ de 1992 a 1995, e passou para zero a partir de 1996, quando o timerosal foi totalmente descontinuado. A cobertura de SCR foi estimada por meio de levantamento das taxas de vacinação. Um aumento linear estatisticamente significativo na prevalência do TEA foi observado durante o período de estudo, concluindo que em crianças que receberam vacinas sem timerosal a prevalência foi significativamente maior do que em crianças expostas a timerosal $(82,7 / 10.000$ e 59,5/10.000).

0 estudo apresenta várias limitações, como: dados obtidos por meio dos códigos administrativos de diagnóstico de TEA; crianças não avaliadas individualmente para confirmação diagnóstica (apesar da maioria das crianças ter sido diagnosticada em centro médico terceirizado); impossibilidade de determinar se um grande número de crianças com TEA 
migrou para outras escolas conhecidas por sua política proativa de integração e apoio de crianças com TEA; dados indisponíveis sobre a regressão no decurso do desenvolvimento de crianças com TEA ${ }^{23}$.

Outro estudo, realizado na Dinamarca ${ }^{26}$, utilizou 0 sistema de registo civil para examinar a proporção de taxas de TEA em crianças que receberam vacinas contendo timerosal e as que receberam vacinas isentas. $\mathrm{Na}$ Dinamarca, a única vacinação com timerosal ocorreu após 1970, com a difteria, tétano e coqueluche (DTP), sendo que o timerosal foi removido em 1992. A vacina contra difteria, tétano e coqueluche de célula inteira (DTwP) - livre de timerosal continuou a ser administrada até 1997, período em que a Dinamarca mudou para uma vacina acelular. 0s históricos médicos das crianças foram acompanhados até que os diagnósticos pertinentes fossem concluídos - ou as crianças eram retiradas do sistema ou atingiam os 11 anos.

Com base nas doses administradas nas 5 primeiras semanas, 9 semanas e 10 meses de vida, uma criança na Dinamarca, antes de 1992, poderia receber um total de $125 \mu \mathrm{g}$ de EtHg. Após 1992, a exposição se tornou nula. A proporção de taxa de autismo para crianças que receberam vacinas que continham timerosal (1.220.006 pessoas/ano) em comparação com crianças que receberam apenas vacinas sem timerosal (1.660.159 pessoas/ano) foi apresentada como 0,85 (intervalo de confiança - IC - de 95\%: 0,06-1,20) para outros TEA, a razão da taxa foi de 1,12 (IC de 95\%: 0,88-1,43). Quando acréscimos de 25, 75 e $125 \mu \mathrm{g}$ de mercúrio são comparados, os indices de taxa e o IC foram semelhantes.

Uma deficiência do estudo foi o fato da validade dos diagnósticos de TEA não terem sidos verificados. 0 s autores se basearam em artigo publicado usando os mesmos dados, no qual a validade do diagnóstico de TEA foi confirmada em 37 de 40 crianças (92\%). A exposição máxima ao timerosal na Dinamarca foi de $125 \mu \mathrm{g}$ de EtHg, ou seja, menor do que a exposição máxima potencial relatada em estudos anteriores nos EUA. No entanto, a exposição ao timerosal começou em uma idade precoce e seria importante se a sensibilidade ao timerosal fosse relacionada à idade, o que não ocorreu neste estudo.

Um estudo retrospectivo realizado no Reino Unido ${ }^{24}$ usou dados de Pesquisa de Prática Geral (General Practice Research Database - GPRD), onde 100.572 crianças a termo e 2.471 crianças pré-termo nasceram de 1988 a 1997 e tiveram pelo menos 2 anos de acompanhamento de seus históricos de

\section{...seria importante \\ se a sensibilidade \\ ao timerosal fosse \\ relacionada à \\ idade...}

vacinação e diagnósticos de vários transtornos de desenvolvimento neurológico. A dose total de vacina DTP contendo timerosal e DT e a idade de vacinação foram obtidas, de modo que comparações poderiam ser feitas entre crianças que receberam uma dose mais alta de EtHg no início da vida e as crianças que receberam vacinações mais tarde e/ou as doses que faltaram. No grupo de termos, onde $96 \%$ das crianças receberam as 3 doses de DTP/DT, foram realizados 104 diagnósticos $(0,1 \%)$ para TEA.

Semelhante às bases de dados VSD e dinamarquesas, o GPRD inclui dados longitudinais sobre cuidados de saúde e imunização em uma grande coorte de crianças. Embora das 152.898 crianças na base de dados apenas 100.572 tenham sido incluídas para análise, a grande maioria de exclusões decorreu de datas de nascimento indisponíveis, o que não seria uma fonte de viés. As exclusões remanescentes, de recém-nascidos prematuros e lactentes com condições termo ou prétermo que afetariam o recebimento da vacinação e os desfechos de transtornos do neurodesenvolvimento (TND), foram adequadas para evitar possíveis confusões. Os métodos, a abordagem analítica e a técnica estatística são descritos de modo claro e adequado. Houve elevada proporção de diagnósticos de desenvolvimento validados, mas a amostra avaliada foi pequena e as taxas de validação não foram apresentadas por diagnóstico. 0s autores discutiram vários impactos potenciais de confusão sobre os resultados do estudo. 0 efeito protetor aparente da vacinação para vários transtornos pode refletir uma incapacidade de excluir todas as crianças com condições subjacentes que aumentam o risco desses resultados e diminuem a probabilidade de vacinação a tempo ${ }^{24}$.

0 s autores também reconheceram a necessidade de controlar o status socioeconômico ou considerar condições médicas não registradas, embora o possível impacto desses fatores não seja claro.

Nos EUA ${ }^{25}$, um estudo de coorte retrospectivo de 2 fases utilizou dados informatizados de organizações de manutenção de saúde (health maintenance 
organizations - HMO). Na Fase I, examinou as associações entre TEA e exposição ao timerosal em 124.170 crianças nascidas entre 1992 e 1999 em 2 HMO (A e B). Na fase II, os distúrbios mais comuns associados à exposição na fase I foram reavaliados em 16.717 crianças nascidas entre 1991 e 1997 em outro HMO (C). Foram calculados riscos relativos para TEA por dose de $12,5 \mu \mathrm{g}$ de EtHg no $1^{\circ}, 3^{\circ}$ e $7^{\circ}$ mês de vida. Em nenhuma análise foram encontrados riscos significativos para TEA.

\section{CONCLUSÃO}

Esta revisão de literatura buscou analisar os estudos epidemiológicos recentemente publicados sobre a associação entre a exposição ao timerosal presente em vacinas infantis e o risco de TEA, bem como avaliar se há um consenso entre os pesquisadores em todo o mundo. Observou-se que as pesquisas apresentaram várias limitações semelhantes, principalmente devido ao fato de que os dados, em sua maioria, foram baseados nos registros eletrônicos de eventos adversos com vacinas, passiveis de incertezas quanto à precisão dos diagnósticos; datas em que os indivíduos foram expostos, influência de outras fontes de mercúrio e quantidades de doses recebidas.

Esta pesquisa demonstra que não houve melhora de qualidade dos estudos epidemiológicos em relação às limitações apresentadas desde as primeiras pesquisas em 2003 até as publicações atuais. Ficou claro nos estudos realizados nos últimos anos, particularmente nos EUA, que a mesma base de dados e os mesmos períodos de exposição foram utilizados em diversos artigos, variando em apenas alguns aspectos, como subcategoria de TEA e tipo de vacina, ou adotando outros eventos adversos não relacionados ao TEA como forma de controlar os resultados.

Não há consenso entre os pesquisadores sobre a associação entre a exposição ao timerosal e TEA. Dentre os 16 estudos, os que relataram ter encontrado uma associação foram realizados nos EUA. Nos demais países, como Japão, Dinamarca, Suécia, Canadá e Reino Unido, os pesquisadores não associaram TEA à exposição ao timerosal. Mesmo nos EUA, os resultados são controversos, pois 3 estudos não associaram TEA ao timerosal quando utilizaram bases de dados diferentes.

Os resultados demonstram que os estudos ainda são incipientes para confirmar uma relação causal entre timerosal e TEA. Se, por um lado, estudos com

\section{Não há consenso entre os pesquisadores sobre a associação entre a exposição ao timerosal e TEA.}

amostras menores tendem a ser mais controlados, eles não garantem uma representatividade da população, por outro lado, estudos com amostras representativas não apresentam um nível de controle adequado.

Fatores como exposição a outras fontes de mercúrio, dependência química, tabagismo, estado psiquiátrico materno, medicamentos durante a gravidez, infecções e poluição do ar ou presença de metais podem influenciar o resultado e não foram considerados. Assim como o diagnóstico de TEA que, devido a variações na classificação ao longo dos anos, também pode apresentar falhas de registro. A imprecisão das doses recebidas, sobre as quais pode ter havido alterações para maiores ou menores quantidades, devido à multiplicidade de fabricantes, reforços em esquemas de vacinação ou esquema incompleto também podem ter influenciado resultados.

A prevalência dos TEA, como informado anteriormente, tem aumentado em todo o mundo, devido a vários fatores ainda desconhecidos e que devem ser investigados. Acesso aos sistemas de saúde e diagnósticos mais abrangentes são condições básicas para identificar causas e prevenir a exposição, assim como atividades de educação continuada para profissionais da saúde proporcionam impacto positivo nos serviços de saúde e reafirmam o compromisso deles com o aprimoramento dos cuidados oferecidos às pessoas com transtornos mentais ${ }^{29}$. A falta de capacitação e de infraestrutura prejudica o desenvolvimento de ações integrais por parte das equipes de profissionais da saúde ${ }^{30}$.

Assim, este estudo conclui que, diante das limitações e das condições em que as pesquisas foram realizadas, não há evidências significativas de associação entre timerosal e TEA.

\section{REFERÊNCIAS}

1. Paula CS, Ribeiro SH, Fombonne E, Mercadante MT. Brief report: prevalence of pervasive developmental disorder in 
Brazil - a pilot study. J Autism Dev Disord. 2011;41(12):173842.

2. American Psychiatry Association. DSM-V-TR: manual diagnóstico e estatístico de transtornos mentais. 5. ed. Washington (DC): APA; 2013.

3. Alsagob M, Colak D, Kaya N. Genetics of autism spectrum disorder: an update on copy number variations leading to autism in the next generation sequencing era. Discov Medicin. 2015. 19:367-379.

4. Lee YJ, Hwang IC. Relationship between serum ferritin level and blood mercury concentration using data from the Korean National Health and Nutrition Examination Survey (2010-2012). Environ Res. 2014;135:271-5.

5. Landrigan PJ, Lambertini L, Birnbaum LS. A research strategy to discover the environmental causes of autism and neurodevelopmental disabilities. Environ Health Perspect. 2012;120(7):2002-4.

6. Lyall K, Schmidt RJ, Hertz-Picciotto I. Maternal lifestyle and environmental risk factors for autism spectrum disorders. Int J Epidemiol. 2014;43(2):443-64.

7. Harari R, Harari F, Gerhardsson L, Lundh T, Skerfving S, Strömberg $U$, et al. Exposure and toxic effects of elemental mercury in gold-mining activities in Ecuador. Toxicol Lett. 2012;213(1):75-82.

8. Geier DA, Hooker BS, Kern JK, King PG, Sykes LK, Geier MR. A two-phase study evaluating the relationship between thimerosal-containing vaccine administration and the risk for an autism spectrum disorder diagnosis in the United States. Translational Neurodegeneration. 2013;2(1):25.

9. Pichichero ME, Gentile A, Giglio N, Umido V, Clarkson T, Cernichiari $\mathrm{E}$, et al. Mercury levels in newborns and infants after receipt of thimerosal-containing vaccines. Pediatrics. 2008;121(2):e208-14.

10. Yau VM, Green PG, Alaimo CP, Yoshida CK, Lutsky M, Windham GC, et al. Prenatal and neonatal peripheral blood mercury levels and autism spectrum disorders. Environ Res. 2014;133:294-303.

11. Geier DA, Kern JK, Homme KG, Geier MR. Abnormal brain connectivity spectrum disorders following thimerosal administration. Dose-Response. 2017;15(1): 155932581769084.

12. Geier DA, Kern JK, Geier MR. Increased risk for an atypical autism diagnosis following thimerosal-containing vaccine exposure in the United States: a prospective longitudinal case-control study in the Vaccine Safety Datalink. J Trace Elem Med Biol. 2017;42:18-24.

13. Geier DA, Geier MR. An evaluation of the effects of thimerosal on neurodevelopmental disorders reported following DTP and Hib vaccines in comparison to DTPH vaccine in the United States. J Toxicol Environ Health. 2006;69(15):1481-95.

14. Price CS, Thompson WW, Goodson B, Weintraub ES, Croen LA, Hinrichsen VL, et al. Prenatal and infant exposure to thimerosal from vaccines and immunoglobulins and risk of autism. pediatrics. 2010;126(4):656-64.

15. Uno $Y$, Uchiyama $T$, Kurosawa $M$, Aleksic B, Ozaki N. Early exposure to the combined measles-mumps-rubella vaccine and thimerosal-containing vaccines and risk of autism spectrum disorder. Vaccine. 2015;33(21):2511-6.

16. Geier DA, Kern JK, Geier MR. A two-phase case-control study of autism risk among children born from the late 1990s through the early 2000s in the United States. Med Sci Monit. 2016;22:5196-202.

17. Majewska MD, Urbanowicz E, Rok-Bujko P, Namysłowska I, Mierzejewski P. Age-dependent lower or higher levels of hair mercury in autistic children than in healthy controls. Acta Neurobiol Exp. 2010;70(2):196-208.

18. Gallagher CM, Goodman MS. Hepatitis B vaccination of male neonates and autism diagnosis, NHIS 1997-2002. J Toxicol Environ Health. 2010;73(24):1665-77.

19. Geier M, Geier D. thimerosal in childhood vaccines, neurodevelopment disorders, and heart disease in the United States. Journal of the American Physicians and Surgeons. $2003 ; 8(1): 6-11$.

20. Geier DA, Geier MR. Neurodevelopmental disorders following thimerosal-containing childhooh immunizations: a follow-up analysis. Int J Toxicol. 2004;23:369-76.

21. Geier DA, Geier MR. A two-phased population epidemiological study of the safety of thimerosalcontaining vaccines: a follow-up analysis. Med Sci Monit. $2005 ; 11(4)$ :CR160-70.

22. Geier MR, Geier DA. Neurodevelopmental disorders after thimerosal-containing vaccines: a brief communication. Exp Biol Med. 2003;228(6):660-4.

23. Fombonne E, Zakarian R, Bennett A, Meng L, McLeanHeywood D. Pervasive developmental disorders in Montreal, Quebec, Canada: prevalence and links with immunizations. Pediatrics. 2006;118(1):e139-50.

24. Andrews N, Miller E, Grant A, Stowe J, Osborne V, Taylor B. thimerosal exposure in infants and developmental disorders: a retrospective cohort study in the United Kingdom does not support a causal association. Pediatrics. 2004;114(3):584-91.

25. Verstraeten $T$, Davis RL, DeStefano F, Lieu TA, Rhodes $\mathrm{PH}$, Black SB, et al. Safety of thimerosal-containing vaccines: a two-phased study of computerized health maintenance organization databases. Pediatrics. 2003;112(5):1039-48. 
26. Hviid A, Stellfeld M, Wohlfahrt J, Melbye M. Association between thimerosal-containing vaccine and autism. JAMA. $2003 ; 290(13): 1763-6$.

27. Geier DA, Geier MR. A comparative evaluation of the effects of MMR immunization and mercury doses from thimerosal-containing childhood vaccines on the population prevalence of autism. Med Sci Monit. 2004;10(3):PI33-9.

28. Geier DA, Geier MR. A two-phased population epidemiological study of the safety of thimerosal-containing vaccines: a follow-up analysis. Med Sci Monit. 2005;11(4):CR160-70.

29. Vidal CP, Souza MM, Siniak DS. A importância da educação continuada com os agentes comunitários de saúde: relato de experiência. Sanare (Sobral, 0nline) [serial on the internet]. 2017 [cited 2018 May 18];16(1):130-5. Available from: https://sanare.emnuvens.com.br/sanare/article/ viewFile/1104/615

30. Rosemiro F, Ximenes G. Necessidades de qualificação, dificuldades e facilidades dos técnicos de enfermagem na Estratégia Saúde da Família. Sanare (Sobral, 0nline) [serial on the internet]. 2016 [cited 2018 May 18];15(1):47-54. Available from: file:///D:/927-2057-1-SM.pdf

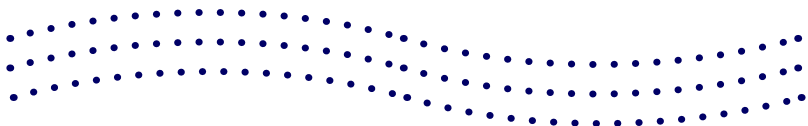
...

. $\cdots \cdots \cdots \cdots \cdots$

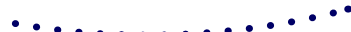

$\ldots \ldots \ldots \ldots \ldots \ldots$

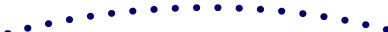

$\ldots \ldots \ldots \ldots \ldots \ldots \ldots$ $\ldots \ldots \ldots \ldots \ldots \ldots \ldots$ $\ldots \ldots \ldots \ldots \ldots$
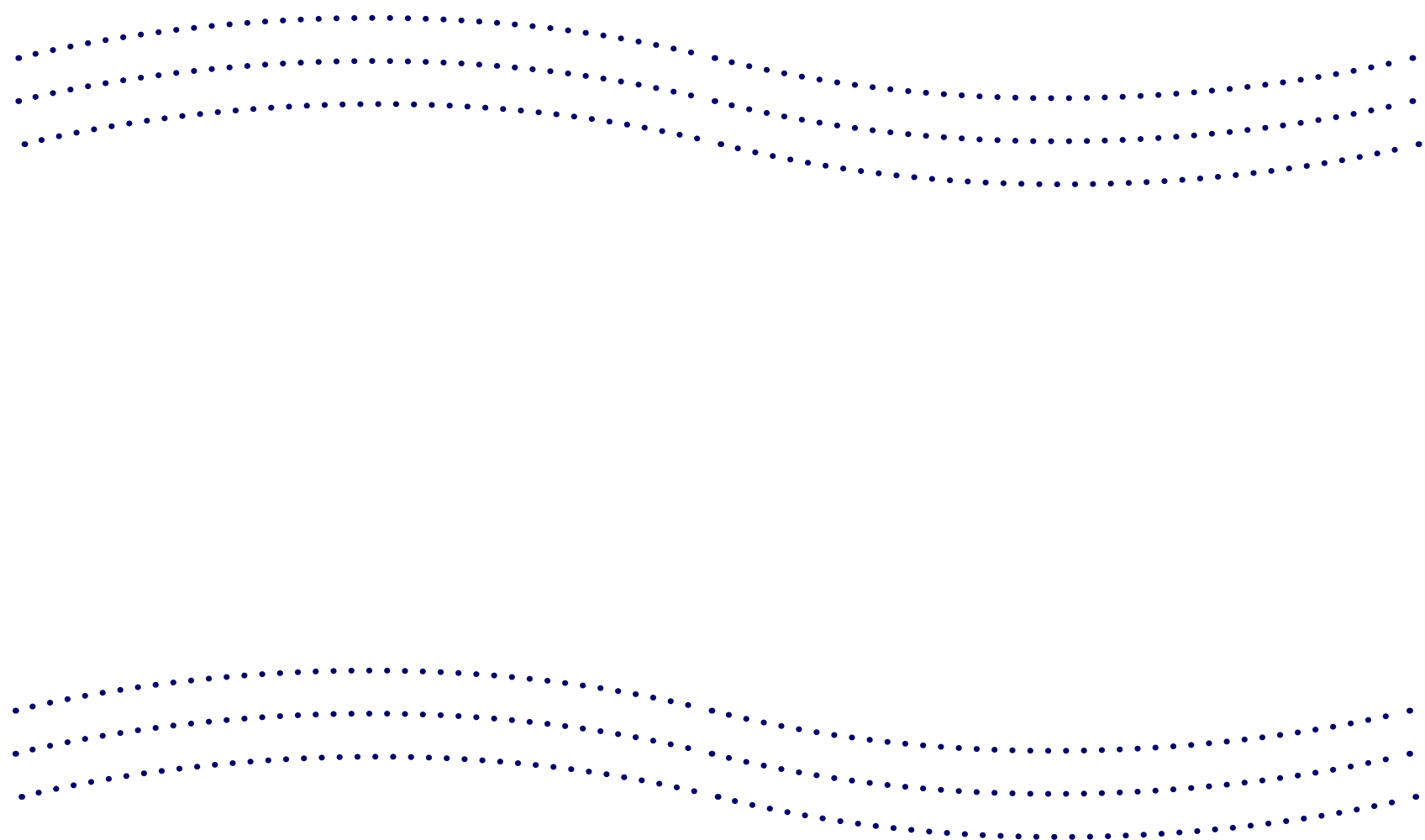


\section{ACOLHIMENTO ÀS PESSOAS EM SOFRIMENTO PSÍQUICO: DESAFIO À REFORMA PSIQUIÁTRICA}

EMBRACING PEOPLE WHO SUFFER FROM PSYCHOLOGICAL STRESS:

CHALLENGE TO THE PSYCHIATRIC REFORM

ACOGIMIENTO A LAS PERSONAS QUE SUFREN DE ESTRÉS PSICOLÓGICO: DESAFÍO A LA REFORMA PSIQUIÁTRICA

Palavras-chave: Reforma Psiquiátrica; Sofrimento Psíquico; Acolhimento; Psicologia.

Keywords:

Psychiatric Reform; Psychological Stress; User Embracement; Psychology.

Palabras clave: Reforma Psiquiátrica; Estrés Psicológico; Acogimiento; Psicología.

Submetido: $14 / 12 / 2017$

Aprovado: 02/05/2018

\section{Autor(a) para Correspondência:} Karolyne Braga Moreira End: Av. Santo Antônio, 591, Centro, Reriutaba-CE, CEP 62260-000 E-mail:karolbragam@hotmail.com

\section{RESUMO}

o modo como o profissional que atua nos equipamentos substitutivos da Reforma Psiquiátrica brasileira acolhe os sujeitos que apresentam ou descrevem alguma queixa de sofrimento psíquico representa um desafio. Assim, esta pesquisa buscou levantar em que medida as atuais práticas cotidianas na relação entre profissionais da saúde e usuários dos serviços de saúde se aproximam ou se afastam do ideal proposto pela Reforma Psiquiátrica no Brasil. Os acontecimentos políticos e sociais dos movimentos da Reforma Sanitária e da Reforma Psiquiátrica são retomados, para configurar o modo como o sujeito em sofrimento psíquico é acolhido atualmente nos serviços substitutivos da Reforma Psiquiátrica. Trata-se de pesquisa bibliométrica, com base em 29 artigos selecionados - que, em sua maioria, revelam os desafios e os impasses nos serviços de saúde, como: dificuldade de adotar práticas diferentes; não participação da categoria médica; desafios da implantação do apoio matricial; precarização das condições de trabalho; e não efetivação de ações cotidianas embasadas nas diretrizes propostas pelo Sistema Único de Saúde (SUS). As práticas observadas revelam que o Brasil ainda carece de uma Reforma Psiquiátrica de fato.

\footnotetext{
1. Graduada em Psicologia pela Universidade Federal do Ceará (UFC). Reriutaba (CE), Brasil. E-mail: karolbragam@hotmail.com

2. Professora na UFC. Meste em Psicologia e Doutora em Saúde Coletiva pela UFC. Pós-Doutora em Psicanálise pela Universidade do Estado do Rio de Janeiro (UERJ). Sobral (CE), Brasil. E-mail: tgd.camilla@gmail.com
} 


\section{ABSTRACT}

The way how a professional who works in the substitutive equipment of the Brazilian Psychiatric Reform embraces the subjects presenting or describing some complaint of psychological stress represents a challenge. Thus, this research sought to survey the extent to which current daily practices in the relation between health professionals and users of health services have been coming closer to or detaching from the ideal as proposed by the Psychiatric Reform in Brazil. The political and social events of the Health Care Reform and the Psychiatric Reform are resumed in order to set up the way how a subject suffering from psychological stress is currently embraced in the substitutive services of the Psychiatric Reform. This is a bibliometric survey, based on 29 selected articles - which, for the most part, reveal the challenges and deadlocks in health services, such as: difficulty in adopting different practices; no participation of the medical category; challenges to deploy the matrix support; precariousness of working conditions; and non-implementation of daily actions based on the guidelines proposed by the Brazilian National Health System (SUS). The practices observed reveal that Brazil still lacks a de facto Psychiatric Reform.

\section{RESUMEN}

La forma en que un profesional que trabaja en el equipo sustitutivo de la Reforma Psiquiátrica brasileña acoge a los sujetos que presentan o describen alguna queja de estrés psicológico representa un desafío. Así, esta investigación buscó encuestar hasta qué punto las actuales prácticas cotidianas en la relación entre profesionales de salud y usuarios de servicios de salud se han acercado o separado del ideal propuesto por la Reforma Psiquiátrica en Brasil. Los eventos políticos y sociales de la Reforma de la Atención de Salud y la Reforma Psiquiátrica se reanudan con el fin de establecer la forma en que un sujeto que sufre de estrés psicológico se acoge actualmente en los servicios sustitutivos de la Reforma Psiquiátrica. Esta es una encuesta bibliométrica, basada en 29 artículos seleccionados, que, en su mayoría, revelan desafíos e impasses en los servicios de salud, como: dificultad para adoptar prácticas diferentes; no participación de la categoría médica; desafíos para implementar el apoyo matricial; precariedad de las condiciones de trabajo; y no implementación de acciones cotidianas basadas en las directrices propuestas por el Sistema Único de Salud brasileño (SUS). Las prácticas observadas revelan que Brasil todavía carece de una Reforma Psiquiátrica de facto.

\section{INTRODUÇÃO}

0 modo como o profissional que atua nos equipamentos substitutivos da Reforma Psiquiátrica brasileira acolhe os sujeitos que apresentam ou descrevem alguma queixa de sofrimento psíquico representa um desafio às diretrizes em questão, tendo em vista que, muitas vezes, as práticas cotidianas na relação entre profissionais da saúde e usuários dos serviços de saúde fogem aos princípios dessa reforma.

Para falar sobre os principais aspectos que resultaram na criação do Sistema Único de Saúde (SUS), estabelecido pela Constituição Federal de 1988, deve-se compreender o contexto anterior à Reforma Sanitária. Em 1964, o Brasil passava pelo Golpe Militar, caracterizado pela desarticulação da participação social e pela busca de destruir todas as iniciativas de movimentos socialistas. No que diz respeito ao setor saúde, os governos militares buscaram incentivar a expansão da iniciativa privada.

As ideias do psiquiatra italiano Franco Basaglia (1924-1980) chegaram ao Brasil no final da década de 1970, acompanhando uma tendência internacional de mudanças para a superação do modelo asilar.
Desde então, as instituições de saúde foram identificando-se com tais mudanças e passaram a desenvolver ações com o objetivo de melhorar 0 atendimento nesse sentido. Na década de 1990, 0 país assinou a Declaração de Caracas, firmando seu compromisso com a implantação dos serviços embasados nos ideais da Reforma Sanitária ${ }^{1}$.

A partir disso, o Ministério da Saúde criou políticas e diretrizes para o funcionamento dos serviços substitutivos da Reforma Psiquiátrica com base nas conferências nacionais de saúde mental, que representam um processo político fundamental para mudanças em prol da melhoria nos serviços de saúde.

A I Conferência Nacional de Saúde Mental, de junho de 1987, apontou que as ações e os serviços de saúde deveriam formar o SUS, gratuito, descentralizado, regionalizado e hierarquizado. Dentre as principais novidades assistenciais havia a reversão da tendência "hospitalocêntrica e psiquiatrocêntrica", atribuindo prioridade ao sistema extra-hospitalar e multiprofissional como referência para o paciente, inserindo-se na estratégia de desospitalização. Também se determinou que o setor público não instalaria novos leitos psiquiátricos em 
unidades psiquiátricas hospitalares tradicionais, reduzindo progressivamente o número de tais leitos e substituindo-os por leitos psiquiátricos em hospitais gerais públicos ou por serviços inovadores alternativos à internação psiquiátrica. 0 acolhimento aos usuários de serviços de saúde mental deveria implicar a implantação de equipes multiprofissionais, de modo a reverter 0 modelo assistencial organicista e medicalizante ${ }^{2}$.

$\mathrm{Na}$ II Conferência Nacional de Saúde Mental, determinou-se a necessidade de estimular a criação de grupos de reflexão nos quais os profissionais de saúde mental possam repensar suas práticas ${ }^{3}$. De uma conferência para a outra foram propostas novas formas de acolher os sujeitos em sofrimento psíquico. Por exemplo, passou a se indicar que, em situações de crise, as intervenções devem ser realizadas em liberdade, recompondo os laços sociais do sujeito em sofrimento psíquico, tendo em vista a possibilidade do cuidado sem uso de violência, exclusão ou negação.

Nesse sentido, as reorientações do modelo assistencial propostas na III Conferência de Saúde Mental baseiam-se no lema “Cuidar, sim. Excluir, não: efetivando a Reforma Psiquiátrica, com Acesso, Qualidade, Humanização e Controle Social"4:11; houve significativo aumento do investimento em redes de atenção psicossocial substitutivas ao modelo "hospitalocêntrico" como eixo assistencial ${ }^{4}$.

$\mathrm{Na}$ IV Conferência Nacional de Saúde Mental, em 2010, pela primeira vez um evento intersetorial, houve grande participação de usuários, trabalhadores e gestores do setor saúde e de outros campos, a área da saúde mental passou a englobar direitos humanos, assistência social, educação, justiça, trabalho e economia solidária, habitação, cultura, lazer e esportes etc ${ }^{5}$. A partir dessa conferência, adotou-se, ainda, um modo menos estigmatizante de designar os usuários de serviços de saúde mental - surgiu a nomenclatura "pessoa em sofrimento psíquico"5:144, que distancia a concepção de portadora de alguma doença, antes atrelada aos usuários de tais serviços.

Em suas diretrizes, as conferências nacionais de saúde mental buscaram a desinstitucionalização, a inclusão social e a implantação de uma rede de assistência pautada no acolhimento dos sujeitos em sofrimento psíquico - que, segundo Emerson Merhy, deve ocorrer por meio de tecnologias leves de cuidado, um acolhimento pautado por um processo relacional, "mediante a escuta, o interesse, a construção de vínculos, de confiança; é [o] que

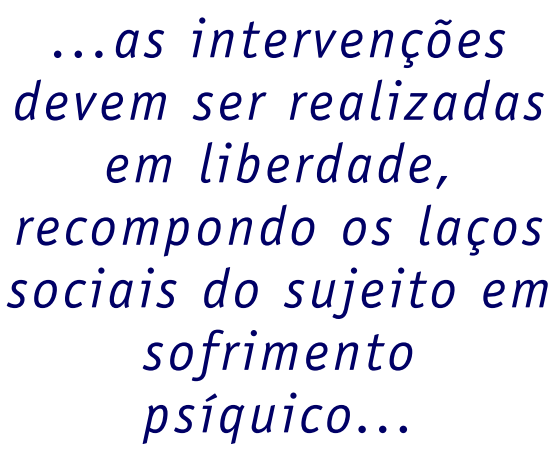

possibilita mais precisamente captar a singularidade, o contexto, o universo cultural"6:6.

Assim, esta pesquisa buscou levantar em que medida as atuais práticas cotidianas na relação entre profissionais da saúde e usuários dos serviços de saúde se aproximam ou se afastam do ideal proposto pela Reforma Psiquiátrica no Brasil.

\section{METODOLOGIA}

Trata-se de pesquisa bibliométrica baseada em artigos selecionados, isto é, textos científicos que trazem as informações relevantes diante dos objetivos em foco. Toda especialidade conta com determinado número de periódicos científicos onde se supõe encontrar os artigos mais importantes sobre os assuntos essenciais; a bibliometria proporciona meios para identificar tais periódicos, também denominados "nucleares", partindo da prática estabelecida na comunidade científica de informar as referências bibliográficas consultadas durante a elaboração de qualquer estudo ${ }^{7}$.

Por meio da pesquisa bibliométrica de trabalhos sobre o tema publicados no período de 2007 a 2017, foram elencadas as principais formas de atuação dos profissionais nos serviços substitutivos da Reforma Psiquiátrica. Identificou-se o que tem sido feito e de que modo o sujeito em sofrimento psíquico tem sido acolhido. Nessa perspectiva, adotou-se um recorte atualizado sobre tais questões, considerando que uma década constitui período de tempo significativo para levantar as publicações importantes acerca do tema.

$0 s$ artigos foram selecionados nas bases da Scientific Electronic Library Online (SciELO) e do Centro Latino-Americano e do Caribe de Informação em Ciências da Saúde (Bireme) - que reúnem periódicos científicos de qualidade de modo acessível e organizado, constituindo fontes de credibilidade em termos de produção científica.

Os critérios de inclusão dos artigos partiram das 
buscas por meio dos descritores em ciências da saúde (DeCS) sofrimento psíquico, acolhimento e reforma psiquiátrica. Como a palavra-chave crise advém, no setor saúde, do contexto das doenças orgânicas, constitui um emaranhado de possibilidades conceituais; assim, o DeCS sofrimento psíquico se mostrou mais efetivo em buscas específicas do que crise e, neste estudo, sujeito em crise se refere a sujeito em sofrimento psíquico. 0 DeCS acolhimento foi de suma importância para a seleção dos artigos, visto que o referencial teórico adotado o indica como vital para a atuação dos profissionais da saúde nos equipamentos substitutivos da Reforma Psiquiátrica. Por fim, o DeCS reforma psiquiátrica é indispensável nesse contexto, pois as novas formas de acolher os sujeitos em sofrimento psíquico se enquadram nas diretrizes propostas a partir dessa reforma.

Após a seleção dos artigos com base nos 3 DeCS indicados, eles foram submetidos a análise bibliométrica de títulos e resumos, para identificação das principais temáticas abordadas.

\section{RESULTADOS E DISCUSSÃO}

Os critérios de inclusão levaram à identificação de 57 artigos no total. Após a análise bibliométrica, foram selecionados 29 artigos para embasar a discussão dos paradigmas de funcionamento dos serviços substitutivos da Reforma Psiquiátrica. Todos esses artigos foram lidos na íntegra, com a finalidade de extrair as informações mais relevantes diante dos objetivos em foco.

Os dispositivos de saúde mais citados foram: a) centros de atenção psicossocial (Caps) - 12 artigos; b) serviços de atendimento básico - como Unidades Básicas de Saúde (UBS), Unidades de Atenção Primária à Saúde (APS), Unidades de Acolhimento (UA) e unidades de saúde mista - juntos, somam 8 artigos no total; e c) os outros serviços se referem a políticas do trabalhador (2 artigos), ambulatório de saúde mental (1 artigo) e hospital psiquiátrico (1 artigo).

A região onde mais se publicou sobre o assunto 0 Sudeste (15 artigos), seguida pelo Nordeste (7 artigos), pelo Sul (6 artigos) e pelo Centro-0este (1 artigo). Nesse sentido, percebe-se que o Sudeste concentra maior investimento em publicações, não significando necessariamente que em outras regiões se trabalhe menos.

No que se refere à relação entre as práticas e os ideais que norteiam a Reforma Psiquiátrica, 10 das publicações se referem a serviços cujos princípios são

\section{...entre os principais desafios estão as questões relacionadas ao acolhimento dos sujeitos...}

- acolhimento, a escuta, a integralidade do atendimento, a organização de uma rede de saúde mental, o apoio matricial, a intersetorialidade, a interdisciplinaridade, a desinstitucionalização e a promoção da cidadania - o que favorece a autonomia dos usuários. Nesse sentido, percebe-se que o universo total das publicações não faz referência a tais conceitos.

0 s artigos que se referem às práticas vivenciadas nos Caps parecem estar mais articulados aos princípios da Reforma Psiquiátrica brasileira. Pode-se citar como exemplo a experiência relatada em 2 artigos com construção de novos modos de fazer no âmbito da saúde mental. Um deles relata uma experiência em um Caps de São Paulo (SP), com a criação de um grupo de contação de histórias, criando espaços de escuta, acolhimento, lembranças e ressignificação de sentidos ${ }^{8}$. A outra experiência, em um Caps de Maceió $(A L)$, envolve a execução de oficinas com uso das Tecnologias da Informação e Comunicação (TIC); a partir da criação de um blog, a pessoa em sofrimento psíquico pode se expressar, compartilhar seus saberes, integrar-se em uma comunidade, ser reconhecida ao expor sua criatividade, dentre outras possibilidades. 0 s autores reforçaram a importância de produzir as oficinas como espaço clínico-político, permitindo que o sujeito estabeleça laços de cuidado consigo em vez da mera ocupação do tempo ${ }^{9}$.

Outros 19 artigos abordaram desafios referentes à efetivação das diretrizes da Reforma Psiquiátrica, apresentando as dificuldades envolvidas nas práticas alternativas, na criação de uma rede articulada de atenção e na falta de integralidade do atendimento. Cita-se como exemplo a experiência de Fortaleza (CE), que descreve estratégias de cuidado não articuladas aos princípios e às diretrizes do SUS, trazendo intervenções baseadas na prescrição medicamentosa e na internação ${ }^{10}$. Outro artigo revela a falta de articulação entre os serviços substitutivos e a APS, destacando que entre os principais desafios estão as questões relacionadas ao acolhimento dos sujeitos 
em sofrimento psíquico nos serviços da rede de saúde ${ }^{11}$.

Ainda no que se refere aos desafios, 11 artigos apontam a falta de cuidado interdisciplinar. Um deles relata uma experiência no Rio de Janeiro com práticas predominantemente baseadas no modelo biomédico de atenção à saúde, na psiquiatrização do cuidado em saúde mental, na burocratização do processo de trabalho e na centralização em ações intramuros. Nesse exemplo, a escuta e o acolhimento dos usuários se concentra na figura de um único profissional da saúde ${ }^{12}$.

Também há situações em que a discussão dos casos se realiza em equipe, exceto o médico, que permanece restrito a atendimentos individuais, como citado em um artigo, a partir de uma experiência em um Caps de Fortaleza ${ }^{13}$. Ao falar sobre a prática da equipe multiprofissional no serviço, revela-se que a categoria médica não se inclui no atendimento interdisciplinar, realizando apenas consultas individuais e demonstrando a prevalência do modelo biomédico com foco no diagnóstico e na doença em vez da escuta do sujeito ${ }^{13}$.

Contudo, nessa mesma experiência são descritas práticas que revelam articulação na rede de saúde, com profissionais que passaram a ampliar sua clínica com apoio matricial dos profissionais do serviço de referência - isto é, o Caps. Percebe-se uma tentativa de articular a proposta de matriciamento, de criar estratégias de capacitação para a APS, para que esta saiba lidar com as demandas de saúde mental por meio do trabalho em equipe. Contudo, ainda se mostra muito difícil e pontual a execução desse modelo proposto pelo SUS.

Em 4 artigos, os profissionais da saúde relatam sentir-se despreparados para atender o público no âmbito da saúde mental, corroborando a ideia de que acabam focalizando suas ações no cuidado do corpo em detrimento de questões subjetivas. Dessa forma, quando recebem pessoas em sofrimento psíquico, encaminham ao atendimento psicológico e/ou psiquiátrico, não demonstrando disponibilidade para o acolhimento, a escuta, a formação de vínculos e 0 apoio social. Por exemplo, 1 artigo indica 0 desconhecimento dos profissionais acerca do termo sofrimento psíquico, repercutindo uma prática distante dos princípios do SUS ao não considerar o conceito ampliado de saúde e de integralidade do atendimento ${ }^{14}$.

Percebe-se que os principais impasses relativos à atuação em serviços de APS, onde as práticas

\author{
...deve-se \\ possibilitar que o \\ usuário produza \\ vida para além dos \\ equipamentos $d a$ \\ saúde...
}

inovadoras constituem desafios e empecilhos para a equipe de saúde, corroboram o impedimento de tais práticas no cotidiano de trabalho. Ademais, assim como nos serviços de APS, há artigos relatando que a equipe do Caps, por vezes, também se vê limitada pela rotina do serviço, restringindo as ações do projeto terapêutico singular aos espaços institucionais. Isso implica o não reconhecimento das potencialidades dos territórios onde as pessoas vivenciam seus laços afetivos e de pertencimento com vistas ao cuidado em rede. No entanto, para efetivar a Reforma Psiquiátrica, deve-se possibilitar que 0 usuário produza vida para além dos equipamentos da saúde, de modo a estabelecer trocas simbólicas em seu território e exercitar sua cidadania.

Limitar as práticas aos espaços institucionais diverge da proposta de desinstitucionalização, o que se apresenta em pelo menos 6 artigos, nos quais as ações de acolhimento são descritas apenas no serviço e não na comunidade. Citamos o exemplo do Caps de João Pessoa (PB), que retrata a falta de interesse e de conhecimento teórico por parte da equipe da Estratégia Saúde da Família (ESF) para discutir os casos que demandam cuidado em saúde mental no território.

Dessa forma, os espaços comunitários e suas estratégias de produção de vida são, em sua maioria, invisibilizados ${ }^{15}$.

Outro achado desta pesquisa envolve o sofrimento psíquico dos cuidadores de usuários dos serviços de saúde mental: 5 artigos revelam a relevância de adotar políticas que também acolham os familiares e os profissionais desses serviços. Um dos artigos retrata a falta de acolhimento da família dos usuários, acarretando sua dificuldade de frequentar os serviços de saúde junto com o usuário por falta de apoio e escuta com foco no sofrimento ${ }^{16}$. Esse artigo reforça, ainda, a importância dos profissionais que atuam nos serviços de saúde mental buscarem a inclusão dos familiares nos projetos terapêuticos, integrando uma rede social; contudo, alerta-se que a inclusão não 
deve limitar-se à família, estendendo-se à comunidade em geral, o que contribui para a efetivação dos conceitos de integralidade do atendimento e de territorialidade.

Os profissionais da saúde consideram relevante 0 acolhimento com foco no sofrimento, que auxilie na promoção da saúde tanto dos usuários como dos cuidadores e dos próprios profissionais, revelando a necessidade de criar espaços para acolhimento e escuta de todos os envolvidos com vistas à redução do sofrimento psíquico no contexto do trabalho em serviços de saúde. Outro artigo traz uma experiência na qual as reuniões de equipe para discussão dos casos dos usuários dos serviços constituíram espaços importantes para acolher as angústias dos próprios profissionais da saúde, que, nessas situações, sentiam-se acolhidos e apoiados, encontrando suporte para o enfrentamento das situações de sofrimento ${ }^{17}$. Contudo, há outro artigo que revela 0 distanciamento nessa relação de cuidado com o profissional da saúde, denunciando, ainda, a precarização das condições de trabalho ${ }^{18}$. Nesse sentido, assim como nesse novo modo de cuidado com o sujeito em sofrimento há necessidade de assistência à família e de uma visão do sujeito inserido em seu território, também há necessidade de que a própria equipe de saúde possa ser cuidada.

A partir das considerações traçadas sobre os 29 artigos selecionados, pode-se dizer que este estudo apresenta dados relevantes para demonstrar que a Reforma Psiquiátrica ainda não se concretizou no Brasil, representando um desafio para todos os envolvidos. 0 cuidado com o chamado sujeito em crise não implica exclusivamente a assistência pontual por parte de um profissional da saúde, mas o trabalho em equipe multiprofissional para fortalecer a percepção das demandas em suas múltiplas dimensões ${ }^{19}$, devendo, ainda, articular a rede de cuidados e amparo ao sujeito dentro de seu território, a partir dos laços sociais e afetivos, sendo relevante o envolvimento de todos os profissionais da saúde nesse cuidado inclusive aqueles da categoria médica ${ }^{20,21}$.

\section{CONCLUSÃO}

Considerando os artigos identificados e selecionados, que relatam os desafios e impasses para efetivar ações cotidianas embasadas nas diretrizes propostas pelo SUS, as práticas revelam que o Brasil ainda carece de uma Reforma Psiquiátrica de facto.

\section{Deve-se considerar que a Reforma Psiquiátrica assume um amplo escopo na sociedade...}

As publicações apresentam os desafios inerentes à adoção de práticas diferentes no setor saúde, isto é, as dificuldades enfrentadas pelos profissionais em busca de novas formas de acolher os usuários dos serviços de saúde. Também se relata a não participação dos profissionais da categoria médica, ainda considerados no topo de uma pirâmide hierárquica, por deterem um saber mais especializado.

$\mathrm{Na}$ base dessa pirâmide se encontram profissionais mais numerosos de outras especialidades que trabalham de modo individualizado. Tal hierarquia de saberes rompe com a proposta de apoio e cogestão de Gastão Wagner, o chamado método paideia, também conhecido como método da roda, que visa a diminuir a fragmentação do trabalho em saúde, de modo a facilitar a promover 0 trabalho em equipe ${ }^{20}$. 0 s resultados e as discussões oferecidos por esta pesquisa ilustram que tal modelo de gestão ainda não se materializou no âmbito do SUS, pois em inúmeros serviços de saúde persiste o modelo hierárquico.

Deve-se considerar que a Reforma Psiquiátrica assume um amplo escopo na sociedade, no sentido de que também se trata de uma atualização jurídica, política, econômica e cultural. Quando se pensa a prática de um profissional da saúde para proporcionar suporte a um sujeito em crise, o foco recai sobre um aspecto de uma estrutura completa que precisa ser modificada para satisfazer as demandas desse sujeito em sofrimento psíquico.

Esta pesquisa envolve, ainda, as demandas de cuidado dos profissionais da saúde, o que implica, por exemplo, a necessidade de melhores condições de trabalho, de estabilidade no emprego, de concursos públicos e de planos de cargos e carreiras, para que esses profissionais se sintam pertencentes aos territórios onde trabalham e que não se sintam desmotivados diante das precárias condições de trabalho e da falta de reconhecimento profissional. Nesse sentido, a Reforma Psiquiátrica precisa se colocar como uma atualização que promove os laços trabalhistas, visto que a saúde do trabalhador afeta 
diretamente o cuidado oferecido pelo serviço a seus usuários.

Embora sejam notórios os avanços da Reforma Sanitária no Brasil, ainda há diversos impasses que precisam ser superados a fim de oferecer cuidado pautado em seus princípios aos usuários dos serviços de saúde que foram condenados por tanto tempo a maus tratos, isolamento e exclusão.

Indica-se a necessidade de continuação desta pesquisa, tendo em vista a relevância de aprofundar os conhecimentos acerca do cuidado e acolhimento às pessoas em sofrimento psíquico no âmbito da saúde mental brasileira.

\section{CONTRIBUIÇÃO DAS AUTORAS}

\author{
Karolyne Braga Moreira contribuiu com 0 \\ delineamento e a realização da pesquisa e a \\ estruturação e redação do manuscrito. Camilla Araújo \\ Lopes Vieira contribuiu com o delineamento da \\ pesquisa e a revisão crítica do manuscrito.
}

\section{REFERÊNCIAS}

1. Amarante P. Uma aventura no manicômio: a trajetória de Franco Basaglia. Hist Ciênc Saúde-Manguinhos [serial on the internet]. 1994 [cited 2017 0ct 11];1 (1):61-77. Available from: http://www.scielo.br/pdf/hcsm/v1n1/a06v01n1.pdf

2. Brasil. I Conferência Nacional de Saúde Mental: relatório final/8 ${ }^{a}$ Conferencia Nacional de Saúde [document on the internet]. Brasília (DF): Ministério da Saúde; 1988 [cited 2017 0ct 3]. Available from: http://bvsms.saude.gov.br/ bvs/publicacoes/0206cnsm_relat_final.pdf

3. Brasil. Relatório final da $2^{\text {a }}$ Conferência Nacional de Saúde Mental [document on the internet]. Brasília (DF): Ministério da Saúde; 1994 [cited 2017 Oct 3]. Available from: http://bvsms.saude.gov.br/bvs/publicacoes/2conf mental.pdf

4. Brasil. III Conferência Nacional de Saúde Mental: caderno informativo [document on the internet]. Brasília (DF): Ministério da Saúde; 2002 [cited 2018 May 7]. Available from: http://bvsms.saude.gov.br/bvs/ publicacoes/0210IIIcnsm.pdf

5. Brasil. Relatório Final da IV Conferência Nacional de Saúde Mental - Intersetorial [document on the internet]. Brasília (DF): Ministério da Saúde; 2010 [cited 2018 May 7]. Available from: http://conselho.saude.gov.br/biblioteca/ Relatorios/relatorio_final_IVcnsmi_cns.pdf

6. Merhy EE, Feuerwerker LCM. Novo olhar sobre as tecnologias de saúde: uma necessidade contemporânea. In: Mandarino ACS, Gomberg E, organizers. Leituras de novas tecnologias e saúde. São Cristóvão (SE): Ed. UFS; 2009. p. 29-74.
7. Cunha MV. Os periódicos em ciência da informação: uma análise bibliométrica. Ciência e Informação. 1985;14(1):3745.

8. Campos-Brustelo TN, Bravo FF, Santos MA. Contando e encantando histórias de vida em um centro de atenção psicossocial. SMAD, Rev Eletrônica Saúde Mental Alcool Drog [serial on the internet]. 2010 [cited 2017 0ct 18];6(1):111. Available from: http://pepsic.bvsalud.org/pdf/smad/ v6n1/07.pdf

9. Bittencourt IGS, Francisco DJ, Mercado LPL. Autoria em blog por pessoas em sofrimento psíquico: aprendizagem compartilhada, reconhecimento e promoção da saúde mental. Psicol Ciênc Prof [serial on the internet]. 2013 [cited 2017 0ct 18];33(4):988-99. Available from: http:// www.scielo.br/pdf/pcp/v33n4/v33n4a16.pdf

10. Lima DWC, Silveira LC, Vieira AN, Cunha BMC, Almeida ANS, Guerreiro EM. Referenciais teóricos que norteiam a prática de enfermagem em saúde mental. Esc Anna Nery Rev Enferm [serial on the internet]. 2014 [cited 2017 0ct 18];18(2):336-42. Available from: http://www.scielo.br/ pdf/ean/v18n2/1414-8145-ean-18-02-0336.pdf

11. Costa A, Silveira M, Vianna P, Silva-Kurimoto T. Desafios da atenção psicossocial na rede de cuidados do Sistema Único de Saúde do Brasil. Rev Port Enferm Saúde Mental [serial on the internet]. 2012 [cited 2017 0ct 18];7:46-53. Available from: http://www.scielo.mec.pt/pdf/rpesm/n7/ n7a08.pdf

12. Silveira DP, Vieira ALS. Saúde mental e atenção básica em saúde: análise de uma experiência no nível local. Ciênc Saúde Colet [serial on the internet]. 2009 [cited 2017 0ct 18];14(1):139-48. Available from: http://www.scielo.br/ $\mathrm{pdf} / \mathrm{csc} / \mathrm{v} 14 \mathrm{n} 1 / \mathrm{a} 19 \mathrm{v} 14 \mathrm{n} 1 . \mathrm{pdf}$

13. Andrade $A B, B o s i$ MLM. Qualidade do cuidado em dois centros de atenção psicossocial sob o olhar de usuários. Saúde Soc [serial on the internet]. 2015 [cited 2017 0ct 18];24(3):887-900. Available from: http://www.scielo.br/ pdf/sausoc/v24n3/0104-1290-sausoc-24-03-00887.pdf

14. Amarante AL, Lepre AS, Gomes JLD, Pereira AV, Dutra VFD. As estratégias dos enfermeiros para o cuidado em saúde mental no Programa Saúde da Família. Texto \& Contexto Enferm [serial on the internet]. 2011 [cited 2017 0ct 18];20(1):85-93. Available from: http://www.scielo.br/pdf/ tce/v20n1/10.pdf

15. Ferreira TPS. Produção do cuidado em saúde mental: desafios para além dos muros institucionais. Interface Comun Saúde Educ [serial on the internet]. 2017 [cited 2017 0ct 18];21(61):373-84. Available from: http://www. scielo.br/pdf/icse/v21n61/1807-5762icse-1807-576220160139.pdf

16. Covelo BSR, Badaró-Moreira MI. Laços entre família e serviços de saúde mental: a participação dos familiares no cuidado do sofrimento psíquico. Interface Comun Saúde Educ [serial on the internet]. 2015 [cited 2017 0ct 
18];19(55):1133-44. Available from: http://www.scielo.br/ pdf/icse/v19n55/1807-5762-icse-1807-576220140472.pdf

17. Lembo AP, Oliveira AP, Carrelli E. Conversando sobre desgaste mental no trabalho e suas possibilidades de enfrentamento: uma experiência no serviço público municipal de Guarulhos. Rev Bras Saúde 0cup [serial on the internet]. 2016 [cited 2017 0ct 18];41:e12. Available from: http://www.scielo.br/pdf/rbso/v41/2317-6369-rbso41-e12.pdf

18. Perez KV, Bottega CG, Merlo ARC. Análise das políticas de saúde do trabalhador e saúde mental: uma proposta de articulação. Saúde Debate [serial on the internet]. 2017 [cited 2017 0ct 18];41(Spec):287-98. Available from: http://www.scielo.br/pdf/sdeb/v41nspe2/0103-1104-sdeb41-spe2-0287.pdf

19. Goya N, Andrade LOM. Percepções de trabalhadores da saúde sobre práticas instituintes e desafios do Sistema Único de Saúde. Sanare (Sobral, Online) [serial on the internet]. 2015 [cited 2018 Apr 30];14(2):7-16. Available from: https://sanare.emnuvens.com.br/sanare/article/ view/824/495

20. Cunha GT, Campos GWS. Método paideia para co-gestão de coletivos organizados para o trabalho. Revista ORG \& DEMO [serial on the internet]. 2010 [cited 2018 May 7];11(1):31-46. Available from: http://www2.marilia.unesp. br/revistas/index.php/orgdemo/article/view/468/364

21. Brasil. Saúde mental no SUS: acesso ao tratamento e mudança do modelo de atenção. Brasília (DF): Ministério da Saúde; 2007.

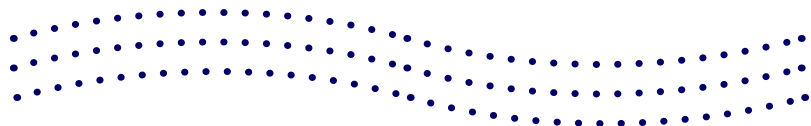

$\ldots \ldots \ldots \ldots \ldots \ldots \ldots$

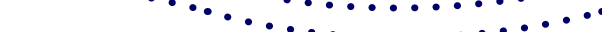

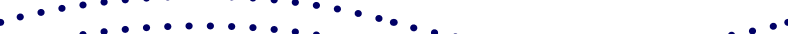

( $\ldots \ldots \ldots \ldots \ldots \ldots \ldots \ldots$ •
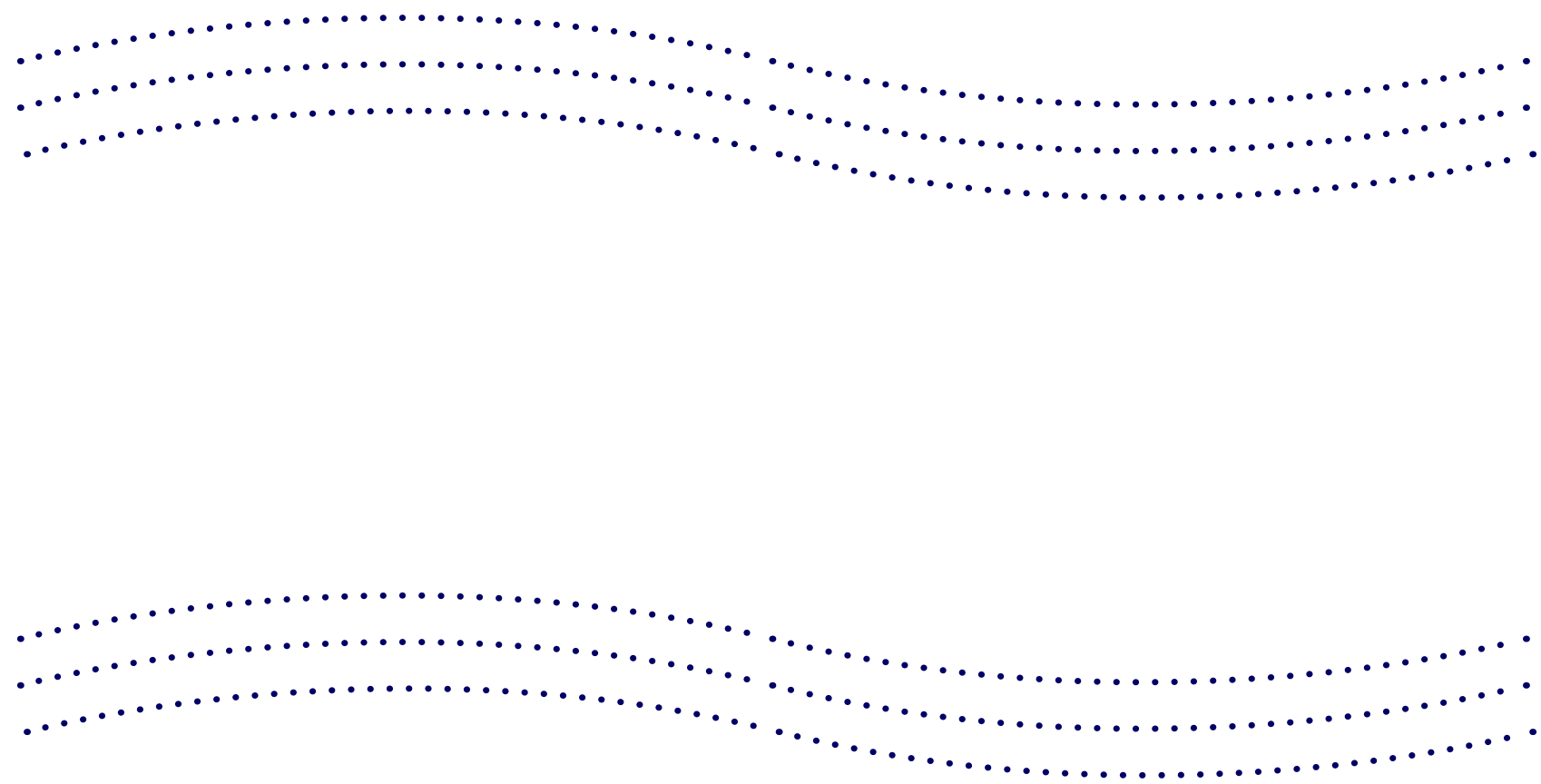


\section{VIVÊNCIAS NA REDE DE SAÚDE E PSICOLOGIA: INTERAÇÕES DA RESIDÊNCIA MULTIPROFISSIONAL EM SAÚDE DA FAMÍLIA}

EXPERIENCES IN HEALTH NETWORK AND PSYCHOLOGY: INTERACTIONS OF THE MULTIPROFESSIONAL RESIDENCY IN FAMILY HEALTH

VIVENCIAS EN LA RED DE SALUD Y PSICOLOGÍA: INTERACCIONES DE LA RESIDENCIA MULTIPROFESIONAL EN SALUD DE LA FAMILIA

Ana Karina de Sousa Gadelha Amanda Colares Bezerra ${ }^{1}$ George Luiz Costa de Paula 3

Paulo Cesar de Moura Luz ${ }^{4}$

Palavras-chave: Recursos Humanos em Saúde; Saúde da Família; Psicologia.

Palabras clave: Recursos Humanos en Salud; Salud de la Familia; Psicología.

Submetido: 28/10/2017

Aprovado: 07/04/2018

Autor(a) para Correspondência: Ana Karina de Sousa Gadelha End: Av. John Sanford, 1320, Junco CEP: 62030-240, Sobral-CE E-mail: Karina_gadelha@yahoo.com.br

\section{RESUMO}

Este artigo consiste em um relato da vivência obrigatória em rede do programa de Residência Multiprofissional em Saúde da Família da Escola de Formação em Saúde da Família Visconde de Sabóia (RMSF/EFSFVS), em Sobral-CE. Assim, o objetivo é apresentar, refletir e discutir os serviços vivenciados, para analisar suas idiossincrasias e indicar como o contato com tais serviços pode contribuir com as articulações em rede relativas à atuação da Psicologia na Estratégia Saúde da Família (ESF), como categoria profissional e equipe multiprofissional. A vivência obrigatória está prevista na proposta pedagógica da RMSF/EFSFVS, com carga horária de 80 horas, distribuídas no primeiro ano de residência. A experiencia apresentada neste relato foi realizada no periodo de julho a dezembro de 2015, em 6 serviços municipais de saúde. 0 relato ilustra as impressões e afetações dos residentes em relação aos serviços vivenciados, bem como as contribuições da vivência obrigatória para estreitamento de vínculos entre serviços, melhorando a resolutividade dos problemas enfrentados no cotidiano da Atenção Primária à Saúde (APS).

\footnotetext{
1. Psicóloga. Preceptora de núcleo no programa de Residência Multiprofissional em Saúde da Família (RMSF). Sobral (CE), Brasil. E-mail: karina_gadelha@yahoo.com.br

2. Psicóloga. Residente no programa de RMSF. Sobral (CE), Brasil. E-mail: amandacolaresb@gmail.com

3. Psicólogo. Residente no programa de RMSF. Sobral (CE), Brasil. E-mail: luiz.george@ymail.com

4. Psicólogo. Residente no programa de RMSF. Sobral (CE), Brasil. E-mail: paulo.cesarluz@hotmail.com
} 


\section{ABSTRACT}

This article consists in a report of the mandatory experience in a network of the Brazilian program of Multiprofessional Residency in Family Health of the Family Health Education School 'Visconde de Sabóia' (RMSF/EFSFVS), in Sobral, Ceará, Brazil. Thus, the aim is presenting, thinking through, and discussing the services experienced, in order to analyze their idiosyncrasies and indicate how the contact with such services can contribute to the network interconnections related to Psychology working in the Family Health Strategy (FHS), both as a professional category and a multiprofessional team. The mandatory experience is provided for in the pedagogical proposal of the RMSF/EFSFVS, with a 80-hour workload, distributed in the first year of residency. The experience presented in this report took place within the period from July to December 2015, in 6 municipal health services. The report depicts the residents' impressions and affections regarding the services experienced, as well as the contributions of the mandatory experience to narrow the relations between services, improving the problem-solving performance in the daily routine of the Primary Health Care $(P H C)$.

\section{RESUMEN}

Este artículo consiste en un informe de la vivencia obligatoria en una red del programa brasileño de Residencia Multiprofesional en Salud de la Familia de la Escuela de Formación en Salud de la Familia "Visconde de Sabóia" (RMSF/EFSFVS), en Sobral, Ceará, Brasil. Así, el objetivo es presentar, reflejar y discutir los servicios vivenciados, para analizar sus idiosincrasias e indicar cómo el contacto con dichos servicios puede contribuir a las articulaciones en red relativas a la actuación de la Psicología en la Estrategia Salud de la Familia (ESF), como categoría profesional y equipo multiprofesional. La vivencia obligatoria está prevista en la propuesta pedagógica de la RMSF/EFSFVS, con una carga de trabajo de 80 horas, distribuidas en el primer año de residencia. La experiencia presentada en este informe se realizó en el periodo de julio a diciembre de 2015, en 6 servicios municipales de salud. El informe ilustra las impresiones y afectaciones de los residentes con respecto a los servicios experimentados, asícomo las contribuciones de la vivencia obligatoria para estrechar relaciones entre servicios, mejorando el desempeño de la resolución de problemas en el cotidiano de la atención primaria de salud (APS).

\section{INTRODUÇÃO}

Sobral, município localizado no norte do Ceará, caracteriza-se pela existência de um Sistema Saúde Escola, que busca contemplar as diretrizes propostas pela Política Nacional de Educação Permanente em Saúde (PNEPS). Esse sistema é compreendido como um modelo ampliado de organização dos processos de ensino-aprendizagem integrado à rede local de saúde, tendo na Secretaria Municipal de Saúde e na Escola de Formação em Saúde da Família Visconde de Sabóia (EFSFVS) seus representantes institucionais.

Viabilizando a proposta de converter toda a rede de serviços de saúde do município em espaços de educação contextualizada, a EFSFVS assumiu localmente o desafio de subsidiar, no campo da saúde pública, as novas políticas e práticas decorrentes das profundas mudanças implantadas em Sobral a partir de 1997 - quando se estabeleceu um novo projeto político-administrativo municipal ${ }^{1}$.

0 programa de Residência Multiprofissional em Saúde da Família (RMSF), efetivado pela EFSFVS em parceria com a Universidade Estadual Vale do Acaraú (UVA) desde 1999, consiste em uma pós-graduação com caráter de residência e tem por objetivos qualificar a atuação no setor saúde com base em uma mudança de mentalidade não necessariamente proveniente da apreensão de conteúdos - comum em cursos nesse nível de formação ${ }^{2}$.

Caracterizado como um programa que adota 0 processo de trabalho tendo como princípio e finalidade os processos de formação, a RMSF adota igualmente uma pedagogia dialógica e problematizadora. A educação/formação em serviço proposta para os programas de Residência Multiprofissional em Saúde (RMS) avança quando consegue conectar-se à prática dos profissionais, com base no encontro entre as pessoas, no diálogo e na transformação permanente de si e do mundo ${ }^{3}$.

0 marco teórico-metodológico da RMSF/EFSFVS advém da promoção da saúde, da educação permanente, da educação popular e da educação por competências ${ }^{2}$, cada uma delas articulada em uma perspectiva de aprendizagem significativa, que considera os afetos e sentidos envolvidos no processo de educação. 0 modelo pedagógico do programa de RMSF se distribui entre: a) vivências teóricoconceituais, atreladas aos ciclos temáticos; b) vivências nos territórios, articulando a formação em serviço; e c) vivências de produção científica, 
concomitante a esses processos e vivências de extensão ${ }^{2}$.

Esta última, como objeto principal deste texto, caracteriza-se como um rico momento que intensifica e aprimora o fazer profissional pertinente a cada categoria integrante da RMSF/EFSFVS, a partir da busca de conhecimentos e experiências relevantes, sempre visando a contribuir para aumentar a efetividade das praticas e dos saberes ${ }^{2}$.

0 objetivo deste relato de vivência é apresentar reflexões sobre a vivência da categoria de Psicologia na RMSF/EFSFVS (turma número 12) e suas contribuições para as articulações na rede municipal de saúde.

\section{METODOLOGIA}

Este artigo consiste em um relato de experiência que apresenta as vivências de extensão da RMSF/ EFSFVS, sob a perspectiva da categoria de Psicologia (turma número 12), composta por 3 psicólogos residentes e 1 psicóloga preceptora. As vivências obrigatórias de extensão têm carga horária de 80 horas, distribuídas pelos serviços de saúde do município afins à categoria, sendo a carga horária mínima de 12 horas por serviço.

A preceptoria, em acordo com os psicólogos residentes, elegeu 6 serviços a vivenciar, considerando a relevância para a formação, bem como o estreitamento de laços na rede de saúde. Optou-se por vivenciar os seguintes serviços: a) Centro de Atenção Psicossocial Geral (CAPS Geral) - 16 horas; b) Centro de Atenção Psicossocial Álcool e Drogas (CAPS AD) - 16 horas; c) Centro de Orientação e Apoio Sorológico (Coas) - 12 horas; d) Centro de Referência em Saúde do Trabalhador (Cerest) - 12 horas; e) Estratégia Trevo de Quatro Folhas - 12 horas; e f) Hospital Dr. Estevam Ponte - 12 horas.

0 período de vivências compreendeu o período de julho a dezembro de 2015. Todos os momentos foram articulados e agendados previamente por meio de mediação realizada pela preceptora de núcleo da RMSF/EFSFVS. As vivências foram de observação/ intervenção e não causaram nenhum prejuízo ou constrangimento aos envolvidos, sendo conduzidas de modo íntegro e respeitoso.

\section{RESULTADOS E DISCUSSÃO}

0s resultados apresentados a seguir foram organizados por tópico, com a descrição das

\section{A implantação da \\ RAISM contribuiu com a transformação do lugar social das pessoas com transtorno mental...}

atividades e os contextos experimentados pelos psicólogos residentes, bem como a problematização e reflexão sobre o processo. Consideramos, para fins da organização deste relato, a Rede de Atenção Integral à Saúde Mental (RAISM) um só tópico agrupando 3 serviços vivenciados: CAPS Geral, CAPS Ad e Unidade de Internação Psiquiátrica em Hospital Geral (UIPHG) do Hospital Dr. Estevam Ponte. Em seguida, trazemos os tópicos Estratégia Trevo de Quatro Folhas, Coas e Cerest.

\section{Rede de Atenção Integral à Saúde Mental}

A RAISM surgiu no contexto da reforma psiquiátrica em Sobral, como estratégia substitutiva ao modelo psiquiátrico hospitalocêntrico que imperava na assistência ao sujeito em sofrimento ou adoecimento mental - com caráter manicomial da Casa de Repouso Guararapes. Essa instituição foi criada em 1974 e consolidou-se como referência regional na assistência psiquiátrica, permanecendo até a data de 10 de julho de 2000, quando foi descredenciada pela Secretaria de Saúde e Ação Social de Sobral, por meio da Portaria n. 113, devido a uma série de denúncias de maustratos, abusos e irregularidades ${ }^{4,5}$.

A implantação da RAISM contribuiu com a transformação do lugar social das pessoas com transtorno mental, uma vez que a rede se orienta por uma atuação humanizada, integral e territorial ${ }^{4}$, além de ser basilar para a política de saúde mental de Sobral.

Dentre os dispositivos que compõem a RAISM foi possivel estabelecer um contato vivencial com o CAPS Geral II, CAPS AD e a UIPHG do Hospital Dr. Estevam Ponte.

0 CAPS Geral de Sobral é do tipo II, que, conforme a Portaria n. $336 / \mathrm{GM}$ de $2002^{6}$ assiste territórios com população entre 70.000 e 200.000 habitantes, trabalha com várias equipes e funciona das 8:00 às 18:00, de segunda a sexta-feira. Trata-se de um dos serviços da atenção secundária à saúde imprescindível 
para o atendimento à demanda de saúde mental do município. Em seu projeto, ressaltam-se como principais características a integração com outros níveis de atenção, integração a sistemas de política social, acessibilidade, multiplicidade de funções e técnicas, prática multiprofissional e interdisciplinar, educação permanente e redução crítica da hierarquia assistente/assistido. Com isso, o CAPS busca trabalhar o protagonismo e a (co)responsabilização dos usuários no que diz respeito ao seu tratamento, promovendo maior autonomia e transformando a clínica tradicional ${ }^{4}$.

Foram vivenciados quatro turnos de atividades nesse serviço. 0 primeiro contato consistiu na apresentação do serviço, contextualizando-o a partir da RAISM do município, a importância social e comunitária, a constituição das equipes multiprofissionais e a integração e atuação multiprofissional, bem como o fluxograma do serviço e a articulação com a rede.

Outra atividade vivenciada foi o acolhimento, realizado por técnicos designados para a atividade no dia, objetivando a escuta inicial e uma triagem institucional. Durante o período de vivência, observamos que existem diversas formas de acolhimento, variando de acordo com o manejo/a metodologia do técnico do acolhimento. Um dos tipos vivenciados foi o acolhimento coletivo, em que é realizado um convite a todos os usuários que se encontram no serviço naquele turno. Inicialmente, o profissional de referência faz uma breve introdução, explicando aos usuários como funciona o momento, acordando algumas regras (respeitar os colegas e a fala do outro, não dar conselho, falar de si etc.) e faz uma escuta inicial de cada usuário, coletando informações relevantes para a condução do caso. Depois disso, os usuários são convidados a deixar a sala de acolhimento e aguardar na sala de espera, enquanto o técnico discute os casos do acolhimento com o médico psiquiatra para adotar os devidos encaminhamentos. Finalmente, retorna com o coletivo de usuários e acompanhantes para as devolutivas de cada caso individualmente e orientações gerais.

Observa-se que, embora seja inovador, esse espaço poderia ser potencializado, podendo a equipe incrementar metodologias ativas para promover maior interação ao invés de agrupar os usuários e escutálos individualmente.

As outras atividades acompanhadas no serviço foram o grupo de lazer e o grupo de práticas corporais. São atividades realizadas por técnicos, onde a maioria

\section{0 acolhimento sempre é realizado por profissionais de referência designados por turno.}

dos participantes são usuários intensivos do serviço. As duas atividades se assemelham, pois exercem um importante papel de desconstrução de uma lógica manicomial, ao passo que também objetivam a ocupação e/ou a utilização de espaços públicos pelos usuários do serviço, que muitas vezes se afastam e/ ou são afastados desses espaços sociais, como praças públicas, teatro, museu, dentre outros.

Durante a vivência, também destinamos quatro turnos voltados a CAPS AD. 0 primeiro deles consistiu na apresentação do serviço, contemplando seu espaço físico, profissionais e serviços ofertados. Conforme relato da coordenadora do serviço, o CAPS AD de Sobral foi criado em outubro de 2002, atendendo a população do município e cidades vizinhas. Caracteriza-se como porta aberta para pessoas com transtornos decorrentes do uso de sustâncias psicoativas.

0 serviço realiza atendimentos individuais, grupais, visitas domiciliares, apoio matricial, oficinas terapêuticas, atendimento aos familiares, dentre outros. Conta com equipe multiprofissional composta por assistente social, enfermeiro, médico clínico, psiquiatra, psicólogo, terapeuta ocupacional, técnico de enfermagem e oficineiro.

0 acolhimento sempre é realizado por profissionais de referência designados por turno; diferentemente do acolhimento realizado pelo CAPS Geral, ele tem uma forma muito particular de procedimento. É realizado individualmente, com acompanhamento de um familiar. Após a escuta inicial pelo técnico de referência do dia, o caso é encaminhado para a renovação de receita de medicamento e agendado para médico clínico, psiquiatra, psicólogo ou grupo do serviço.

Durante o turno de acolhimento vivenciado foi possível perceber uma especificidade do serviço: o grande número de pessoas que buscam o serviço após as recaídas e abandono do tratamento por um período significativo de tempo.

0 grupo de lazer vivenciado foi um piquenique na 
margem esquerda do Rio Acaraú, regado a músicas e conversas sobre o papel de cada um na sociedade. Já nosso último turno de vivência consistiu em uma roda de conversa sobre a participação dos usuários nas reivindicações de melhoria para o serviço, pois naquele dia a atividade que seria realizada deixou de ocorrer por falta de material, além de outras limitações levantadas pelo grupo.

Esses dois momentos constituíram uma experiência muito rica, de muitas trocas e empoderamento e colaboram para alcançar um dos grandes objetivos do serviço, que é contribuir para o resgate da cidadania e da inclusão social das pessoas com transtornos decorrentes do uso e da dependência de substâncias psicoativas.

A UIPHG funciona no Hospital Geral Dr. Estevam Ponte, em Sobral. Trata-se de uma instituição privada, conveniada ao Sistema Único de Saúde (SUS), referência para a macro e microrregião estadual em que o município se encontra, contando atualmente com 17 leitos e mais 5 leitos flutuantes na clínica. A unidade é referência para urgência, emergência, internação e pronto atendimento psiquiátrico ${ }^{7}$.

Instituída no ano 2000, após o descredenciamento da Casa de Repouso Guararapes, a unidade tem por objetivo garantir a retaguarda de internação às pessoas que apresentem crises de maior gravidade. A regulação das internações psiquiátricas da UIPHG é realizada pelos serviços extra-hospitalares CAPS, CAPS AD e Centro de Especialidades Médicas (CEM), depois de esgotadas outras possibilidades de tratamento ${ }^{7}$.

A UIPHG se insere no contexto da Reforma Psiquiátrica brasileira, que preconiza a progressiva adoção de serviços substitutivos de saúde mental de base territorial, que contemplem a atenção psicossocial. Assim, os objetivos específicos do serviço se referem ao pronto atendimento a usuários em situação aguda de sofrimento mental, a redução do tempo e do estigma da internação psiquiátrica e a recondução do usuário a seu meio social ${ }^{8}$.

Para nós, a visita à UIPHG foi de significativa relevância, tanto profissional como pessoal. Ao longo da carga horária de 12 horas, realizamos diferentes atividades com usuários e familiares, abordando questões reflexivo-vivenciais. Nosso contato com o ambiente, a equipe de trabalho e os usuários gerou em nós efeitos desmistificantes, em especial quando trazemos uma bagagem social carregada de preconceito para com os sujeitos que lá se encontram. Consideramos que o simples fato de poder refletir

\section{...as músicas mobilizaram falas e afetos, mesmo no silêncio de alguns...}

sobre essas questões já foi de fundamental importância dentro dos objetivos da vivência.

Mesmo com pouco tempo, permitimo-nos realizar algumas atividades que pudessem suscitar reflexões junto aos usuários e familiares. Ao proporcionar espaços de escuta, percebemos sofrimentos, desejos, receios e alegrias, que, inseridos no contexto do momento, expressam de modo singular a história pessoal de cada sujeito. Até para nós, que estávamos há poucos dias no serviço, mostrou-se expressivo o contato com essas realidades - que mobilizou e desconstruiu muitas de nossas concepções anteriores.

Uma de nossas formas de estabelecer vínculos e afetos se deu a partir de uma intervenção que não trazia grandes pretensões, mas terminou por se mostrar um poderoso instrumento de escuta e conhecimento da realidade dos usuários da unidade. Tratou-se de uma intervenção musical, realizada com um violão, músicas e convite ao uso da palavra.

Organizamos uma roda com cadeiras e deixamos em aberto o convite para aqueles que se sentissem à vontade para integrar aquele espaço. Aos poucos, alguns se aproximavam, sentavam e contavam suas histórias. A metodologia era simples: o usuário escolhia uma música que gostava, nós tocávamos e cantávamos a música juntos e, em seguida, abríamos a conversa aproveitando a escolha do usuário para convidá-lo a falar sobre sua história de vida ou outras questões.

Percebemos o quanto as músicas mobilizaram falas e afetos, mesmo no silêncio de alguns, uma vez que a recordação de fatos e memórias do passado e a relação daquela música com o momento presente se mostraram uma nítida oportunidade terapêutica. Ressaltamos, aqui, o modo como a arte é capaz de elaborar e dizer o que não se diz, de subverter ordens e apontar outros caminhos, de trazer à tona verdades e compreensões até então imperceptíveis aos próprios usuários.

Consideramos que essa intervenção foi a forma de escapar a uma lógica de tratamento que, por vezes, acaba traduzindo-se em uma readaptação do indivíduo 
à engrenagem doente ${ }^{9}$. Assim, para que as bases plantadas pela Reforma Psiquiátrica não se apresentem como mero rearranjo de instituições e práticas tradicionais ${ }^{10}$, intervindo diretamente nos cenários de ações e provocando questionamentos políticos, faz-se necessário que as atividades realizadas sempre fomentem a autonomia dos sujeitos.

Sabemos que apenas a saída da instituição asilar e a oposição à lógica hospitalocêntrica não significam que acabamos com os manicômios que nos habitam, pois ainda há alguns aprisionamentos que nos impedem de inventar e de resistir, inviabilizando a criação de novas formas de lidar com a loucura ${ }^{11}$.

Perspectivas como essa nos levam a atentar para a necessária e contínua criação de linhas de fuga que resistam às capturas do cotidiano de uma atividade profissional acrítica, a saber: a) burocratização do cuidado; b) precarização das condições de trabalho; e c) economia de tempo em detrimento da otimização da produtividade.

\section{Estratégia Trevo de Quatro Folhas}

A Estratégia Trevo de Quatro Folhas foi implantada em Sobral em 2001, surgindo a partir da necessidade de reorganizar a atenção materno-infantil no município, quando se identificou, a partir da análise de óbitos materno-infantis, diversos problemas relacionados às condições de vida das mulheres durante a gestação e nos períodos iniciais do cuidado com os filhos, sobressaindo-se a ausência do apoio social nessa fase do ciclo de vida da mulher ${ }^{12}$.

A estratégia se divide em 4 etapas: a) assistência ao pré-natal; b) parto/puerpério; c) nascimento; e d) acompanhamento até os 2 anos de vida do bebê. Constitui-se como política pública municipal e é desenvolvida com o apoio da sociedade civil e de pessoas jurídicas. Outra característica importante é que se encontra ligada à comunidade tanto pelo atendimento como pelo papel imprescindível das Mães Sociais ${ }^{12}$ - pessoas da comunidade capacitadas para acompanhar gestantes e puérperas em situação de vulnerabilidade social.

0 serviço conta com uma atuação multiprofissional e interdisciplinar e realiza outras ações, como: a) acompanhamento às gestantes usuárias de drogas; b) identificação de recém-nascidos de risco; c) internamento e alta de gestantes e crianças e repasse diário dessas informações aos Centros de Saúde da Família (CSF); d) operacionalização do Comitê de Prevenção da Mortalidade Materna, Perinatal e

\section{o SUS tem como um de seus objetivos cuidar integralmente da saúde da população...}

Infantil (CPMMPI) de Sobral; e e) doação de Kit Gestante ${ }^{12}$.

Nesse serviço, acompanhamos três turnos de atividades. A primeira atividade foi a apresentação do serviço pela coordenadora, que contextualizou e explicitou a estratégia, desde sua origem e as principais linhas de ação/intervenção até o fluxo e as estratégias de operacionalização do serviço.

As atividades seguintes foram visitas domiciliares às gestantes e puérperas em situação de vulnerabilidade social que se encontram em acompanhamento pelo serviço. Nessas visitas foi percebida a necessidade e a importância da articulação com os CSF para a efetivação do trabalho do trevo de quatro folhas - de grande auxílio no cuidado dessas famílias em suas condições de vida.

Ressaltamos que experienciar algumas atividades desenvolvidas por esse serviço foi essencial para nossa formação profissional, ao passo que essa estratégia está em constante diálogo com as equipes de Saúde da Família, na atenção integral à mulher/ gestante/puérpera, devendo ser comum à articulação interdisciplinar e ao olhar para a subjetividade.

\section{Centro de Orientação e Apoio Sorológico}

0 SUS tem como um de seus objetivos cuidar integralmente da saúde da população e é sob essa perspectiva que foram desenvolvidas ações voltadas à prevenção e controle das Infecções Sexualmente Transmissiveis (IST) ${ }^{13}$. É nesse contexto que o Coas se insere como equipamento articulado aos demais serviços do SUS para a ampliação do acesso ao diagnóstico das IST, o acompanhamento e a descentralização de ações que compreendam a temática.

Como forma de conhecimento do serviço, distribuímos nossa carga horária de 12 horas entre a observação da estrutura física do espaço, a conversa com a equipe de profissionais, os usuários e os familiares, a compreensão da rotina de trabalho e a 
facilitação de grupo terapêutico. Nesses momentos, observamos a importância de compreender a política que preconiza as ações na área, especialmente como modo de ofertar uma atenção mais qualificada aos usuários que dela necessitam.

De modo semelhante aos outros serviços vivenciados, pudemos notar que o contato com os usuários e familiares se mostrou importante para a compreensão de suas vivências e desafios. 0 perfil do público acompanhado é composto predominantemente por pessoas residentes em outros municípios da região, o que nos aponta as dificuldades enfrentadas semanalmente por esses usuários, que não contam com suporte de qualidade em seus locais de origem.

A facilitação de um grupo terapêutico na Casa de Apoio Rosa Gatorno, uma instituição não governamental ( $O N G$ ) de Sobral que também acolhe os usuários do Coas, constituiu um dos momentos mais potentes desse processo. Ao trabalhar questões vivenciais e proporcionar um espaço de escuta para usuários e familiares, observamos quanto o acompanhamento terapêutico faz diferença no prognóstico da doença e na forma como os usuários soropositivos e seus familiares veem esse aspecto.

\section{Centro de Referência em Saúde do Trabalhador}

0 primeiro contato com o serviço ocorreu em um espaço com todos os residentes, onde foram apresentados seu objetivo e funcionamento. 0 Cerest apresenta como finalidade ampliar a Rede Nacional de Atenção à Saúde dos Trabalhadores (Renast), com vistas a atuar na prevenção dos adoecimentos decorrentes das atividades laborais, bem como nos problemas de acidentes, morte e doenças relacionadas ao trabalho.

0 Cerest de Sobral é caracterizado como 1 dos 7 centros regionais do estado do Ceará, tendo sobre sua área de abrangência 47 municípios, e é composto pelas seguintes coordenadorias regionais de saúde (CRES): Acaraú, Camocim, Crateús e Sobral, contando com equipe multiprofissional.

Durante a vivência, participamos de outros 2 turnos no serviço, sendo que em 1 acompanhamos a psicóloga do serviço em uma atividade de divulgação para estudantes, do fazer e das contribuições do Cerest, com a finalidade de repassar os fluxos do serviço, como e em que casos podem ser adotados os encaminhamentos, a fim de ressaltar sua importância na rede de saúde.

No outro turno de vivência, acompanhamos uma

\section{o Cerest de Sobral é caracterizado como 1 dos 7 centros regionais do estado do Ceará...}

atividade realizada em parceria com o CSF Centro, onde ocorreu a "Saúde no Mercado", que constitui uma atividade mensal de promoção de saúde realizada pelo CSF, no mercado público de Sobral. Nessa atividade foi abordada a temática saúde do trabalhador, por meio de educação em saúde com os funcionários do mercado. Foram abordadas algumas temáticas, como: postura, lesões por esforços repetitivos ou distúrbios osteomusculares relacionados ao trabalho (LER/DORT) e saúde auditiva, visando a levar informação aos trabalhadores e incentivar as práticas laborais saudáveis, objetivando reduzir os riscos ambientais no trabalho.

Sob essa perspectiva, concebemos a atuação do Cerest na rede municipal de saúde de Sobral como fundamental para a saúde dos trabalhadores, pois ele vem realizando atividades que buscam promover a saúde na tentativa de evitar agravos decorrentes das atividades laborais.

\section{CONCLUSÃO}

A experiência vivenciada foi bastante significativa para o processo formativo da residencia multiprofissional, possibilitando desenvolver conhecimento, articulação e diálogo entre diversos serviços, espaços e sujeitos da rede de assistência à saúde de Sobral. Endossamos que esses momentos proporcionaram a construção de vínculos entre profissionais e serviços que, apesar de fazerem parte da mesma rede, ainda apresentam restrições na comunicação por questões burocráticas. Atualmente, constatamos a ampliação do diálogo e vínculo, entre residentes e alguns profissionais e serviços, conseguindo maior articulação e condução do cuidado.

Como limitação percebida durante a vivência de extensão apontamos a atual configuração desse processo no projeto pedagógico da RMSF/EFSFVS, que delimita a realização das vivências apenas nos serviços da rede de saúde, em detrimento de outros 
serviços que compõem as redes intersetoriais. Acreditamos que esse processo deve ser pensado como espaço formativo para além do setor saúde, possibilitando outros diálogos, como preconizado pelas políticas de organização do SUS. Desse modo, concretizamos 0 aspecto $d a$ intersetorialidade enquanto diretriz do sistema de saúde.

A experiência mostrou-se um momento de impacto e estranhamento das múltiplas formas de fazer psicologia. Estranhamentos necessários, pois fazem parte do processo natural de conhecimento dos espaços e práticas a que nos propomos observar. Por vezes, deparamo-nos com atuações que subvertem a lógica eminentemente clínica e superam as circunscrições do tradicional modo de fazer da psicologia, supostamente voltado à atenção individualista. Sob essa perspectiva, mostrou-se possível visualizar contextos amplos de compreensão da psicologia como profissão e que, por isso mesmo, podemos observar diferentes desdobramentos dessa compreensão refletidos nos efeitos e implicações da prática.

$\mathrm{Na}$ vivência de extensão, essas inquietações iniciais serviram de base para a adoção de um específico posicionamento que muito nos auxiliou na problematização das realidades observadas. Percebemos que é necessário repensar a prática da Psicologia refletindo sobre novos e possiveis modos de intervenção, que possibilitem aproximações efetivas com a realidade dos serviços visitados e que, observando especialmente o contexto do SUS, possam contribuir para a promoção da saúde e para a compreensão dos caracteres múltiplos do processo saúde-doença.

Assim, a vivência de extensão constituiu ricos momentos de interrupção de fluxos e recriação de percursos, processos valiosos que possibilitaram repensar questões relativas à prática do psicólogo e observar perspectivas que se desdobram em relação a essa prática. Diferentemente do que poderia se pensar, a finalização desses escritos aponta não para

$$
\text { ...atuações que }
$$

subvertem a lógica eminentemente clinica e superam as circunscrições do tradicional... o término, mas para a continuação de um processo que ainda tem muito a percorrer. Um caminho longo e ao mesmo tempo diferente dos demais: o único que só faz sentido à medida que não tem fim. Ponhamos, então, os pés no chão e o experimentemos...

\section{CONTRIBUIÇÃO DOS AUTORES}

Ana Karina de Sousa Gadelha contribuiu com o delineamento da pesquisa e a estruturação e revisão crítica do manuscrito. Amanda Colares Bezerra, George Luiz Costa e Paulo Cesar de Moura Luz contribuíram com o delineamento e a realização da pesquisa e a redação do manuscrito.

\section{REFERÊNCIAS}

1. Andrade LOM, Barreto ICHC, Martins Júnior T, Amaral MIV, Parreiras PC. Escola de Formação em Saúde da Família Visconde de Sabóia: três anos construindo a tenda invertida e a educação permanente no SUS. Sanare (Sobral, Online) [serial on the internet]. 2004 [cited 2018 May 4];5(1):33-9. Available from: https://sanare.emnuvens.com.br/sanare/ article/view/120/112

2. Martins Júnior T, Parente JRF, Souza FL, Sousa MST. A residência multiprofissional em Saúde da Família de SobralCeará. Sanare (Sobral, Online) [serial on the internet]. 2008 [cited 2018 May 14];7(2):23-30. Available from: https:// sanare.emnuvens.com.br/sanare/article/viewFile/28/23

3. Carvalho AB, Nepomuceno LB. A residência multiprofissional em Saúde da Família potencializando a transformação através da formação: uma utopia necessária. Sanare (Sobral, Online) [serial on the internet]. 2008 [cited 2018 May 14];7(2): 31-7. Available from: https://sanare. emnuvens.com.br/sanare/article/view/29/24

4. Barros MMM, Jorge, MSB. Concepções e práticas de atenção a saúde mental: o discurso do sujeito coletivo. Fortaleza (CE): Ed. UECE; 2011.

5. Quindere PHD, Jorge MSB. (Des)construção do modelo assistencial em saúde mental na composição das práticas e dos serviços. Saúde Soc [serial on the internet]. 2010 [cited 2018 May 14];19(3):569-83. Available from: http://www. scielo.br/pdf/sausoc/v19n3/09.pdf

6. Brasil. Portaria n. 336/GM, de 19 de fevereiro de 2002 [document on the internet]. Brasília (DF): Ministério da Saúde; 2002 [cited 2018 May 14]. Available from: https:// edisciplinas.usp.br/pluginfile.php/4175108/mod resource/ content/1/Portaria\%20GM\%20336-2002.pdf

7. Sá RAR, Barros MMM, Costa MSA. Saúde mental em Sobral-CE: atenção com humanização e inclusão social. Sanare (Sobral, Online) [serial on the internet]. 2007 [cited 2018 May 14];6(2):26-33. Available from: https://sanare. emnuvens.com.br/sanare/article/view/150/142 
8. Souza FSP, Silva CAF, Oliveira EN. Serviço de emergência psiquiátrica em hospital geral: estudo retrospectivo. Rev Esc Enferm USP [serial on the internet]. 2010 [cited 2018 May 14];44(3):796-802. Available from: http://www.scielo.br/ $\mathrm{pdf} / \mathrm{reeusp} / \mathrm{v} 44 \mathrm{n3} / 35 . \mathrm{pdf}$

9. Bezerra Júnior B. Considerações sobre terapêuticas ambulatoriais em saúde mental. In: Tundis AS, Costa NR, organizers. Cidadania e loucura: políticas de saúde mental no Brasil. 7. ed. Petrópolis, RJ: Vozes; 2001. p. 134-169.

10. Amarante P. A (clínica) e a reforma psiquiátrica. In: Amarante $P$, coordinator. Arquivos de saúde mental e atenção psicossocial. Rio de Janeiro: Nau; 2003. p. 45-65.

11. Romagnoli RC, Paulon SM, Amorim AKMA, Dimenstein M. Por uma clínica da resistência: experimentações desinstitucionalizantes em tempos de biopolítica. Interface Comun Saúde Educ [serial on the internet]. 2009 [cited 2018 May 14];13(30):199-207. Available from: http://www. scielo.br/pdf/icse/v13n30/v13n30a16.pdf

12. Sousa FJS, Sucupira ACSL, Aguiar ISM, Mesquita VAL, Sales ENBG. Programa Trevo de Quatro Folhas: uma ação efetiva para a redução da mortalidade infantil em Sobral Ceará. Sanare (Sobral, 0nline) [serial on the internet]. 2012 [cited 2018 May 14];11(1):60-5. Available from: https:// sanare.emnuvens.com.br/sanare/article/view/268/241

13. Brasil. Práticas profissionais dos(as) psicólogos(as) no campo das DST/AIDS. Brasília (DF): Conselho Federal de Psicologia; 2009. $\ldots \ldots \ldots \ldots \ldots \ldots . . . .$.

$\ldots \ldots \ldots \ldots \ldots \ldots \ldots$

${ }^{\circ}$ $\ldots \ldots \ldots \ldots \ldots \ldots \ldots$

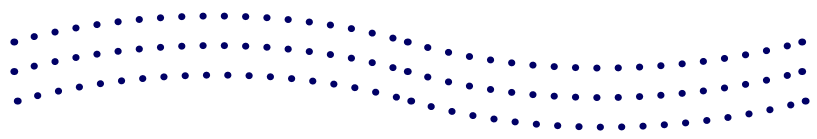

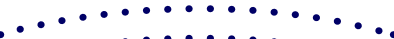

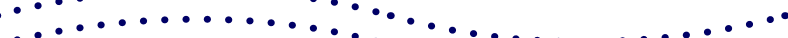

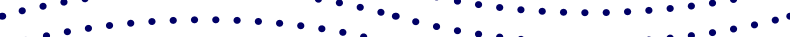

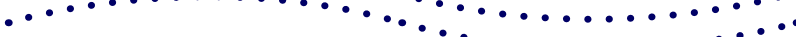
$\cdots \ldots \ldots$
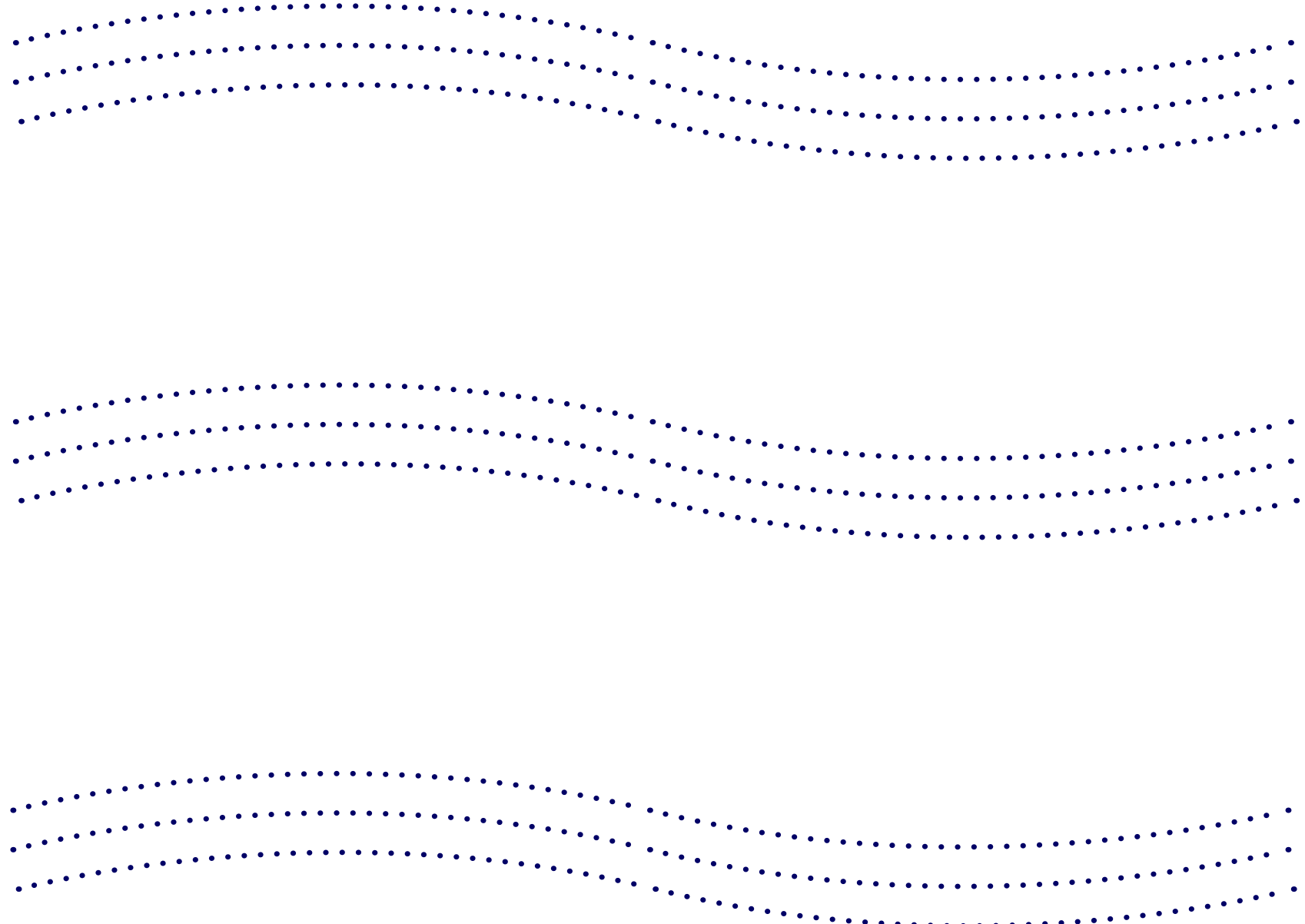


\section{VIVÊNCIAS E ESTÁGIOS NA REALIDADE DO SISTEMA ÚNICO DE SAÚDE: DEBATENDO GÊNERO, FEMINISMO E DIVERSIDADE}

EXPERIENCES AND INTERNSHIPS IN THE REALITY OF THE BRAZILIAN NATIONAL HEALTH SYSTEM: DEBATING GENDER, FEMINISM AND DIVERSITY

EXPERIENCIAS Y PASANTÍAS EN LA REALIDAD DEL SISTEMA ÚNICO DE SALUD BRASILEÑO: DEBATIENDO GÉNERO, FEMINISMO Y DIVERSIDAD

Gilson Aquino Cavalcante ${ }^{1}$

Jonatas Gomes Neri 2

Sueli Alves Castanha ${ }^{3}$

Juciano de Sousa Lacerda ${ }^{4}$

Palavras-chave: Sistema Único de Saúde; Identidade de Gênero; Saúde Pública; Educação em Enfermagem.

Keywords:

Brazilian National Health System; Gender Identity; Public Health; Education, Nursing.

Palabras clave: Sistema Único de Salud Brasileño; Identidad de Género; Salud Pública; Educación en Enfermería.

Submetido: 19/09/2017

Aprovado: $18 / 04 / 2018$

Autor(a) para Correspondência: Gilson Aquino Cavalcante End: Rua Henrique Dias, 39 - G - Igapó - CEP: 59104-300, Natal-RN

E-mail: aquinogilson@yahoo.com.br

\section{RESUMO}

Este artigo descreve a experiência de estudantes de graduação em Enfermagem no programa "Vivências e Estágios na Realidade do Sistema Único de Saúde" (VER-SUS), versão 2016.1, que ocorreu em Natal (RN), e sua abordagem às temáticas gênero, feminismo e população de lésbicas, gays, bissexuais, travestis, transexuais e transgêneros (LGBT). Trata-se de um relato de experiência descrito pelos estudantes por meio de um portfólio entregue ao final das vivências, como forma de comprovar a participação e obter a certificação do programa. No decorrer de toda a vivência, os estudantes se depararam com os mais diferentes cenários $e$ realidades da saúde brasileira no que tange ao Sistema Único de Saúde (SUS), como as unidades básicas de saúde (UBS) e sua organização. Esse contato possibilitou a observação do desconhecimento dos estudantes sobre o SUS e sua organização, bem como acerca das temáticas gênero, feminismo e população LGBT. O VER-SUS constitui um importante dispositivo que possibilita aos estudantes participantes adentrar um espaço diversificado de aprendizagem e vivências relacionadas a seu futuro cotidiano de trabalho. Assim sugere-se a continuação e divulgação desse programa, que proporciona capacitação em diversas temáticas no que se refere a atenção à saúde e organização do sistema de saúde brasileiro.

1. Aluno de Graduação em Enfermagem no Centro Universitário Maurício de Nassau (Uninassau). Natal (RN), Brasil. E-mail: aquinogilson@yahoo.com.br

2. Aluno de Graduação em Enfermagem no Uninassau. Natal (RN), Brasil. E-mail: jonatasgomesneri@gmail.com 3. Enfermeira. Especialista em Saúde Coletiva e Saúde da Família. Instituto Superior e Centro Educacional Luterano "Bom Jesus" (IELUSC). Joinville (SC), Brasil. E-mail: sualves13@gmail.com

4. Doutor em Ciências da Comunicação. Professor na Universidade Federal do Rio Grande do Norte (UFRN). Membro do Núcleo de Estudos em Saúde Coletiva (Nesc) da UFRN. Coordenador do Laboratório de Pesquisa e Estudos em Comunicação Comunitária e Saúde Coletiva (Lapeccos) da UFRN. Natal (RN), Brasil. E-mail: juciano. lacerda@gmail.com 


\section{ABSTRACT}

This article describes the experience of undergraduate Nursing students in the program 'Experiences and Internships in the Reality of the Brazilian National Health System' (VER-SUS), version 2016.1, which took place in Natal, Rio Grande do Norte, Brazil, and its approach to the themes gender, feminism, and lesbian, gay, bisexual, and transgender (LGBT) population. This is an experience report described by students through a portfolio delivered when the experiences came to an end, as a way to prove participation and obtain certification from the program. Throughout the experience, students faced the most varied Brazilian health scenarios and realities regarding the Brazilian National Health System (SUS), such as Brazilian primary health centers (UBS) and their organization. This contact made it possible to observe the lack of knowledge on the SUS and its organization among students, as well as about the themes gender, feminism, and LGBT population. The VER-SUS is a significant device that enables participating students to get into a diversified space for learning and experiences related to their future everyday work. Thus, we suggest the continuation and dissemination of this program, which provides training in various themes concerning health care and organization of the Brazilian health system.

\section{RESUMEN}

Este artículo describe la experiencia de estudiantes de pregrado en Enfermería en el programa "Experiencias y Pasantías en la Realidad del Sistema Único de Salud Brasileño" (VER-SUS), versión 2016.1, que tuvo lugar en Natal, Rio Grande do Norte, Brasil, y su abordaje a los temas género, feminismo y población de lesbianas, gays, bisexuales y transexuales (LGBT). Este es un informe de experiencia descrito por los estudiantes a través de un portafolio entregado cuando las experiencias llegaron a su fin, como una forma de probar la participación y obtener la certificación del programa. A lo largo de la experiencia, los estudiantes se enfrentaron a los escenarios y las realidades más diversas de la salud brasileña con respecto al Sistema Nacional de Salud Brasileño (SUS), como los centros primarios de salud brasileños (UBS) y su organización. Este contacto permitió observar la falta de conocimiento acerca del SUS y su organización entre los estudiantes, así como sobre los temas género, feminismo y población LGBT. El VER-SUS es un importante dispositivo que permite a los estudiantes participantes adentrar en un espacio diversificado para el aprendizaje y las experiencias relacionadas con su futuro cotidiano de trabajo. Así, se sugiere la continuación y difusión de este programa, que brinda capacitación en diversos temas relacionados con atención a la salud y organización del sistema de salud brasileño.

\section{INTRODUÇÃO}

O Sistema Único de Saúde (SUS) é considerado um dos mais amplos sistemas públicos de saúde do mundo, pautando-se por um arcabouço de princípios e diretrizes. Idealizado na VIII Conferência Nacional de Saúde, realizada em 1986, foi instituído pela Constituição Federal de 1988, acatando as proposições do movimento da Reforma Sanitária Brasileira (RSB), que teve como principal bandeira a luta pela democratização da saúde. Para tanto, incorporou mudanças no papel do Estado no setor saúde, a fim de garantir acesso integral, universal e gratuito - o SUS garante atendimento a toda a população, independente de sexo, situação econômica, idade, cor da pele e orientação sexual. Para uma operação eficiente desse sistema de saúde, em consonância com seus princípios, além de gestão, são necessários trabalhadores capacitados em suas respectivas áreas. No entanto, com frequência se observa certo despreparo técnico, científico e político entre esses profissionais ${ }^{1-3}$.

Há significativa lacuna na formação e no preparo dos profissionais da saúde considerados qualificados para atuar nas diversas instâncias do SUS ${ }^{2-4}$. Romper com os modelos assistenciais hegemônicos se mostra um desafio constante, visto que as matrizes curriculares em saúde não atendem adequadamente as propostas do processo saúde-doença e seus determinantes. 0 ordenamento jurídico brasileiro assimilou a Teoria da Determinação Social no processo saúde-doença, nos termos da medicina social e da saúde coletiva. Contudo, atualmente não se observa valorização desse princípio por parte da sociedade e do Estado nem reconhecimento da "saúde da população como resultante das formas de organização social da produção"1:252. Ao analisar currículos de escolas de Enfermagem, pesquisadores observaram que o perfil dos profissionais continua voltado a modelos hospitalocêntricos - há sinalização de reorientação da formação, porém, trata-se de um processo lento ${ }^{2}$. 
Nessa mesma ótica, as abordagens da diversidade, do gênero e da sexualidade são pouco debatidas durante a formação em saúde; as discussões se restringem às funções e disfunções do sistema sexual e reprodutor. Na escola, os temas transversais sobre gênero e sexualidade ficam à margem dos debates e, quando entram em pauta, surgem dúvidas quanto à sua credibilidade e desqualificação dos profissionais/ docentes que buscam discuti-los ${ }^{5}$. No Ensino Superior, essas mesmas questões balizam uma formação que reafirma papéis sociais de gênero previamente estabelecidos. Michel Foucault caracteriza tal contexto como poder disciplinador da escola - que treina e silencia os corpos, constituindo o indivíduo necessário à manutenção do capital ${ }^{6}$.

Abordar gênero, sexualidade e diversidade nas várias especialidades do setor saúde, dentro e fora das instituições de formação, busca reafirmar a universalidade, integralidade e gratuidade no âmbito do SUS.

Com vistas a minimizar as lacunas na formação de profissionais do SUS, surgiu em 2002 o programa “Vivências e Estágios na Realidade do Sistema Único de Saúde" (VER-SUS) - projeto financiado pelo Ministério da Saúde (MS) e coordenado pela Rede Unida e pela União Nacional dos Estudantes (UNE), que incentiva o protagonismo estudantil ao organizar a imersão de estudantes de graduação no SUS, sejam estes do setor saúde ou de outros setores, interessados em estabelecer vivências durante o período de férias de instituições públicas e privadas ${ }^{7}$. 0 VER-SUS capacita e complementa a formação desses estudantes, pois discute diversas questões que permeiam todos os níveis de atenção à saúde no âmbito do SUS, dentre as quais se encontram as temáticas gênero, diversidade e feminismo.

Este artigo descreve a experiência de estudantes de graduação em Enfermagem no programa VER-SUS, versão 2016.1, que ocorreu em Natal (RN), com abordagem das temáticas gênero, feminismo e população de lésbicas, gays, bissexuais, travestis, transexuais e transgêneros (LGBT).

\section{METODOLOGIA}

Trata-se de relato de experiência de estudantes de graduação em Enfermagem, de instituição de Ensino Superior privada, no programa VER-SUS, versão 2016.1.

A vivência ocorreu em Natal, de 08/01/2016 a 19/01/2016, coincidindo com o período de férias da

\section{O VER-SUS \\ capacita \\ e complementa a \\ formação desses \\ estudantes...}

instituição em questão. Participaram do programa VER-SUS, versão 2016.1, cerca de 60 estudantes de graduação de diversas instituições públicas e privadas e de diferentes áreas do conhecimento, dentre as quais: Enfermagem, Medicina, Odontologia, Nutrição, Fisioterapia, Gestão de Políticas Públicas, Psicologia, Direito e Jornalismo. Esses participantes ficavam alojados durante o dia, dormiam e realizavam as refeições no centro de treinamento, com saída apenas para os locais das práticas de vivências.

Para organizar e desenvolver o projeto, os participantes foram divididos em 5 núcleos de base (NB), compostos por 10 viventes (estudantes) e 2 facilitadores (participantes de edições anteriores) selecionados para mediar as atividades com base na experiência adquirida.

A seleção para participar do programa foi realizada on-line, na plataforma Observatório de Tecnologias de Informação e Comunicação em Sistemas de Saúde (OTICS), conveniada ao MS ${ }^{8}$. 0 formulário de inscrição consistia em um questionário sobre as variáveis sociodemográficas e acadêmicas. Os critérios de inclusão foram: a) disponibilidade de participação em tempo integral; e b) estar matriculado e frequentando curso de graduação em instituição de Ensino Superior pública ou privada.

A discussão a seguir resultou dos relatos de viventes que participaram do VER-SUS, versão 2016.1, em Natal. Tais relatos foram produzidos no final de cada dia de vivência, por meio dos debates entre os $N B$, onde eram colocadas as vivências e percepções do dia. No fim das vivências, todos os relatos de cada vivente foram enviados, por meio de um portfólio, na plataforma 0TICS; a visualização ficou restrita aos viventes de todos os NB e à coordenação. Essa é uma forma de compartilhar as experiências entre os viventes, além de comprovar a participação e obter a certificação do programa.

\section{RESULTADOS E DISCUSSÃO}

No decorrer de toda a vivência, os estudantes se 
depararam com os mais diversos cenários e realidades da saúde brasileira no que tange ao SUS, como as unidades básicas de saúde (UBS) e sua organização. Esse contato possibilitou a observação do desconhecimento dos estudantes sobre o SUS e sua organização, bem como acerca das temáticas gênero, feminismo e população LGBT.

Após cada dia de vivência, os viventes organizavam rodas de conversa e confeccionavam relatórios dos principais pontos de cada instância ou formação no projeto. Para contribuir com as discussões e enriquecer a capacitação, também contavam com recursos textuais, audiovisuais e lúdicos, como filmes, pintura, artesanato e dramatização. Todas essas tarefas eram executadas com o apoio dos facilitadores.

Quando foi abordada a temática gênero, percebeuse que os estudantes desconheciam o atual conceito de gênero, bem como as características e as necessidades específicas de cada grupo. Inclusive as concepções acerca do feminismo, como movimento social e cultural, e da população LGBT.

\section{Gênero}

0 projeto em si foi todo pautado pela temática gênero. Desde a seleção dos participantes, a comissão responsável buscou garantir a igualdade do número de participantes entre mulheres, homens e população LGBT.

Diante do desconhecimento dos viventes do VERSUS sobre o referido tema foram realizadas oficinas de formação, com o propósito de esclarecer conceitos e promover debates e discussões acerca dessas questões. Foram disponibilizados textos sobre conceituação de gênero para cada NB e no final do dia houve uma reunião com todos os participantes, com vistas a promover capacitação voltada às diversas definições de gênero, estabelecido em 1993 como elemento constitutivo de relações sociais fundadas sobre as diferenças percebidas entre os sexos - sendo o gênero o primeiro modo de atribuir significado às relações de poder ${ }^{9}$. E em 2011, o MS definiu gênero como a construção histórica, cultural e política das diversas possibilidades do ser feminino e/ou masculino. Ultrapassa, portanto, o "ser macho" ou "ser fêmea", originando diferentes papéis e funções sociais, cuja consequência é a distribuição desigual do poder e das oportunidades a partir do que é definido social e culturalmente como "coisa de homem" ou "coisa de mulher"10.

\section{As vivências buscaram a compreensão e o diálogo com o movimento feminista...}

Assim, os viventes foram expostos às atuais particularidades da diversidade, principalmente no que tange às necessidades e aos direitos da população feminina e da população LGBT. Esses debates objetivam preparar os viventes para o contato direto com a diversidade como profissionais das diversas áreas, proporcionando um cuidado livre de preconceito.

\section{Feminismo}

No percurso do programa VER-SUS, versão 2016.1, em Natal, reservou-se um período para o debate sobre a temática do feminismo. Em um primeiro momento surgiu um espaço misto, com a presença de homens e mulheres, onde foi abordada a coparticipação da população masculina no movimento feminista. Posteriormente, surgiu um espaço auto-organizado, composto somente por mulheres, que tratou de versar sobre as dificuldades vivenciadas pelas mulheres na sociedade e a luta pela garantia de direitos igualitários.

Durante o período de vivência ocorreram diversas intervenções, uma delas por meio de frases colocadas em cima das mesas no refeitório que explicitavam atitudes que fortalecem condutas machistas, ainda disseminadas pela sociedade na vida cotidiana.

As vivências buscaram a compreensão e o diálogo com o movimento feminista, que tem como interesse central a igualdade de direitos entre homens e mulheres, questionando a subordinação à qual as mulheres são submetidas ${ }^{11}$. Com base nisso, a comissão político-pedagógica do projeto garantiu a biparidade de gênero durante a realização das atividades, de modo que todos os diálogos ocorreram com proporcionalidade entre homens e mulheres.

Muitos dos viventes não conheciam o conceito e a origem desse movimento, principalmente em relação a ser um movimento social e cultural evidenciado em meados dos anos 1960, em resposta à opressão 
enfrentada ao longo dos tempos pelas mulheres.

Observou-se que, além da falta de informação, ainda há resistência em relação ao termo feminismo, colocado como sinônimo de machismo e não discutido em sua essência. Desse modo, os momentos vivenciados no âmbito desse tema se mostraram de suma importância para a desconstrução e a desnaturalização dos papéis que distinguem homens e mulheres, marcadores sociais que geram desigualdades e vulnerabilidades e permeiam um conjunto de determinantes que interferem no processo de viver, adoecer e morrer das diversas populações.

\section{População LGBT}

Seguindo o mesmo método trabalhado no feminismo, no espaço misto foram debatidas as especificidades da população LGBT e o enfrentamento das dificuldades que ela enfrenta na sociedade, principalmente quando relacionadas ao acesso a serviços de saúde. Esse tema foi trabalhado por meio da dramatização do uso do nome social no SUS e da terapia hormonal para adequação corpórea à identidade de gênero. Assim, essas estratégias têm o intuito de capacitar os estudantes para que, em sua prática profissional, tratem todas as pessoas de modo livre de preconceitos e estigmas.

A dramatização se mostrou importante por promover o debate da experiência pessoal relatada por cada indivíduo presente. Como, por exemplo, o caso de um dos viventes que havia sido expulso de casa depois de assumir sua homossexualidade. Ele recebeu apoio dos demais, o que serviu para promover o companheirismo no âmbito do programa.

Todas as questões abordadas tiveram a finalidade de garantir o direito constitucional da universalidade do SUS. Mostrou-se possível promover a saúde integral da população LGBT, sem discriminação e preconceito institucional, contribuindo para a redução das desigualdades e a consolidação do SUS nos termos da Política Nacional de Saúde da População LGBT ${ }^{12}$.

\section{CONCLUSÃO}

0 VER-SUS constitui um importante dispositivo que possibilita aos estudantes participantes adentrar um espaço diversificado de aprendizagem e vivências relacionadas a seu futuro cotidiano de trabalho.

Nos tempos atuais, constata-se a necessidade de reorientar a formação dos profissionais da saúde e modificar as grades curriculares no setor saúde, com

\section{...promover a saúde integral da população LGBT, sem discriminação $e$ preconceito institucional...}

a retirada de disciplinas das áreas de Ciências Humanas e a oferta de cursos na modalidade educação a distância. Isso contribui para a manutenção da lacuna entre formação e preparo e não favorece o estabelecimento de diálogos que busquem a compreensão das doenças que acometem a população.

Nesse sentido, o programa VER-SUS oferece um ambiente ímpar para a formação social e política de futuros profissionais da saúde. Considerando que, em muitas realidades, a depender da grade curricular e da missão da instituição de Ensino Superior, os profissionais da saúde são formados no SUS (por meio de estágios obrigatórios), porém, não são formados para o SUS, a formação desses profissionais demanda avanços para atender às concepções dispostas nas bases legais do SUS, que permeiam as necessidades e as práticas de saúde em todo o país.

0 programa VER-SUS deve seguir promovendo a formação de profissionais comprometidos ética e politicamente com as demandas de saúde das populações atendidas por eles - como aquelas permeadas pela temática gênero, com base na Política Nacional de Saúde da População LGBT, tendo em vista que o preconceito é um determinante social do adoecimento nessa população.

Assim, sugere-se a continuação, a divulgação e o fortalecimento desse programa, que proporciona capacitação em diversas temáticas da atenção e do cuidado no âmbito do sistema de saúde brasileiro.

\section{CONTRIBUIÇÃO DOS AUTORES}

Gilson Aquino Cavalcante contribuiu com a concepção do estudo e a preparação do manuscrito. Jonatas Gomes Neri contribuiu com a concepção do estudo e a preparação e estruturação do manuscrito. Sueli Alves Castanha contribuiu com a redação e a revisão crítica do manuscrito. Juciano de Sousa Lacerda contribuiu com a revisão crítica do manuscrito. 


\section{REFERÊNCIAS}

1. Paim JS. Reforma sanitária brasileira: contribuição para a compreensão e crítica. 2007. Tese (Doutorado em Saúde Pública) - Instituto de Saúde Pública, UFBA, Bahia. Available from: https://repositorio.ufba.br/ri/bitstream/ ri/10376/1/5555555555.pdf

2. Silva RPG, Rodrigues RM. Sistema Único de Saúde e a graduação em enfermagem no Paraná. Rev Bras Enferm [serial on the internet]. 2010 [cited 2018 Apr 22];63(1):6672. Available from: https://pdfs.semanticscholar.org/8728/ 5761bf2a5165d15c0955a6471af914952b68.pdf

3. Gomes AMT, Oliveira DC, Sá CP. As representações sociais do Sistema Único de Saúde no município do Rio de Janeiro. Rev Latinoam Enferm [serial on the internet]. 2008 [cited 2018 Apr 22];16(1):122-9. Available from: http://www. scielo.br/pdf/rlae/v16n1/pt_18

4. Lira Neto JCG, Freitas RWJF, Brito ECC, Santos LR, Alves LEP, Alves LRA. VER-SUS: an experience report about a life experience-stage in the reality of the Unified Health System. Rev Enferm UFPE On Line [serial on the internet]. 2013 [cited 2018 Apr 22];7(Spec):1042-6. Available from: https://periodicos.ufpe.br/revistas/revistaenfermagem/ article/viewFile/11574/13572

5. Leal CJ, Oliveira LB. A escola e a desnaturalização do gênero e da sexualidade: na construção de uma sociedade de respeito às diferenças. In: Bento $B$, Félix-Silva $A V$, organizer. Desfazendo gênero: educação da diferença, masculinidades, feminismos e literatura. Natal: Ed. UFRN; 2015. p. 21-46.

6. Gore JM. Foucault e educação: fascinantes desafios. In: Silva TT, organizer. 0 sujeito da educação: estudos foucaultianos. 7. ed. Petrópolis (RJ): Vozes; 2010. p. 9-20.

7. Pedrosa R, Ferla AA. Refletindo o Programa Mais Médicos em Novo Hamburgo, Rio Grande do Sul, a partir do olhar dos participantes do VER-SUS, edição verão 2014. IV Congresso Piauiense de Saúde Pública; 2015; Parnaíba. Anais. (Sanare (Sobral, Online) [serial on the internet]. 2015 [cited 2018 Apr 22];14(Suppl 1):42). Available from: https://sanare. emnuvens.com.br/sanare/article/viewFile/666/369

8. VER-SUS [homepage on the internet]. Porto Alegre: Ministério Saúde; [s.d] [cited 2018 Apr 22]. Available from: http://www.otics.org/estacoes-de-observacao/versus

9. Oliveira EN, Araújo MFM. Gênero e saúde. Sanare (Sobral, Online) [serial on the internet];2002 [cited 2017 May 4];3(1):59-62. Available from: http://sanare.emnuvens. com.br/sanare/article/view/90/82

10. Brasil. Diversidades sexuais. Brasília (DF): Ministério da Saúde; 2011.

11. Levatti EG. Um breve olhar acerca do movimento feminista. Bauru (SP): Unesp; 2011.
12. Brasil. Política Nacional de Saúde Integral de Lésbicas, Gays, Bissexuais, Travestis e Transexuais. Brasília (DF): Ministério da Saúde; 2012.
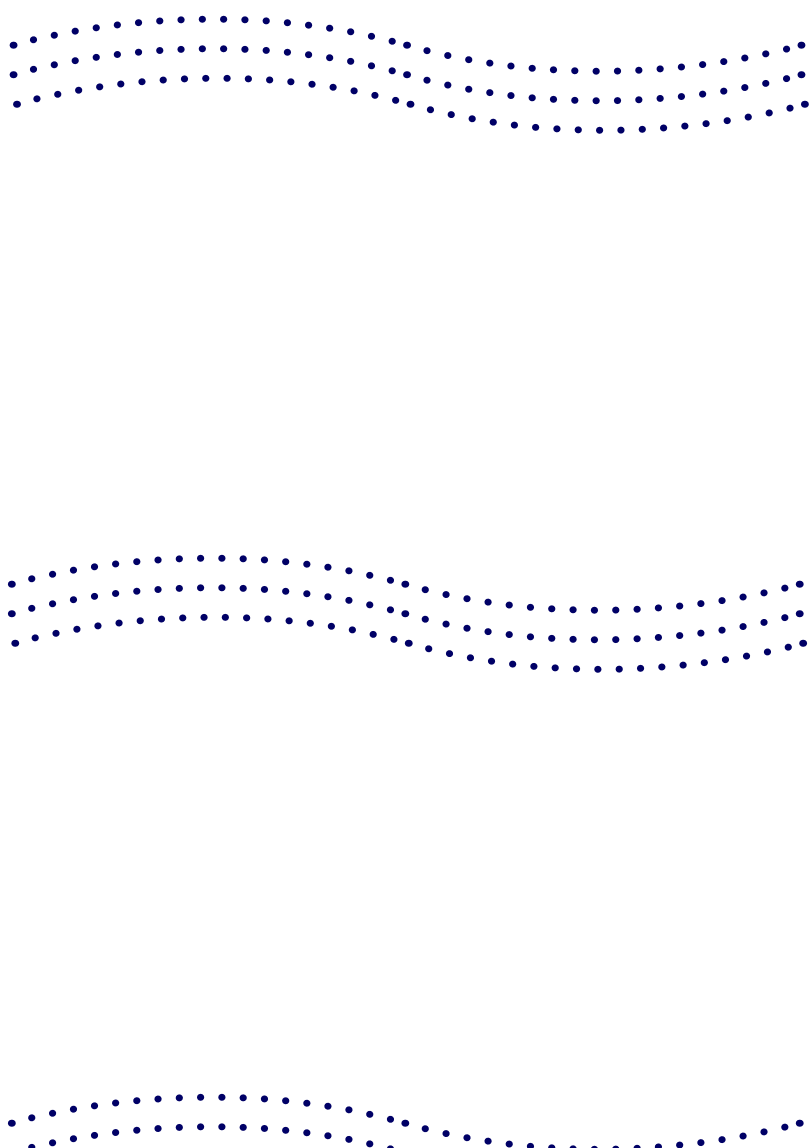
$\ldots \ldots \ldots \ldots \ldots \ldots \ldots$ $\ldots \ldots \ldots \ldots \ldots \ldots$

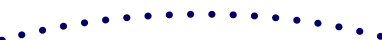
$\ldots \ldots \ldots \ldots \ldots \ldots \ldots$ $\ldots \ldots \ldots \ldots \ldots$ ค......... 


\section{SOBRECARGA DOS CUIDADORES DE IDOSOS: RELATO DE EXPERIÊNCIA}

OVERLOAD OF CAREGIVERS OF THE ELDERLY: EXPERIENCE REPORT

SOBRECARGA DE LOS CUIDADORES DE ANCIANOS: RELATO DE EXPERIENCIA

Gabriela Medeiros Steindorff ${ }^{1}$

Sidnei Batista de Oliveira Junior 2

Diogo da Rosa Viana ${ }^{3}$

João Nunes Maidana Júnior 4

Cenir Gonçalves Tier ${ }^{5}$

Vanessa Alvez Mora da Silva ${ }^{6}$

Palavras-chave:

Cuidadores; Enfermagem em Saúde Comunitária; Serviços de Saúde para Idosos; Visita Domiciliar.

Keywords: Caregivers; Community Health Nursing; Health Services for the Elderly; House calls.

Palabras clave: Cuidadores; Enfermería en Salud Comunitaria; Servicios de Salud para Ancianos; Visita Domiciliaria.

Submetido: $15 / 09 / 2017$

Aprovado: $16 / 03 / 2018$

Autor(a) para Correspondência: Gabriela Medeiros Steindorff End: Rua Santana $n^{\circ} 4547$, Bairro Santana, CEP: 97502-214 Uruguaiana Rio Grande de Sul - Brasil E-mail: gsteindorff20@gmail.com

\section{RESUMO}

Este artigo descreve a experiência de estudantes de Enfermagem no que se refere à sobrecarga do cuidador de idosos. Trata-se de relato de experiencia cujo cenário consistiu no domicílio de idosos de um município de médio porte na região da Fronteira Oeste do Rio Grande do Sul, com visitas domiciliares aos idosos. As visitas foram realizadas em 3 encontros, em abril e maio de 2017, com 7 famílias de idosos indicadas por Agentes Comunitários de Saúde (ACS) da Estratégia Saúde da Família (ESF). 0 cuidador do idoso se mostra fundamental para sanar dúvidas da equipe de saúde. Nas 7 famílias visitadas, os cuidadores, todos do sexo feminino, relataram sentir-se sozinhos no cuidado ao idoso. Observou-se necessidade de: monitorar o uso de medicação e a pressão arterial; realizar consultas periódicas; e proporcionar ajuda nas atividades diárias. Nas visitas domiciliares, constatou-se que a sobrecarga do cuidador assume diferentes formas, tanto psicológicas como físicas. Nesse sentido, mostra-se necessário que os profissionais da saúde tenham um olhar voltado à integralidade do cuidado ao idoso, que também engloba a atenção à saúde do cuidador.

1. Estudante de Graduação em Enfermagem na Universidade Federal do Pampa (Unipampa). Uruguaiana (RS), Brasil. E-mail: gsteindorff20@gmail.com

2. Estudante de Graduação em Enfermagem na Unipampa. Uruguaiana (RS), Brasil. E-mail: juniorboj30@gmail. com

3. Enfermeiro graduado pela Unipampa.Uruguaiana (RS),Brasil. E-mail: diogoviana95@yahoo.com.br

4. Enfermeiro graduado pela Unipampa. Uruguaiana (RS), Brasil. E-mail: juniordana@hotmail.com

5. Enfermeira. Doutora em Enfermagem. Professora na Unipampa. Uruguaiana (RS), Brasil. E-mail: cgtier@ hotmail.com

6. Enfermeira. Mestre em Ciências da Saúde. Professora na Unipampa. Uruguaiana (RS), Brasil. E-mail: valvez_ enfermagem@hotmail.com 


\section{ABSTRACT}

This article describes the experience of Nursing students regarding the overload of caregivers of the elderly. This is an experience report whose scenario consisted of the elderly's household in a medium-sized municipality in the Fronteira Oeste region of Rio Grande do Sul, Brazil, with house calls to the elderly. The visits were carried out in 3 meetings, in April and May 2017, with 7 families of the elderly indicated by Community Health Workers (CHWs) from the Family Health Strategy (FHS). The caregiver of the elderly is crucial to solve the health team's doubts. In the 7 families visited, the caregivers, all of them women, reported feeling alone when caring for the elderly. There was a need to: monitor medication use and blood pressure; conduct regular appointments; and provide help in daily living activities. In the house calls, it was found that the caregiver's overload takes various forms, both psychological and physical. Thus, it is necessary that health professionals have a focus on comprehensive care for the elderly, which also encompasses providing the caregiver with care.

\section{RESUMEN}

Este artículo describe la experiencia de estudiantes de Enfermería con respecto a la sobrecarga del cuidador de ancianos. Este es un informe de experiencia cuyo escenario consistió en el hogar de ancianos en un municipio de tamaño medio en la región de la Fronteira Oeste de Rio Grande do Sul, Brasil, con visitas domiciliarias a los ancianos. Las visitas se llevaron a cabo en 3 reuniones, en abril y mayo de 2017, con 7 familias de ancianos indicadas por Agentes Comunitarios de Salud (ACS) de la Estrategia Salud de la Familia (ESF). El cuidador del anciano es crucial para resolver dudas del equipo de salud. En las 7 familias visitadas, los cuidadores, todos del sexo femenino, informaron sentirse solos cuando cuidaban al anciano. Hubo una necesidad de: monitorear el uso de medicación y la presión arterial; realizar consultas regulares; y proporcionar ayuda en las actividades de la vida diaria. En las visitas domiciliarias, se constató que la sobrecarga del cuidador toma diversas formas, tanto psicológicas como físicas. En este sentido, es necesario que los profesionales de salud se centren en la atención integral para los ancianos, lo que también incluye brindar atención al cuidador.

\section{INTRODUÇÃO}

0 Brasil é um país que envelhece a passos largos. As alterações na pirâmide populacional são claras, inequívocas e irreversíveis. Nos últimos anos, é entre a população idosa que temos observado as taxas mais altas de crescimento populacional ${ }^{1}$.

0 Instituto Brasileiro de Geografia e Estatística (IBGE) corrobora essa afirmativa. Em 2016, os indivíduos acima de 65 anos representavam $8,1 \%$ da população no Brasil e a estimativa para 2030 é de que representarão $13,4 \%^{2}$.

Atualmente, a Atenção Primária à Saúde (APS) desempenha importante papel em relação à população idosa, pois se caracteriza por um conjunto de ações de saúde, no âmbito individual e coletivo, que abrange a promoção e a manutenção da saúde para proporcionar uma atenção integral que aumente a autonomia das pessoas e melhore seus determinantes e condicionantes de saúde ${ }^{3}$.

Sabe-se que, para dar conta de toda essa amplitude da APS, surgiu em 1994 o Programa de Saúde da Família (PSF) - conhecido atualmente como Estratégia Saúde da Família (ESF) -, que busca reorientar o modelo assistencial, antes biomédico, com o intuito de formar equipes de saúde multi e transdisciplinares ${ }^{4}$. Tais mudanças exigem cada vez mais que as equipes da ESF busquem estratégias diferentes na abordagem a toda a população atendida, mais especificamente aos idosos, tendo em vista que a APS é a porta de entrada no Sistema Único de Saúde (SUS) e que ela se fortalece cada vez mais em âmbito nacional, captando e acompanhando os idosos para garantir a equidade e integralidade das ações de saúde voltadas a eles ${ }^{5}$.

Nessa perspectiva, a Política Nacional do Idoso surgiu como uma estratégia/ferramenta de fomento dos direitos sociais dessa população, buscando um cuidado integral tanto do indivíduo como de sua família ${ }^{6}$. É de suma importância que se conheça o contexto social desse idoso e seu relacionamento com os cuidadores para que a equipe da APS possa traçar estratégias segundo as necessidades de saúde de cada indivíduo. Assim, a caderneta de saúde da pessoa idosa é um instrumento auxiliar para uma adequada atenção à saúde do idoso, usado tanto pelas equipes de saúde com pelos idosos e seus familiares e cuidadores ${ }^{7}$.

Logo, quanto maior o grau de fragilidade, maior 0 nível de dependência funcional do idoso, que demandará cuidados - formais ou informais. 
Desse modo, a sobrecarga do cuidador do idoso é algo comum, principalmente devido ao seu despreparo para desempenhar essa função, e isso pode causar problemas de saúde, tanto psicológicos como físicos ${ }^{8}$. Nesse contexto, mostra-se fundamental o apoio dos profissionais da saúde ao cuidador do idoso.

A sobrecarga pode implicar graves consequências tanto para o cuidador (formal ou informal) como para o idoso e sua família. A falta de suporte e orientação adequada para as ações de cuidado aumenta a possibilidade de adoecimento do cuidador.

Considera-se cuidador informal alguém que reside no mesmo local do idoso, geralmente um membro da família. Já o cuidador formal recebe um salário e geralmente se desloca para sua casa ao final de seu expediente. A atenção de enfermagem voltada à saúde da família e à saúde do idoso deve pautar-se pela compreensão das crenças e dos significados apresentados pela realidade social e familiar. Buscase romper tabus e preconceitos para auxiliar na formulação de estratégias para proporcionar cuidado integral. 0 foco do cuidado ao idoso acaba sendo individual, mas advém de construção e interação com a família buscando o bem-estar comum ${ }^{9}$.

A enfermagem deve repensar suas atitudes diante do modelo biomédico de cuidado, revendo conceitos e abordagens ao idoso e ao cuidador. A pessoa deve ser entendida como um ser individual e coletivo, participante ativo de uma comunidade - que deve respeitar seus significados e sua liberdade de ação e tomada de decisão em sua vida e nos cuidados recebidos ${ }^{9}$.

Por sua vez, alguns profissionais da saúde ainda apresentam uma visão de cuidado limitado à assistência técnica, fato que revela a necessidade de expandir o conhecimento dos aspectos conceituais do cuidado para além das obrigações funcionais ${ }^{6}$ - que incluem as orientações para garantir uma atenção também focada na saúde mental do cuidador.

Diante do exposto, este artigo descreve a experiência de estudantes de graduação em Enfermagem no que se refere à sobrecarga do cuidador de idosos, com a realização de visitas domiciliares.

\section{METODOLOGIA}

Trata-se de um relato de experiência que descreve a vivência de estudantes durante as atividades práticas da disciplina "Cuidado à Saúde do Idoso", no âmbito do curso de Graduação em Enfermagem da Universidade Federal do Pampa (Unipampa).

\section{...alguns profissionais da saúde \\ ainda apresentam uma \\ visão de cuidado \\ limitado à assistência \\ técnica...}

0 cenário consistiu no domicílio de idosos de um município de médio porte na região da Fronteira Oeste do Rio Grande do Sul, com visitas domiciliares de uma equipe da ESF - para preencher a caderneta de saúde do idoso n. 19. Essa vivência ocorreu em 3 encontros, em abril e maio de 2017, realizados com 7 famílias adscritas no território de uma unidade da ESF localizada na zona urbana do município em questão.

Essa unidade da ESF possui 2 equipes, compostas por 2 enfermeiros, 2 médicos generalistas, 3 técnicos de enfermagem, 1 nutricionista, 1 educador físico e 8 Agentes Comunitários de Saúde (ACS). A área de abrangência desse serviço de saúde é composta por 13 microáreas, atendendo no território, de acordo com o Sistema de Informações da Atenção Básica (Siab), uma população de 8.800 pessoas, das quais cerca de $35 \%$ têm 60 anos ou mais.

Nesse serviço, o atendimento à comunidade ocorre nos turnos matutino e vespertino, respectivamente, das $7: 30$ às $11: 30$ e das $13: 30$ às $17: 30$, estruturandose a partir do acolhimento à livre demanda, segundo critérios da classificação de risco.

Ressalta-se que os domicílios que constituíram o cenário deste relato foram indicados por um ACS - um dos principais personagens na implementação do SUS, pois fortalece a integração entre os serviços de saúde da ESF e a comunidade.

\section{RESULTADOS E DISCUSSÃO}

Os enfermeiros que atuam no âmbito da APS devem identificar casos de sobrecarga do cuidador de idosos e propor ações de cuidado ao cuidador que contribuam para a manutenção de sua saúde física e mental e de sua qualidade de vida ${ }^{10}$.

Durante as práticas da disciplina "Cuidado à Saúde do Idoso", a proposta das visitas domiciliares surgiu com a finalidade de conhecer a população idosa na área de abrangência da unidade da ESF, para preencher sua caderneta do idoso. As residências foram 
indicadas e selecionadas conforme o cadastro dos ACS. As visitas domiciliares por parte dos estudantes de graduação em Enfermagem se mostram importantes por proporcionar o diálogo e o levantamento da população idosa em foco.

Uma das ferramentas mais expressivas das unidades da ESF são as visitas domiciliares, pois constituem momentos de integração entre os serviços de saúde e a população, fixando e fortalecendo o vínculo entre a equipe multidisciplinar de saúde e os usuários da APS ${ }^{11}$.

Essa aproximação também visa a acompanhar as necessidades de saúde da comunidade, zelando pelas condições de vida adequadas (saneamento, higiene, moradia etc.) no território ${ }^{12}$.

Treinamento ou experiência insuficiente e falta de conhecimento para a visita domiciliar podem influenciar o cuidado domiciliar, gerando desafios para a atuação do enfermeiro, que podem ser amenizados por meio de iniciativas de formação profissional13. Assim, necessita-se cada vez mais trabalhar sob a perspectiva de capacitar esses profissionais para a visita domiciliar.

Durante as visitas domiciliares, identificou-se que o papel do cuidador é fundamental para sanar dúvidas da equipe de saúde sobre o idoso, pois ele se apresenta como um sujeito conhecedor da vida e das necessidades desse idoso. Durante o preenchimento da caderneta do idoso, em vários momentos os pesquisadores necessitaram da ajuda do cuidador para responder algumas questões, principalmente no que se refere às medicações e à alimentação. Entretanto, todos os cuidadores relatam sobrecarga emocional e física, mencionando que, no cuidado ao idoso, as dúvidas e incertezas ficam sob sua responsabilidade e que geralmente vivenciam esses momentos sozinhos.

A literatura científica alerta que o cuidador, com o sofrimento decorrente de tais dúvidas e incertezas, necessita do apoio da equipe multidisciplinar de saúde para auxiliá-lo a conduzir as atividades corretas referentes ao idoso ${ }^{14}$.

Todos os cuidadores que participaram do estudo relataram sentir-se responsáveis tanto pela saúde do idoso como pelo manejo de suas limitações físicas e emocionais. Durante os diálogos, eles declararam que sempre buscam conversar com o idoso sobre a importância de manter seu cérebro ativo e de adotar bons hábitos de alimentação.

Um estudo científico valida tais achados e conclui ser fundamental para os profissionais da saúde o

\section{...a saúde do cuidador, tanto física como mental, afeta o cuidado e a saúde do idoso.}

acompanhamento de um cuidador de idosos para atender plenamente as necessidades dos idosos ${ }^{14}$.

Todos os cuidadores que participaram deste relato de experiência tinham vínculo familiar com os idosos e eram do sexo feminino - esses indivíduos relataram sentir-se sozinhos no cuidado a idoso, carecendo de ajuda dos demais membros da família.

Integrar a família e o idoso de modo harmonioso constitui um desafio. Para que isso aconteça, é preciso intervir no sofrimento familiar com foco em suas singularidades. As práticas profissionais no setor saúde demandam cada vez mais capacitação para compreender e atender as necessidades de saúde individuais e promover a cooperação entre os membros da família ${ }^{15}$.

0 membro da família que assume a função de cuidador deve adquirir novos hábitos. Sua vida se transforma por completo - desde assuntos menos relevantes do cotidiano até temas significativos, como privacidade, férias e viagens. Tais mudanças potencializam cada vez mais a sobrecarga do cuidador ${ }^{14}$.

Neste estudo, os cuidadores relataram sentir-se angustiados e tristes com a própria vida diariamente e identificam-se com sintomas de depressão. A grande maioria já buscou ajuda voltada à sua saúde mental e faz uso de medicação, porém, não apontam melhora de seu quadro nem significância no acompanhamento desses agravos psicológicos.

É essencial incluir a avaliação do sofrimento psíquico do cuidador, a fim de detectar distúrbios mentais precocemente. Sabe-se que a saúde do cuidador, tanto física como mental, afeta o cuidado e a saúde do idoso ${ }^{16}$.

Nos diálogos, além de sobrecarga emocional, os cuidadores indicaram limitações físicas decorrentes de dores osteomusculares, causadas tanto pelos afazeres domésticos como pela dependência física do idoso. Ademais, esses cuidadores não têm vínculo com a ESF, não frequentam grupos e sentem-se desestimulados a cuidar de sua própria saúde.

A participação em grupos de saúde melhora 
questões relacionadas tanto à saúde física como à saúde mental, tendo em vista que assumem o papel de estimuladores de uma vida mais saudável e promovem a autoestima, proporcionando a inclusão no meio social e evitando o isolamento ${ }^{11}$.

Enfatiza-se a importância dos grupos de atividades físicas de idosos, bem como a participação de seus cuidadores, pois melhoram a aptidão funcional, que é vital para a vida cotidiana. Almeja-se que os idosos sejam capazes de realizar suas atividades diárias com esforço muscular, condicionamento físico e equilíbrio ${ }^{17}$. Esses grupos de atividades físicas constituem uma ferramenta de vínculo entre o idoso e seu cuidador e a ESF.

É necessário que o enfermeiro tenha sensibilidade no momento do diálogo com esses cuidadores; quando necessário, deve-se ter conhecimento acerca do modo de identificar a sobrecarga desses indivíduos, por exemplo, por meio de uma escala ou outro recurso de avaliação.

0 inventário de carga do cuidador é um exemplo de escala que pode ser aplicada na ESF. Esse instrumento avalia a carga do cuidador e fornece informações valiosas sobre o impacto dos idosos em vários domínios da vida dos cuidadores e familiares, podendo ajudar os enfermeiros a desenvolver intervenções para prevenir problemas de saúde entre os cuidadores e melhorar sua qualidade de vida ${ }^{18}$.

Ressalta-se que também existem escalas para cuidadores informais aplicáveis na APS, por exemplo, - Questionário de Avaliação da Sobrecarga do Cuidador Informal, que avalia a qualidade de vida relacionada aos aspectos físicos, emocionais e sociais da saúde ${ }^{10}$.

Observam-se dificuldades para que a equipe de saúde entenda a proposta de integralidade do cuidado. Neste estudo, identificou-se que os ACS limitam seu foco ao idoso, não englobando a saúde de sua família - a maioria das questões para 0 cuidador se referem à saúde do idoso.

Outro estudo semelhante comprova essa afirmação, pois conclui que alguns profissionais valorizam e fazem uso da tecnologia relacional, alicerçada em acolhimento, vínculo, interação etc. Em algumas unidades da ESF, contudo, ainda predomina a visão biologicista do cuidado, com ênfase em procedimentos, normas e medicamentos ${ }^{19}$.

0 embasamento científico alerta os enfermeiros quanto às questões do acolhimento em suas ações, evidenciando que a reorganização de seu processo de trabalho depende somente de fatores externos e

\section{...grupos de atividades físicas constituem uma ferramenta de vínculo entre o idoso e seu cuidador e a ESF.}

desconsidera seu compromisso com o cuidado humanizado ${ }^{20}$. Portanto, deve-se discutir cada vez mais a necessidade de manter os vínculos profissionalusuários, o acolhimento e a escuta.

Assim, a visita domiciliar se torna um espaço de escuta e de diálogo e um momento de acolhimento e de criação de vínculo, proporcionando novos modos de cuidar - mais humanos e mais acolhedores, ao envolver a afetividade e os laços de confiança entre profissionais, usuários, família e comunidade ${ }^{21}$.

Durante a escuta, os pesquisadores observaram que quanto maior o grau de dependência desses idosos, mais frequentes os relatos de sobrecarga dos cuidadores. Dentre os tipos de dependência, constatase a necessidade de monitorar o uso de medicação e a pressão arterial; realizar consultas periódicas; e proporcionar ajuda nas atividades diárias, como vestir roupas e tomar banho.

Nesse sentido, há maior sobrecarga dos cuidadores de idosos que necessitam de apoio para lidar com as morbidades, o que aumenta o nível de dependência do idoso e, por conseguinte, a demanda de cuidado. Por isso, quanto maior a dependência do idoso, maior a sobrecarga do cuidador ${ }^{22}$.

As visitas domiciliares disponibilizam momentos para que os pesquisadores ofereçam educação em saúde, por meio de orientações sobre alimentação, quedas, doenças crônicas e saúde mental, assim como de fortalecimento do vínculo com a ESF e entre o profissional e o usuário.

0 risco de queda entre idosos serve de alerta para os profissionais observarem fatores como a prevalência do sexo feminino, a má qualidade de sono e a baixa força muscular23. Torna-se imprescindivel que os enfermeiros estejam cientes de tais fatores para fins de prevenção, podendo ser abordados nas visitas domiciliares.

Considerando as características do processo de envelhecimento, com suas múltiplas facetas, as fragilidades envolvidas e os níveis de independência dos idosos, há necessidade de intervenções de outros 
campos além do setor saúde para o desenvolvimento de estratégias que melhorem o cuidado ao idoso ${ }^{24}$, portanto, deve-se trabalhar cada vez mais sob a perspectiva multiprofissional na APS.

É essencial que o enfermeiro dedique atenção ao contexto do cuidado ao idoso como um todo ao planejar ações de saúde voltadas a essa população.

\section{CONCLUSÃO}

Vivenciar as complexidades da saúde do idoso na APS se mostra de vital importância para a formação acadêmica em Enfermagem, com vistas à reflexão acerca da atuação dos profissionais da saúde diante da sobrecarga do cuidador de idosos.

Nas visitas domiciliares, identificou-se que tal sobrecarga assume diferentes formas, tanto psicológicas como físicas. Além de sintomas relacionados à depressão, levantaram-se relatos de dores osteomusculares. Ademais, as visitas domiciliares caracterizam-se como um momento oportuno para a educação em saúde voltada à família como um todo.

Os obstáculos deste estudo consistiram no estabelecimento de vínculo com cada idoso e seus cuidadores em um único encontro, porém, tais dificuldades foram contornadas por meio do acolhimento e da escuta desses indivíduos. Há necessidade de maior discussão e reflexão acerca da visita domiciliar para que ela possa ser aperfeiçoada.

Sugerem-se novas pesquisas voltadas a essa temática, bem como novos estudos que acompanhem os tipos de sobrecarga que acometem os cuidadores. Considera-se necessário que os profissionais adotem um olhar voltado à integralidade do cuidado ao idoso - e isso inclui a atenção ao cuidador.

\section{CONTRIBUIÇÃO DOS AUTORES}

Gabriela Medeiros Steindorff contribuiu com a concepção e realização da pesquisa e a redação do manuscrito. Sidnei Batista de Oliveira Junior contribuiu com a realização da pesquisa e a redação do manuscrito. Diogo da Rosa Viana contribuiu com a redação e revisão crítica do manuscrito. João Nunes Maidana Júnior contribuiu com a redação e revisão crítica do manuscrito. Cenir Gonçalves Tier contribui com a revisão crítica do manuscrito. Vanessa Alvez Mora da Silva contribuiu com a revisão crítica do manuscrito.

\section{REFERÊNCIAS}

1. Kuchemann BA. Envelhecimento populacional, cuidado e cidadania: velhos dilemas e novos desafios. Sociedade e Estado [serial on the internet]. 2012 [cited 2017 Jul 7];27(1):165-80. Available from: http://www.scielo.br/pdf/ se/v27n1/09.pdf

2. Brasil. Projeção da população do Brasil e das unidades da Federação [document on the internet]. Rio de Janeiro: IBGE; 2017 [cited 2018 Apr 22]. Available from: https://www. ibge.gov.br/apps/populacao/projecao/

3. Brasil. Política Nacional de Atenção Básica. Brasília (DF): Ministério da Saúde; 2012.

4. Soratto J, Pires DEP, Dornelles S, Lorenzetti J. Family Health Strategy: a technological innovation in health. Texto \& Contexto Enferm [serial on the internet]. 2015 [cited 2017 Aug 6];24(2):584-92. Available from: http://www. scielo.br/pdf/tce/v24n2/0104-0707-tce-24-02-00584.pdf

5. Santos M, Mattos IE. Condições de vida e saúde da população idosa do município de Guaramiranga-CE. Epidemiol Serv Saúde [serial on the internet]. 2011 [cited 2017 Jul 7];20(2):193-201. Available from: https://www.arca.fiocruz. br/bitstream/icict/5029/2/1082.pdf

6. Stackfleth R, Diniz MA, Fhon JRS, Vendruscolo TRP, Whebe SCCF, Marques $S$, et al. Sobrecarga de trabalho em cuidadores de idosos fragilizados que vivem no domicílio. Acta Paul Enferm [serial on the internet]. 2012 [cited 2017 Jul 7];25(5):768-74. Available from: http://dx.doi. org/10.1590/S0103-21002012000500019

7. Morais JC, Santos KF, Andrade CG, Costa ICP, Brito FMB, Fernandes MGM. Significado de cuidado: o olhar de profissionais e idosos institucionalizados. Rev Enferm UFPE On Line [serial on the internet]. 2015 [cited 2017 Jul 7];9(Suppl 7):8937-45. Available from: file:///D:/10683-22613-1-PB.pdf

8. Brasil. Caderneta de saúde da pessoa idosa [document on the internet]. Brasília (DF): Ministério da Saúde; 2014 [cited 2018 Apr 22]. Available from: http://bvsms.saude. gov.br/bvs/publicacoes/caderneta_saude_pessoa_ idosa 3ed.pdf

9. Perseguino MG, Horta ALM, Ribeiro CA. A família frente a realidade do idoso de morar sozinho. Rev Bras Enferm [serial on the internet]. 2017 [cited 2017 Jul 7];70(2):235-41. Available from: http://www.scielo.br/pdf/reben/v70n2/ pt 0034-7167-reben-70-02-0235.pdf

10. Monteiro EA, Mazin SC, Dantas RAS. Questionário de avaliação da sobrecarga do cuidador informal: validação para o Brasil. Rev Bras Enferm [serial on the internet]. 2015 [cited 2017 Aug 1];68(3):421-8. Available from: http:// www.scielo.br/pdf/reben/v68n 3/0034-7167reben-68-03-0421.pdf 
11. Gomes MFP, Fracolli LA, Machado BC. Atenção domiciliar do enfermeiro na Estratégia Saúde da Família. Mundo Saúde [serial on the internet]. 2015 [cited 2017 Jul 7];39(4):4705. Available from: https://www.saocamilo-sp.br/pdf/ mundo saude/155572/A08.pdf

12. Kebian LVA, Acioli S. A visita domiciliar de enfermeiros e agentes comunitários de saúde da Estratégia Saúde da Família. Rev Eletrônica Enferm [serial on the internet]. 2014 [cited 2017 Jul 7];16(1):161-9. Available from: file:///D:/20260-126142-1-PB.pdf

13. Andrade AM, Silva KL, Seixas CT, Braga PP. Atuação do enfermeiro na atenção domiciliar: uma revisão integrativa da literatura. Rev Bras Enferm [serial on the internet]. 2017 [cited 2017 Aug 6];70(1):210-9. Available from: http:// www.scielo.br/pdf/reben/v70n1/0034-7167reben-70-01-0210.pdf

14. Reis RD, Pereira EC, Pereira Maria IM, Soane AMNC, Silva JV. Significados, para os familiares, de conviver com um idoso com sequelas de acidente vascular cerebral (AVC). Interface (Botucatu, Online) [serial on the internet]. 2017 [cited $2017 \mathrm{Jul}$ 7];21(62):641-50. Available from: http:// www.scielo.br/pdf/icse/v21n62/1807-5762icse-1807-576220160206.pdf

15. Avelino ACA, Cunha ARR, Silva PMC, Azevedo EB, Silva JB, Ferreira FMO. 0 cuidado ao idoso portador de transtorno mental sob a ótica da família. Referência [serial on the internet]. 2013 [cited 2017 Jul 7];(9):75-83. Available from: $\quad$ http://www.scielo.mec.pt/pdf/ref/vserIIIn9/ serIIIn9a08.pdf

16. Medrano M, Rosario RL, Payano AN, Capellán NR. Burden, anxiety and depression in caregivers of Alzheimer patients in the Dominican Republic. Dement Neuropsychol [serial on the internet]. 2014 [cited 2017 Jul 7];8(4):84-8. Available from: $\quad$ http://www.scielo.br/pdf/dn/v8n4/1980-5764dn-08-04-00384.pdf

17. Vagetti GC, Oliveira V, Silva MP, Pacífico AB, Costa TRA, Campos W. Association of body mass index with the functional fitness of elderly women attending a physical activity program. Rev Bras Geriatr Gerontol [serial on the internet]. 2017 [cited 2017 Aug 4];20(2):214-24. Available from: http://www.scielo.br/pdf/rbgg/v20n2/1809-9823rbgg-20-02-00214.pdf

18. Valer DB, Aires M, Fengler FL, Paskulin LMG. Adaptation and validation of the Caregiver Burden Inventory for use with caregivers of elderly individuals. Rev Latinoam Enferm [serial on the internet]. 2015 [cited 2017 Aug 1];23(1):1308. Available from: http://www.scielo.br/pdf/rlae/ v23n1/0104-1169-rlae-23-01-00130.pdf

19. Santos FPA, Nery AA, Matumoto S. A produção do cuidado a usuários com hipertensão arterial e as tecnologias em saúde. Rev Esc Enferm USP [serial on the internet]. 2013 [cited 2017 Aug 1];47(1):107-14. Available from: http:// www.scielo.br/pdf/reeusp/v47n1/a14v47n1.pdf
20. Costa PCD, Francischetti GAPR, Pellegrino TV. Expectativa de enfermeiros brasileiros acerca do acolhimento realizado na atenção primária em saúde. Rev Salud Pública [serial on the internet]. 2016 [cited 2017 Aug 1];18(5):74655. Available from: https://revistas.unal.edu.co/index.php/ revsaludpublica/article/view/45304/62553

21. Maria INCB, Maria José MRL, Ylana CPL. A visita domiciliar como ferramenta de cuidado da fisioterapia na Estratégia Saúde da Família. Sanare (Sobral, Online) [serial on the internet]. 2015 [cited 2017 Aug 6];14(1)76-80. Available from: https://sanare.emnuvens.com.br/sanare/ article/view/612/329

22. Loureiro LSN, Fernandes MGM, Nóbrega MML, Rodrigues RAP. Sobrecarga em cuidadores familiares de idosos: associação com características do idoso e demanda de cuidado. Rev Bras Enferm [serial on the internet]. 2014 [cited 2017 Aug 3];67(2):227-32. Available from: http:// www.scielo.br/pdf/reben/v67n2/0034-7167reben-67-02-0227.pdf

23. Prato SCF, Andrade SM, Cabrera MAS, Dip RM, Santos HG, Dellaroza MSG, et al. Frequência e fatores associados a quedas em adultos com 55 anos e mais. Rev Saúde Pública [serial on the internet]. 2017 [cited 2017 Aug 4];51:37. Available from: http://www.scielo.br/pdf/rsp/v51/pt_00348910-rsp-S1518-87872017051005409.pdf

24. Gavasso WC, Beltrame V. Functional capacity and reported morbidities: a comparative analysis in the elderly. Rev Bras Geriatr Gerontol [serial on the internet]. 2017 [cited 2017 Aug 4];20(3):398-408. Available from: http:// www.scielo.br/pdf/rbgg/v20n3/1809-9823rbgg-20-03-00398.pdf
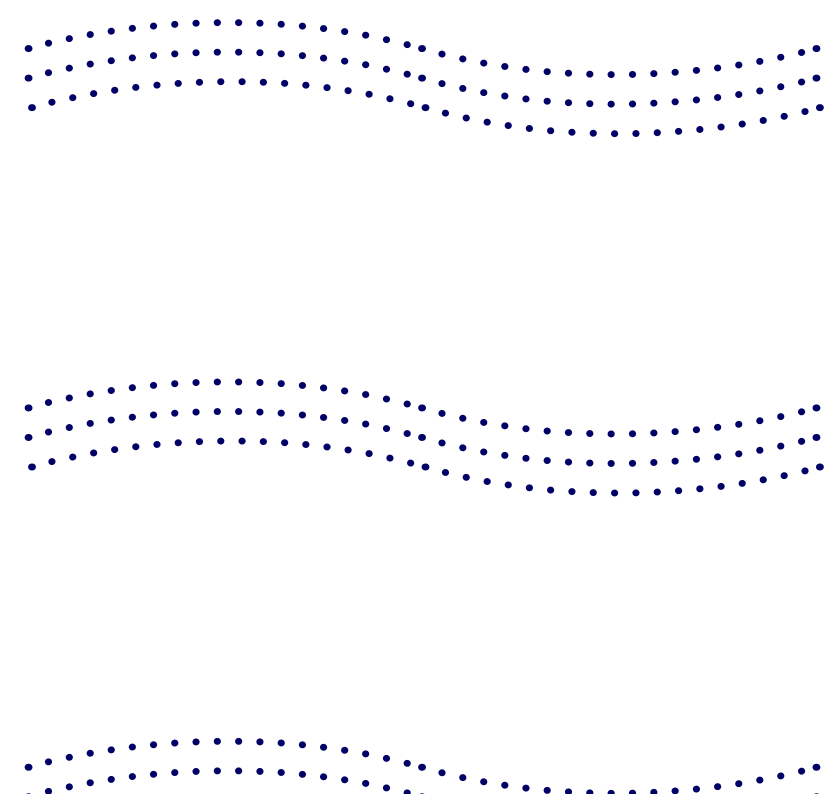
$\ldots \ldots \ldots \ldots \ldots \ldots \ldots \ldots \ldots \ldots \ldots \ldots \ldots \ldots \ldots \ldots$ $\ldots \ldots \ldots \ldots \ldots \ldots \ldots$

SANARE, Sobral - v.17, n.01,p.125-131, Jan./Jun. - 2018 - 131 


\section{DIRETRIZES PARA AUTORES}

SANARE (tornar sã, em latim) é uma revista que tem por finalidade divulgar toda e qualquer experiência, prática e teórica, em políticas públicas na área de Saúde Coletiva, como forma de contribuir com o processo de elaboração e sistematização voltado para a construção de novos paradigmas sobre a gestão governamental. A Revista, de periodicidade semestral, publica artigos que contribuem com saberes e práticas na área da saúde coletiva passando pelo debate da construção da interdisciplinaridade nessa seara. A submissão dos artigos farse-á pela plataforma online: http://sanare.emnuvens.com.br

\section{CATEGORIAS DE ARTIGOS}

A SANARE - Revista de Políticas Públicas publica artigos temáticos, originais, relatos de experiências, revisões sistemáticas e integrativas.

A apresentação dos manuscritos deve obedecer às regras de formatação definidas nessas Diretrizes para Autores, diferenciando-se apenas pelo número permitido de palavras em cada uma das categorias.

- Artigo Original: de caráter original, podendo ser revisão crítica, meta-análise ou resultado de pesquisas de natureza empírica, experimental ou conceitual sobre o assunto, avaliação de programas e análises de custoefetividade. Cada artigo deve conter objetivos e/ou hipóteses claras, desenho e métodos utilizados, resultados, discussão e conclusões. Incluem também ensaios teóricos (críticas e formulação de conhecimentos teóricos relevantes) e artigos dedicados à apresentação e discussão de aspectos metodológicos e técnicas utilizadas na pesquisa em saúde coletiva. Neste caso, o texto deve ser organizado em tópicos para guiar os leitores quanto aos elementos essenciais do argumento desenvolvido (entre 4.000 a 5.000 palavras - exceto folha de rosto, resumos e seção referência);

- Relatos de Experiência: São relatos curtos de achados que apresentam interesse para a saúde coletiva de caráter intervencionista, mas que não comportam uma análise mais abrangente e uma discussão de maior aprofundamento (entre 3.000 a 4.000 palavras - exceto folha de rosto, resumo e seção referência).

- Revisão Sistemática ou Integrativa: compreende a análise da literatura sobre temas específicos. Deve incluir uma seção que descreva os métodos utilizados para localizar, selecionar, extrair e sintetizar os dados e as conclusões (entre 4.000 a 5.000 palavras - exceto folha de rosto, resumo e seção referência).

\section{Do ineditismo do material}

0 conteúdo dos artigos enviados para publicação não pode ter sido publicado anteriormente ou encaminhado simultaneamente a outro periódico. A identificação de plágio implica em exclusão imediata do sistema de avaliação.

\section{Da autoria}

0 número máximo de autores do manuscrito está limitado a seis.

As pessoas designadas como autores devem ter participado na elaboração dos artigos de modo que possam assumir publicamente a responsabilidade pelo seu conteúdo. A qualificação como autor deve pressupor: concepção e o delineamento ou a análise e interpretação dos dados; redação do artigo ou a sua revisão crítica; e aprovação da versão a ser publicada.

No final do texto devem ser especificadas as contribuições individuais de cada autor na elaboração do artigo.

\section{Importante!}

Após a aprovação do Artigo e recebimento de Carta de Aprovação, os autores devem atender os seguintes passos:

- Confirmar a intenção de publicação dentro de 72 horas e, na sequência, cumprir os requisitos do processo de edição de texto, 
- enviando o manuscrito para o Editor de Texto oficial da Revista.

A Revista não cobra taxas de submissão e publicação. Contudo, o processo de revisão da língua portuguesa e tradução dos títulos e resumos para o inglês e espanhol serão financiados pelos autores.

\section{FORMA E PREPARO DOS MANUSCRITOS Formato}

0 arquivo contendo o manuscrito deve ser elaborado no Editor de Textos MS Word com a seguinte configuração de página: papel tamanho A4, margens de $2 \mathrm{~cm}$ em todos os lados; fonte Times New Roman, tamanho 12 com espaçamento entrelinhas de 1,5 pt.

\section{Estrutura}

I. A ordem dos elementos que compõem o corpo do manuscrito deve obedecer ao seguinte padrão: título em português, inglês e espanhol; resumo e descritor; abstract e descriptor; resumen e descriptor; texto; contribuição dos autores e referências.

II. Deverá conter as seguintes informações no cabeçalho, na seguinte ordem: 1) título do artigo, com no máximo 15 palavras em cada idioma (Português, Inglês e Espanhol). 0 texto não deve incluir qualquer informação que permita a identificação de autoria; os dados de todos os autores deverão ser informados apenas nos campos específicos do formulário de submissão (Passo 3 - Inclusão de Metadados).

III. Resumo: Português/Inglês/Espanhol. 0 resumo deverá conter de 150 a 200 palavras em cada um dos idiomas, apresentando: objetivo da pesquisa, metodologia adotada, principais resultados e as conclusões. Deverão ser destacados os novos e mais importantes aspectos do estudo. Os resumos em inglês e espanhol são de responsabilidade dos autores. Porém, pode ser revisto e solicitadas modificações a partir do parecer do Conselho Editorial da SANARE - Revista de Políticas Públicas. Apresentar sequencialmente os resumos nesta página de identificação.

IV. Descritores: incluir 3 a 5 descritores segundo o índice dos Descritores em Ciências da Saúde - DeCS (http://decs.bvs.br), separados entre si por ponto-e-vírgula.

V. Às tabelas e quadros deve-se atribuir um título breve. Notas explicativas podem ser colocadas abaixo da tabela/quadro. Se houver tabela extraída de outro trabalho, previamente publicado, os autores devem fazer a citação do autor e revista; devem ser elaboradas para reprodução direta pelo Editor de Layout, sem cores, inseridas no texto, com a primeira letra da legenda em maiúscula descrita na parte superior, numeradas consecutivamente com algarismos arábicos na ordem em que foram citadas no texto. Conteúdo em fonte $12 p t$ com a primeira letra em maiúscula, apresentadas em tamanho máximo de $14 \times 21 \mathrm{~cm}$ (padrão da Revista) e comprimento não deve exceder 55 linhas, incluindo título.

VI. As ilustrações (fotografias, desenhos, gráficos, etc.) devem ser citadas como figuras. Devem ser numeradas consecutivamente com algarismos arábicos, na ordem em que foram citadas no texto; as ilustrações devem ser suficientemente claras para permitir sua reprodução, utilize escala de cinza e outros recursos para impressão em preto e branco. Não se permite que figuras representem os mesmos dados de Tabela. Nas legendas das figuras, os símbolos, flechas, números, letras e outros sinais devem ser identificados e seu significado esclarecido. Se houver figura extraída de outro trabalho, previamente publicado, os autores devem fazer a citação do autor e revista.

VII. A quantidade de Tabelas e Figuras não deve ser superior a cinco (05).

VIII. Abreviaturas e símbolos: Não deve conter abreviações no título e no resumo. 0s termos por extenso aos quais as abreviações correspondem devem preceder sua primeira utilização no texto, a menos que sejam unidades de medidas padronizadas.

IX. Aspectos Éticos: nas pesquisas que envolvem seres humanos, os autores deverão deixar claro que as mesmas atenderam à Resolução 466/12 do Conselho Nacional de Saúde (CNS) e apresentar número do protocolo de aprovação e ano. 0 documento de aprovação do Comitê de Ética em Pesquisa (CEP) deve ser encaminhado sob a forma de documento digitalizado via Documentos Suplementares (Passo 4 da submissão do artigo). 
X. Citação de Referência: numerar as referências de forma consecutiva de acordo com a ordem em que forem mencionadas pela primeira vez no texto. Identificar as referências no texto por números arábicos sobrescritos e antes da pontuação necessária, sem a identificação do autor e ano, e sem uso de parênteses. Quando se tratar de citação sequencial, separe os números por traço (ex: 1-3); quando intercalados, use vírgula (ex:1,3,5). Quando a citação for direta, deve acrescer o número da página (ex.: 4:54).

XI. NÃO USAR rodapé/notas/espaçamento entre parágrafos.

XII. Cada autor deverá assinar uma "Declaração de Responsabilidade" na qual seja especificada a contribuição de cada um, conforme modelo (Anexo 1), e anexada via Documentação Suplementar. Entretanto, no corpo do manuscrito deve conter a CONTRIBUIÇÃO DOS AUTORES; este item deve ser apresentado antes da seção "Referências".

Exemplo:

Eliany Nazaré Oliveira contribuiu com a concepção e preparação do manuscrito, Maristela Inês Osawa Vasconcelos e Maria Socorro de Araújo Dias contribuíram com a preparação do manuscrito, Paulo César de Almeida participou desenvolvendo a análise estatística, Sara Cordeiro Eloia e Tamires Alexandre Felix colaboraram com a revisão final do artigo.

\section{REFERÊNCIAS}

Serão aceitas, no máximo, 30 referências, orientando-se incluir apenas aquelas estritamente pertinentes e relevantes à problemática abordada. Deve-se evitar a inclusão de número excessivo de referências numa mesma citação. 0s autores são os responsáveis pela exatidão das referências.

I. As referências seguem o estilo Vancouver, tendo como base as normas adotadas pelo Comitê Internacional de Editores de Revistas Médicas (estilo Vancouver), publicadas no ICMJE - Uniform Requirements for Manuscripts Submitted to Biomedical Journals (http://www.icmje.org/index.html).

II. Os títulos de periódicos devem ser referidos abreviados, de acordo com o Index Medicus: http://www. ncbi.nlm.nih.gov/sites/entrez?db=journals.

III. Para abreviatura dos títulos de periódicos nacionais e latino-americanos, consultar o site: http://portal. revistas.bvs.br eliminando os pontos da abreviatura, com exceção do último ponto para separar do ano.

IV. As referências devem ser numeradas consecutivamente, conforme a ordem que foram mencionadas pela primeira vez no texto.

V. NÃO APRESENTAR referências de monografias, dissertações e teses (exceto quando a pesquisa incluir Banco de dissertações/teses em pesquisas de Revisões).

Exemplos:

- Livros como um todo:

Dias FAC, Dias MAS. Território, cultura e identidade. Rio de Janeiro: Abrasco; 2010.

- Capítulo de livro:

Lachapelle R. L'expertise Québécoise Dáction Territorialeen Promotion de La Santé. In: Dias FAC, Dias MSA, organizadores. Território, Cultura e Identidade. Rio de Janeiro (RJ): Abrasco; 2010. p. 48-79.

- Trabalhos apresentados em eventos científicos:

Moreira V. 0 método fenomenológico mundano na pesquisa em saúde. In: Anais do $4^{\circ}$ Congresso de Pesquisa Ibero americano de Pesquisa Qualitativa em Saúde; 2010; Fortaleza: Abrasco; 2010. p.143.

- Artigos de periódicos:

1) Artigo Padrão 
Mendes EV. As redes de atenção à saúde. Cien Saude Colet 2010;15(5):2297-305.

2) Com mais de seis autores

Carneiro Neto MC, Carneiro JC, Moreira AP, Soares CHA, Pinto VPT, Melo MSS, et al. Aspectos jurídicos do enfrentamento da dengue no município de Sobral, Ceará. Sanare 2010;9(1):27-8.

3) Instituição como autor

Fundação 0swaldo Cruz. 0 legado de 0swaldo Cruz. Hist Cienc Saude Manguinhos. 2007;10:40-1.

- Material eletrônico

4) Artigo de revista em formato eletrônico

Vilela EM, Mendes IJM. Interdisciplinaridade e saúde: estudo bibliográfico. Rev Lat Am Enfermagem [Internet]. 2003 [cited 2012 Apr 21];11(4):525-31. Available from: http://www.scielo.br/pdf/rlae/v11n4/v11n4a16.pdf

Castro SS, Pelicioni AF, Cesar CLG, Carandina L, Barros MBA, Alves MCGP et al. Uso de medicamentos por pessoas com deficiências em áreas do estado de São Paulo. Rev saúde pública [Internet]. 2010 [cited 2012 Jun 10];44(4):601-10. Available from: http://www.scielo.br/pdf/rsp/v44n4/03.pdf

Rozenfeld M. Prevalência, fatores associados e mau uso de medicamentos entre os idosos: uma revisão. Cad saúde pública [Internet]. 2003 [cited 2012 May 10];19(3):717-24. Available from: http://www.scielosp.org/pdf/csp/ v19n3/15875.pdf

Matéria publicada na Internet

Brasil. Ministério da Saúde. Centro Brasileiro de Análise e Planejamento. Pesquisa Nacional de Demografia e Saúde da Criança e da Mulher: Dimensões do Processo Reprodutivo e da Saúde da Criança - 2006 [home-page on the Internet]. [cited 2014 Mar 20]. Available from: http://bvsms.saude.gov.br/bvs/pnds

\section{ANEXO 1}

Declaração de Responsabilidade (MODELO)

Eu, (nome por extenso), certifico que participei da autoria do manuscrito intitulado (título) nos seguintes termos: “Certifico que participei suficientemente do trabalho para tornar pública minha responsabilidade pelo seu conteúdo". “Certifico que o manuscrito representa um trabalho original e que nem este manuscrito, em parte ou na íntegra, nem outro trabalho com conteúdo substancialmente similar, de minha autoria, foi publicado ou está sendo considerado para publicação em outra revista, quer seja no formato impresso ou no eletrônico, exceto o descrito em anexo."

"Atesto que, se solicitado, fornecerei ou cooperarei totalmente na obtenção e fornecimento de dados sobre os quais o manuscrito está baseado, para exame dos editores."

Contribuição:

Local, data Assinatura

OBS: A contribuição de cada um dos autores deve ser explicitada na declaração. Não se justifica a inclusão de nome de autores cuja contribuição não se enquadre nos critérios. 